Wilson Munemassa Arata

\title{
Representação computacional de Sistemas a Eventos Discretos considerando a heterogeneidade e a integração dos modelos
}

Tese apresentada à Escola Politécnica da Universidade de São Paulo para obtenção do Título de Doutor em Engenharia. 
Wilson Munemassa Arata

\section{Representação computacional de Sistemas a Eventos Discretos considerando a heterogeneidade e a integração dos modelos}

Tese apresentada à Escola Politécnica da Universidade de São Paulo para obtenção do Título de Doutor em Engenharia.

Área de concentração:

Engenharia de Controle e Automação

Orientador:

Prof. Dr. Paulo Eigi Miyagi 
Este exemplar foi revisado e alterado em relação à versão original, sob responsabilidade única do autor e com a anuência de seu orientador.

São Paulo, 16 de novembro de 2005.

Autor: Wilson Munemassa Arata

Orientador: Prof. Dr. Paulo Eigi Miyagi

\section{FICHA CATALOGRÁFICA}

Arata, Wilson Munemassa

Representação computacional de sistemas a eventos discretos considerando a heterogeneidade e a integração dos modelos / W.M. Arata. - ed. rev - São Paulo, 2005.

$188 p$.

Tese (Doutorado) - Escola Politécnica da Universidade de São Paulo. Departamento de Engenharia Mecatrônica e de Sistemas Mecânicos.

1.Sistemas a eventos discretos 2.Modelos heterogêneos 3.Integração de modelos 4.Ferramentas computacionais I.Universidade de São Paulo. Escola Politécnica. Departamento de Engenharia Mecatrônica e de Sistemas Mecânicos II.t. 


\section{Dedicatória}

Aos meus pais e ao meu sobrinho Joe. 


\section{Agradecimentos}

Ao Prof. Dr. Paulo Eigi Miyagi, pela orientação, pela paciência e pelo apoio ao longo destes anos.

Aos colegas da Mecatrônica, pelas discussões, muitas vezes extrapolando os limites da Engenharia, o que, também, é importante num ambiente universitário.

À minha família, pela paciência, pelo apoio, pelo que passamos e pelo que ainda passaremos.

Em especial, ao meu sobrinho Joe, pela alegria trazida e por vencer tantos obstáculos ainda tão jovem. 


\section{Resumo}

Para estudar os chamados Sistemas a Eventos Discretos (SEDs), existe uma variedade de tipos de modelos, mas, entretanto, estes acabam tratando de aspectos sistêmicos específicos, da mesma forma que suas análises. Para ter uma visão mais completa de tais sistemas, é importante lidar com esses tipos heterogêneos de modelos e com as técnicas desenvolvidas para sua integração. Este trabalho foca na questão da representação computacional desses modelos e de como adequá-la à heterogeneidade e à integração desses modelos. No que diz respeito à heterogeneidade, é proposta uma descrição matemática das ferramentas computacionais de modelagem e análise de SEDs, com a qual se pode visualizar as interações entre a heterogeneidade dos modelos, o poder de expressão e de montagem de representações de modelos e os processamentos de análise. Baseado nesta descrição e considerando-se os diversos custos envolvidos, diversas características são analisadas, de modo que, ao final, determina-se quais aquelas que são favoráveis para o caso de heterogeneidade e integração de modelos. Porém, existe ainda a heterogeneidade inerente aos modelos que não pode ser eliminada e isso constitui um obstáculo no caso de ter de lidar com modelos heterogêneos, representando um custo adicional para o aproveitamento de sua integração. Em relação a este caso, a proposta deste trabalho é de representar as informações semânticas associadas aos diversos modelos como forma de obter uma descrição integrada da dinâmica sendo modelada. Desde que as condições de consistência dessas representações sejam atendidas, com tal descrição, é possível visualizar os relacionamentos entre os diversos modelos e realizar análises sem ter que lidar com as diferenças estruturais dos vários tipos de modelos. Além disso, tais informações são úteis na construção de representações de modelos de SEDs e no estabelecimento de relacionamentos entre modelos de dinâmicas diferentes. Dessa discussão fica claro que tais representações têm papel fundamental para um efetivo processamento computacional das informações que a modelagem e análise oferecem.

Palavras-chaves: Sistemas a Eventos Discretos, Modelos heterogêneos, Integração de modelos, Ferramentas computacionais. 


\section{Abstract}

Discrete Event Dynamic Systems (DEDS) can be approached by a variety of types of models, but each one deals with specific system aspects and whose analysis provides a limited set of information. For a more comprehensive understanding of DEDS, it is important to deal with these heterogeneous types of models and with techniques that integrate them. This work focus on the issue of computational representation of such models and of how to handle their heterogeneity and integration. In the case of the heterogeneity, a mathematical description of computational tools for modeling and analysis of DEDS is developed, based on which it is possible to visualize the interactions involving model heterogeneity, the capability of expressing and building model representations, and analysis processing. Based on this description and considering the various costs involved in the adoption of such tools, several characteristics are assessed, so that guidelines for configurations favourable to heterogeneity and integration of models are established. However, handling the heterogeneity of models does not eliminate it, remaining as a major obstacle when dealing with models of different types, representing an additional cost in their integration. Related with this issue, an approach based on the representation of the semantic information associated to the models as a means to generate an integrated description of the dynamics being modeled is introduced. As long as this representation presents consistency features, it is possible to visualize the various relationships between models and execute analysis without dealing, directly, with the structural differences observed in models of different types. Besides, the information being represented is helpful in the construction of representations of DEDS models and in establishing relationships between models referring to different dynamics. From all this discussion, it is clear that the proposed computational representation of information plays a fundamental role in the effective processing of the information provided by modeling and analysis.

Keywords: Discrete Event Dynamic Systems, Heterogeneous models, Integration of models, Computational tools. 


\section{Lista de Figuras}

2.1 Interação entre um sistema $\mathfrak{S}$ e uma carga $\mathfrak{L}$ provoca um comportamento dinâmico d . . . . . . . . . . . . . . . . . . . . . . . 32

2.2 Processo de abstração $M$ mapeando dinâmica d e modelo $\mu$. . . . 33

2.3 Análise e modelos endógenos e exógenos . . . . . . . . . . . . . . 34

2.4 Transcrição . . . . . . . . . . . . . . . . . . . . 34

2.5 MFG detalhando atividade representada pelo PFS . . . . . . . . . 37

2.6 Modelos de alto nível (cadeia de Markov) e de nível inferior (rede de filas) — exemplo de composição de modelos na abordagem do sistema SHARPE . . . . . . . . . . . . . . . . . . . . 39

2.7 Redes de Petri e os componentes Möbius correspondentes . . . . . 40

2.8 Padrão típico de atividades de um experimento de modelagem e

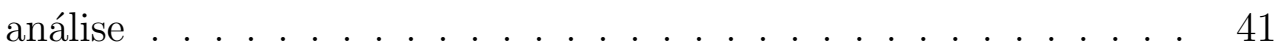

2.9 Representações computacionais de cadeias de Markov . . . . . . . 45

2.10 Modelos que compartilham partes . . . . . . . . . . . . . . . . 46

2.11 Abordagem de Campos et al. (1994) para análise de grafos marcados estocásticos . . . . . . . . . . . . . . . . . 47

3.1 Formulário referente a uma rede de Petri . . . . . . . . . . . . 51

3.2 Exemplo de linguagem de composição . . . . . . . . . . . . . . . . 52

3.3 Exemplo: linguagem de montagem $L_{B} \ldots \ldots \ldots$

3.4 Exemplo: linguagem de montagem $L_{B}^{\prime} \ldots \ldots$. . . . . . . . 54

3.5 Exemplo de capacidade analítica de um AMA . . . . . . . . . 56

3.6 Função de transcrição $\tau_{L_{C}, \Phi}: \Omega_{\Phi} \longrightarrow E_{C} \ldots \ldots$. . . . . . . . 57 
3.7 Coordenação de conjuntos-alvos referentes a um AMA para tratamento de modelos de tipo $\Phi \ldots \ldots$. . . . . . . . . . . . 58

3.8 Linguagem de composição e modelos de redes de Petri e cadeias de Markov . . . . . . . . . . . . . . . . . . . . . . . 59

3.9 Reaproveitamento de estruturas na construção de representações de modelos . . . . . . . . . . . . . . . . . . . . . 60

3.10 Flexibilidade na montagem de representações: pode-se chegar a uma mesma representação por vários caminhos . . . . . . . . . 60

3.11 As estruturas em $E_{B}-E_{C}$ podem ser utilizadas como estruturas intermediárias para a montagem de estruturas em $E_{C} \ldots \ldots 1$

3.12 Estendendo a linguagem de modelagem $\left\langle L_{C}, L_{B}\right\rangle$ (com conjuntosalvos $E_{C}$ e $E_{B}$ ) para $\left\langle L_{C}^{\prime}, L_{B}^{\prime}\right\rangle$ (com conjuntos-alvos $E_{C}$ e $E_{B}$ ) para comportar novo tipo $\Phi_{2} \quad \ldots \ldots \ldots$

3.13 Interpretações ambíguas . . . . . . . . . . . . . . . . 63

3.14 Modelos de cadeias de Markov de tempo contínuo e discreto . . . 63

3.15 Particionamento dos termos em tipos de dados diferentes . . . . . 65

3.16 Redundância de representações num mesmo AMA . . . . . . . . . 65

3.17 Exemplo de metamodelo . . . . . . . . . . . . . . . . . 66

3.18 Custos operacionais: transcrição e processamento $\quad \ldots$. . . . . . 67

3.19 Custos existenciais: representações de modelos . . . . . . . . . . . 67

3.20 Custos de transição: (a) transição devida ao trabalho com representações de diferentes tipos de modelos, (b) transição devida ao trabalho com diferentes formas de expressão de modelos, (c) transição devida ao trabalho com diferentes conjuntos de operações para montagem de modelos . . . . . . . . . . . . . . . 68

3.21 Configuração de AMA para um único tipo de modelo . . . . . . . 70

3.22 Configuração de AMAs específicos . . . . . . . . . . . . . . . . 70

3.23 Configuração de AMA abrangente . . . . . . . . . . . . . . . 71

3.24 Custos na configuração de AMAs específicos . . . . . . . . . . . . 72 
3.25 Custos na configuração de AMA abrangente . . . . . . . . . . 72

4.1 Anotações nas transições referem-se ao início e ao fim de um mesmo fato ........................ 83

4.2 Rede de Petri com lugares referentes a situações que envolvem um mesmo fato . . . . . . . . . . . . . . . . 84

4.3 Adicionando rotina de reinicialização à rede de Petri da figura $4.2 \quad 85$

4.4 Um exemplo de rede de Petri anotada por functores . . . . . . . . 87

4.5 Isomorfismo entre rede de Petri estocástica e cadeia de Markov e a representação de vínculos entre os estados de ambos modelos . . 88

4.6 Uma rede de Petri (em sua marcação inicial) e seu grafo de alcançabilidade ...................... . . 90

4.7 O termo state4 correspondente a uma marcação da rede de Petri ilustrada pode ser utilizado associado às anotações dessa rede, manifestando um vínculo entre rede de Petri e sua marcação . . . 90

4.8 Centro de processamento de peças . . . . . . . . . . . . . . . . . . 91

4.9 Rede de Petri estocástica generalizada GSPN1 . . . . . . . . . . . 91

4.10 Marcações tangíveis e a cadeia de Markov correspondente (via isomorfismo) . . . . . . . . . . . . . . . . . . 92

4.11 Trechos de diferentes redes de Petri . . . . . . . . . . . . . . 96

4.12 Rede de Petri estocástica generalizada GSPN2, o respectivo grafo de alcançabilidade tangível e o termo utilizado para representar o estado tangível . . . . . . . . . . . . . . . . . . . . . 97

5.1 Diagrama com os conjuntos-alvos da linguagem de composição $\left(E_{C}\right)$, da linguagem de montagem $\left(E_{B}\right)$ e das transcrições referentes aos tipos de modelos $\Phi$ e $\Phi^{\prime}\left(E_{\tau_{L_{C}, \Phi}}\right.$ e $E_{\tau_{L_{C}, \Phi^{\prime}}}$ respectivamente). 109

5.2 Cadeia de pontos . . . . . . . . . . . . . . . . 116

5.3 Operação merge para unir um módulo a uma proto-representação 117

5.4 Primeira rede de Petri estocástica generalizada inicial (GSPN1) 125

5.5 Segunda rede de Petri estocástica generalizada inicial (GSPN2) 125 
5.6 Os conjuntos nas variáveis \$protos e \$anotacoes . . . . . . . 126

5.7 Módulo referente a processamento de peça com características especiais (os ítens em cinza representam os elementos do modelo que interagem ou que sejam avizinhados ao módulo) . . . . . . . . . . 129

5.8 Relações entre anotações no caso de processamento de peças com características especiais . . . . . . . . . . . . . . . 130

5.9 Módulo referente à ocorrência de falha e seu reparo (os ítens em cinza representam os elementos do modelo que interagem ou que sejam avizinhados ao módulo) . . . . . . . . . . . . . . . . 132

5.10 Elementos adicionais não repetitivos e módulo de reinicialização (os ítens em cinza representam os elementos do modelo que interagem ou que sejam avizinhados ao módulo) . . . . . . . . . . . . 134

5.11 Geração de modelos e os vínculos entre elementos intermodelos . 139

5.12 Isomorfismo . . . . . . . . . . . . . . . . . . . 140

5.13 Rede de Petri estocástica generalizada GSPN1 . . . . . . . . . . . 141

5.14 Rede de Petri estocástica generalizada GSPN2 . . . . . . . . . . . 141

5.15 Rede de Petri estocástica generalizada GSPN3 . . . . . . . . . . 141

5.16 Centro de processamento para peças comuns e peças de tipo B . . 141

5.17 Diagrama de conjuntos-alvos para a linguagem LiMA . . . . . . . 149

A.1 Rede de Petri . . . . . . . . . . . . . . . . . . . . 161

A.2 Efeitos dos disparos de transições . . . . . . . . . . . . . . . 162

A.3 Paralelização ("fork") . . . . . . . . . . . . . . . . . . . . . 163

A.4 Sincronização ("join") . . . . . . . . . . . . . . . 163

A.5 Conflito . . . . . . . . . . . . . . . . . . . 164

A.6 Rede de Petri $R d P$ com marcação $M_{0} \ldots \ldots$. . . . . . . . 165

A.7 Grafo de alcançabilidade $G A\left(R, M_{0}\right)$ relativo a $R d P \ldots 165$

A.8 Rede $R_{\text {dead }}$ com "deadlock" . . . . . . . . . . . . . . . . . . 165

A.9 Grafo de alcançabilidade da rede $R_{\text {dead }}$ com "deadlock" . . . . . . 166 
A.10 Rede que permite acúmulo infinito de marcas em $\mathrm{P}$. . . . . . 166

A.11 Rede não viva . . . . . . . . . . . . . . . . . . . . . . 167

A.12 Colocação de rodas num carro feita numa estação . . . . . . . . . 169

A.13 Decisão sobre a rota da peça . . . . . . . . . . . . . . . . 170

A.14 Competição por recurso (máquina $M$ ) . . . . . . . . . . . . . . . 170

A.15 CMTC com dois estados $\{\mathrm{i}, \mathrm{j}\} \ldots \ldots \ldots$. . . . . . . . . . 172

A.16 CMTC com 3 estados $\{i, j, k\} \ldots \ldots \ldots . \ldots \ldots$

A.17 CMTC com 4 estados $\left\{E_{1}, E_{2}, E_{3}, E_{4}\right\} \ldots \ldots 174$

A.18 Interpretação gráfica da ausência de memória . . . . . . . . . . 176

A.19 CMTC finita e redutível . . . . . . . . . . . . . . . . 177

A.20 Cadeia de Markov ergódica (isto é, finita e irredutível) . . . . . 177

A.21 CMTC do ciclo disponibilidade-processamento-quebra . . . . . . 178

A.22 CMTC para 2 máquina no ciclo D-P-Q . . . . . . . . . . . . . 179

A.23 Transição temporizada de uma rede SPN . . . . . . . . . . . . . . 181

A.24 Transições das redes GSPN . . . . . . . . . . . . . . . 183

A.25 Conflito entre transições temporizadas . . . . . . . . . . . . . . 184

A.26 "Random switch" no caso de um lugar à entrada . . . . . . . . . . . 184

A.27 Os conflitos que variam conforme a marcação . . . . . . . . . . 185

A.28 Confusão . . . . . . . . . . . . . . . . . . . . . . . . . . . . 186

A.29 Múltiplos "random switches" numa marcação . . . . . . . . . . . 187

A.30 Conflito entre transições imediata e temporizada . . . . . . . . . . 187 


\section{Lista de Tabelas}

1.1 Abordagens de tratamento de SEDs . . . . . . . . . . . . . . 25

3.1 Comparação de custos entre duas configuração de AMAs para tratamento de modelos heterogêneos . . . . . . . . . . . . . . . 73 


\section{Lista de listagens}

5.1 Metamodelo de cadeia de Markov de tempo contínuo . . . . . . . 104

5.2 Metamodelo de redes de Petri marcadas . . . . . . . . . . . 105

5.3 Metamodelo de grafo de solicitação/alocação . . . . . . . . . . . 107

5.4 Metamodelo de cadeias de pontos . . . . . . . . . . . . . . 115

5.5 Metamodelo para redes de Petri generalizadas estocásticas marcadas e com arcos inibidores (tipo de dado GSPNType) . . . . . . . 125

5.6 Definição de functores e predicados (somente os utilizados no experimento) . . . . . . . . . . . . . . . . . 126

5.7 Exemplo de montagem de representações envolvendo estruturas intermediárias e informações semânticas (continua) . . . . . . . 128

5.8 Exemplo de montagem de representações envolvendo estruturas intermediárias e informações semânticas (continuação - 1). . . . 130

5.9 Exemplo de montagem de representações envolvendo estruturas intermediárias e informações semânticas (continuação - 2). . . . . 131

5.10 Exemplo de montagem de representações envolvendo estruturas intermediárias e informações semânticas (continuação - 3). . . . 133

5.11 Exemplo de montagem de representações envolvendo estruturas intermediárias e informações semânticas (conclusão - 4) . . . . . . 135

5.12 Definição dos metamodelos referentes aos grafos de alcançabilidade tangível e aos conjuntos de alcançabilidade tangível . . . . . . . 137

5.13 Programa para montagem da cadeia de Markov isomórfica a uma rede de Petri estocástica . . . . . . . . . . . . . . . . . . . . . 138

5.14 Experimento: montagem e análise de modelos . . . . . . . . . . . 143

5.15 Experimento: montagem dos conjuntos de predicados . . . . . . . 144

5.16 Experimento: conjuntos de predicados referentes às dinâmicas modeladas pelas redes de Petri estocásticas apresentadas nas figuras $5.13,5.14$ e $5.15 \ldots \ldots \ldots \ldots \ldots$

5.17 Experimento: análise horizontal . . . . . . . . . . . . . . . 146 


\section{Lista de abreviaturas}

AIASM Ambiente integrado de análise de sistemas de manufatura

AMA Ambiente de modelagem e análise

DSPN Deterministic and stochastic Petri nets ou redes de Petri determinísticas e estocásticas

GSPN Generalized stochastic Petri nets ou redes de Petri estocásticas generalizadas

IDEAS Integrated Design Environment for Assessment of Computer Systems

LiMA Linguagem de modelagem e análise

MFG Mark flow graph

MFG/PFS Metodologia MFG/PFS

PFS Production flow schema

SED Sistema a Eventos Discretos

SHARPE Symbolic Hierarchical Automated Reliability and Performance Evaluator

SMART Simulation and Markovian Analyzer for Reliability and Timing

SPN Stochastic Petri Nets ou redes de Petri estocásticas 


\title{
Lista de símbolos
}

\section{Capítulo 2}

\author{
$5 \quad$ Sistema \\ $\mathfrak{L} \quad$ Carga \\ $\mathfrak{d} \quad$ Comportamento dinâmico \\ $\mu \quad$ Modelo \\ $\Gamma_{A} \quad$ Informações dos aspectos sistêmicos considerados num processo \\ de modelagem \\ $\Gamma_{W} \quad$ Informações que se deseja obter com atividades envolvendo um \\ modelo \\ $\Phi \quad$ Tipo de modelo \\ $M_{\left(\Gamma_{A}, \Gamma_{W}, \Phi\right)} \quad$ Processo de modelagem considerando as informações $\Gamma_{A}$ e $\Gamma_{W}$ e \\ um tipo de modelo $\Phi$ \\ $\mu_{\text {exo }} \quad$ Modelo exógeno \\ $\mu_{\text {endo }}, \mu_{\text {endo }}^{\prime} \quad$ Modelos endógenos \\ $\pi, \pi^{\prime} \quad$ Análises \\ $r \quad$ Representação de modelo \\ $\alpha \quad$ Taxa de falha (exemplo de SHARPE) \\ $\gamma \quad$ Taxa de reconfiguração (exemplo de SHARPE) \\ $\delta \quad$ Taxa de reinicialização (exemplo de SHARPE) \\ $\beta \quad$ Taxa de reparo (exemplo de SHARPE) \\ c Probabilidade de falha recuperável por reconfiguração (exemplo \\ de SHARPE) \\ $n \quad$ Número de servidores (exemplo de SHARPE) \\ $b \quad$ Número de vagas no buffer (exemplo de SHARPE) \\ $i \quad$ Número de servidores ativos (exemplo de SHARPE) \\ $x_{i} \quad$ Estado de configuração de $i$ para $i-1$ servidores (exemplo de \\ SHARPE)
}



SHARPE)

\section{Capítulo 3}

$A$

$L_{C}$

$T_{C}$

$E_{C}$

$L_{B}$

$P_{B}$

$E_{B}$

$C_{A}$

$n_{A}$

$P_{(A, j)}$

$i_{(A, j), k}$

$n_{(A, j), I}$

$O_{(A, j), k}$

$n_{(A, j), O}$

$I_{(A, j), k}$

$O_{(A, j), k}$

$L_{M}$

$E_{\tau_{L_{C}, \Phi}}$
Ambiente de modelagem e análise

Linguagem de composição de um ambiente de modelagem e análise

\section{Termos de uma linguagem de composição}

Conjunto-alvo de uma linguagem de composição

Linguagem de montagem de um ambiente de modelagem e análise

Operações de uma linguagem de montagem

Conjunto-alvo de uma linguagem de montagem

Capacidade analítica de um ambiente de modelagem e análise

Número de procedimentos de análise que compõem uma capacidade analítica

j-ésimo procedimento de uma capacidade analítica

k-ésima entrada do j-ésimo procedimento de uma capacidade analítica

Número de estruturas de entrada do j-ésimo procedimento de uma capacidade analítica

k-ésima saída do j-ésimo procedimento de uma capacidade analítica

Número de estruturas resultantes do j-ésimo procedimento de uma capacidade analítica

Conjunto com as estruturas da k-ésima entrada do j-ésimo procedimento de uma capacidade analítica

Conjunto com as estruturas da k-ésima saída do j-ésimo procedimento de uma capacidade analítica

Linguagem de modelagem

Conjunto alvo de transcrição de modelos do tipo $\Phi$ numa linguagem de composição $L_{C}$ 
$\tau_{L_{C}, \Phi} \quad$ Função de transcrição de modelos de tipo $\Phi$ usando uma linguagem de composição $L_{C}$

$\Omega_{\Phi} \quad$ Conjuntos dos modelos de tipo $\Phi$

$E_{\tau_{L_{C}, \Phi}} \quad$ Conjunto alvo de transcrição de modelos do tipo $\Phi$ numa linguagem de composição $L_{C}$

$r^{\prime}, r_{1}, r_{2}, r_{3} \quad$ Representações de modelos

$I_{A} \quad$ Conjunto-alvo de procedimento de capacidade analítica voltada a um único tipo de modelo

$n_{\Phi} \quad$ Número de tipos de modelos

$\mu_{1}, \ldots, \mu_{n_{\Phi}} \quad n_{\Phi}$ modelos de diferentes tipos

$\Phi_{1}, \ldots, \Phi_{n_{\Phi}} \quad n_{\Phi}$ tipos de modelos diferentes

$\bar{C}_{i m p l} \quad$ Custo médio de implementação de um AMA simples

$C_{i m p l}^{*}\left(n_{\Phi}\right) \quad$ Custo de implementação de um AMA abrangente em função do número de tipos a considerar

$n_{\text {users }} \quad$ Número de usuários a utilizar o(s) AMA(s)

$\bar{C}_{\text {learn }} \quad$ Custo médio de aprendizagem de um AMA simples

$C_{\text {learn }}^{*}\left(n_{\Phi}\right) \quad$ Custo de aprendizagem de um AMA abrangente em função do número de tipos a considerar

$n_{\text {trans }} \quad$ Número de transições entre AMAs da primeira configuração

$\bar{C}_{\text {trans }} \quad$ Custo médio de transição entre AMAs da primeira configuração

$C_{\text {trans }}^{*} \quad$ Custo médio de transição entre operações sobre modelos de diferentes tipos da configuração de AMA abrangente

$C_{\text {other }} \quad$ Outros custos

$C_{\text {total }}^{\text {especificos }}$ Custos totais da configuração de AMAs específicos

$C_{\text {total }}^{\text {abrangente }}$ Custos totais da configuração de AMA abrangente

$K_{i m p l} \quad$ Constante representando custos de implantação de uma AMA com linguagem de modelagem abrangente e uniforme

$K_{\text {learn }} \quad$ Constante representando custos de aprendizagem de uma AMA com linguagem de modelagem abrangente e uniforme

\section{Capítulo 4}




\begin{tabular}{|c|c|}
\hline$f$ & $\begin{array}{l}\text { Função bijetora que mapeia estados de redes de Petri estocásticas } \\
\text { e de cadeias de Markov }\end{array}$ \\
\hline$S P N$ & spaço de estados de uma rede de Petri estocástica \\
\hline CTMC & spaço de estados de uma cadeia de Markov \\
\hline$s_{S P N}, s_{S P N}^{\prime}$ & Estados de uma rede de Petri estocástica \\
\hline$R S\left(m_{0}\right)$ & $\begin{array}{l}\text { Conjunto de alcançabilidade de uma rede de Petri com marcação } \\
\text { inicial } m_{0}\end{array}$ \\
\hline GSPN1 & Exemplo de rede de Petri generalizada estocástica \\
\hline M & Máquina de processamento referida nos exemplos \\
\hline $\mathrm{p}$ & Referência a uma peça \\
\hline buf & Um buffer \\
\hline$\lambda$ & $\begin{array}{l}\text { Taxa de disparo de transição de rede de Petri estocástica gene- } \\
\text { ralizada referente a processamento de peças numa máquina } \mathrm{M}\end{array}$ \\
\hline$\lambda_{i}$ & $\begin{array}{l}\text { Taxa de disparo de transição de rede de Petri estocástica gene- } \\
\text { ralizada referente a processamento de peças numa máquina M } \\
\text { sendo inspecionada }\end{array}$ \\
\hline$\lambda_{s}$ & $\begin{array}{l}\text { Taxa de disparo de transição de rede de Petri estocástica gene- } \\
\text { ralizada referente a sinalizações de inspeções }\end{array}$ \\
\hline$\pi$ & $\begin{array}{l}\text { Vetor com a distribuição de probabilidades de regime perma- } \\
\text { nente dos estados de uma cadeia de Markov }\end{array}$ \\
\hline GSPN2 & Exemplo de rede de Petri generalizada estocástica \\
\hline$T_{p}$ & $\begin{array}{l}\text { Taxa de processamentos finalizados numa máquina } \mathrm{M} \text { de um } \\
\text { sistema }\end{array}$ \\
\hline$s$ & Estado de um sistema \\
\hline$T_{p \mid s}$ & $\begin{array}{l}\text { Taxa de processamentos finalizados numa máquina M com o sis- } \\
\text { tema num estado } s\end{array}$ \\
\hline$\pi(s)$ & $\begin{array}{l}\text { Probabilidade de regime permanente de um estado } s \text { de um sis- } \\
\text { tema }\end{array}$ \\
\hline$f$ & $\begin{array}{l}\text { Functor utilizado para o cálculo de uma taxa de processamentos } \\
\text { finalizados }\end{array}$ \\
\hline$H(s)$ & $\begin{array}{l}\text { Conjunto de functores referentes a atividades que ocorrem num } \\
\text { estado } s\end{array}$ \\
\hline$r($ ativ $)$ & Taxa de finalização de uma atividade ativ \\
\hline$P(s)$ & Conjunto de functores referentes a processamentos de peça numa \\
\hline
\end{tabular}




\section{Capítulo 5}

$R \quad$ Conjunto de recursos

$r_{1}, \ldots, r_{R} \quad$ Recursos

$Q \quad$ Conjunto de produtos

$q_{1}, \ldots, q_{Q} \quad$ Produtos

$n_{q} \quad$ Número de etapas

$S_{q} \quad$ Seqüência de etapas para um produto $q$

$s_{q}(k) \quad k$-ésima etapa da seqüência de processos para o produto $q$

$r_{q}(k) \quad$ Recurso utilizado na $k$-ésima etapa da seqüência de processos para o produto $q$

GSPN1 Exemplo de rede de Petri generalizada estocástica

GSPN2 Exemplo de rede de Petri generalizada estocástica

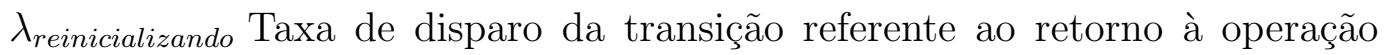
normal, após permanecer numa condição de reinicialização

M Máquina de processamento referida nos exemplos

p Referência a uma peça

buf Um buffer

$\lambda \quad$ Taxa de disparo de transição de rede de Petri estocástica generalizada referente a processamento de peças numa máquina $\mathrm{M}$

$\lambda_{i} \quad$ Taxa de disparo de transição de rede de Petri estocástica generalizada referente a processamento de peças numa máquina $\mathrm{M}$ sendo inspecionada

$\lambda_{s} \quad$ Taxa de disparo de transição de rede de Petri estocástica generalizada referente a sinalizações de inspeções

$\lambda_{B} \quad$ Taxa de disparo de transição de rede de Petri estocástica generalizada referente a processamento de peças de tipo B numa máquina $\mathrm{M}$

GSPN3 Exemplo de rede de Petri generalizada estocástica 


\section{Sumário}

1 Introdução $\quad 23$

1.1 Motivações . . . . . . . . . . . . . . . . . . . . . . . . . 24

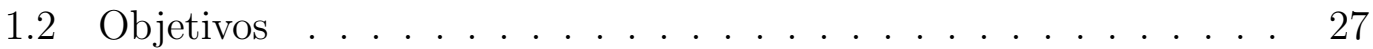

1.3 Metodologia . . . . . . . . . . . . . . . . . . 28

1.4 Estrutura do texto . . . . . . . . . . . . . . . . . . . . . 29

2 Fundamentos e contexto 31

2.1 Conceitos básicos . . . . . . . . . . . . . . . . . . 31

2.2 Discussão sobre a heterogeneidade dos modelos de SEDs . . . . . 35

2.3 Integração de modelos . . . . . . . . . . . . . . . . . . . . 37

2.4 Os aspectos formais e semânticos nos experimentos de modelagem e análise . . . . . . . . . . . . . . . . . . . . 40 40

2.5 Tratamento computacional de modelos heterogêneos na literatura 43

2.6 Representação computacional de modelos . . . . . . . . . . . . . . 45

2.7 Comentários do capítulo . . . . . . . . . . . . . . . . . . . . . . . 49

3 Representação computacional e a heterogeneidade formal dos modelos

3.1 Ambientes de modelagem e análise . . . . . . . . . . . . . 51

3.1.1 Descrição matemática de um AMA . . . . . . . . . . . . 52

3.1.2 Representação de tipos de modelos . . . . . . . . . . . 55

3.1.3 Conjuntos-alvos e sua coordenação . . . . . . . . . . . 57 
3.2 Questões envolvendo os elementos dos AMAs . . . . . . . . . 59

3.2.1 Estruturas intermediárias e flexilidade na montagem de representações . . . . . . . . . . . . . . . . . . 59

3.2.2 Abrangência e uniformidade da linguagem de composição . 61

3.2.3 Ambigüidade . . . . . . . . . . . . . . . 63

3.2.4 Redundância de representação e de processamento . . . . . 64

3.3 Consideração dos aspectos econômicos . . . . . . . . . . . . . 66

3.4 Análise de configurações de AMAs . . . . . . . . . . . . . . . 68

3.5 Diretrizes para um AMA para modelos heterogêneos . . . . . . . . 74

3.6 Comentários do capítulo . . . . . . . . . . . . . . . . 75

4 Representação de informações semânticas e integração de modelos heterogêneos

4.1 Integração de informações oriundas de estruturas heterogêneas de informação . . . . . . . . . . . . . . . . . . . 78

4.2 Predicados e estruturas afins . . . . . . . . . . . . . . . 80

4.3 Representação de informações da semântica dos modelos . . . . . 82

4.4 Representação integrada das informações associadas a modelos referentes a uma mesma dinâmica . . . . . . . . . . . . . . . 87

4.5 Consistência horizontal . . . . . . . . . . . . . . . . . . 95

4.6 Comentários do capítulo . . . . . . . . . . . . . . . . . . . . . 98

5 Exemplo de implementação de linguagem 100

5.1 Linguagem LiMA . . . . . . . . . . . . . . . . . . . . 100

5.1.1 Expressão das representações . . . . . . . . . . . . . . . . 101

5.1.2 Exemplo: cadeias de Markov de tempo contínuo . . . . . . 103

5.1.3 Exemplo: redes de Petri marcadas . . . . . . . . . . . . . . 104

5.1.4 Exemplo: grafos de solicitação/alocação . . . . . . . . . 106 
5.2 Operações da linguagem LiMA . . . . . . . . . . . . . 107

5.2 .1 Variáveis . . . . . . . . . . . . . . . . . . . . . . . 108

5.2.2 Operações envolvendo proto-representações . . . . . . . . . 110

5.2.3 Operações envolvendo representações bem-formadas . . . . 113

5.2 .4 Módulos . . . . . . . . . . . . . . . . . . . . . . 115

5.2.5 Elementos de controle de fluxo de execução . . . . . . . . . 117

5.3 Representação de informação semântica na linguagem LiMA . . . 118

5.4 Exemplo: montagem de representações . . . . . . . . . . . . . . . 124

5.5 Exemplo: integração e montagem de representações . . . . . . . . 136

5.6 Exemplo: relacionamentos horizontais . . . . . . . . . . . . 140

5.7 Comentários do capítulo . . . . . . . . . . . . . 146

$\begin{array}{llr}6 & \text { Conclusões } & 150\end{array}$

$\begin{array}{ll}\text { Referências } & 154\end{array}$

Apêndice A - Formalismos de Sistemas a Eventos Discretos 160

A.1 Redes de Petri . . . . . . . . . . . . . . . . 160

A.1.1 Estruturas observadas nas redes de Petri . . . . . . . . 163

A.1.2 Grafo de alcançabilidade . . . . . . . . . . . . . . 164

A.1.3 Propriedades das redes de Petri . . . . . . . . . . . . 166

A.1.4 Modelagem por redes de Petri . . . . . . . . . . . . . 168

A.2 Cadeias de Markov de tempo contínuo . . . . . . . . . . . 171

A.2.1 Equações da cadeia de Markov . . . . . . . . . . . . . . . 173

A.2.2 Propriedade da ausência de memória . . . . . . . . . . 175

A.2.3 Cadeias de Markov de tempo contínuo ergódicas . . . . . . 175

A.2.4 Aplicação . . . . . . . . . . . . . . . . . 177 
A.3 Redes de Petri estocásticas . . . . . . . . . . . . . . . . . . 180

A.3.1 Redes de Petri estocásticas $(\mathrm{SPN}) \ldots \ldots$. . . . . . . . 180

A.3.2 Redes de Petri estocásticas generalizadas (GSPN) . . . . . 182 


\section{Introdução}

Os chamados Sistemas Dinâmicos a Eventos Discretos (CASSANDRAS, 1993) (ou SEDs) representam uma classe de sistemas sob cuja perspectiva é possível abordar aspectos estruturais e funcionais de sistemas como os de comunicação, de computação e de produção, caso de interesse deste trabalho. É do estudo desses sistemas que aspectos como a lógica de coordenação de operações, as estratégias de alocação de recursos e a taxa de execução de tarefas podem ser avaliadas.

Do ponto de vista da abstração de sistemas que abordam, os SEDs se caracterizam por apresentarem:

- estados discretos;

- transições instantâneas entre estados;

- transições associadas a ocorrências de eventos.

Ou seja, o foco dessa caracterização está no comportamento dinâmico ou dinâmica dos sistemas: estes termos são definidos com mais detalhe na seção 2.1, mas por ora, é suficiente dizer que a dinâmica de um sistema refere-se a uma particular configuração de estados e transições de estados.

Este trabalho é sobre o tratamento computacional de SEDs, em particular, considerando-se um contexto de diversidade na modelagem matemática desses sistemas e, conseqüentemente, nas técnicas de análise matemáticas com as quais suas propriedades são avaliadas.

Neste capítulo, apresentam-se uma visão geral das motivações, os objetivos do trabalho, a metodologia e a estrutura do texto. 


\subsection{Motivações}

Conforme mencionado no início, existe uma variedade de abordagens de modelagem e análise de SEDs. Na tabela 1.1, encontram-se algumas das abordagens mais conhecidas. Dentro do enfoque deste trabalho, é importante observar que cada uma delas trata de aspectos específicos dos sistemas e que as conclusões que podem ser obtidas da análise dos modelos são também limitadas a certas propriedades. Assim, tem-se que a heterogeneidade dos modelos de SEDs enfocada por este trabalho é aquela determinada pela diversidade e especificidade dessas abordagens.

Em razão das especificidades, há vários motivos para se envolver com modelos heterogêneos, entre os quais:

- por motivos didáticos (SANDERS et al., 2003);

- para a comparação de técnicas de análise (SANDERS et al., 2003);

- para verificar consistência de resultados;

- pois certos projetos exigem a cobertura de diversos aspectos sistêmicos e/ou uma variedade de informações a serem obtidas por análise;

- para desenvolver abordagens baseadas na integração de modelos (algumas das quais são discutidas no capítulo 2).

Com relação aos experimentos de modelagem e análise de SEDs referentes a essas atividades, observa-se uma preocupação de ordem formal e outra de ordem semântica.

A questão formal é decorrente da exigência pelas técnicas matemáticas de que somente modelos bem-formados sejam propostos para análise. Isto é decorrência do fato de que o ferramental matemático em geral é aplicável em condições bastante específicas. Assim, o que é observado numa dinâmica deve ser expresso nos padrões exigidos pelos formalismos associados aos modelos para que estes possam ser analisados. Portanto, quando modelos heterogêneos estão envolvidos, a sua heterogeneidade matemático-formal acaba sendo uma fonte de complexidade, em virtude da especificidade de seus tratamentos matemáticos. 
Tabela 1.1: Abordagens de tratamento de SEDs

\begin{tabular}{|c|c|}
\hline Abordagem & Características \\
\hline Redes de Petri & $\begin{array}{l}\text { Modelam relações de nexo causal entre as variáveis de } \\
\text { estado de um SED e, entre as características que per- } \\
\text { mite representar, tem-se o paralelismo, as sincronizações } \\
\text { e as decisões; de sua análise obtém-se informações sobre } \\
\text { propriedades qualitativas, como vivacidade e reiniciabi- } \\
\text { lidade. (MURATA, 1989). }\end{array}$ \\
\hline Teoria de Filas & $\begin{array}{l}\text { Modela fenômenos relacionados a congestionamentos } \\
\text { que ocorrem quando entidades denominadas clientes } \\
\text { procuram entidades denominadas servidores para rece- } \\
\text { berem algum tipo de serviço; as informações típicas que } \\
\text { se procura são os tempos de espera de um cliente após } \\
\text { entrar na fila, o grau de ocupação de servidores e a taxa } \\
\text { de atendimento; no caso de Redes de Filas, os clien- } \\
\text { tes percorrem uma malha de servidores (KLEINROCK, } \\
\text { 1975; GELENBE; PUJOLLE, 1987). }\end{array}$ \\
\hline Cadeias de Markov & $\begin{array}{l}\text { Modelam os estados, as transições entre estados e as pro- } \\
\text { babilidades destas ocorrerem; de sua análise, determina- } \\
\text { se a probabilidades de cada estado num certo instante de } \\
\text { tempo (KLEINROCK, 1975; KULKARNI, 1995; BOLCH } \\
\text { et al., 1998). }\end{array}$ \\
\hline Álgebra Minimax & $\begin{array}{l}\text { Trata-se de uma álgebra baseada nos operadores min } \\
\text { e max, com a qual se monta as relações de inícios e } \\
\text { fins de uma malha de atividades, com a qual pode-se } \\
\text { ter informações, por exemplo, de qual o período que } \\
\text { uma atividade (dentro dessa malha) pode ser iniciada } \\
\text { (COHEN et al., 1985). }\end{array}$ \\
\hline $\begin{array}{l}\text { Análise de Per- } \\
\text { turbação }\end{array}$ & $\begin{array}{l}\text { A partir de uma amostra (sample path) dos resultados } \\
\text { da simulação de uma rede de filas, faz-se uma análise, } \\
\text { baseado nessa amostra, sobre o que ocorre se uma per- } \\
\text { turbação num dos parâmetros do sistema for introdu- } \\
\text { zida, podendo-se fazer uma análise de sensibilidade de } \\
\text { uma medida de desempenho em relação ao parâmetro } \\
\text { perturbado (CAO, 1989). }\end{array}$ \\
\hline
\end{tabular}


Além da adequação formal, existe a da semântica dos modelos. Semântica (SHETH, 1995), de forma geral, refere-se ao significado de uma expressão. Neste texto, semântica refere-se aos aspectos observados na dinâmica que os modelos matemáticos descrevem. Assim, para serem úteis, a semântica dos modelos e dos resultados das análises devem estar em conformidade com os aspectos observáveis no sistema.

Além dessa correspondência entre expressão formal e objeto da modelagem, tem-se que a integração de modelos decorre dos relacionamentos entre as suas semânticas (o que também é observado, analogamente, em diversos casos de integração de informações de fontes heterogêneas (URBAN, 1991; ZISMAN, 1995; MACKAY, 1999; CRUZ et al., 2002)); com efeito, o simples fato de se referirem a uma mesma dinâmica representa um vínculo. Também, é através das semânticas dos modelos que se pode observar relacionamentos entre modelos referentes a dinâmicas diferentes (decorrentes de sistemas e/ou regras dinâmicas diferentes): existem padrões nas semânticas de tais modelos que permitem que questões sobre uma mesma característica possam ser formuladas de forma que façam sentido, mesmo em modelos muito diferentes - por exemplo, sobre a taxa de produção ou sobre o grau de ocupação de um certo equipamento. Aos relacionamentos que ocorrem relativos a uma mesma dinâmica, o texto dá o nome de relacionamentos verticais; quando ocorre entre dinâmicas diferentes, recebem a denominação de horizontais. A consideração desses relacionamentos semânticos é importante na formação de uma interpretação integrada dos modelos e dos resultados das análises que ocorrem num experimento.

Com relação aos trabalhos computacionais de modelagem e análise, estas ocorrem no que o texto chama de ambientes de modelagem e análise ou AMAs. Entre as ferramentas computacionais que lidam com modelos heterogêneos, podese citar o IDEAS (FRICKS et al., 1997), o FREUD (MOORSEL; HUANG, 1998), o AIASM (ARATA; MIYAGI, 2005), o SMART (CIARDO et al., 2003), o SHARPE (TRIVEDI, 2002) e o Möbius (SANDERS et al., 2003). Estes AMAs apresentam diferentes abordagens com relação à heterogeneidade formal dos modelos e à integração destes.

Um elemento importante nos AMAs para modelos heterogêneos é o da sua representação computacional desses modelos. A forma de tais representações determina a facilidade na visualização dos modelos, os tipos de operações para a 
montagens dessas representações, e a facilidade na implementação dos procedimentos computacionais que executam os métodos de análise. Ainda, no caso de integração de modelos, formas de representações muito diferentes significam esforço adicional além daquele para lidar com a complexidade oriunda da heterogeneidade de modelos.

A partir desta discussão, tem-se que as motivações deste trabalho são:

- suportar computacionalmente experimentos de modelagem e análise envolvendo modelos heterogêneos de SEDs, cujas utilização e integração atendem as necessidades apontadas no texto;

- dentro da busca de uma solução computacional adequada para o item anterior, no que se refere às representações computacionais dos modelos, tem-se:

- a necessidade de compatibilizar as diferenças matemático-formais entre os modelos de diversos tipos;

- a perspectivas na elaboração de um esquema de representação da integração de modelos com a consideração de suas semânticas, de forma que se possa ter um tratamento computacional adequado.

\subsection{Objetivos}

Tal como os AMAs citados na seção anterior, este trabalho igualmente envolve o emprego de um AMA voltado a modelos heterogêneos de SEDs. Isto implica que tal AMA deve comportar as representações computacionais de tais modelos e os procedimentos computacionais que implementam os respectivos métodos de análise. Entretanto, focando na questão das representações computacionais, os objetivos, isto é, as contribuições originais do trabalho, são:

- identificar as característica que fazem um AMA (com uma linguagem de modelagem que consiga montar, expressar e manipular representações computacionais de modelo heterogêneos de SEDs) ser mais eficiente que outras configurações em termos de utilização mais racional de recursos computacionais e humanos;

- apresentar descrições baseadas nas semânticas dos diferentes modelos de SEDs como meio de tratar as diversas formas de integração envolvidas na 
modelagem (seja intra ou intermodelos, seja verticais ou horizontais), representado as informações trazidas pelos modelos de forma que espelhem tal integração e seus vínculos semânticos.

No primeiro item, o trabalho busca uma forma de compatibilizar a heterogeneidade matemático-formal dos modelos de forma a minimizar essa heterogeneidade até o ponto em que resta apenas as diferenças inerentes aos modelos. Porém, essa compatibilização não implica integração de modelos, mesmo porque ainda existem essas diferenças inerentes. É no segundo objetivo que se procura o elemento que faz essa articulação entre modelos que se integram e, aqui, a abordagem é o de utilizar descrições orientadas às semânticas dos modelos.

No decorrer do texto, considera-se que a capacidade de lidar com modelos heterogêneos de SEDs implica multiplicidade e extensibilidade. Com relação à primeira característica, para que se possa lidar com a integração, deve-se pode trabalhar com múltiplos modelos. Quanto à segunda, a heterogeneidade não deve se limitar ao caso de alguns tipos de modelos específicos, devendo, tanto quanto possível, ser extensível, ou seja, deve poder abranger tipos de modelos que não foram considerados inicialmente (por exemplo, porque ainda serão desenvolvidos).

\subsection{Metodologia}

Os próprios objetivos estabelecidos refletem uma decisão metodológica na qual, primeiramente, tratou-se das condições para que modelos heterogêneos de SEDs sejam representadas de uma maneira uniforme. Assim, neste item, a metodologia adotada compreendeu os seguintes pontos:

- elaboração de um modelo matemático para AMAs, com o qual se pode visualizar as relações entre os tipos de modelos, suas representações computacionais e as linguagens em que estas são feitas;

- identificação de características que auxiliam ou atrapalham no tratamento de modelos heterogêneos com base no modelo elaborado;

- introdução dos custos relevantes no desenvolvimento, adoção e operação das ferramentas computacionais; 
- comparação de configurações de ferramentas computacionais, considerandose os custos relevantes, direcionando as conclusões para a indicação dos fatores que levam a adoção de ferramentas que utilizam linguagem de modelagem voltada a modelos heterogêneos de SEDs;

- elaboração de diretrizes para ferramentas computacionais com linguagem de modelagem voltada a modelos heterogêneos de SEDs, com base no que foi concluído nos itens anteriores (como o modelo para ferramentas basicamente trata da linguagem de modelagem, as conclusões aqui têm relação com esta).

Uma vez resolvida a questão do tratamento da heterogeneidade matemáticoformal dos modelos de SEDs, a segunda parte tratou da integração dos modelos, através de descrições baseadas nas semânticas dos modelos. Neste caso, os pontos considerados foram:

- introdução de predicados e elementos afins para a descrição de fatos pertinentes à semântica do modelos para ilustrar a apresentação dos conceitos;

- caracterização da semântica dos modelos e de sua representação;

- discussão do papel da semântica dos modelos na integração dos mesmos e elaboração da forma desta integração ser representada;

- exame da questão dos relacionamentos horizontais e de como as semânticas dos modelos e sua representação podem tirar proveito deles.

\subsection{Estrutura do texto}

O presente texto está dividido nos seguintes capítulos:

- Capítulo 1 - Introdução: este capítulo.

- Capítulo 2 - Fundamentos e contexto: apresenta os conceitos básicos considerados no texto e uma discussão mais aprofundada da heterogeneidade dos modelos de SEDs e da integração destes e de aspectos relevantes para o seu tratamento computacional. 
- Capítulo 3 - Representação computacional e a heterogeneidade formal dos modelos: apresenta uma descrição das ferramentas computacionais e dos tipos de modelos para SEDs baseada em conjuntos. Juntamente com considerações de custos, argumenta-se que as ferramentas voltadas para a heterogeneidade de modelos é uma solução com melhor relação custo/benefício que aquelas menos integradas; ao mesmo tempo, aponta quais características devem possuir e quais as questões a serem resolvidas.

- Capítulo 4 - Representação de informações semânticas e integração de modelos heterogêneos: apresenta as descrições de aspectos da semântica dos modelos de SEDs (em termos de entidades, fatos e relacionamentos observáveis na dinâmica modelada) como uma forma de se obter um quadro descritivo integrado com as informações fornecidas pelos modelos, o que é importante para visualização das relações entre os elementos dos modelos e para a implementação de análises que pressupõem a integração de modelos.

- Capítulo 5 - Exemplo de implementação de linguagem: apresenta uma implementação dos conceitos desenvolvidos e exemplos de como utilizá-la.

- Capítulo 6 - Conclusões.

- Apêndice A - Formalismos de Sistemas a Eventos Discretos: faz uma exposição introdutória dos principais modelos citados no texto e das suas técnicas de análise. 


\section{Fundamentos e contexto}

O objetivo deste capítulo é de apresentar um quadro mais detalhado e estruturado correspondente ao contexto deste trabalho. Assim, inicialmente, faz-se uma apresentação dos conceitos básicos na forma como são entendidos no trabalho. A seguir discute-se a natureza da heterogeneidade dos modelos de SEDs (Sistemas a Eventos Discretos), a integração desses modelos, os aspectos formais e semânticos nos experimentos de modelagem e análise, uma breve descrição de AMAs (Ambientes de Modelagem e Análise) voltados para modelos heterogêneos de SEDs e o papel das representações computacionais nos AMAS.

\subsection{Conceitos básicos}

Os conceitos são apresentados numa ordem em que aqueles relacionados à observação do mundo real vêm primeiro, seguido daqueles referentes ao tratamento matemático dos sistemas e, enfim, aqueles referentes ao âmbito computacional.

O primeiro conceito é o de sistema, ao qual todos os demais se referem:

\section{Definição 2.1 (Sistema)}

Sistema é um conjunto de entidades que interagem entre si e com o ambiente ao redor.

No contexto deste trabalho (e todos aqueles que se referem a SEDs), sempre associado aos sistemas aqui considerados, outro conceito importante é o de carga (JAIN, 1991):

\section{Definição 2.2 (Carga)}

Carga são as interações externas ao sistema que atuam sobre este e induzem uma resposta do sistema.

Da interação entre sistema e carga, tem-se o seguinte: 


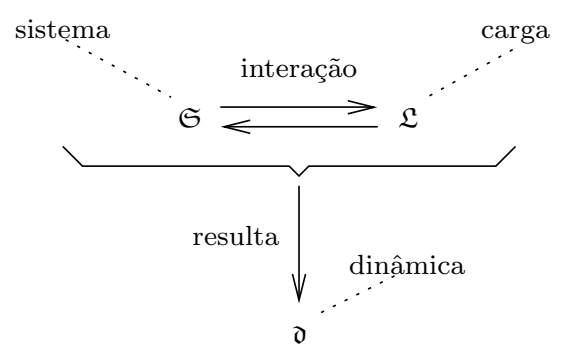

Figura 2.1: Interação entre um sistema $\mathfrak{S}$ e uma carga $\mathfrak{L}$ provoca um comportamento dinâmico $\mathfrak{d}$

\section{Definição 2.3 (Comportamento de um sistema)}

Comportamento de um sistema é o conjunto de fenômenos que nele ocorrem ao ser submetido a uma carga.

Um classe importante de sistemas são os sistemas dinâmicos (ORSINI, 1985):

\section{Definição 2.4 (Sistema dinâmico)}

Sistemas dinâmicos são aqueles cuja evolução futura de estados depende de estados que ocuparam anteriormente.

Para o comportamento dos sistemas dinâmicos, utiliza-se a expressão comportamento dinâmico ou simplesmente dinâmica. Este é o foco das abordagens que estudam SEDs (inclusive daquelas da tabela 1.1), ou seja, as dinâmicas de sistemas submetidas a uma certa carga. A figura 2.1 esquematiza os relacionamentos desses conceitos.

Para um tratamento matemático das dinâmicas de SEDs, um conceito importante é o de modelos (BOOCH, 1991; BOOCH; RUMBAUGH; JACOBSON, 1998):

\section{Definição 2.5 (Modelo)}

Modelo é uma descrição abstrata de um aspecto do sistema.

Portanto, um modelo tem, com os sistemas, uma relação de abstração (BOOCH, 1991), ou seja, considera os elementos relevantes (seletividade) e ignora os demais (parcialidade).

Uma outra definição é a de tipos.

\section{Definição 2.6 (Tipo de modelo)}

Tipo de modelo (ou simplesmente tipo) é uma referência a um conjunto de modelos que utilizam os mesmos elementos matemáticos e podem ser tratados com 


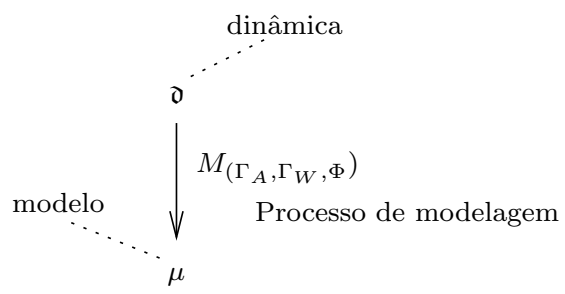

Figura 2.2: Processo de abstração $M$ mapeando dinâmica $\mathfrak{d}$ e modelo $\mu$

o mesmo ferramental matemático.

Tal definição é importante para distinguir tipos de modelos e instâncias de tipos (que são os modelos propriamente ditos).

\section{Exemplo 2.1 (Modelo versus tipo de modelo)}

Uma rede de Petri (ver apêndice $A$ ) enquanto modelo, refere-se a uma descrição de um sistema específico (por exemplo, rede de Petri modelando a operação de uma célula de manufatura sendo projetada). Redes de Petri (enquanto tipo de modelo) é uma referência a um conjunto de modelos que tratam dos mesmos aspectos sistêmicos e das mesmas propriedades (redes de Petri modelam sistemas envolvendo processos concorrentes e assíncronos).

A figura 2.2 representa o processo de modelagem, onde um modelo $\mu$ descrevendo uma dinâmica $\mathfrak{d}$ é gerado por um processo de modelagem denotado por $M_{\left(\Gamma_{A}, \Gamma_{W}, \Phi\right)}$, que indica os elementos considerados no processo, ou seja, $\Gamma_{A}$ denota as informações dos aspectos sistêmicos consideradas, $\Gamma_{W}$, as informações que se deseja obter e $\Phi$, o tipo do modelo.

Com estes conceitos, pode-se apresentar a seguinte definição da heterogeneidade de modelos:

\section{Definição 2.7 (Modelos heterogêneos)}

Modelos são ditos heterogêneos se forem de tipos diferentes.

Assim, tem-se que, neste texto, modelos heterogêneos são uma referência a modelos de SEDs de tipos diferentes (ou seja, uma distinção estrutural); enquanto isso, a distinção entre dois modelos de SEDs de mesmo tipo (duas redes de Petri referentes a sistemas diferentes) é um caso de diferença de instâncias.

Ainda dentro da parte matemática, a seguinte atividade é importante: 


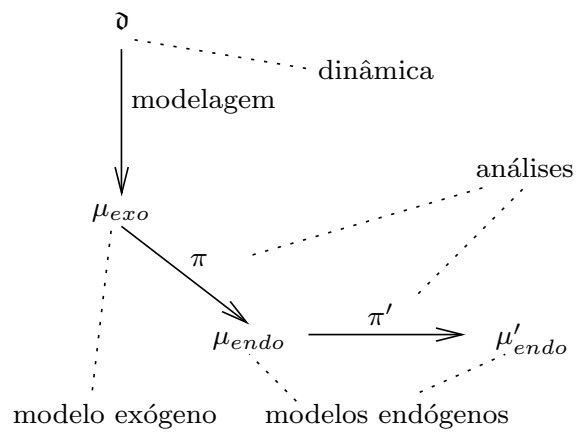

Figura 2.3: Análise e modelos endógenos e exógenos

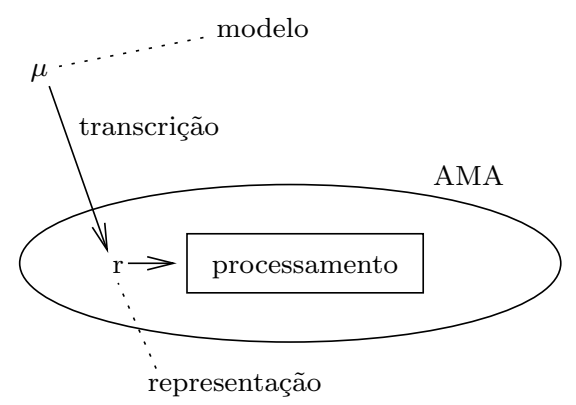

Figura 2.4: Transcrição

\section{Definição 2.8 (Análise)}

A análise é a atividade na qual informações são obtidas de modelos através da utilização de técnicas matemáticas.

Neste trabalho, os resultados das análises de SEDs, são também considerados modelos, uma vez que descrevem aspectos específicos da dinâmica enfocada. Para diferenciar os modelos obtidos por processos de modelagem abstrata e aqueles obtidos da análise de outros modelos, aos primeiros dá-se a denominação de exógenos e, aos últimos, de endógenos (ver figura 2.3).

Relacionando abstrações matemáticas a suas formas voltadas para o processamento computacional, tem-se as transcrições e as representações computacionais:

\section{Definição 2.9 (Transcrição e representação computacional)}

A transcrição é o processo de expressar um modelo do qual resulta uma estrutura contendo símbolos e valores destinada a passar por um processamento computacional. A tal estrutura, dá-se a denominação de representação computacional desse modelo.

A figura 2.4 esquematiza o processo de transcrição e o fato de as repre- 
sentações computacionais existirem dentro dos AMAs; é sobre essas representações que os trabalhos computacionais são realizados; é nelas que recai o foco deste trabalho.

\subsection{Discussão sobre a heterogeneidade dos mo- delos de SEDs}

Conforme já observado antes, uma das características no estudo de SEDs é a existência de múltiplas e diversas abordagens de modelagem e análise. Por trás disso, tem-se que cada uma dessas abordagens trata de aspectos dinâmicos bem delimitados e cujas análises fornecem informações bastante específicas, fato que está relacionado com o seguinte princípio:

\section{Princípio 2.1 (Compromisso entre expressividade e tratabilidade)}

Quanto maior a quantidade e variedade de informações de um modelo, maior a dificuldade em desenvolver uma técnica de análise que tire proveito do conjunto de informações do modelo.

Este princípio tem conseqüências importantes no desenvolvimento das abordagens de modelagem e análise. Segundo o mesmo, um modelo compreendendo uma descrição detalhada e, ao mesmo tempo, abrangente de um sistema (cuja montagem, per se, já pode ser muito custosa) tende a onerar seu tratamento matemático. Na impossibilidade de desenvolver uma técnica analítico-dedutiva que atenda a todas as situações possíveis, uma saída é a utilização de simulações, que, de qualquer maneira, pelas mesmas razões, tendem a ser onerosas.

A dificuldade em ampliar o poder de expressão pode ser também constatada observando-se as técnicas desenvolvidas, pelo fato de algumas delas se aproveitarem de hipóteses relativamente restritivas. Este é o caso das cadeias de Markov (KULKARNI, 1995) e as distribuições exponenciais (ou da propriedade da ausência de memória); graças a essa propriedade, pode-se estudar o comportamento da distribuição das probalidades de estados em termos matriciais relativamente simples. Um outro caso notório é o das redes de filas em forma de produto (BOLCH et al., 1998): neste caso, tem-se a redes de Jackson (filas com chegadas de clientes segundo uma distribuição de Poisson e com execução de serviços com distribuições markovianas). Apesar do caráter restritivo, não se pode questionar 
a utilidade, sobretudo, destes dois modelos, que constituem a base do desenvolvimento de muitos outros tipos de modelos.

Assim, este é um fator que leva à compartimentalização do espaço de estudo, ou seja, para cada aspecto a tratar e para cada tipo de informação que se deseja obter, desenvolve-se um tipo de modelo analítico que procura capturar os padrões essenciais e relevantes daquele aspecto. Os tipos de modelos assim elaborados tendem a ser mais simples que os modelos detalhistas e abrangentes. Uma conseqüência é que o tratamento matemático tende a ser mais factível.

É dessa forma que o princípio acima contribui para a heterogeneidade, ou seja, para cada tipo de estudo, um tipo de modelo de SEDs. Um efeito disso é que as pesquisas ocorrem de forma distribuída, uma vez que diferentes interesses guiam diferentes desenvolvimentos (o que é claramente perceptível pela tabela 1.1).

Com relação aos mecanismos para o desenvolvimento de novos tipos de modelos, um modo é se basear em tipos já existentes. Uma forma disso ocorrer é relaxando algumas hipóteses dos tipos de modelos. Um exemplo disso é a relação entre redes de Petri estocásticas (SPN) e redes de Petri estocásticas generalizadas (GSPN) (ver apêndice A): estas últimas, além das transições temporizadas estocásticas presentes nas primeiras, apresentam transições imediatas. Ainda, as redes de Petri determinísticas e estocásticas (DSPN) (CIARDO; LINDEMANN, 1993) adicionam, às transições imediatas e estocásticas, transições com temporizações determinísticas.

Da mesma forma, os tipos de modelos baseados em filas Bolch et al. (1998) apresentam mecanismos semelhantes: enquanto que os modelos mais simples de filas envolvem distribuições exponenciais, tipos de modelos mais complexos dessa classe são elaborados considerando-se distribuições genéricas (ou seja, não markovianas) e introduzindo-se elementos como bloqueios, sincronizações e diferentes disciplinas de atendimento (BOLCH et al., 1998).

Um outro mecanismo que aumenta a variedade de tipos de modelos é a extensão através da inclusão de diferentes características. As redes de Petri (MURATA, 1989) apresentam muitos desses casos: redes predicado/transição (GENRICH, 1987), redes de Petri coloridas (CHRISTENSEN; HANSEN, 1993), redes de Petri estendidas (VALAVANIS, 1990), redes de Petri com elementos de orientação 


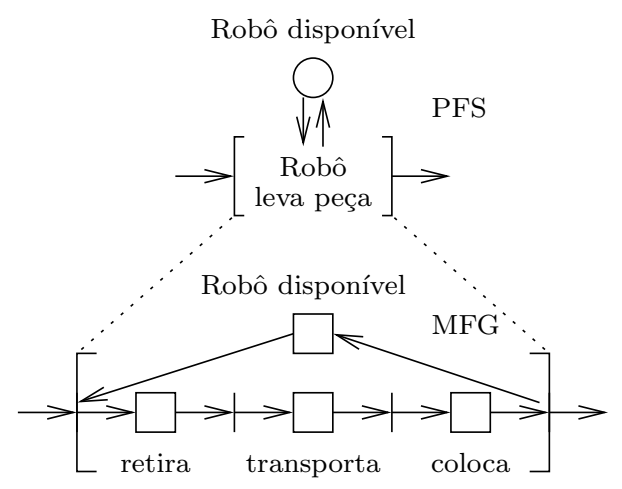

Figura 2.5: MFG detalhando atividade representada pelo PFS

à objetos (LAKOS, 1995) e os já citados tipos de redes de Petri estocásticas (MOLLOY, 1980; MARSAN; CONTE; BALBO, 1984; SANDERS; MEYER, 2002).

Além dos modelos voltados para análise matemática, há tipos de modelos de SEDs para auxiliar na montagem de outros modelos (para serem analisados matematicamente por exemplo). Um exemplo é o do PFS ("Production Flow Schema"), utilizado na metodologia MFG/PFS (HASEGAWA et al., 1999) como uma primeira abordagem na modelagem de sistemas de produção discretos, a partir do qual se contrói um modelo MFG ("Mark Flow Graph", um tipo de modelo baseado em redes de Petri apresentando, entre outros, elementos voltados para o controle de SEDs), conforme ilustrado na figura 2.5.

Um outro caso é o das árvores de falhas (ANDREWS; DUGAN, 1999), que podem ser mapeadas em cadeias de Markov, com as quais análises são efetivamente realizadas.

Estas, portanto, são algumas das razões e dos mecanismos que levam ao desenvolvimento distribuído de tipos de modelos de SEDs e à sua heterogeneidade matemático-formal. Há, também, modelos cuja função é ajudar na análise de outros, caso descrito na seção seguinte.

\subsection{Integração de modelos}

Modelos heterogêneos de SEDs podem ser utilizados integradamente de diferentes formas, como um meio de incrementar as capacidades descritivas e/ou analíticas . Nesta seção, alguns desses meios são discutidos. 
O primeiro caso é aquele onde um modelo existe em função de outro, por exemplo, a fim de auxiliar na análise deste. Este é o caso dos grafos de alcançabilidade e as redes de Petri (ver apêndice A), cujos elementos dos primeiros referem-se a elementos dos últimos: enquanto as redes de Petri, em si, descrevem as regras de evolução dinâmica, os grafos de alcançabilidade mostram os estados e as suas transições, descrevendo estes em termos dos elementos das redes de Petri a que se referem (no caso, de seus lugares e de suas transições).

No caso do isomorfismo entre redes de Petri estocásticas e cadeias de Markov de tempo contínuo (ver apêndice A), o que se observa é um relacionamento entre tipos de modelos desenvolvidos independentemente (Markov apresentou os primeiros resultados no início do século 20 (MARKOV, 1906 apud BASHARIN; LANGVILle; NAUMOV, 2004), enquanto que a tese de Carl A. Petri (PETRI, 1962 apud MURATA, 1989) foi apresentada em 1962). Os benefícios desses relacionamentos são a facilidade na descrição de dinâmicas através das redes de Petri e a capacidade de fornecer informações quantitativas das cadeias de Markov (no caso, sob a forma de probabilidades de estados).

Uma outra forma de integração é a composição hierárquica de modelos como aquela tratada pelo sistema SHARPE (TRIVEDI, 2002) Reproduzindo um exemplo descrito por Bolch et al. (1998), tem-se um modelo composto baseado na cadeia de Markov e na rede de filas apresentadas na figura 2.6. A cadeia de Markov que modela a disponibilidade de um conjunto de $n$ servidores associado a um buffer com $b$ vagas (onde ficam os clientes não atendidos) frente a ocorrências de falhas, a recuperações bem-sucedidas (ou seja, com rápidas reconfigurações) e mal-sucedidas (ou seja, com reinicializações demoradas) e reparos; as taxas de falha, de reconfiguração, de reinicialização e de reparos são denotadas por $\alpha, \gamma$, $\delta$ e $\beta$ respectivamente; as falhas com reconfiguração dão-se com probabilidade $c$ e aquelas com reinicialização, com probabilidade $(1-c)$; por hipótese, nenhum evento ocorre durante as reconfigurações e as reinicializações. Com relação aos estados, $i(0 \leq i \leq n)$ refere-se à quantidade de servidores disponíveis para serviço, $x_{i}$, à reconfiguração do estado $i$ para $i-1, y_{i}$, à reinicialização do estado $i$ para $i-1$. Para cada um dos estados $i(1 \leq i \leq n)$, há uma rede de filas como a apresentada na figura, onde o valor $i$ determina o número de servidores $i$ nessa rede; ou seja, trata-se de um modelo composto por várias redes de filas, cada uma considerada conforme o número de servidores, que é modelado como estado da 

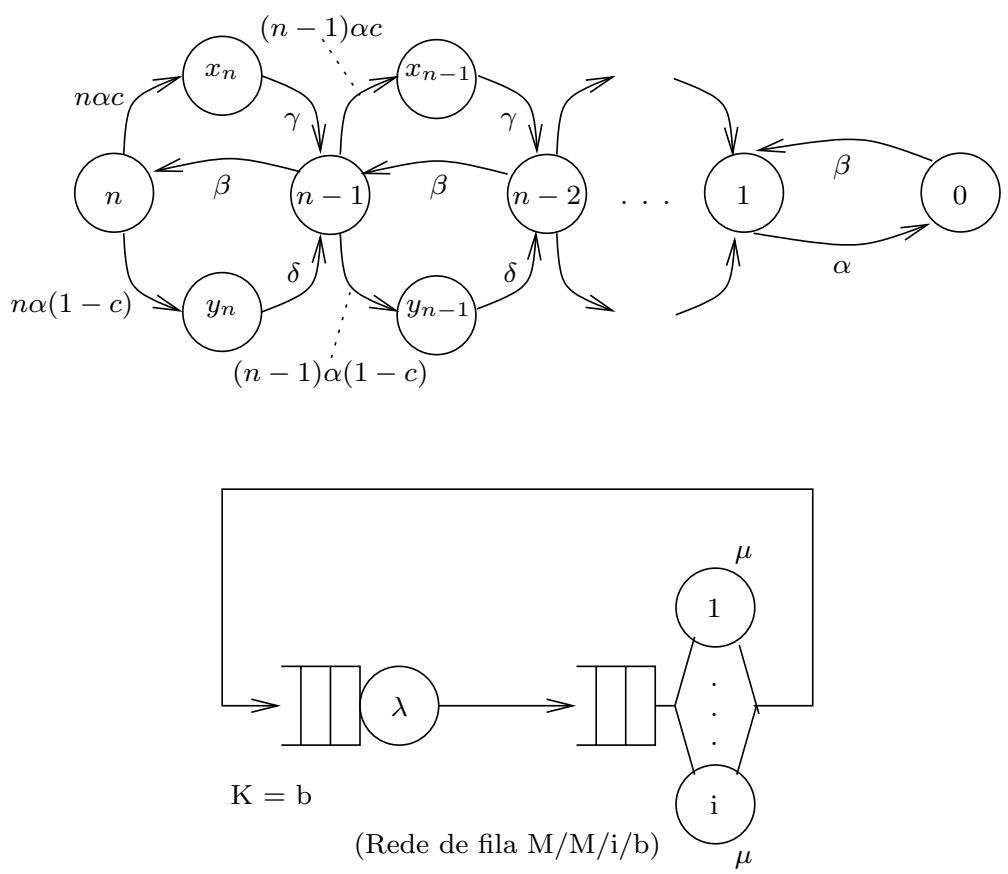

Figura 2.6: Modelos de alto nível (cadeia de Markov) e de nível inferior (rede de filas) - exemplo de composição de modelos na abordagem do sistema SHARPE

cadeia de Markov. Neste caso, tem-se o benefício de se utilizar modelos simples de Markov e de redes de filas ao invés de uma única rede de filas com características complexas.

Uma outra abordagem de integração por composição de modelos é apresentada pelo esquema (framework) Möbius (DEAVOURS; SANDERS, 2001; SANDERS et al., 2003). Neste, os diversos formalismos a serem incluídos devem ter seus elementos expressos em termos de componentes do esquema. Na figura 2.7, os lugares de redes de Petri estocásticas são associados a componentes da classe StateVariable (variável de estado) e as transições dessas redes são associados a componentes da classe Action (ação). Assim, pode-se especificar dinâmicas através de várias redes de Petri estocásticas que o sistema traduz tais modelos em termos de componentes Möbius; é através desses componentes Möbius que o sistema realiza as análises que implementa (como geração do espaço de estados). A integração de modelos pode ser feita com a utilização de modelos de formalismos que foram mapeados com componentes Möbius: diferentes aspectos de uma dinâmica pode ser modelada por esses formalismos, de modo que a integração é feita com os componentes Möbius correspondentes. A característica desta abor- 


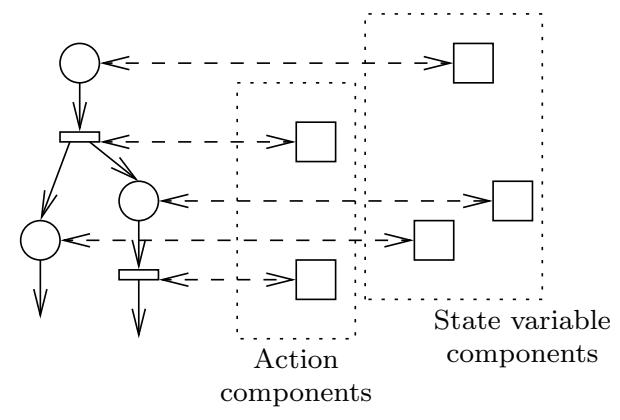

Figura 2.7: Redes de Petri e os componentes Möbius correspondentes

dagem é que se pode utilizar formalismos que sejam adequados para cada aspecto de uma dinâmica.

Estes são alguns exemplos de integração de modelos de SEDs, onde pode-se constatar que, além de um maior aproveitamento das técnicas de análise, o que se procura são melhores maneiras de descrever os problemas sob a forma de modelos, de modo que se tenha algum controle frente à complexidade das dinâmicas.

\subsection{Os aspectos formais e semânticos nos expe- rimentos de modelagem e análise}

Num experimento de modelagem e análise de SEDs, um padrão típico de atividades é ilustrado na figura 2.8, que apresenta as seguintes etapas:

- elaboração do modelo,

- análise do modelo e

- interpretação dos resultados.

Considerando-se esse padrão, uma característica do processo de modelagem de SEDs é que certas decisões relacionadas com as atividades posteriores devem ser tomadas já na elaboração do modelo, quais sejam:

- escolha de um tipo adequado de modelo que consiga considerar os aspectos relevantes para as conclusões almejadas;

- seleção de um método de análise para o tipo de modelo escolhido e que 


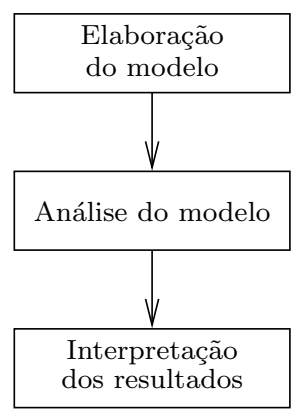

Figura 2.8: Padrão típico de atividades de um experimento de modelagem e análise

consiga fornecer as informações com as quais pode-se inferir as conclusões almejadas;

- estabelecimento de como os elementos do sistema e da dinâmica em foco serão expressos no formalismo associado ao tipo de modelo selecionado;

- estabelecimento de como os resultados das análises podem ser traduzidos em informações a respeito da dinâmica em foco.

A indefinição em qualquer desses itens impede a modelagem de ser concluída, devendo-se revisar as outras decisões até que um conjunto com todos os pontos afirmativamente concluídos seja alcançado.

Portanto, no momento em que um modelo de SED é concebido, este reproduz um padrão observado na dinâmica de modo que possa ser expresso conforme os termos e as regras do formalismo associado ao modelo; ao mesmo tempo, está estruturado de uma maneira que se possa obter as informações necessárias para as conclusões que se espera do experimento. Isto é, além de observar os requisitos formais para que o modelo possa ser analisado, existe uma preocupação de ordem semântica de fazer com que o modelo corresponda à dinâmica enfocada e com que os resultados da análise possam ser interpretados de forma a corresponder às informações objetivadas.

Com relação aos requisitos matemático-formais, o seguinte fato deve estar claro: que os modelos, enquanto construções matemáticas, não são portadores de quaisquer informações que possam relacionar seus elementos com aqueles dos sistemas e das respectivas dinâmicas. Os modelos destinados a análises matemáticas são elaborados tendo em vista a sua adequação aos seus aspectos formais, ou seja, 
à forma como expressam informação. De fato, estritamente do ponto de vista da aplicabilidade das técnicas de análise matemáticas, o requisito básico é que o modelo seja bem formado e as hipóteses de análise sejam observadas. Tanto que a responsabilidade da correção do modelo (no sentido de que representa a dinâmica sendo abordada) é de quem elabora o modelo, pois, se os requisitos formais forem atendidos, o modelo pode ser analisado, mesmo que incorreto (em sentido análogo).

Portanto, do ponto de vista formal, num experimento, na análise de modelos, estruturas matemáticas são manipuladas, gerando outras estruturas matemáticas. Voltando à figura 2.3, tem-se que um modelo $\mu_{\text {exo }}$, concebido por observação e abstração, expressa informações sobre um dinâmica $\mathfrak{d}$ e que um modelo $\mu_{\text {endo, }}$, resultante de análise em $\mu_{\text {exo }}$, refere-se aos elementos de $\mu_{\text {exo }}$; assim, transitivamente, $\mu_{\text {endo }}$ refere-se à $\mathfrak{d}$. No entanto, nenhum dos modelos consegue, per se, relacionar o que expressa com o que é observável nos sistemas e dinâmicas envolvidas. Ou seja, essas informações, produzidas na elaboração dos modelos, devem estar disponíveis para que se possa conhecer a semântica e, portanto, fazer a interpretação de modelos e resultados.

Além, da questão interpretativa dos modelos de SEDs, um outro ponto importante a respeito das semânticas dos modelos, principalmente se heterogêneos, está relacionada a sua integração. Quando os modelos heterogêneos são formalmente disjuntos, ou seja, os elementos de um não são tratados pelo formalismo de outro, a integração ocorre através de relacionamentos entre as semânticas dos modelos. Este é o caso do isomorfismo entre redes de Petri estocásticas e cadeias de Markov de tempo contínuo (MOLLOY, 1980), da composição hierárquica de modelos do sistema SHARPE (TRIVEDI, 2002) e da expressão dos formalismos de modelagem em termos de componentes do esquema (framework) Möbius (SANDERS et al., 2003), conforme descrito na seção anterior. Um exemplo de modelos heterogêneos que podem compartilhar formalmente seus elementos é o caso de redes de Petri e os grafos de alcançabilidade (que se referem a marcações dos lugares e a transições de uma rede); neste caso, o vínculo semântico é mais evidente.

Através da semântica dos modelos de SEDs, pode-se observar relacionamentos envolvendo dinâmicas diferentes (ou seja, observadas ou não em sistemas diferentes). Basicamente, isso está relacionado com a possibilidade de uma mesma 
questão ser pertinente a vários sistemas e dinâmicas, mesmo nos casos em que os modelos sejam muito diferentes. Suponha, por exemplo, que múltiplos conjuntos de modelos referem-se, cada um, a dinâmicas de sistemas onde ocorre que "uma máquina M processa peças do tipo P"; esse fato representa um vínculo entre os conjuntos no qual certas questões relativas a esse fato podem ser propostas, desde que os modelos envolvidos tenham sido concebidos para lidar com as mesmas. Este é um exemplo de relacionamento horizontal, conforme já mencionado na seção 1.1 .

Assim, num experimento envolvendo modelos heterogêneos de SEDs, devese lidar com os requisitos formais da modelagem e análise e com os aspectos semânticos, sob cuja perspectiva pode-se relacionar as informações dos vários modelos relativos a uma mesma dinâmica.

\subsection{Tratamento computacional de modelos he- terogêneos na literatura}

A maioria das ferramentas computacionais de modelagem e análise de SEDs é voltada para um único formalismo. Alguns dos AMAs para modelos heterogêneos de SEDs são os seguintes:

- O sistema IDEAS (FRICKS et al., 1997) é um sistema de integração de ferramentas de modelagem e análise que podem ter sido desenvolvidas independentemente; existe um componente computacional que gerencia o fluxo de informações entre o usuário e as ferramentas e entre as ferramentas (que inclui a conversão de um formato de dados para outro) de forma a deixar as diferenças transparentes ao usuário.

- A idéia do sistema FREUD (MOORSEL; HUANG, 1998) é de servir como um ponto único de acesso a ferramentas voltadas para a rede mundial (Internet), mais precisamente, a partir da chamada World Wide Web; o sistema pressupõe um padrão de utilização de ferramentas (argumenta que, as ferramentas de modelagem de desempenho apresentam um padrão de uso bastante previsível) e, portanto, é uma questão de colocar a ferramenta certa no local certo dentro desse padrão. 
- O AIASM (Ambiente Integrado de Análise de Sistemas de Manufatura) (ARATA; MIYAGI, 2005) é um sistema com grande flexibilidade na realização de diversas configurações de experimentos e que permite tratar modelos de diferentes tipos de uma maneira uniforme graças à padronização de suas representações; a base da uniformização são os metamodelos e a linguagem para descrevê-los, pois faz uso de um conjunto bem delimitado de estruturas representacionais, de modo que todos os modelos podem ser tratados por operações de uma mesma família.

- O sistema SHARPE (HIREL et al., 2000; TRIVEDI, 2002) implementa alguns tipos de modelos diferentes e os resultados das análises podem ser usados na especificação de outros modelos; desta forma, há a formação de hierarquias de modelos, que, no topo, apresenta um modelo constituído pelas informações dos resultados das análises dos modelos no nível abaixo.

- O sistema SMART (CIARDO; MINER, 1996; CIARDO et al., 2001, 2003) implementa uma linguagem que permite construir representações de vários tipos de modelos (se estiverem definidos) e os resultados das análises podem ser empregados em outros modelos.

- O sistema Möbius (SANDERS et al., 2003) faz composição de submodelos que descrevem partes da dinâmica de um sistema e, do modelo agregado, pode-se, por exemplo, gerar o espaço de estados. Permite a inclusão de novos formalismos.

Assim, apesar das diferenças entre tipos de modelos, existe um esforço em se trabalhar com modelos com essas características. Existem diferenças na forma de introduzir modelos heterogêneos nas ferramentas computacionais (no AIASM todos os modelos são expressos numa mesma linguagem, enquanto que no sistema Möbius, cada tipo de modelo tem uma interface específica). A integração de modelos também é feita de formas diferentes, sendo que o SHARPE e o Möbius sugerem formas específicas de integração. Com relação à semântica dos modelos, o suporte é limitado, principalmente para o caso de relacionamentos horizontais entre as dinâmicas. 

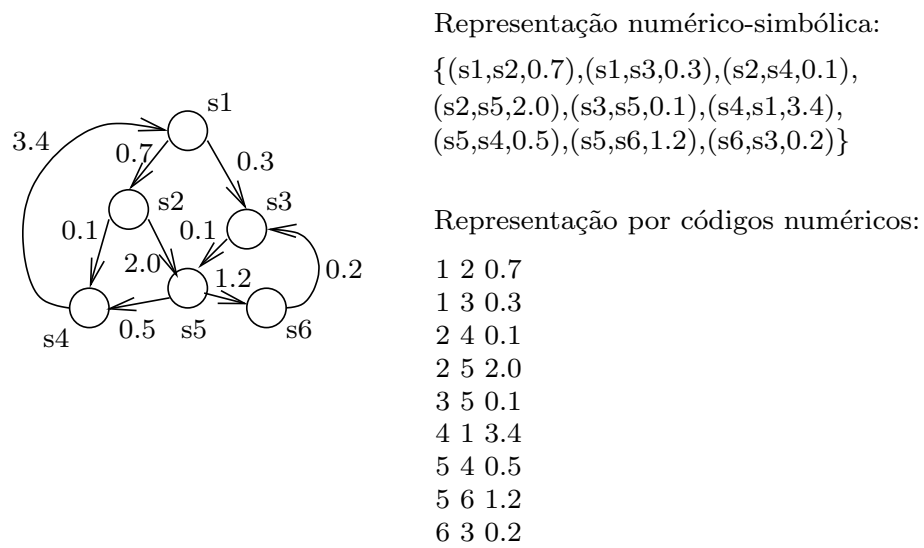

Figura 2.9: Representações computacionais de cadeias de Markov

\subsection{Representação computacional de modelos}

A questão de como os modelos são representados é importante porque está relacionada com a heterogeneidade de implementações de AMAs. Esta heterogeneidade, se somada à heterogeneidade de modelos matemáticos de SEDs, implica que a complexidade ao se lidar com os AMAs pode amplificar a complexidade decorrente desta heterogeneidade. A idéia deste trabalho é, pelo menos, minimizar a complexidade da solução computacional, de modo que a heterogeneidade que se deve controlar seja essencialmente aquela inerente à heterogeneidade dos modelos de SEDs.

Independentemente da questão da heterogeneidade, tem-se que os esquemas de representação de modelos têm grande influência na produtividade dos experimentos de modelagem e análise. Por exemplo, na montagem de modelos é mais interessante que símbolos sejam utilizados para expressar os elementos de um modelo do que códigos numéricos, conforme pode ser constatado pelas representações de um mesma cadeia de Markov (ver apêndice A) na figura 2.9, pois é mais fácil visualizar se a representação computacional é fiel ao modelo. É verdade que uma representação baseada em códigos numéricos tende a ter um processamento mais eficiente: uma maneira de tirar vantagens de ambas as abordagens é utilizar símbolos na interface com o usuário, deixando para o AMA a tarefa de traduzi-los para códigos numéricos, com os quais os processamentos são feitos; abordagem similar é adotada pelo AIASM (ARATA; MIYAGI, 2005).

Também, é importante que se tenha capacidade e flexibilidade de lidar com 


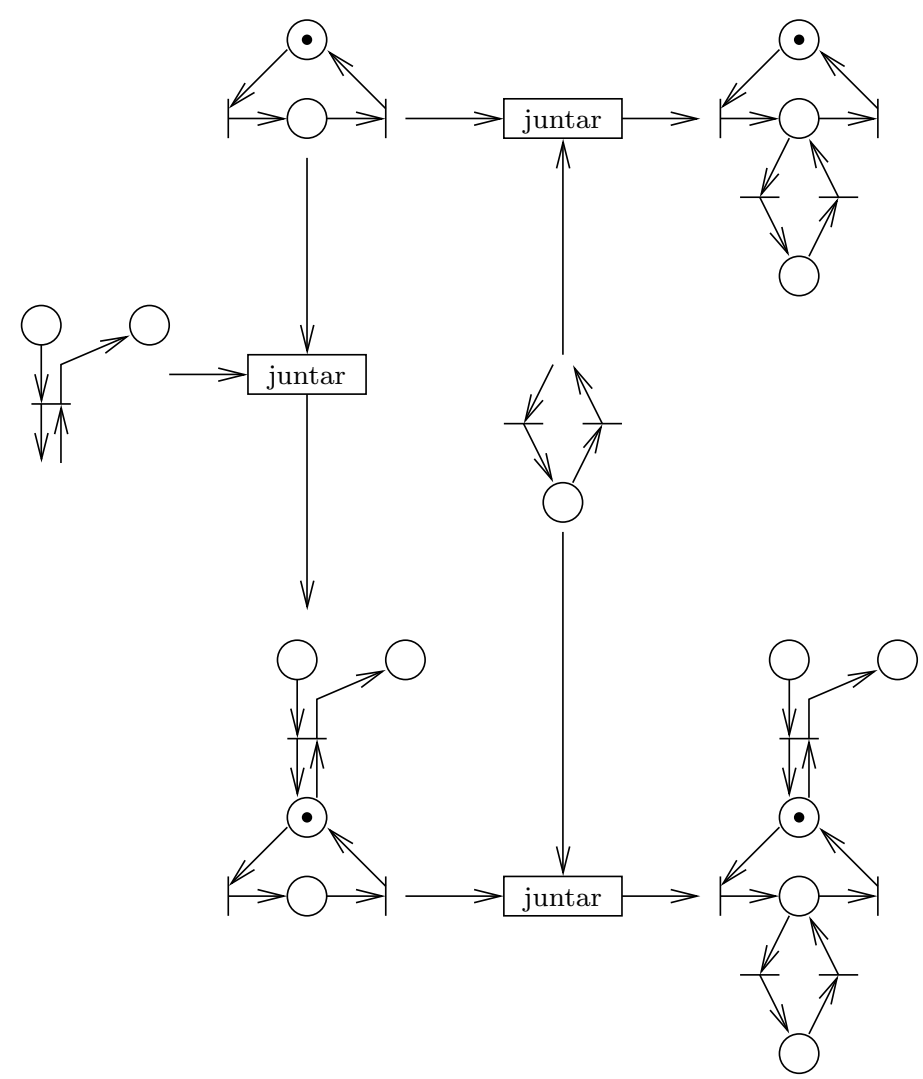

Figura 2.10: Modelos que compartilham partes

várias configurações de experimentos de modelagem e análise. No que se refere às representações computacionais dos modelos, isso pode ocorrer, por exemplo, na montagem de representações de modelos, principalmente quando forem de grande porte e/ou quando envolverem muitos e complexos padrões de interconexão de seus elementos. A figura 2.10 mostra uma situação em que vários redes de Petri podem ser construídos aproveitando-se partes comuns.

Uma outra capacidade que pode ser útil é a de manipular as representações de modelos: por exemplo, na técnica descrita por Campos et al. (1994), um grafo marcado estocástico (um caso particular de rede de Petri estocástica), é "cortado" de forma que três submodelos são gerados: dois relativos a cada "lado" do "corte" e um que faz a interligação entre as partes (ver figura 2.11); nessa abordagem, as análises são realizadas através destes submodelos.

Envolvendo modelos heterogêneos de SEDs, essas questões continuam relevantes, mas o problema ocorre se, para cada tipo de modelo, diferentes convenções léxico-sintáticas forem utilizados pelas correspondentes representações, adicio- 


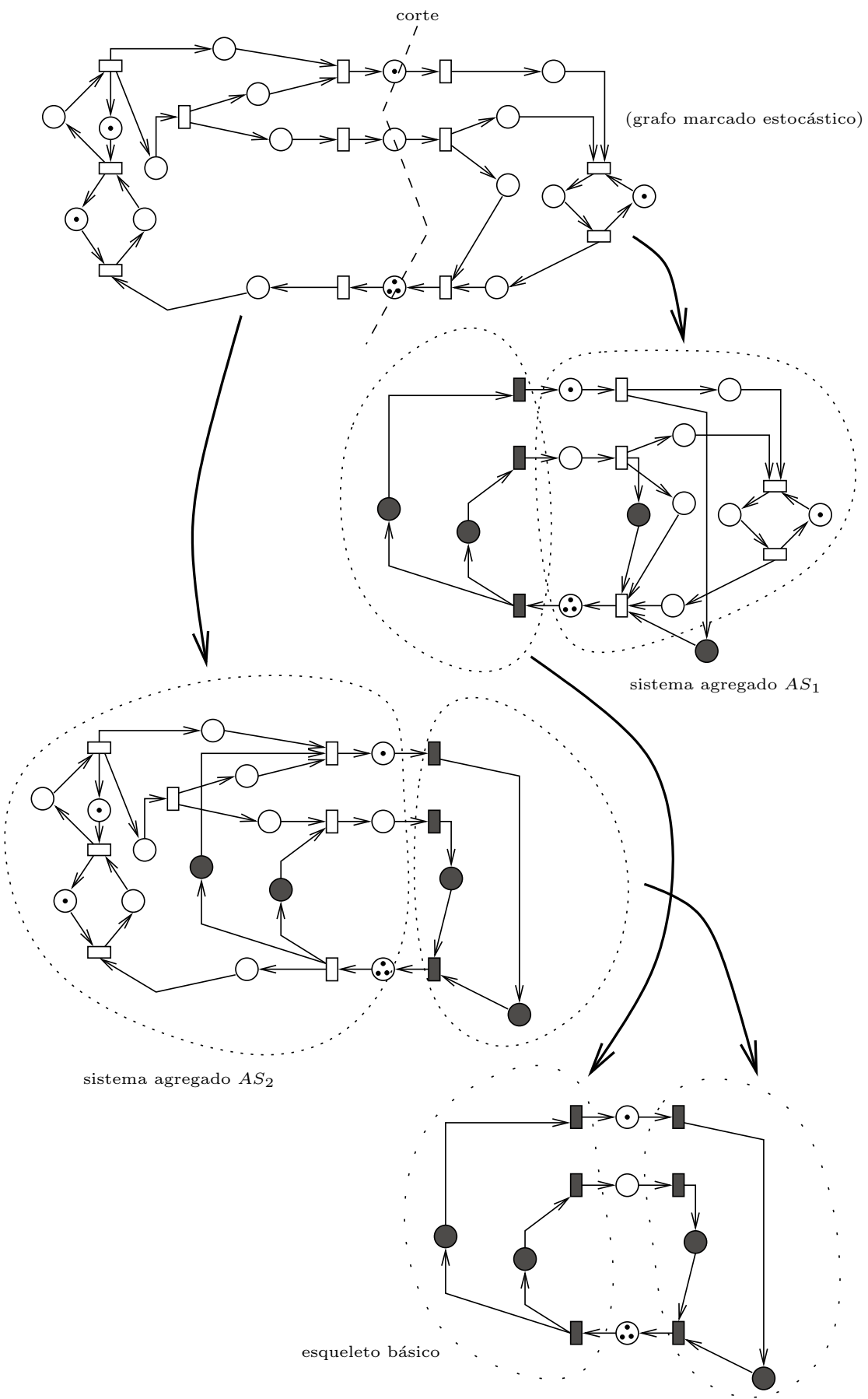

Figura 2.11: Abordagem de Campos et al. (1994) para análise de grafos marcados estocásticos 
nando mais um fator de complexidade relativo à diversidade. Se, além disso, as formas de representação computacional dos modelos heterogêneos forem muito díspares, as operações há pouco mencionadas tendem também a ser. As diversas combinações de formas de representação e operações associadas acabam tendo um forte impacto na aprendizagem de sua utilização (FRICKS et al., 1997). E, no caso de integração de modelos, acaba, também, afetando a fluidez dos trabalhos no sentido de ser necessário compatibilizar e se adaptar a tais diferenças.

No que diz respeito à integração de modelos, os AMAs apresentados anteriormente tratam-na de diversas formas. No AIASM isto deve ser feito manualmente com os elementos e estrutura de dados que o ambiente fornece (no caso, aquelas da linguagem Python). No caso de SHARPE, isso é feito através dos resultados das análises dos submodelos. No caso do Möbius, isso ocorre ao nível dos formalismos dos modelos dos tipos incorporados ao ambiente, através do mapeamento dos elementos desses formalismos em componentes do esquema Möbius. No sistema FREUD, os modelos ocupam uma posição pré-definida dentro de um padrão pré-estabelicido de análise. No caso do IDEAS, que na verdade faz integração de AMAs, o sistema cuida da conversão de dados referentes aos modelos entre os diversos AMAs.

Porém, além disso, o que ocorre é que, mesmo que as diferenças das representações computacionais sejam reduzidas àquelas inerentes à heterogeneidade matemático-formal dos modelos de SEDs, tais diferenças ainda são um obstáculo. De fato, ao ter em mãos modelos referentes a uma mesma dinâmica, a maneira como se relacionam, no caso geral, não é formalmente expressa. Num experimento, a integração das informações dos diferentes modelos só ocorre porque suas atividades são planejadas considerando-se a forma de interpretar os modelos (conforme discutido na seção 2.4). Além disso, as formas de integração são variadas. Também, conforme já tratado, a integração de modelos são decorrência dos relacionamentos de suas semânticas.

Disto, tem-se que a apresentação das informações oriundas dos modelos de uma maneira que forme um conjunto único, integrado e estruturado, refletindo os relacionamentos entre os modelos, permite uma melhor visualização dos relacionamentos entre as informações trazidas pelos diversos modelos e auxilia na realização de análises que pressupõem a integração de modelos (por exemplo, a determinação da freqüência efetiva de disparos de uma transição numa rede de Petri 
estocástica a partir das marcações alcançáveis e das probabilidades da cadeia de Markov isomórfica (MOLLOY, 1980)). Considerando-se que a integração entre os modelos, em vários casos, só é perceptível com relação às suas semânticas, a natureza das informações descritas deve ser interpretativa (ou seja, feita em termos dos aspectos observáveis na dinâmica modelada). Assim, a representação computacional dessas informações beneficia tanto a visualização e como as análises mencionadas.

\subsection{Comentários do capítulo}

Este capítulo contextualiza as motivações do trabalho. Além dos conceitos básicos, este capítulo apresenta algumas das razões para a heterogeneidade e alguns dos mecanismos que levam a esta. Também, mostra que existe um esforço em integrar modelos heterogêneos de SEDs como meio de melhorar as características descritivas e analíticas de tais modelos.

Porém, à medida que se procura suportar computacionalmente atividades com modelos heterogêneos de SEDs, para tirar maior proveito das técnicas desenvolvidas, fica evidente que uma infraestrutura adequada deve estar disponível. Um dos principais elementos dessa infraestrutura é a linguagem de modelagem utilizada para expressar, montar e manipular as representações computacionais de modelos. Um primeiro aspecto a lidar é a heterogeneidade matemático-formal dos modelos, o que é tratado no capítulo seguinte, que trata dos aspectos essenciais para que uma linguagem de modelagem para modelos heterogêneos ofereça condições para um trabalho eficiente com tais modelos. O segundo aspecto enfocado é o da integração desses modelos e de como as suas semânticas se relacionam; o capítulo 4 apresenta descrições baseadas nas semânticas dos modelos como forma de disponibilizar as informações trazidas pelos vários modelos que se referem a uma dinâmica, de modo que se possa vizualizá-las de forma integrada (ou seja, as interrelações são claras) e tratá-las analiticamente (por técnicas que pressupõem a integração de modelos). 


\section{Representação computacional e a heterogeneidade formal dos modelos}

Um fator que pode aumentar a complexidade advinda da heterogeneidade matemático-formal dos modelos de SEDs são as suas representações computacionais. Se estas representações tiverem estruturas e composições muito díspares, o gerenciamento dessas diferenças pode representar um custo significativo dentro de um experimento, uma vez que interfere em atividades importantes, conforme tratado no capítulo anterior. Portanto, um elemento fundamental no tratamento computacional de modelos heterogêneos é a linguagem utilizada para representálos.

O que se propõe é a adoção de um único AMA para lidar com modelos heterogêneos de SEDs (como nos casos exemplificados nos capítulos anteriores), que deve incorporar os vários tipos de modelos (com multiplicidade e extensibilidade, conforme assumido na seção 1.2) e as respectivas técnicas de análise. O elemento principal de tal AMA é a linguagem de modelagem adotada, que é o foco nesta parte do texto. Este capítulo apresenta, de forma estruturada, os diversos elementos envolvidos na representação computacional de modelos, a forma como interagem e o modo como contribuem para um aproveitamento racional e eficiente dos recursos computacionais e humanos. Ao final dessa discussão, tem-se um equacionamento de como tal linguagem de modelagem e a heterogeneidade e a integração de modelos se relacionam.

Nos capítulos anteriores, estabelece-se que a linguagem de modelagem deve suportar diversas configurações de experimentos, possuir capacidade numéricosimbólica de expressão de diferentes modelos e permitir que diversas formas de 

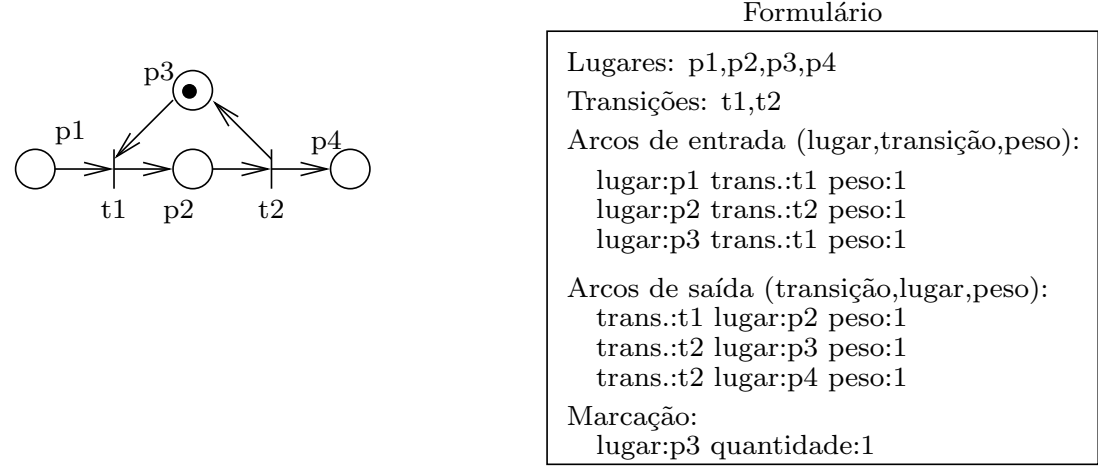

Figura 3.1: Formulário referente a uma rede de Petri

operações para montagem e manipulação de representações de modelos. Neste capítulo, elabora-se uma descrição matemática dos AMAs, com base na qual características das linguagens de modelagem são analisadas; as questões sobre os custos envolvidos também são introduzidas. Ao final, uma comparação entre as configurações de AMAs é feita, cujas conclusões contribuem no equacionamento mencionado e objetivado.

\subsection{Ambientes de modelagem e análise}

O papel dos AMAs é, em última análise, receber, processar e gerar dados simbólicos e/ou numéricos. Se as informações de entrada forem representativas dos modelos a analisar e se o processamento implementar a análise corretamente, os resultados podem ser mapeados nas informações almejadas pela análise. A esses dados estruturados, referentes ou não a modelos, o presente texto dá a denominação genérica de estruturas. As estruturas referentes a modelos são denominadas representações computacionais (ou simplesmente representações) de modelos (conforme a definição 2.9).

Nesta seção, apresenta-se uma descrição matemática de AMAs e dos modelos de SEDs que devem tratar. Essa descrição define o que são denominados de conjuntos-alvos, utilizados na visualização de diversas configurações de AMAs.

A fim de melhor ilustrar os conceitos desenvolvidos, os exemplos consideram que as as representações computacionais dos modelos apresentam-se como formulários. A figura 3.1 apresenta um exemplo de formulário referente a uma rede de Petri (ver apêndice A). 


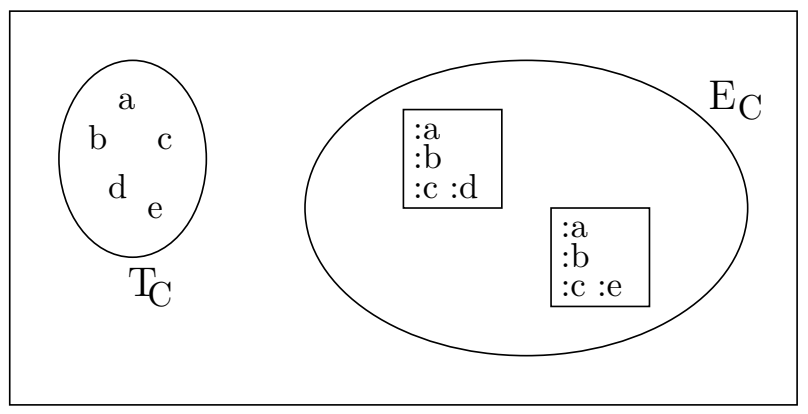

Figura 3.2: Exemplo de linguagem de composição

\subsubsection{Descrição matemática de um AMA}

Os AMAs que este texto trata são definidos por uma tripla $A$, tal que

$$
A=\left\langle L_{C}, L_{B}, C_{A}\right\rangle
$$

onde:

1. $L_{C}$ é uma linguagem de descrição de composição de modelos tal que

$$
L_{C}=\left\langle T_{C}, E_{C}\right\rangle
$$

onde:

(a) $T_{C}$ é um conjunto de símbolos ou termos utilizados pela linguagem;

(b) $E_{C}$ é o conjunto que contém as estruturas que a linguagem pode expressar utilizando elementos de $T_{C}$; trata-se do conjunto de estruturas consideradas válidas para algum propósito, no sentido de que se inserem numa certa ordem, numa certa linha de organização de informações.

Considerando-se formulários como exemplos, $T_{C}$ seria o conjunto de palavras (ou símbolos) e valores utilizados no formulários e $E_{C}$, o conjunto de formulários corretamente preenchidos (ver figura 3.2).

2. $L_{B}$ é uma linguagem de montagem de estruturas que utiliza elementos da linguagem de composição $L_{C}$, tal que

$$
L_{B}=\left\langle P_{B}, E_{B}\right\rangle
$$




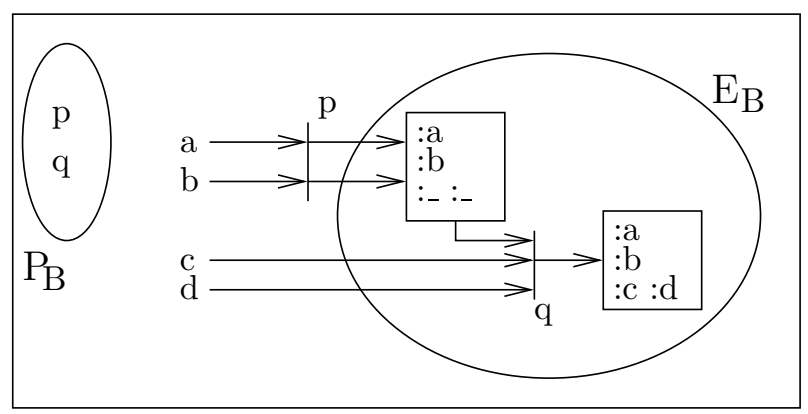

Figura 3.3: Exemplo: linguagem de montagem $L_{B}$

onde:

(a) $P_{B}$ representa os elementos definidos pela linguagem para montagem de estruturas e que atuam sobre termos e estruturas derivadas de $T_{C}$ (por exemplo, operações e instruções de controle do fluxo de execução (MARCOTTY; LEDGARD, 1986));

(b) $E_{B}$ é o conjunto que contém as estruturas que podem ser montadas pela linguagem através dos elementos em $P_{B}$ e usando-se os termos em $T_{C}$.

Considerando-se o caso dos formulários, as figuras 3.3 e 3.4 apresentam dois exemplos de linguagem de montagem, $L_{B}=\left\langle P_{B}, E_{B}\right\rangle$ e $L_{B}^{\prime}=\left\langle P_{B}^{\prime}, E_{B}^{\prime}\right\rangle$. As operações de montagem são representadas seguindo uma notação que lembra redes de Petri, onde, as operações são denotadas por barras, que se ligam aos operandos por setas que se originam destes e aos resultados por setas que terminam nestes. Na figura $3.3, L_{B}$ apresenta um $P_{B}$ contendo as operações de preenchimento de formulários (indicando o campo a ser preenchido e o termo ou valor, pertencente a $T_{C}$, a preencher) e $E_{B}$ é um conjunto contendo formulários vazios, semi-preenchidos e corretamente preenchidos. Na figura 3.4, $E_{B}^{\prime}$ é constituído de formulários vazios, semi-preenchidos ou preenchidos, de modo que $P_{B}^{\prime}$ apresenta operações para o preenchimento de formulários e, também, para fazer a composição de formulários para obter formulários maiores (e devidamente preenchidos ao final do processo de montagem).

3. $C_{A}$ é a capacidade analítica do AMA, tal que

$$
C_{A}=\left\{\left\langle P_{(A, 1)}, I_{(A, 1)}, O_{(A, 1)}\right\rangle, \ldots,\left\langle P_{\left(A, n_{A}\right)}, I_{\left(A, n_{A}\right)}, O_{\left(A, n_{A}\right)}\right\rangle\right\},
$$




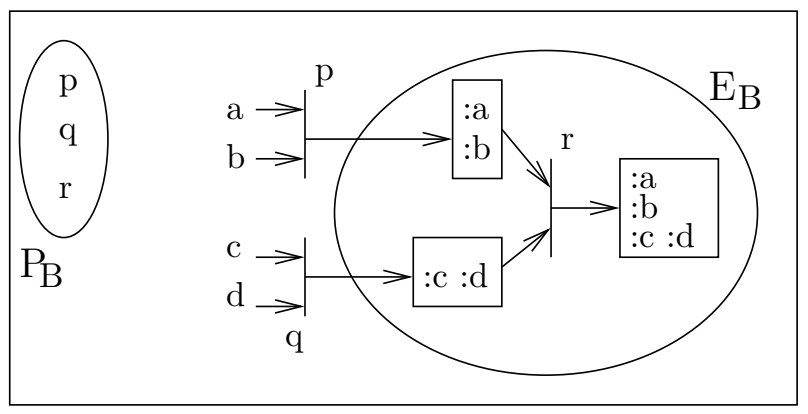

Figura 3.4: Exemplo: linguagem de montagem $L_{B}^{\prime}$

onde se considera que cada tripla $\left\langle P_{(A, j)}, I_{(A, j)}, O_{(A, j)}\right\rangle$ representa um processamento (para execução computacional de análises, por exemplo) e as indicações dos conjuntos das estruturas de entrada e de resultado do processamento, ou seja:

(a) $P_{(A, j)}$ representa uma computação feita em estruturas denominada processamento, que, a partir de $n_{(A, j), I}$ estruturas como entradas, gera $n_{(A, j), O}$ estruturas como resultados, tal que as ênuplas

$$
\left(i_{(A, j), 1}, \ldots, i_{(A, j), n_{(A, j), I}}\right)
$$

e

$$
\left(o_{(A, j), 1}, \ldots, o_{(A, j), n_{(A, j), O}}\right)
$$

representam o que é utilizado como, respectivamente, entrada e saída do processamento, tal que

$$
i_{(A, j), k} \in I_{(A, j), k}\left(k \in\left[1, n_{(A, j), I}\right]\right)
$$

e

$$
o_{(A, j), l} \in O_{(A, j), l}\left(l \in\left[1, n_{(A, j), O}\right]\right),
$$

onde os conjuntos $I_{(A, j), k}\left(k \in\left[1, n_{(A, j), I}\right]\right)$ e $O_{(A, j), l}\left(l \in\left[1, n_{(A, j), O}\right]\right)$ são definidos a seguir;

(b) $I_{(A, j)}$ refere-se aos dados de entrada de $P_{(A, j)}$ e é definida por uma ênupla com $n_{(A, j), I}$ elementos tal que

$$
I_{(A, j)}=\left(I_{(A, j), 1}, \ldots, I_{(A, j), n_{(A, j), I}}\right),
$$

onde $I_{(A, j), k}, k=1, \ldots, n_{(A, j), I}$, são os conjuntos de estruturas que 
podem servir de entrada para $P_{(A, j)} ;$

(c) $O_{(A, j)}$ refere-se aos resultados de $P_{(A, j)}$ e é definida por uma ênupla tal que

$$
O_{(A, j)}=\left(O_{(A, j), 1}, \ldots, O_{(A, j), n_{(A, j), O}}\right),
$$

onde $O_{(A, j), k}, k=1, \ldots, n_{(A, j), O}$, são os conjuntos aos quais as estruturas resultantes de $P_{(A, j)}$ pertencem.

A figura 3.5 mostra dois processamentos de um $C_{A}$, isto é, $P_{(A, 1)}$ e $P_{(A, 2)}$. A notação utilizada para processamentos é a mesma que das operações de montagem. Como se pode observar, as setas indicam que as estruturas de entrada e de resultado pertencem aos conjuntos representados e as posições que ocupam nas ênuplas de entrada e resultado são indicadas pelo rótulos junto às setas (ver ênuplas nas expressões 3.5 e 3.6). O resultado do primeiro processamento é indicado sob forma de texto, ilustrando que os resultados podem ser apresentados de forma não muito estruturada em termos computacionais (contendo elementos pouco aproveitáveis no caso, mas que pode ser confortável a um ser humano); no segundo processamento, os resultados são apresentados como formulários preenchidos, tal como ocorre com as entradas dos processamentos.

No decorrer do texto, algumas das menções a linguagem de modelagem referemse ao par

$$
L_{M}=\left\langle L_{C}, L_{B}\right\rangle
$$

A divisão em $L_{C}$ e $L_{B}$ reflete as diferentes combinações de estruturas descritivas e operações de montagem e manipulação de estruturas, conforme ilustrado pelos exemplos anteriores.

Os conjuntos apresentados são utilizados na visualização de configurações de AMAs, conforme é descrito na subseção 3.1.3.

\subsubsection{Representação de tipos de modelos}

No esquema proposto, juntamente e relacionado com a descrição matemática dos AMAs, um outro elemento a considerar é a representações dos modelos. Isso pode ser feito pela introdução de uma função que representa a transcrição de 

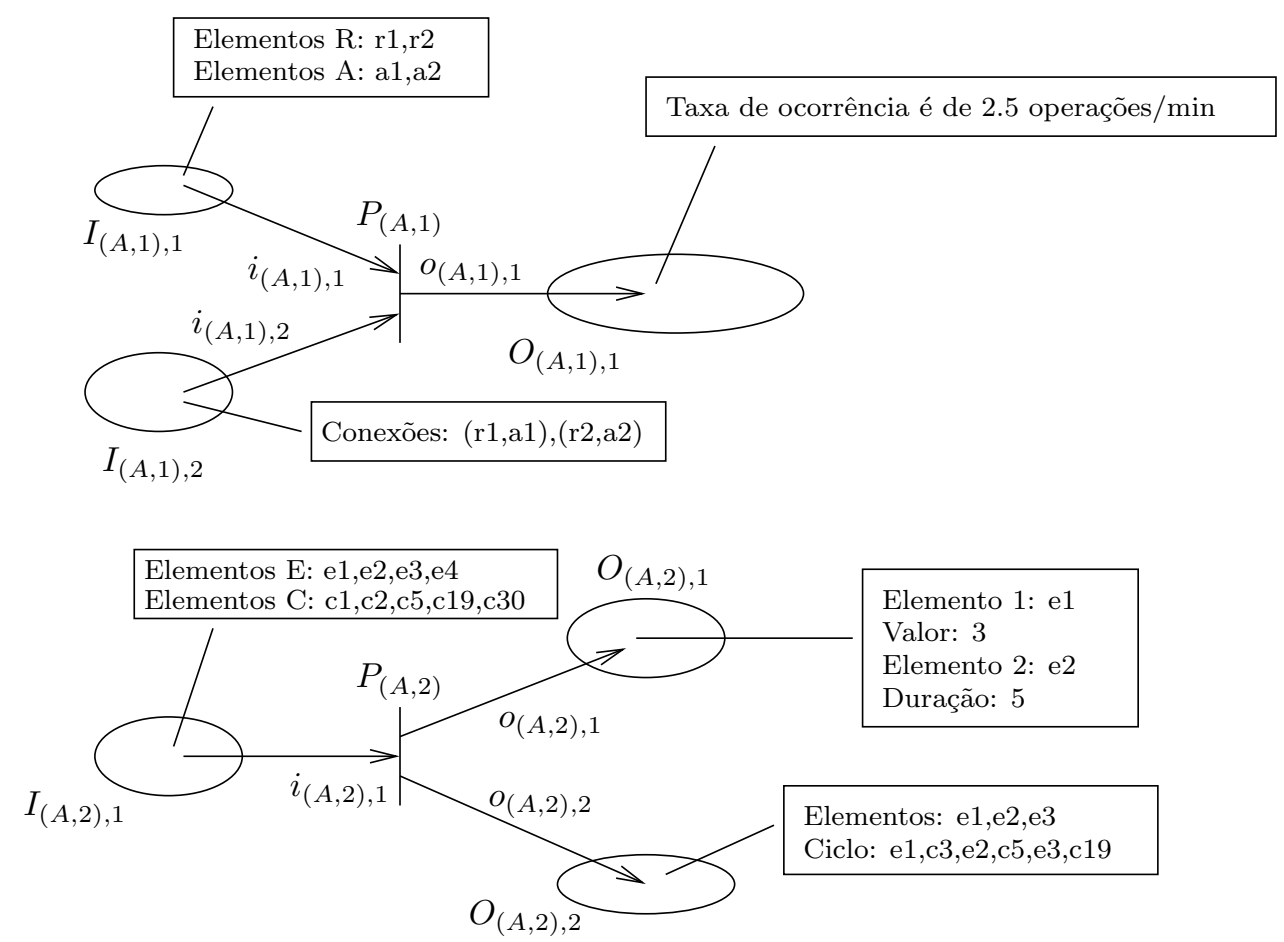

Figura 3.5: Exemplo de capacidade analítica de um AMA

modelos (ver definição 2.9). Trata-se de uma função injetora ${ }^{1}$

$$
\tau_{L_{C}, \Phi}: \Omega_{\Phi} \longrightarrow E_{C}
$$

onde $L_{C}$ é uma linguagem de composição de modelos, $\Phi$ é um tipo de modelo, $\Omega_{\Phi}$ é o conjunto de todos os modelos de tipo $\Phi$ e $E_{C}$ é o conjunto-alvo de $L_{C}$. A figura 3.6 ilustra um exemplo envolvendo redes de Petri.

Conforme é descrito na subseção seguinte, as transcrições são visualizadas com base na imagem da função $\tau_{L_{C}, \Phi}, E_{\tau_{L_{C}, \Phi}}$, ou seja,

$$
\forall r \in E_{\tau_{L_{C}, \Phi}}, \exists \mu \text { tal que } \mu \in \Omega_{\Phi} \text { and } \tau_{L_{C}, \Phi}(\mu)=r
$$

Portanto, $E_{\tau_{L_{C}, \Phi}}$ representa um tipo $\Phi$, na medida que se trata do conjunto das representações de todos os modelos de $\Phi$ segundo uma transcrição $\tau_{L_{C}, \Phi}$.

\footnotetext{
${ }^{1}$ Uma função é injetora se os elementos da imagem correspondem a apenas um elemento do domínio (WOODCOCK; DAVIES, 1996).
} 


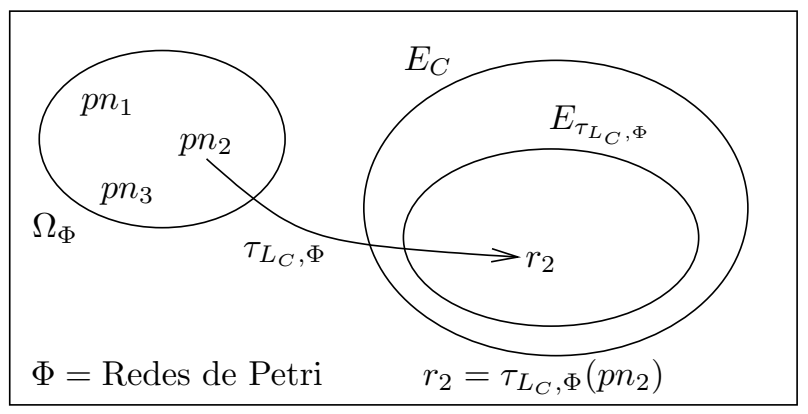

Figura 3.6: Função de transcrição $\tau_{L_{C}, \Phi}: \Omega_{\Phi} \longrightarrow E_{C}$

\subsubsection{Conjuntos-alvos e sua coordenação}

Características importantes dos AMAs podem ser representadas através dos conjuntos apresentados nas subseções anteriores. A tais conjuntos dá-se a denominação de conjuntos-alvos. Assim, os conjuntos $E_{C}, E_{B}, I_{(A, j), k}\left(j \in\left[1, n_{A}\right], k \in\right.$ $\left.\left[1, n_{(A, j), I}\right]\right)$ e $E_{\tau_{L_{C}, \Phi}}$ são conjuntos-alvos da linguagem de composição $\left(L_{C}\right)$, da linguagem de montagem $\left(L_{B}\right)$, do $j$-ésimo processamento de $C_{A}\left(P_{(A, j)}\right)$ e das transcrições de modelos de tipo $\Phi$ numa linguagem $L_{C}$ respectivamente.

Dado um AMA $\left\langle L_{C}, L_{B}, C_{A}\right\rangle$, um tipo $\Phi$ e uma transcrição $\tau_{L_{C}, \Phi}$, os correspondentes conjuntos-alvos devem ser entendidos da seguinte forma:

- $E_{C}$ representa a capacidade de $L_{C}$ especificar informações (seu poder expressivo);

- $E_{B}$ representa a capacidade de $L_{B}$ montar estruturas (podendo vir a ser uma medida da flexibilidade nessa tarefa, conforme tratado na seção 3.2.1);

- os conjuntos $I_{(A, j), k}$ em $C_{A}$ indicam as estruturas analisáveis, ou seja, que podem ser processadas por $P_{(A, j)}$;

- dado um tipo $\Phi, \tau_{L_{C}, \Phi}$ indica como os modelos do tipo $\Phi$ são representados na linguagem $L_{C}$.

Para que um AMA seja adequado para desempenhar suas funções, deve-se coordenar seus elementos (ou seja, as linguagens de composição e montagem e os processamentos de análise) e as transcrições de modelos.

Considerando-se a figura 3.7 que representa o caso de um AMA voltado à análise de modelos de um tipo $\Phi$, pode-se observar que uma linguagem $L_{C}$ e uma 


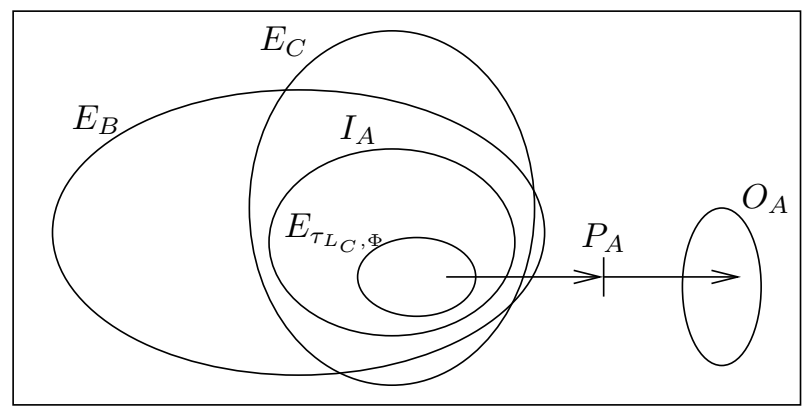

Figura 3.7: Coordenação de conjuntos-alvos referentes a um AMA para tratamento de modelos de tipo $\Phi$

transcrição $\tau_{L_{C}, \Phi}$ foram adequadamente concebidas de forma que todos os modelos de $\Phi$ podem ser representados na linguagem $L_{C}$, o que é manifestado pelo fato de $E_{\tau_{L_{C}, \Phi}} \subset E_{C}$. Analogamente, $E_{\tau_{L_{C}, \Phi}} \subset E_{C}$ indica que a linguagem $L_{B}$ adotada é capaz de construir as representações dos modelos de $\Phi ; I_{A}$ é o conjunto-alvo do processamento $P_{A}$, que gera resultados em $O_{A}$, que é, também, representado na figura; esta mostra que o processamento foi concebido e implementado de forma a aceitar todas as estruturas em $E_{\tau_{L_{C}, \Phi}}$ como entradas para o processamento. Apesar de não ser conjunto-alvo, o conjunto $O_{A}$ também é ilustrado e, nessa situação, mostra que o formato de representação de suas estruturas não é compatível com nenhum dos conjuntos-alvos, o que é típico de situações em que os resultados são apresentados de forma pouco estruturada (como também ilustrado para o caso do primeiro processamento da figura 3.5) e/ou em casos em que os resultados não se destinam a processamentos computacionais posteriores.

Considerando um caso de particular interesse neste trabalho, se uma linguagem de composição $L_{C}=\left\langle T_{C}, E_{C}\right\rangle$ suporta modelos heterogêneos de SEDs, uma configuração como a da figura 3.8 (que ilustra um caso envolvendo redes de Petri e cadeias de Markov, ver apêndice A) deve ocorrer, onde $E_{C}$ compreende as representações de diferentes tipos de modelos.

Eis, portanto, a forma como diagramas envolvendo conjuntos-alvos devem ser intepretados. 


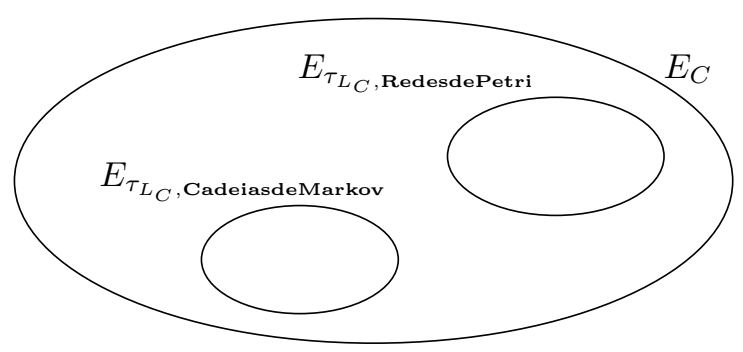

Figura 3.8: Linguagem de composição e modelos de redes de Petri e cadeias de Markov

\subsection{Questões envolvendo os elementos dos AMAs}

Com base na descrição matemática de AMA elaborada na seção 3.1, esta seção discute alguns aspectos que envolvem as representações de modelos.

\subsubsection{Estruturas intermediárias e flexilidade na monta- gem de representações}

Dependendo da linguagem de montagem $L_{B}=\left\langle P_{B}, E_{B}\right\rangle$, particularmente das operações em $P_{B}$, o processo da montagem de uma certa representação de modelo pode ser executado com o uso de várias operações. As estruturas intermediárias são aquelas geradas como resultado dessas operações antes de se chegar à representação final do modelo. As figuras 3.3 e 3.4 ilustram montagens de representações de modelos que envolvem múltiplas operações e estruturas intermediárias.

Uma das características do envolvimento de estruturas intermediárias é que pode ocorrer reaproveitamento de estruturas refletindo o compartilhamento de partes entre modelos (ver figura 3.9). Isto é interessante no caso de muitos modelos compartilharem as mesmas partes e no caso de modelos de grande porte que possuem partes comuns igualmente extensas.

Uma outra característica é que, quanto maior a disponibilidade e diversidade de estruturas intermediárias, mais opções de seqüências de operações podem ser seguidas (ver figura 3.10). Essa característica é importante nos experimentos em que se deseja flexibilidade na montagem das representações dos modelos (por exemplo, flexibilidade no padrão de reaproveitamento de estruturas intermediárias ou na especificação de modelos via interface com o usuário). 


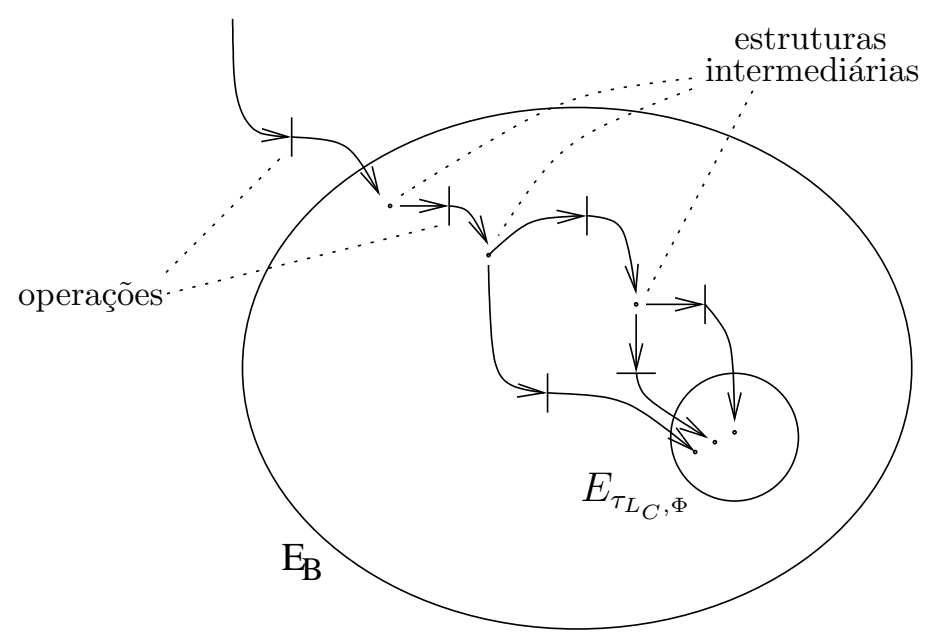

Figura 3.9: Reaproveitamento de estruturas na construção de representações de modelos

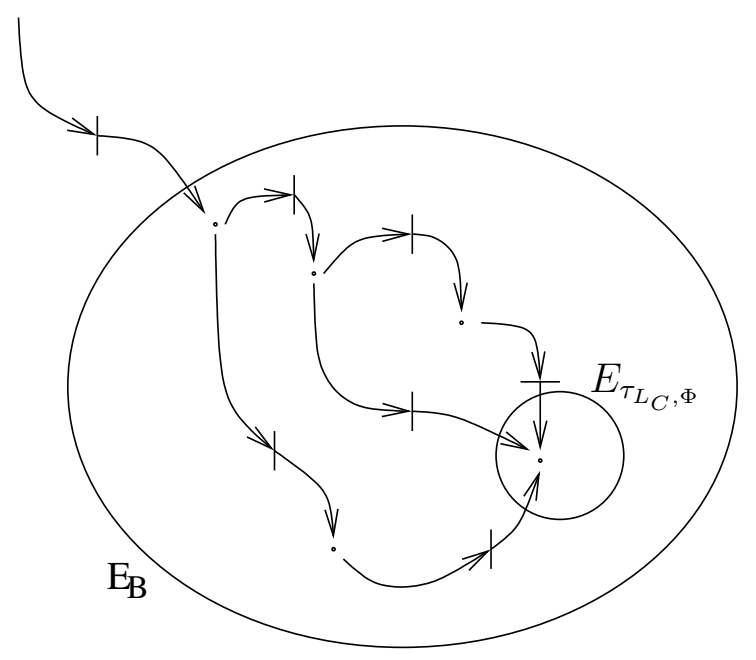

Figura 3.10: Flexibilidade na montagem de representações: pode-se chegar a uma mesma representação por vários caminhos 


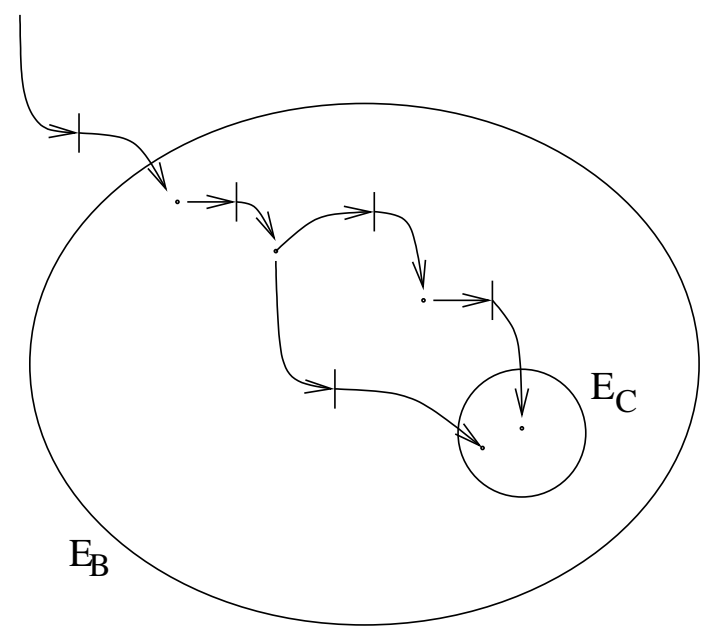

Figura 3.11: As estruturas em $E_{B}-E_{C}$ podem ser utilizadas como estruturas intermediárias para a montagem de estruturas em $E_{C}$

Como este trabalho visa direcionar as conclusões para uma maior eficiência na realização de experimentos, então, considera-se, como hipótese, que a linguagem de montagem deve fornecer as operações adequadas para lidar com estruturas intermediárias. Desta forma, a disponibilidade de variadas estruturas em seu conjunto-alvo é um indicativo da flexibilidade da linguagem de montagem.

Em termos de conjuntos-alvos, observadas as hipóteses há pouco firmadas, dadas as linguagens de composição $\left\langle T_{C}, E_{C}\right\rangle$ e $\left\langle P_{B}, E_{B}\right\rangle$, a diferença $E_{B}-E_{C}{ }^{2}$ contém estruturas que podem ser usadas para a montagem de estruturas em $E_{C}$ (ver figura 3.11).

\subsubsection{Abrangência e uniformidade da linguagem de com- posição}

A abrangência da linguagem de composição refere-se a sua capacidade de expressar variadas formas de estruturas, como nos casos envolvendo modelos heterogêneos de SEDs. Em termos dos conjuntos-alvos, essa ocorrência é representada pelo fato de o conjunto-alvo $E_{C}$ de uma linguagem de composição poder comportar, como subconjuntos, vários conjuntos-alvos de transcrições, conforme já ilustrado na figura 3.8.

Um atributo importante das linguagens de modelagem abrangentes é a uni-

\footnotetext{
${ }^{2}$ Dados dois conjuntos $A$ e $B$, a diferença $A-B$ refere-se ao conjunto de elementos que pertencem a $A$, mas que não pertencem a $B$
} 


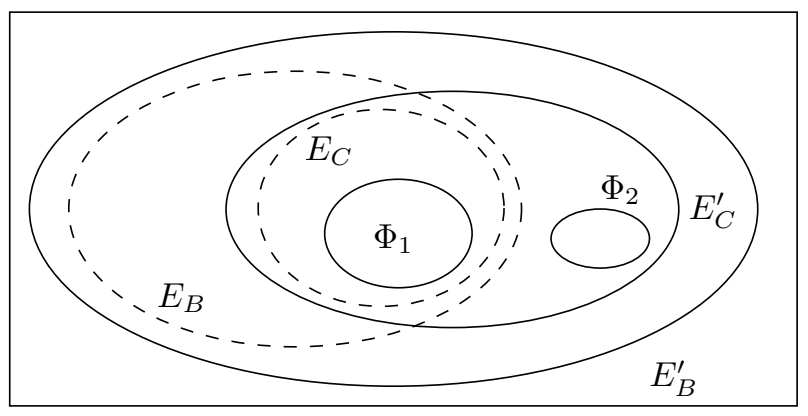

Figura 3.12: Estendendo a linguagem de modelagem $\left\langle L_{C}, L_{B}\right\rangle$ (com conjuntos-alvos $E_{C}$ e $E_{B}$ ) para $\left\langle L_{C}^{\prime}, L_{B}^{\prime}\right\rangle$ (com conjuntos-alvos $E_{C}$ e $E_{B}$ ) para comportar novo tipo $\Phi_{2}$

formidade. A uniformidade no tratamento de modelos heterogêneos de uma linguagem de composição está relacionada à sua capacidade de expressar diversos tipos de modelos segundo a seguinte definição:

\section{Definição 3.1 (Liguagem de modelagem abrangente e uniforme ideal)}

Uma linguagem de modelagem abrangente e uniforme ideal é aquela que, com um mesmo conjunto de termos e as mesmas regras de formação de estruturas mais complexas, é capaz de comportar representações de modelos de uma variedade indefinida de tipos.

Essa capacidade é especialmente importante quando um novo tipo de modelo deve ser considerado para ser tratado num AMA abrangente: uma linguagem sem essa capacidade teria de ser alterada para que novos tipos de modelos sejam considerados; como efeito colateral, um AMA implementando tal linguagem de composição possivelmente teria, também, de reestruturar a linguagem de montagem utilizada (conforme ilustrado na figura 3.12).

A definição trata de um caso ideal, mas em casos mais pragmáticos, a uniformidade traduz-se no pouco impacto na estrutura da linguagem de modelagem ao se considerar novos tipos de modelos.

A linguagem usada pelo AIASM (ARATA; MIYAGI, 2003) utiliza elementos da teoria de conjuntos, podendo ser usada para uma grande variedade de tipos de modelos e, assim, dentro desse escopo, pode ser considerada uma linguagem uniforme. Pode-se dizer que uma característica básica das linguagens uniformes é a flexibilidade dos elementos léxico-sintáticos na composição de modelos. 


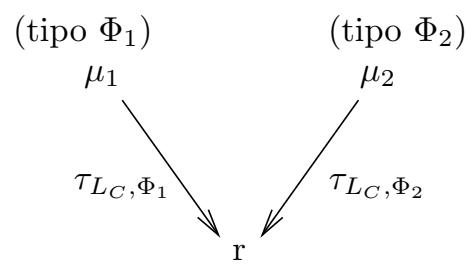

Figura 3.13: Interpretações ambíguas

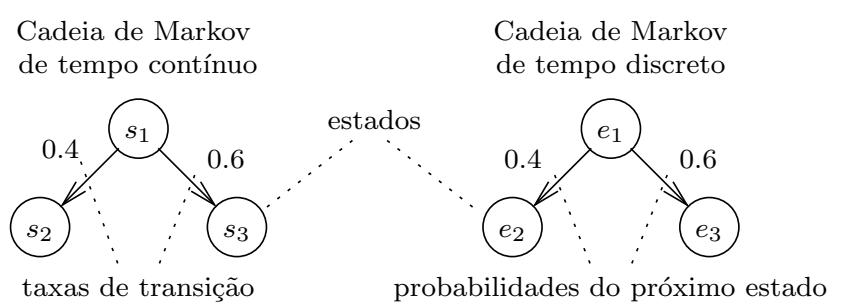

Figura 3.14: Modelos de cadeias de Markov de tempo contínuo e discreto

\subsubsection{Ambigüidade}

Uma maior abrangência da linguagem de composição de modelos $L_{C}$, apesar de poder ser uma solução para habilitar a coabitação de representações de modelos heterogêneos de SEDs, pode trazer novos problemas também. A ambigüidade na interpretação das representações é uma delas.

Considerando-se (ver figura 3.13) os modelos heterogêneos $\mu_{1}$ e $\mu_{2}$ de tipos $\Phi_{1}$ e $\Phi_{2}$ respectivamente, se forem elaboradas duas transcrições para ambos os tipos, $\tau_{L_{C}, \Phi_{1}}$ e $\tau_{L_{C}, \Phi_{2}}$ respectivamente, tal que

$$
\tau_{L_{C}, \Phi_{1}}\left(\mu_{1}\right)=\tau_{L_{C}, \Phi_{2}}\left(\mu_{2}\right),
$$

tem-se um caso de ambigüidade (ou seja, uma estrutura tem duas interpretações e existe a possibilidade de análises serem feitas sobre modelos não destinados para isso).

Por exemplo, a figura 3.14 ilustra duas cadeias de Markov, uma delas de tempo contínuo e outra de tempo discreto. Ambos são representados por grafos topologicamente idênticos e, aos arcos, são associados os mesmos valores numéricos. Porém, enquanto que no caso contínuo esses valores referem, em geral, a taxas de transições entre estados, no caso discreto, costumam se referir a probabilidades de transição entre estados. 
Suponha, agora, uma linguagem em que os modelos são expressos pelas seguintes representações:

$(\{e 1, e 2, e 3\},\{(e 1, e 2,0.4),(e 1, e 3,0.6)\})$

$(\{\mathrm{s} 1, \mathrm{~s} 2, \mathrm{~s} 3\},\{(\mathrm{s} 1, \mathrm{~s} 2,0.4),(\mathrm{s} 1, \mathrm{~s} 3,0.6)\})$

onde os primeiros elementos das ênuplas indicam os estados da respectiva cadeia e o segundo, um conjunto de ênuplas, cada uma denotando um estado de origem e outro de destino de uma transição e o valor associado à transição. Se a linguagem considerar que os termos e1,e2,e3,s1,s2 e s3 fazem parte uma mesma categoria de símbolos ou se não houver categorização, pode ocorrer de uma das representações ser tomada como sendo de outro tipo.

Essa confusão pode trazer dificuldades na interpretação dos resultados: se um conjunto de cadeias de Markov de tempo contínuo estiver sendo analisado, tomar um cadeia de tempo discreto como sendo de tempo contínuo nesse experimento vai, salvo expectativas otimistas, gerar resultados que serão inconsistentes com os demais.

Utilizando técnicas de disjunção como a utilização de sistemas de tipos de dados (CARDELLI; WEGNER, 1985) é possível amenizar o problema: trata-se de uma forma de particionar o conjunto de termos da linguagem de composição, que possibilita que cada tipo de modelo utilize um subconjunto de termos diferentes dos outros tipos de modelos. Assim, havendo suporte para um sistema de tipos de dados, bastaria indicar que os termos relativos aos estados de cada tipo de cadeia de Markov são de tipos de dados diferentes e, antes da análise, pode-se projetar mecanismos para verificação dos tipos de dados das estruturas a analisar (ver figura 3.15).

\subsubsection{Redundância de representação e de processamento}

Dentro de um AMA, pode ocorrer de a linguagem de composição de modelos de SEDs ser flexível a ponto de permitir a redundância de representação e de processamento referentes a modelos de um mesmo tipo. Conforme representado na figura 3.16, isso ocorre se duas transcrições $\tau_{L_{C}, \Phi}$ e $\tau_{L_{C}, \Phi}^{\prime}$ para o mesmo tipo de modelo $\Phi$ tiverem sido elaborados, de forma que, para um mesmo modelo $\mu$ 


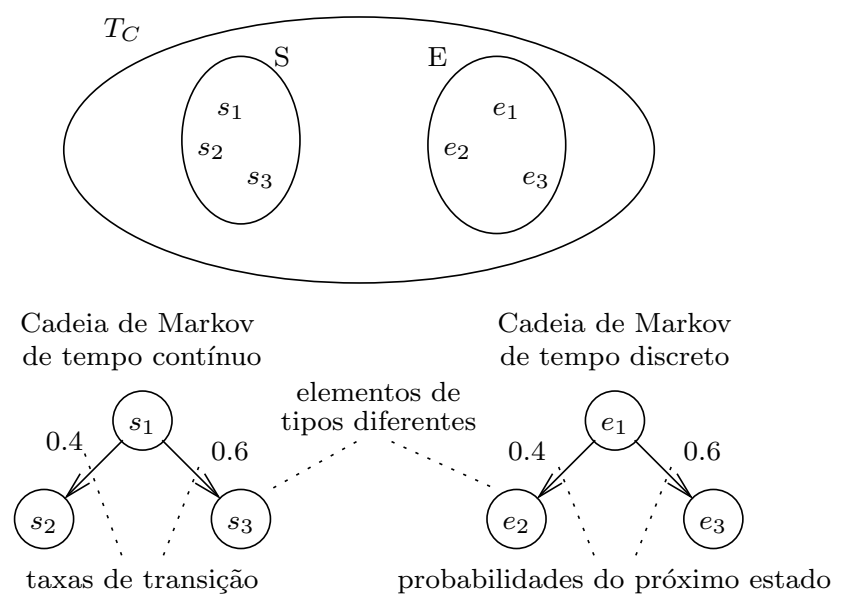

Figura 3.15: Particionamento dos termos em tipos de dados diferentes

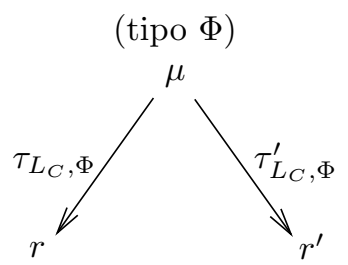

Figura 3.16: Redundância de representações num mesmo AMA

de tipo $\Phi$,

$$
\tau_{L_{C}, \Phi}(\mu) \neq \tau_{L_{C}, \Phi}^{\prime}(\mu)
$$

Da mesma forma, tais diferentes transcrições podem levar à implementação de procedimentos de análise redundantes.

Se a indulgência pode ser aceitável do ponto de vista da correção do processamento das análises, a questão da eficiência na utilização de recursos (ou seja, custos) e do gerenciamento da diversidade de informações nos experimentos de modelagem e análise apresentam argumentos objetivos contrários a essa redundância.

Uma forma de resolver este problema é com a utilização de metamodelos. Metamodelos são descrições de modelos (que, por sua vez, têm papel de descrições também). A figura 3.17 apresenta um exemplo de metamodelo referente a representações de redes de Petri. Assim, se esse metamodelo for adotado como referência e padrão de representações de redes de Petri, o problema da redundância pode ser minimizado. Em (ARATA; MIYAGI, 2003), além desse uso, metamodelos são utilizados como especificação contra a qual se faz a verificação de que um 


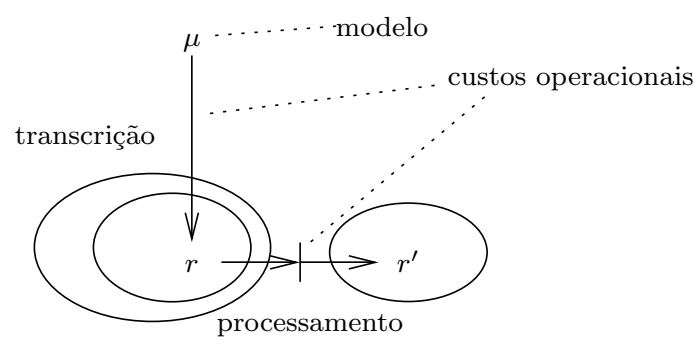

Figura 3.18: Custos operacionais: transcrição e processamento

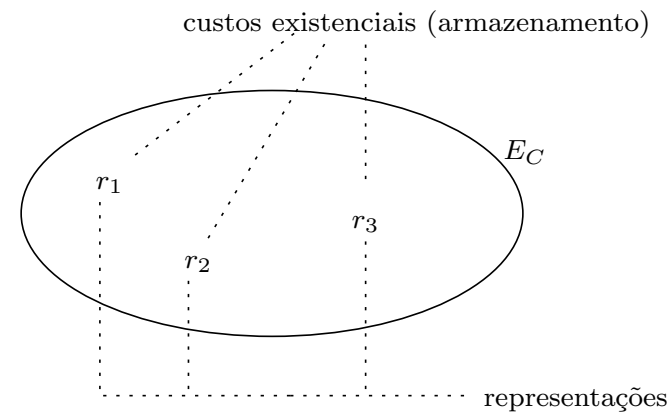

Figura 3.19: Custos existenciais: representações de modelos

Os custos existenciais referem-se àqueles necessários para a manutenção de alguma entidade, como é o caso de armazenamento de representações (ver figura 3.19). São computados por entidade e pelo tempo no qual é mantida.

Custos de transição referem-se aos custos verificados ao se passar de uma atividade a outra ${ }^{3}$, por exemplo:

- saindo de um AMA com interface gráfica para outro orientado a textos, tem-se um tempo de adaptação;

- o tempo gasto para encerrar e sair de um AMA num computador e ativar um AMA diferente em outro computador;

- em alguns casos, deve-se incluir os custos de conversão de formato de representação de modelos.

Basicamente, referem-se aos inconvenientes ao passar de um contexto de trabalho a outro. A figura 3.20 apresenta as três formas de custos de transição considerados: relativo à mudança de linguagem de modelagem, à mudança de linguagem

\footnotetext{
${ }^{3}$ Smith (1985), ao tratar da divisão do trabalho (tema de estudos organizacionais), faz referência ao tempo necessário para adaptação a uma atividade após estar executando outra diferente.
} 


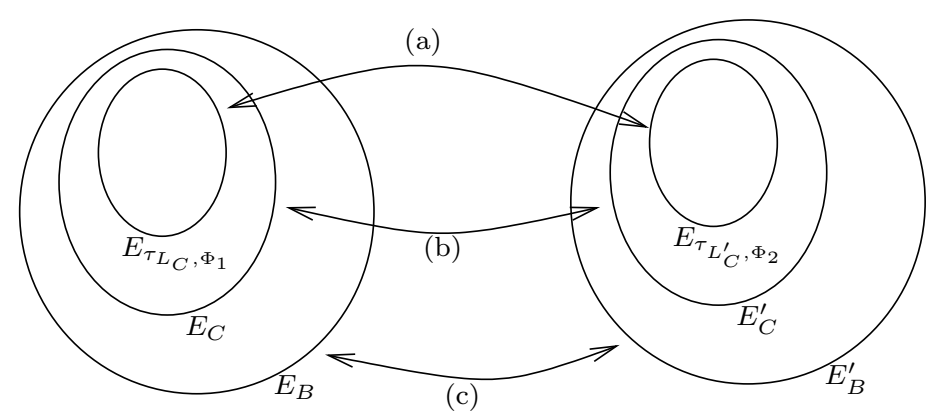

Figura 3.20: Custos de transição: (a) transição devida ao trabalho com representações de diferentes tipos de modelos, (b) transição devida ao trabalho com diferentes formas de expressão de modelos, (c) transição devida ao trabalho com diferentes conjuntos de operações para montagem de modelos

de montagem (ou seja, forma de interagir) e às conversões de representações (no caso de utilização de resultados de análise e de aproveitamento de transcrições já feitas).

Os custos de aprendizagem são, basicamente, aqueles relativos ao treinamento de usuários, cuja minimização é também enfatizada por Fricks et al. (1997). São computados por usuário envolvido.

Os custos de implantação referem-se, conforme o caso, ao desenvolvimento e implementação do AMA, à aquisição de um sistema implementado por terceiros (seleção e compra) ou à adoção de um sistema disponível. Neste trabalho, considera-se o ponto de vista do desenvolvimento; de qualquer forma, se o desenvolvimento é custoso, isso se propaga, por exemplo, aos custos de aquisição. Estes custos ocorrem apenas uma vez por implantação.

Assim, na avaliação de AMAs aqui desenvolvido, os aspectos técnicos e a questão dos custos devem ser considerandos em conjunto, o que é feito a seguir.

\subsection{Análise de configurações de AMAs}

Utilizando os elementos até aqui desenvolvidos, faz-se, agora, uma avaliação de algumas configurações de AMA para realização de experimentos de modelagem e análise de SEDs.

As configurações escolhidas são: 
- AMA para o caso de um único tipo de modelo;

- configuração para modelos heterogêneos, com AMAs específicos para cada tipo de modelo;

- configuração para modelos heterogêneos, com um AMA abrangente.

Há configurações intermediárias entre as duas últimas da lista, mas as conclusões obtidas podem ser aplicadas para estes casos também.

A primeira configuração, para o caso de um único tipo de modelo, é apresentada na figura 3.21. O diagrama mostra que o tal tipo, indicado por $\Phi$, é representado pelo conjunto-alvo da transcrição adotada para a linguagem $L_{C}=\left\langle T_{C}, E_{C}\right\rangle$, $E_{\tau_{L_{C}, \Phi}}$. Conforme indicado, tem-se que $E_{\tau_{L_{C}, \Phi}}=E_{C}$, ou seja, a linguagem de composição de modelos foi feita para lidar com aquele tipo de modelo apenas; a mesma conclusão pode ser tirada para o fato de que $E_{\tau_{L_{C}, \Phi}}=I_{A}$, onde $I_{A}$ é o conjunto-alvo de um processamento de análise para modelos de tipo $\Phi$, isto é, o processamento foi projetado sob medida para lidar com aqueles modelos naquela linguagem de composição. Enquanto isso, o fato de a linguagem de montagem $L_{B}=\left\langle P_{B}, E_{B}\right\rangle$ disponibilizar mais estruturas que os demais elementos indica uma flexibilidade baseada em operações envolvendo estruturas intermediárias. Neste particular caso, o fato de não se representar o conjunto das estruturas resultantes do processamento relacionado a $I_{A}$ significa que as estruturas resultantes não se encaixam no esquema de expressão definido pelos conjuntos-alvos do diagrama.

Do ponto de vista dos custos, a adoção desta configuração faz sentido em termos de abrangência da linguagem de composição e do(s) procedimento(s) de análise (representados por $E_{C}$ e $I_{A}$ respectivamente): dado que o objetivo é lidar com apenas um tipo de modelo, não há razão para que esse dois fatores tratem de estruturas diferentes das representações desse tipo de modelo, o que, em geral, representa custos maiores de implementação. Por outro lado, julga-se que a flexibilidade na montagem de representações (representada por $E_{B}$ com mais estruturas que $\left.E_{\tau_{L_{C}, \Phi}}\right)$ de modelos compensa os custos relativos a implementação e uso de uma linguagem mais complexa (o que está, também, de acordo com o interesse em suportar diversas configurações de experimentos expressa neste trabalho).

As duas próximas configurações lidam com modelos heterogêneos de SEDs, 


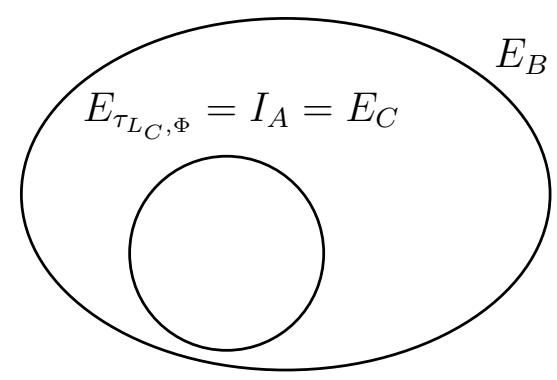

Figura 3.21: Configuração de AMA para um único tipo de modelo

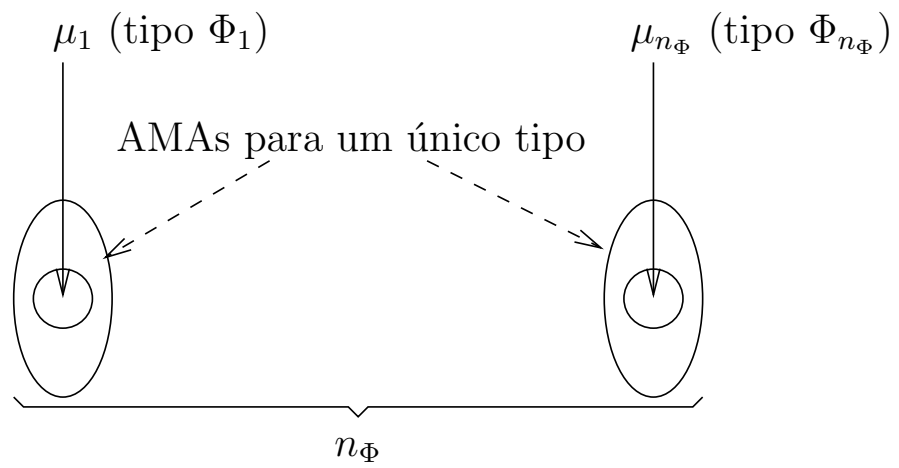

Figura 3.22: Configuração de AMAs específicos

que são comparadas a seguir. A primeira configuração envolve vários AMAs, cada um encarregado da análise de um único tipo de modelo, conforme ilustrado na figura 3.22. Cada um dos AMAs segue a configuração de AMA para um tipo de modelo descrita anteriormente.

A segunda configuração, trata-se de um único AMA abrangente, ou seja, apresenta um linguagem de modelagem ampla o suficiente para expressar e construir representações de diversos tipos de modelos, conforme ilustrado na figura 3.23; nota-se que, na figura, os resultados da análise são também abrangidos pela linguagem de modelagem, reflexo do fato que resultados de certas análises passam também por outras análises.

Para efeito de comparação, considera-se que ambas as configurações tratam dos mesmos $n_{\Phi}$ tipos de modelos $\left(\Phi_{1}, \ldots, \Phi_{n_{\Phi}}\right)$ e que o mesmo padrão de operações é executado (ou seja, transcrição e análise dos mesmos modelos, na mesma seqüência) e que ambos apresentam os mesmos custos operacionais e existenciais. Também, os custos de implementação referem-se basicamente às linguagens de composição e de modelagem, sendo considerados iguais aqueles referentes a implementação dos processamentos. 


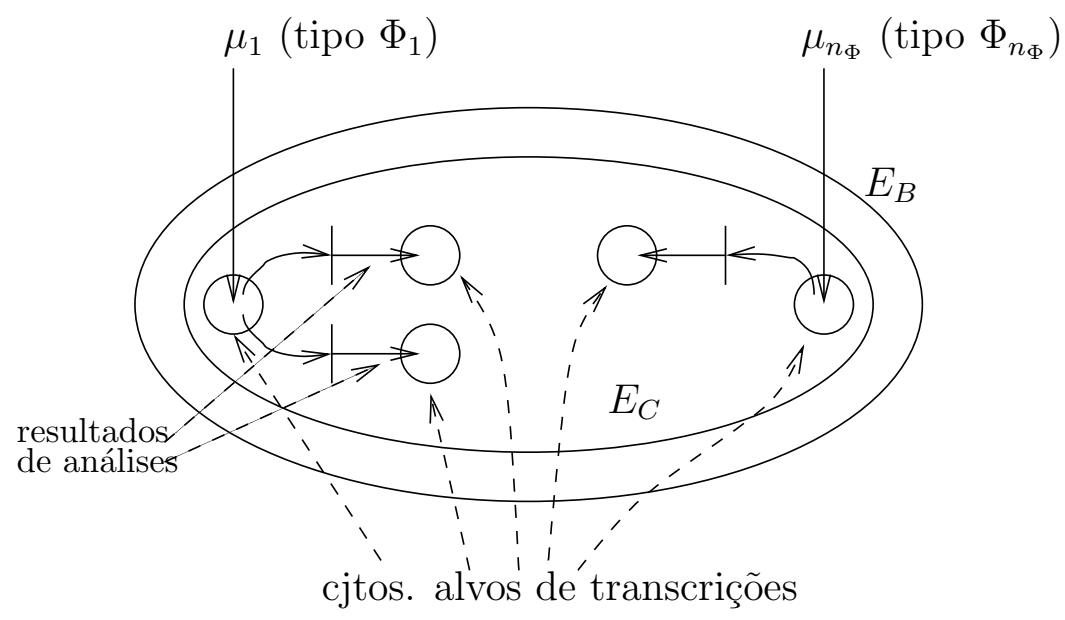

Figura 3.23: Configuração de AMA abrangente

As figuras 3.24 e 3.25 mostram os custos envolvidos em ambas as configurações, que são organizados na tabela 3.1 .

A tabela 3.1 mostra os custos envolvidos em cada configuração (também ilustrados nas figuras 3.22 e 3.23). Os elementos envolvidos são:

- $n_{\Phi}$ é o número de tipos de modelos (ou seja, uma medida da heterogeneidade);

- $\bar{C}_{i m p l}$ é o custo médio de implementação de um AMA simples;

- $C_{i m p l}^{*}\left(n_{\Phi}\right)$ é o custo de implementação de um AMA abrangente em função do número de tipos a considerar;

- $n_{\text {users }}$ é o número de usuários a utilizar o(s) AMA(s);

- $\bar{C}_{\text {learn }}$ é o custo médio de aprendizagem de um AMA simples;

- $C_{\text {learn }}^{*}\left(n_{\Phi}\right)$ é o custo de aprendizagem de um AMA abrangente em função do número de tipos a considerar;

- $n_{\text {trans }}$ é o número de transições entre AMAs da primeira configuração;

- $\bar{C}_{\text {trans }}$ é o custo médio de transição entre AMAs da primeira configuração;

- $C_{\text {trans }}^{*}$ é o custo médio de transição entre operações sobre modelos de diferentes tipos da configuração de AMA abrangente. 


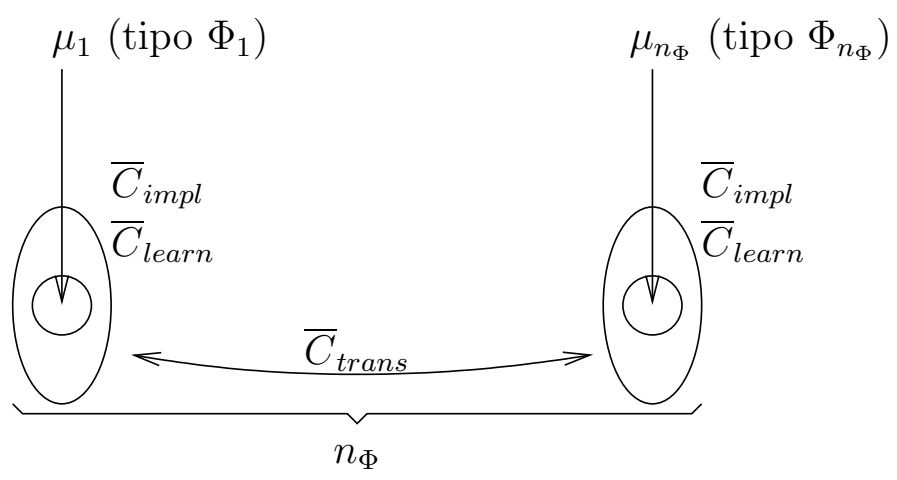

Figura 3.24: Custos na configuração de AMAs específicos

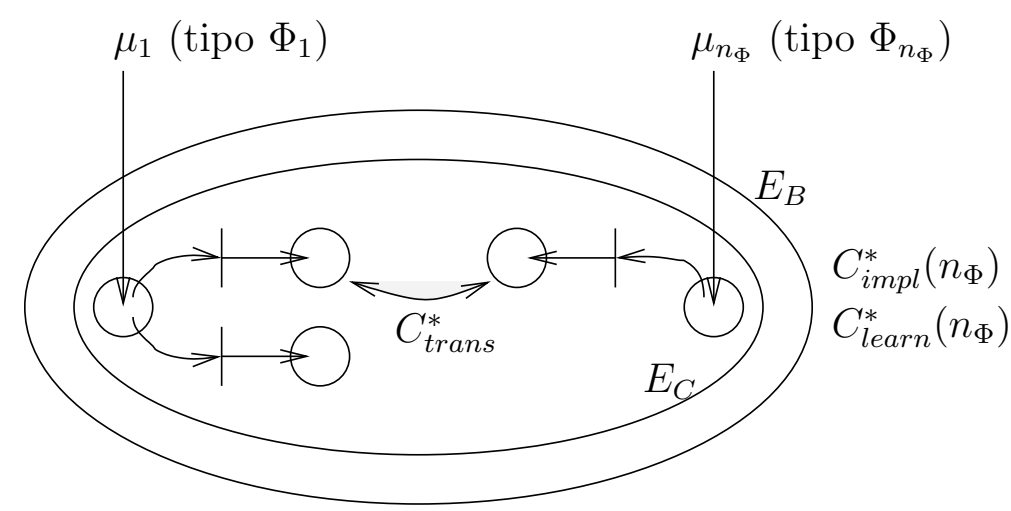

Figura 3.25: Custos na configuração de AMA abrangente

Com relação à configuração de AMAs específicos para cada tipo, a fim de tratálos abstratamente, supõe que existe um levantamento de custos e um cálculo de sua média; ao final, seu real valor não invalida as conclusões atingidas. Também, considera-se o mesmo número de usuários para ambos os casos.

Sendo $C_{\text {total }}^{\text {especificos }}$ e $C_{\text {total }}^{\text {abrangente }}$ os custos totais das configurações de AMAs específicos e de AMA abrangente respectivamente, tem-se que:

$$
C_{\text {total }}^{\text {especifico }}=n_{\Phi} \bar{C}_{\text {impl }}+n_{\Phi} n_{\text {users }} \bar{C}_{\text {learn }}+n_{\text {trans }} \bar{C}_{\text {trans }}+C_{\text {other }}
$$

e

$$
C_{\text {total }}^{\text {abrangente }}=C_{\text {impl }}^{*}\left(n_{\Phi}\right)+n_{\text {users }} C_{\text {learn }}^{*}\left(n_{\Phi}\right)++n_{\text {trans }} C_{\text {trans }}^{*}+C_{\text {other }}
$$

onde $C_{\text {other }}$ são os outros custos, que, por hipótese, são os mesmos em ambas as configurações.

O que se deseja é determinar os casos em que a configuração de AMA abran- 
Tabela 3.1: Comparação de custos entre duas configuração de AMAs para tratamento de modelos heterogêneos

\begin{tabular}{|c|c|c|}
\hline Custo & Configuração da figura 3.22 & Configuração da figura 3.23 \\
\hline Implementação & $n_{\Phi} \bar{C}_{i m p l}$ & $C_{\text {impl }}^{*}\left(n_{\Phi}\right)$ \\
\hline Aprendizagem & $n_{\Phi} n_{\text {users }} \bar{C}_{\text {learn }}$ & $n_{\text {users }} C_{\text {learn }}^{*}\left(n_{\Phi}\right)$ \\
\hline Transição & $n_{\text {trans }} \bar{C}_{\text {trans }}$ & $n_{\text {trans }} C_{\text {trans }}^{*}$ \\
\hline Existencial & \multicolumn{2}{|c|}{ Iguais por hipótese } \\
\hline Operacional & \multicolumn{2}{|c|}{ Iguais por hipótese } \\
\hline
\end{tabular}

gente é melhor, ou seja,

$$
C_{\text {total }}^{\text {especificos }}>C_{\text {total }}^{\text {abrangente }}
$$

O primeiro caso a analisar, considera o caso em que modelos heterogêneos de SEDs são abordados isoladamente, ou seja, exclui-se os casos de integração ou qualquer atividade envolvendo trabalho conjunto de modelos heterogêneos, o que implica

$$
n_{\text {trans }}=0
$$

Desta forma, a configuração de AMA único e abrangente é interessante se

$$
\bar{C}_{i m p l}+n_{\text {users }} \bar{C}_{\text {learn }}>\frac{C_{\text {impl }}^{*}\left(n_{\Phi}\right)}{n_{\Phi}}+\frac{n_{\text {users }} C_{\text {learn }}^{*}\left(n_{\Phi}\right)}{n_{\Phi}}
$$

Agora, se além de abrangente, a linguagem de modelagem for uniforme e ideal (conforme a definição 3.1), isso se traduz em custos de implantação e de aprendizagem constantes:

$$
C_{i m p l}^{*}\left(n_{\Phi}\right)=K_{i m p l}
$$

e

$$
C_{\text {learn }}^{*}\left(n_{\Phi}\right)=K_{\text {learn }}
$$

Neste caso, existe um $\check{n}_{\Phi}$ tal que, se $n_{\Phi}>\check{n}_{\Phi}$, a condição dada pela desigualdade 3.9 é verdadeira. Ou seja, quanto maior a heterogeneidade, maior a tendência de a configuração de AMA abrangente e uniforme ideal ser a mais favorável. Num caso mais pragmático, para que continue favorável, tem-se que o impacto de uma maior heterogeneidade na configuração abrangente deve ser menor que o custo de se implementar um novo AMA para o novo tipo de modelo.

Agora, considera-se o caso em que se fixa o grau de heterogeneidade $\left(n_{\Phi}\right.$ é 
fixo) e em que há operações que exigem transições entre AMAs, ou seja,

$$
n_{\text {trans }}>0
$$

A condição para a adoção da configuração de AMA único e abrangente é dada por

$$
\bar{C}_{\text {trans }}>\frac{C_{\text {impl }}^{*}\left(n_{\Phi}\right)+n_{\text {users }} C_{\text {learn }}^{*}\left(n_{\Phi}\right)+n_{\text {trans }} C_{\text {trans }}^{*}-n_{\Phi} \bar{C}_{\text {impl }}-n_{\Phi} n_{\text {users }} \bar{C}_{\text {learn }}}{n_{\text {trans }}}
$$

ou seja, existe um $\check{n}_{\text {trans }}$ tal que, se $n_{\text {trans }} \geq \check{n}_{\text {trans }}$, a condição dada pela desigualdade 3.10 é verdadeira. Em palavras, quanto maior o grau de consideração conjunta de modelos heterogêneos, mais vantajosa tende a ser a adoção de um AMA único e abrangente.

Considerando-se ainda a condição dada por 3.10, se a linguagem de modelagem for, além de abrangente, uniforme, quanto maior o grau de heterogeneidade (maior $n_{\Phi}$ ), maior o impactos dos custos de implementação e aprendizagem na configuração de AMAs específicos; também, os custos de transição tornam-se muito menores, uma vez que as representações podem ser tratadas de maneira muito similar; portanto, tem-se uma maior a tendência para se adotar um AMA único e abrangente. Disto, pode-se concluir que a heterogeneidade de modelos e a integração destes se beneficiam de uma linguagem de modelagem abrangente e uniforme.

\subsection{Diretrizes para um AMA para modelos he- terogêneos}

Assim, considerando-se a multiplicidade de tipos de modelos de SEDs, os elementos dos AMAs e as transcrições de modelos e a questão dos custos, pode-se levantar as seguintes diretrizes para um AMA:

- deve ter capacidade de expressão numérico-simbólica;

- seus elementos e as transcrições dos modelos a tratar devem estar coordenados: deve-se poder expressar, montar e analisar as representações dos múltiplos tipos de modelos que compõem o quadro de heterogeneidade;

- deve apresentar flexibilidade na montagem das representações dos modelos; 
- deve assegurar abrangência e uniformidade da linguagem de composição de modelos;

- deve possuir mecanismos para minimizar as ambigüidades das representações;

- deve possuir mecanismos para minimizar as redundâncias de representações.

A heterogeneidade dos modelos de SEDs e o grau de integração entre os mesmos são particularmente beneficiados pela abrangência das linguagens de composição das representações de modelos.

A uniformidade da linguagem, na medida que os mesmos elementos léxicosintáticos são utilizados para compor as representações de modelos, traz uma compatibilização da heterogeneidade matemático-formal dos modelos de SEDs. Essa heterogeneidade inerente não é eliminável, mas a afinidade entre as representações permite que sejam tratadas de maneira uniforme: por exemplo, é possível definir um único conjunto de operações para montagem, acesso e manipulação de modelos. Isso se manifesta também nos custos, onde se mostra que a uniformidade reduz o impacto da heterogeneidade.

Estas são as diretrizes básicas que se deve observar para que um AMA para SEDs possa oferecer um fluxo de trabalho sem obstruções ao minimizar as incompatibilidades que acompanham a heterogeneidade de modelos e a realização de suas análises.

\subsection{Comentários do capítulo}

A abordagem de descrição dos AMAs para SEDs adotada trata, essencialmente, dos aspectos macro-representacionais ao invés de uma abordagem microrepresentacional. Na última, o enfoque é nos elementos léxico-sintáticos das linguagens de modelagem. No caso deste capítulo, tratou-se da maneira como os tipos de modelos interagem com os elementos dos AMAs e estes entre si, através das transcrições e dos conjuntos-alvos. Características importantes podem ser visualizadas através dessa forma agregada, sem que os detalhes da composição das estruturas sejam necessários.

As conclusões aqui obtidas podem ser aplicadas a implementações de ambientes que sigam o modelo de AMA apresentado. Este, por sua vez, não é muito 
restritivo, sendo representativo de muitos casos, bastando possuir os elementos definidos pelo modelo.

Com relação às conclusões, os elementos dos AMAs e das transcrições e as considerações de custos, permitem levantar diretrizes que atuam no sentido de melhorar o fluxo de trabalho nos experimentos de modelagem e análise envolvendo modelos heterogêneos de SEDs. Também, fica claro o papel que a uniformidade da representação de modelos pode ter no suporte computacional a tais experimentos.

Enquanto este capítulo se concentrou na compatibilização da heterogeneidade formal dos modelos de SEDs via uniformidade e abrangência, o que basicamente habilita a coabitação de tais modelos dentro de um mesmo esquema de representação computacional, o próximo capítulo trata da integração desses modelos. 


\section{Representação de informações semânticas e integração de modelos heterogêneos}

O capítulo 3 trata das bases para que múltiplos e heterogêneos modelos de SEDs possam ser tratados de maneira eficiente. O contexto apresentado é o de um ambiente computacional que adota uma linguagem de modelagem cujas principais características são a abrangência e a uniformidade no que se refere ao tratamento de modelos de diversos tipos. Porém, a compatibilização da heterogeneidade formal desses modelos de SEDs não implica que haja um suporte ao aproveitamento das técnicas de integração de tais modelos (alguns dos quais já citados na seção 2.3). Em termos de representações computacionais, a adequação de tal suporte significa:

- que a heterogeneidade de modelos deve ser, tanto quanto seja possível, transparente, ou seja, que a apresentação das informações sobre a dinâmica modelada e analisada não seja obstruída por tal heterogeneidade;

- que a representação de tais informações deve ser organizada de modo que a implementação de análises que pressupõem a integração de modelos possa tirar vantagem disso.

O que este capítulo se propõe é apresentar os elementos de representação de modelos de SEDs que tenham as características há pouco mencionadas. A abordagem descrita é baseada na semântica dos modelos, o que está relacionado com o fato de a integração entre modelos se basear em relacionamentos de ordem semântica (conforme discutido na seção 2.4). 
Assim, como tópicos deste capítulo, tem-se a questão da integração de informações associadas a estruturas heterogêneas, uma apresentação de predicados como meio de representar informações semânticas, descrição da abordagem de representação da semântica dos modelos, descrição de formas para obter uma representação integrada e consistente de informações associadas a vários modelos relativos a uma mesma dinâmica e, por fim, a questão dos relacionamentos horizontais, brevemente mencionada em capítulos anteriores.

Nesta parte do texto, assume-se um tom "petricêntrico" para ilustrar os conceitos, uma vez que as redes de Petri permitem a modelagem de SEDs em vários níveis de detalhe e têm uma relativa riqueza de recursos de modelagem, simplificando a exposição dos conceitos, além do que muitos tipos de modelos lhes são associados. Vale lembrar, também, que existe uma grande variedade de formalismos baseados em redes de Petri, como os desenvolvidos por Molloy (1980), Marsan, Conte e Balbo (1984), Hasegawa, Takahashi e Miyagi (1988), Miyagi, Hasegawa e Takahashi (1988) e Bause e Buchholz (1998). Apesar dos exemplos terem tal orientação, a independência com relação aos tipos de modelos dos conceitos apresentados sugere que possam ser úteis, também, a outras abordagens.

\subsection{Integração de informações oriundas de es- truturas heterogêneas de informação}

Conforme tratado no capítulo 2, vários modelos de SEDs podem ser empregados para estudar uma mesma dinâmica; também, esses modelos descrevem e analisam diferentes aspectos dessa dinâmica, sobretudo se forem heterogêneos. Nesse contexto, visando um aproveitamento computacional das informações semânticas associadas a tais modelos de SEDs, deve-se elaborar um meio de representá-las que considere os seguintes pontos:

- é importante haver uma capacidade de descrever uma variedade de informações;

- uma vez que as informações não são independentes, é preciso que isso seja adequadamente explicitado, sob pena de se oferecer uma visualização deficiente dos relacionamentos entre as informações (conforme é detalhado na seção 4.3); 
- a fim de lidar com a complexidade oriunda da diversidade de tipos de modelos, deve-se almejar a transparência da heterogeneidade dos modelos, ou seja, apresentar mecanismos para que não seja necessário, tanto quanto seja possível, ter de lidar com as diferenças de estruturas e composição referentes a tais modelos - isto está relacionado, conforme pode ser constatado no desenvolvimento deste capítulo, com a qualidade da integração das informações associadas aos modelos.

A integração de informações de fontes heterogêneas é uma matéria de interesse de várias áreas, como bancos de dados heterogêneos (URBAN, 1991; ZISMAN, 1995) e gerenciamento de informações geográficas (MACKAY, 1999; CRUZ et al., 2002). Apesar de se tratarem de diferentes disciplinas, algumas idéias básicas são comuns a essas abordagens, como é o caso de a integração se basear na semântica dos dados, isto é, a integração das informações associadas a tais dados ocorre em virtude dos relacionamentos entre aquilo que representam. Vale lembrar que, nessa mesma linha, a integração de modelos ocorre em bases similares, conforme apresentado na seção 2.4. Assim, esta é, também, a direção adotada por este trabalho, ou seja, de que a explicitação da semântica dos modelos de SEDs é necessária para possibilitar um tratamento computacional integrado desses modelos (similarmente ao que foi colocado por Urban (1991)).

Porém, alguns aspectos devem ser tratados no que se refere à representação de informação semântica no caso deste trabalho:

- é necessário um meio comum para representar os aspectos semânticos relevantes de diferentes tipos de modelos de SEDs;

- as formas como as semânticas dos modelos de SEDs se relacionam podem ser muito variadas e, portanto, deve haver uma capacidade de representar tais relacionamentos nessas diferentes formas;

- deve haver meios para que as informações representadas possam ser computacionalmente processadas;

- ao expressar elementos da semântica dos modelos, atenção deve ser dada aos conflitos semânticos (ZISMAN, 1995), como os conflitos estruturais (referentes a fatos que são descritos de formas diferentes em diferentes modelos) e os de vocabulário (como homônimos e sinônimos); 
O que esta parte do trabalho apresenta é uma abordagem baseada em predicados e elementos afins para a representação dos aspectos semânticos dos modelos de SEDs. Tais representações são feitas em termos de entidades, fatos e/ou relacionamentos observáveis na dinâmica modelada de SEDs. Utilizando-se esses elementos de maneira adequada, mostra-se que é possível gerar uma descrição das informações associadas aos modelos onde a heterogeneidade dos modelos é transparente e os relacionamentos entre as informações são visíveis. Além desses atributos, mostra-se que essas representações podem ser manipuladas computacionalmente, o que aumenta a capacidade de aproveitar essa integração e, portanto, a capacidade de lidar com modelos e análises de SEDs.

\subsection{Predicados e estruturas afins}

Neste trabalho, adota-se predicados como a forma de representar as informações semânticas associadas aos modelos de SEDs.

Começando pelos elementos mais básicos, os termos são denotados por uma cadeia de caracteres alfanuméricos (sendo o primeiro um caracter alfabético por uma questão de facilidade de implementação computacional). São utilizados para representar entidades, fatos ou conceitos cuja composição interna é irrelevante para as descrições onde são utilizadas. São exemplos de termos:

maquinaM

pecaTipoB

que podem ser usados para representar "máquina M" e "uma peça de tipo B".

Os functores são uma forma de representar objetos com estruturas complexas, tendo a seguinte estrutura

nome $(\arg 1, \ldots, \arg 2)$

ou seja, possuem um nome seguido, entre parênteses, por uma lista de argumentos separada por vírgulas; os argumentos podem ser termos ou outros functores, isto é, functores podem ser aninhados indefinidamente. Os functores podem ser usados na representação de fatos e relacionamentos relativos aos termos e a outros functores indicados como argumentos. São exemplos de functores: 
$\operatorname{processo}(\mathrm{M}, \mathrm{p})$

inicio (processo $(M, p)$ )

fim $(\operatorname{processo}(M, p))$

onde o primeiro functor pode ser usado para representar "maquina M processando peça p" e os outros dois, que têm o primeiro functor como argumento, podem ser usados para representar o início e o fim do processamento representado pelo primeiro functor.

São também considerados functores, expressões envolvendo functores e/ou termos e que utilizam o operador conjuntivo and, do modo que a expressão:

$\operatorname{inicio(processo(M,p)}$ and $i d a(p, l a b A))$

pode ser usado para representar "início de um processamento, por uma máquina M, de uma peça p cujo destino é o laboratório labA".

Os termos podem também ser considerados como formas degeneradas de functores.

Enfim, um predicado tem a seguinte estrutura:

nome $(\arg 1, \ldots, \operatorname{argn})$.

ou seja, similarmente aos functores, um predicado apresenta um nome, seguido, entre parênteses, por um lista de argumentos separados por vírgulas e um ponto final; os argumentos podem ser termos ou functores. Diferentemente dos functores, predicados não podem ser aninhados. Os predicados são usados em asserções para indicar que o fato representado é verdadeiro. Por exemplo, o predicado

$\operatorname{ocorre}(\operatorname{processo}(M, p), \mathrm{s} 12)$.

pode ser elaborado para indicar que "no estado s12, ocorre o processamento de uma peça p por uma máquina M" é verdadeiro.

Os predicados e os functores são similares aos implementados na linguagem Prolog (DERANSART; CERVONI; ED-DBALI, 1996). Outras formas de representar semântica existem, como as denominadas redes semânticas (SOWA, 2002). Este trabalho adotou essa forma de predicados pela sua simplicidade e pela sua 
eficácia e suficiência em ilustrar os benefícios que uma descrição consistente da semântica do elementos envolvidos pode oferecer aos experimentos de modelagem e análise.

\subsection{Representação de informações da semântica dos modelos}

Um primeiro passo na abordagem aqui desenvolvida é de associar anotações sob a forma de termos e functores aos elementos dos modelos como forma de representar informações semânticas associadas aos modelos de SEDs. A idéia básica é de que, para uma representação efetivamente integrada das informações de diversos modelos, é preciso que as semânticas de seus elementos sejam adequadamente representadas e que haja meios de processar tais representações computacionalmente, uma vez que tais elementos são potenciais participantes de vínculos com outros modelos; observação análoga foi apresentada por Zisman (1995) ao tratar de incompatibilidades entre esquemas de bancos de dados heterogêneos.

No que se refere às anotações, um ponto que deve ser tratado, também mencionado por Zisman (1995), é a questão dos conflitos de nomenclatura, em especial, no presente caso, envolvendo sinônimos e homônimos.

No caso dos sinônimos, ou seja, dois termos diferentes para expressar um mesmo conceito, se tal relação não estiver clara, gera uma ineficiência no sentido de que dois conjuntos de descrições envolvendo um mesmo conceito podem aparentar desconexos, ou seja, desacopla informações que estão relacionadas.

No caso dos homônimos, ou seja, um mesmo termo para expressar dois conceitos diferentes, a situação é inversa, podendo ocorrer de um conjunto de descrições envolvendo esse termo ser associada a situações sem sentidos, por não se saber qual dos conceitos homônimos deve ser considerado.

Computacionalmente, o não tratamento ou a inexistência de mecanismos para lidar com tais conflitos compromete a capacidade de apresentar uma descrição integrada das informações associadas aos modelos, uma vez que certos relacionamentos existentes podem não ser percebidos ou que relacionamentos inexistentes podem ser inferidos.

Um elemento importante para evitar conflitos é a consistência das repre- 


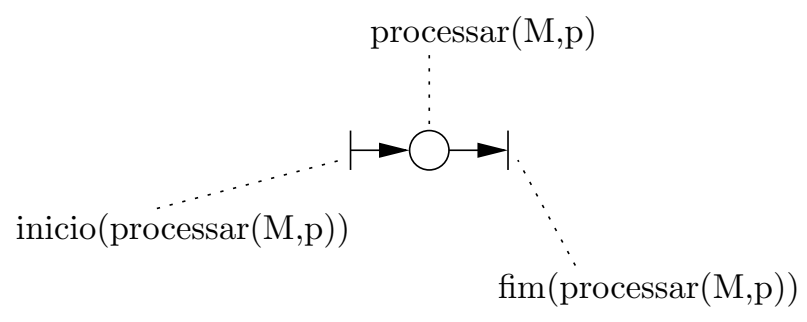

Figura 4.1: Anotações nas transições referem-se ao início e ao fim de um mesmo fato

sentações. Uma das características da consistência na representação de um aspecto é que, se esse aspecto ocorre em várias situações, é possível inferir tal ocorrência da descrição dessa situação sem que haja ambigüidades. Isso é importante, pois se uma situação apresenta um determinado aspecto, os relacionamentos que o envolvem podem ser relevantes naquela situação. É essa consistência que as descrições a serem desenvolvidas devem procurar apresentar.

A rede de Petri da figura 4.1 apresenta exemplos de anotações (a associação das anotações aos elementos dos modelos são indicadas informalmente neste capítulo, sendo que uma implementação é apresentada no capítulo 5). As transições ${ }^{1}$ representam o início e o fim de uma mesma condição (esta, anotada pelo functor processar $(\mathrm{M}, \mathrm{p}))$. O fato de ambas as transições terem esse vínculo é refletido nas respectivas anotações, onde um mesmo functor é utilizado como argumento; computacionalmente, isso pode ser facilmente verificado, bastando examinar se os argumentos desses functores apresentam um mesmo functor. Pode-se perceber que o uso de anotações permite identificar quais os elementos dos modelos que representam determinado aspecto envolvido numa dinâmica. Com a consistência, é simples identificar os outros elementos dos modelos relacionados com aquele aspecto.

Considere, agora, o exemplo da figura 4.2, que ilustra um trecho de rede de Petri. Tal trecho representa o processamento de uma peça p por uma máquina $\mathrm{M}$ em duas situações: uma considerada normal e outra em que a peça sendo processada foi selecionada para se dirigir ao controle de qualidade (CQ). A indicação da seleção é representada por um lugar com a anotação selecionado (p, CQ). O processamento em si ocorre em ambas as situações, representadas pelos outros dois

\footnotetext{
${ }^{1}$ Em particular, os termos e conceitos relacionados a redes de Petri são apresentados em itálicos, como transições, lugares, marcas, marcações e outros (ver apêndice A)
} 


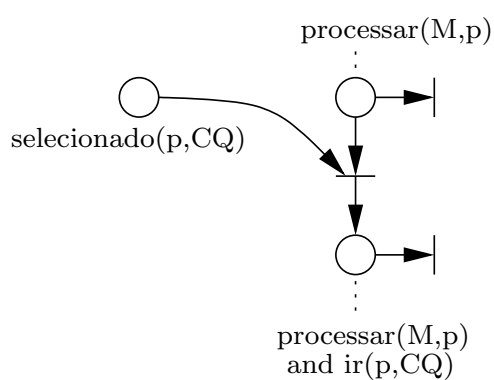

Figura 4.2: Rede de Petri com lugares referentes a situações que envolvem um mesmo fato

lugares (um para cada situação): em termos das anotações, a consistência na representação do processamento é indicada pelo fato de o functor processar (M,p) poder ser inferido de ambas as anotações, sendo uma forma computacional de fazer tal verificação.

Portanto, a consistência intramodelo das representações da semântica dos modelos pode ser conseguida:

- pela utilização consistente de uma única representação para um mesmo aspecto nas descrições de todas as situações em que ocorre;

- pela capacidade de se poder inferir um aspecto (representado por um functor) a partir das anotações.

Essa consistência pode auxiliar na construção de representações computacionais de modelos. Supondo que a rede de Petri ilustrada na figura 4.2 está em construção, considere o caso da inserção de elementos relativos ao fato que "todo processamento pela máquina $\mathrm{M}$ em peças $\mathrm{p}$ deve ser cancelado ao ser sinalizada a reinicialização". O resultado final é mostrado na figura 4.3. O procedimento de inserção é o seguinte:

1. incluir um lugar $p_{R}$ com anotação sinaliza(reset, $\operatorname{processar}(\mathrm{M}, \mathrm{p})$ );

2. para cada lugar $p_{i}$ da rede de cujas anotações possa se inferir o functor $\operatorname{processar}(\mathrm{M}, \mathrm{p})$ :

(a) incluir um transição $t_{i}$ com anotação reset $(\$$ f), onde $\$$ f é a anotação de $p_{i}$;

(b) incluir um arco ligando $p_{i}$ a $t_{i}$; 


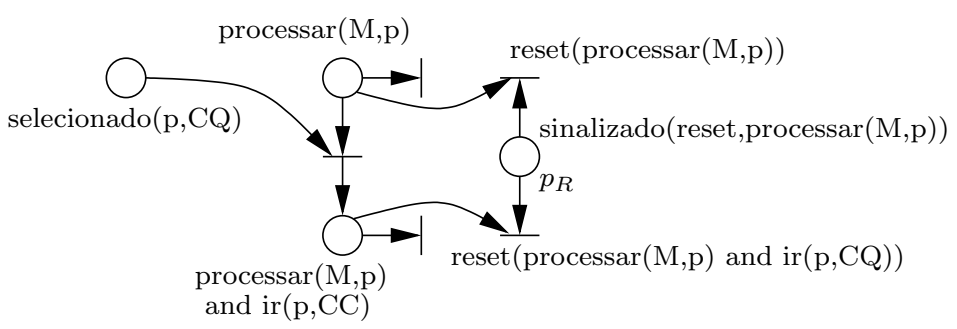

Figura 4.3: Adicionando rotina de reinicialização à rede de Petri da figura 4.2

(c) incluir um arco ligando $t_{i}$ a $p_{R}$.

A consistência e a capacidade de inferir se um certo aspecto ocorre nas anotações dos elementos pode auxiliar, por exemplo, na determinação dos elementos que modelam tal aspecto: determinado quais os lugares que representam "processamento de peça p por máquina M", é possível fazer uma verificação no modelo de que não há situação em que mais de um dos lugares contém marcas. Isso pode ser feito, por exemplo, através dos P-invariantes (MURATA, 1989).

Neste ponto, é importante observar que as anotações, para serem adequadas, não devem entrar em conflito com as propriedades dos modelos. Assim, algumas diretrizes podem ajudar a evitar problemas, como:

- não repetir anotações para um mesmo modelo: no caso geral, elementos diferentes representam situações diferentes, de modo que deve haver um fator que diferencie situações aparentemente idênticas; além disso, a repetição indevida de anotações pode atrapalhar certos procedimentos computacionais (analogamente à presença de sinônimos);

- não entrar em conflito com as propriedades dos modelos: por exemplo, se as anotações descrevem situações mutuamente excludentes (por exemplo, "máquina ligada" e "máquina desligada"), é importante que o modelo confirme essa exclusão, ou seja, que não apresente uma situação em que os fatos descritos por essas anotações ocorram simultaneamente.

Com relação aos modelos de SEDs, através de seus elementos e do padrão de relacionamentos que expressam, descrevem padrões de interação observados numa determinada dinâmica. Assim, a partir de tais padrões e das anotações dos elementos dos modelos, espera-se poder descrever aspectos da dinâmica modelada 
em termos de entidades, fatos e relacionamentos observáveis no sistema e na dinâmica modeladas. A abordagem, aqui, é de se elaborar predicados envolvendo os termos e os functores que anotam os elementos dos modelos.

Por exemplo, a rede de Petri na figura 4.4 modela o seguinte: uma operação de montagem realizada por uma máquina $\mathrm{M}$ que une peças de tipo $\mathrm{A}$ e de tipo B; o fato de que as partes devem estar em buffers específicos para cada tipo de peça (bufA e bufB) antes do início da operação e que os buffers têm capacidade para apenas uma peça. As seguintes asserções podem ser elaboradas:

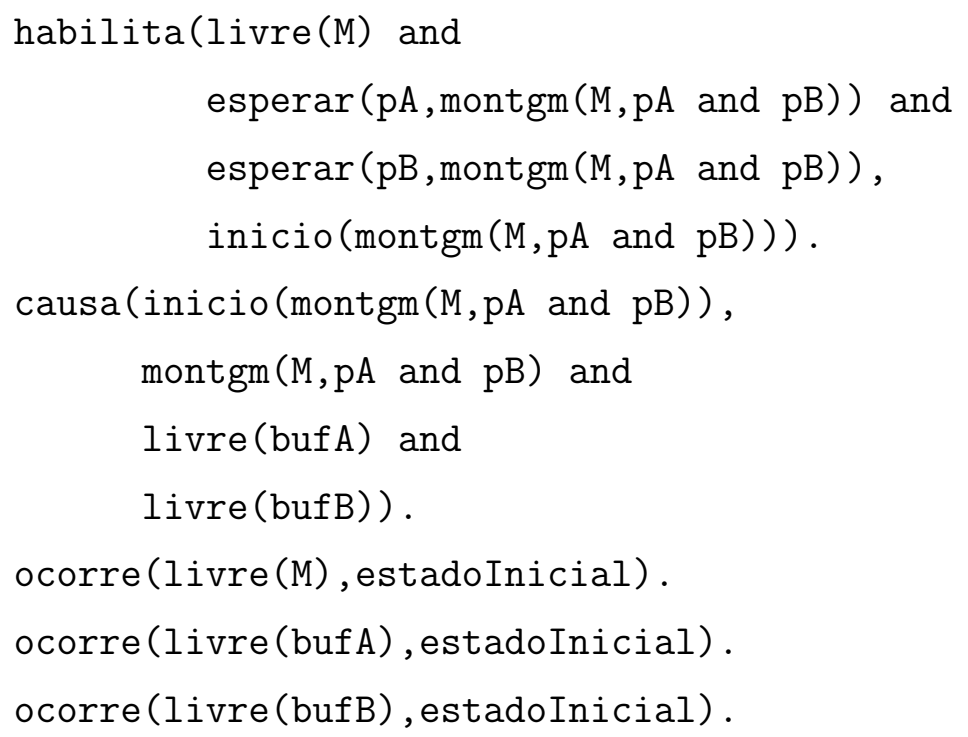

O predicado habilita apresenta as condições para que o início da operação de montagem ocorra (inicio(montgm $(\mathrm{M}, \mathrm{pA}$ and $\mathrm{pB})$ )), representadas pela conjunção

livre(M) and esperar (pA,montgm (M,pA and $\mathrm{pB})$ )

and esperar $(\mathrm{pB}, \operatorname{montgm}(\mathrm{M}, \mathrm{pA}$ and $\mathrm{pB}))\}$

ou seja, quando a máquina $\mathrm{M}$ estiver livre e peças de ambos os tipos estiverem à espera pela montagem nos respectivos buffers. No predicado causa, a expressão 'montgm(M,pA and $\mathrm{pB}$ ) and livre(bufA) and livre(bufB)' indica o que acontece após o início da montagem, ou seja, a montagem propriamente e a liberação dos buffers. Os predicados com nome ocorre indicam o que pode ser observado nos estados do sistema; no caso, indicam que a máquina $\mathrm{M}$ e os buffers bufA e bufB estão livres no estado inicial. 


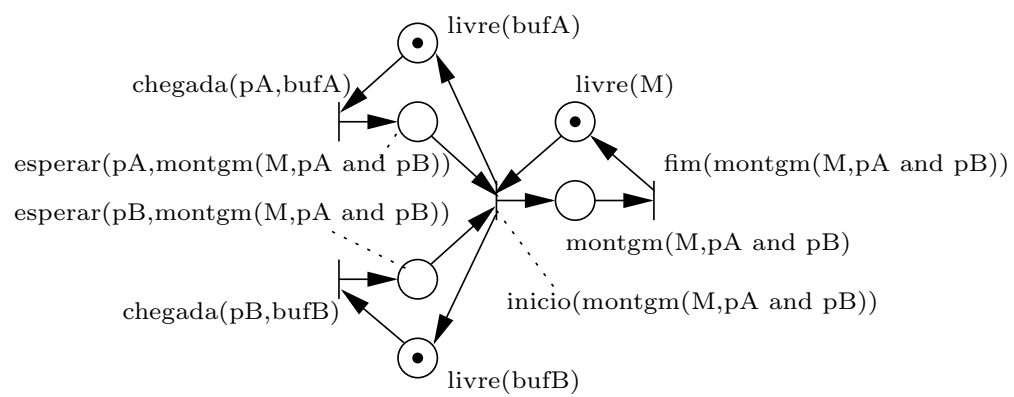

Figura 4.4: Um exemplo de rede de Petri anotada por functores

Este é um exemplo de representação de informações da semântica de um modelo. No caso de vários modelos que se referem a uma mesma dinâmica, representações análogas das informações associadas aos modelos podem ser elaboradas, mas, nesse caso, o desafio é que a descrição reflita a integração de modelos que se apresentarem, o que é tratado no próximo tópico.

\subsection{Representação integrada das informações as- sociadas a modelos referentes a uma mesma dinâmica}

Conforme já discutido na seção 2.4, a natureza dos relacionamentos em que se baseia a integração de modelos apresenta um importante componente semântico. Em termos de representação, é justamente a abordagem dos vínculos semânticos que determina a qualidade de uma representação integrada dos modelos relacionados, principalmente com relação aos conflitos de nomenclatura (caso dos sinônimos e homônimos) e de estrutura (mesmo conceito representado por estruturas diferentes em modelos diferentes) (ZISMAN, 1995). Nesta seção, alguns casos são tratados, os quais fornecem elementos importantes para a representação da integração.

Um caso notório é o do isomorfismo entre redes de Petri estocásticas e cadeias de Markov de tempo contínuo (MOLLOY, 1980). Modelos desses tipos são ditos isomórficos se as três condições a seguir forem atendidas:

- há um mapeamento um-a-um entre seus estados (ou marcações no caso da 


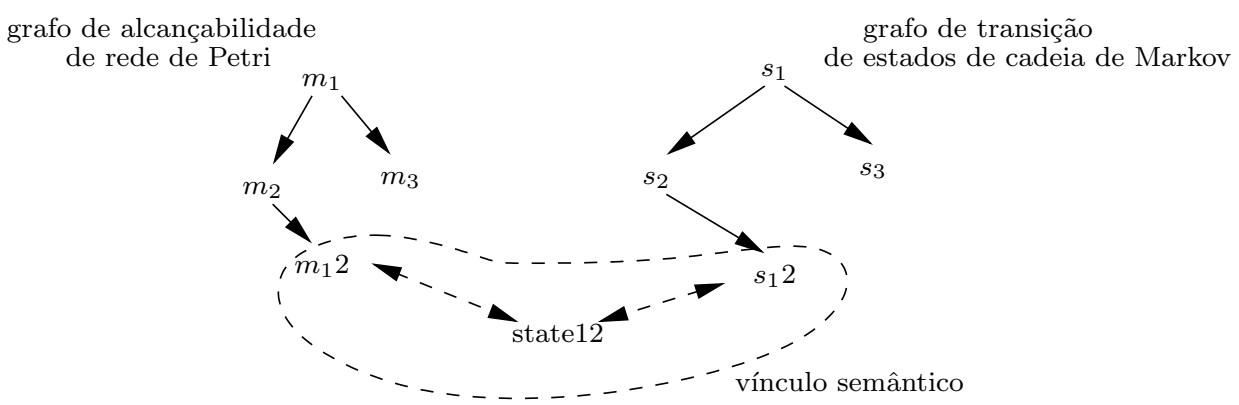

Figura 4.5: Isomorfismo entre rede de Petri estocástica e cadeia de Markov e a representação de vínculos entre os estados de ambos modelos

rede de Petri estocástica), ou seja, há uma função bijetora

$$
f: S_{S P N} \longrightarrow S_{C M T C}
$$

onde $S_{S P N}$ e $S_{C M T C}$ são os estados de espaços da rede de Petri estocástica e da cadeia de Markov respectivamente;

- para cada transição de estado na rede de Petri estocástica, por exemplo $s_{S P N} \rightarrow s_{S P N}^{\prime}$, há uma transição de estado na cadeia de Markov tal que $f\left(s_{S P N}\right) \rightarrow f\left(s_{S P N}^{\prime}\right)$

- o período de permanência no estado $s_{S P N}$ antes de passar ao estado $s_{S P N}^{\prime}$ e o período de permanência no estado $f\left(s_{S P N}\right)$ antes de passar a um estado $f\left(s_{S P N}^{\prime}\right)$ seguem, ambos, distribuições exponenciais de parâmetros idênticos.

Considerando-se esse isomorfismo e os elementos adotados para a representação da semântica, uma abordagem para representar esse vínculo é de associar um mesmo termo (ou functor) aos estados assim vinculados: considerando-se a figura 4.5, por exemplo, se a marcação $m_{12}$ da rede de Petri estocástica corresponde, pelo isomorfismo, ao estado $s_{12}$ da cadeia de Markov, então esse vínculo seria substanciado nas representações das informações semânticas dos modelos pelo uso de um mesmo termo, state12 (por exemplo, quando forem referenciados nos predicados).

Uma outra forma de vínculo semântico ocorre como resultado da propagação de elementos das descrições semânticas de um modelo para outro, possível graças ao compartilhamento de elementos matemático-formais. Considerando-se o caso 
da figura 4.6, tem-se que a análise de uma rede de Petri com marcação inicial $m_{0}$ (ilustrada na figura) gera um grafo de alcançabilidade (ver apêndice A), donde se pode obter, com simplicidade, um conjunto de alcançabilidade $R S\left(m_{0}\right)=\left\{m_{0}, \ldots, m_{N}\right\}$, contendo todas as marcações que podem ser obtidas por seqüências de disparos de transições a partir de $m_{0}$. Da mesma forma que no caso anterior, pode-se associar um termo para cada marcação de $R S\left(m_{0}\right)$, de forma que esse termo possa ser empregado nos predicados que se referirem a essa marcação (ou estado). Para cada uma dessas marcações, juntamente com as anotações dos lugares marcados em cada uma delas, pode-se elaborar predicados descritivos do que se observa nessa marcação. Por exemplo, correspondendo à marcação inicial, pode-se elaborar os seguintes predicados:

ocorre(livre(M), state0).

ocorre(livre(buf), state0).

que pode ser interpretado como "no estado state0, a máquina M e o buffer buf estão disponíveis". Correspondendo à marcação apresentada na figura 4.7, podese elaborar as seguintes asserções:

ocorre (processar (M,p), state4).

ocorre (esperar ( $p, \operatorname{processar}(M, p))$, state4).

ou seja, os predicados denotam que é verdade que "no estado state4, ocorre processamento de uma peça p pela máquina M" e que "no estado state4, ocorre que uma peça p esta à espera por um processamento pela máquina M". Assim, pode-se representar as informações associadas às marcações em $R S\left(m_{0}\right)$ e, ao mesmo tempo, tem-se uma forma de reproduzir os vínculos entre marcações e rede de Petri.

Através dos mecanismos apresentados até aqui, as representações das informações das semânticas dos modelos podem ser elaboradas de modo a apresentar consistência intermodelos, dado que os vínculos semânticos sejam devidamente representados.

Considere-se, agora, um sistema, ilustrado na figura 4.8, que se trata de um centro de processamento de peças composto por um máquina de processamento $\mathrm{M}$ e um buffer buf para peças. A figura 4.9 apresenta uma rede de Petri estocástica 

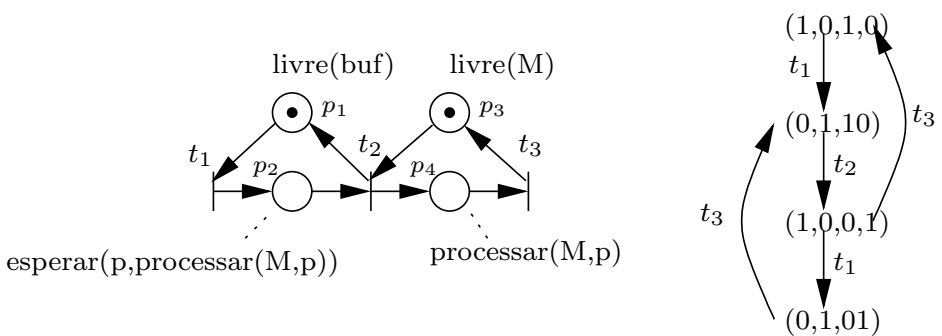

Figura 4.6: Uma rede de Petri (em sua marcação inicial) e seu grafo de alcançabilidade

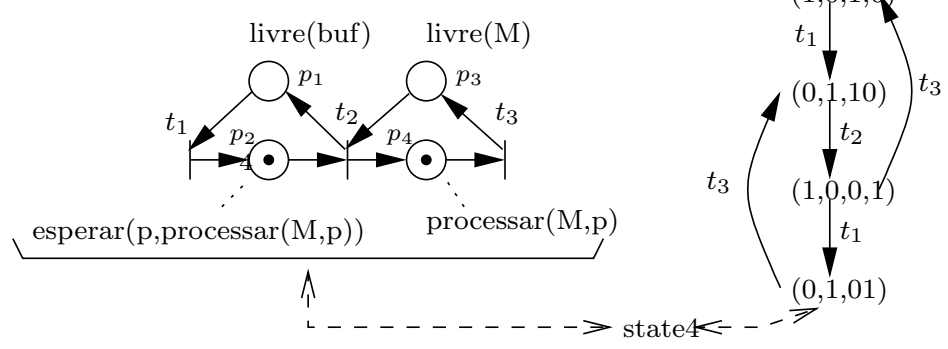

Figura 4.7: O termo state4 correspondente a uma marcação da rede de Petri ilustrada pode ser utilizado associado às anotações dessa rede, manifestando um vínculo entre rede de Petri e sua marcação

generalizada (ver apêndice A) GSPN1, em sua marcação inicial, que modela uma dinâmica desse sistema. A dinâmica representada refere-se ao seguinte:

- a máquina M processa peças p;

- as peças que chegam são colocadas no buffer buf, que tem capacidade para apenas uma peça, e lá esperam pelo seu processamento;

- de tempo em tempo, inspeções são feitas no processamento — as inspeções ocorrem no processamento seguinte à chegada de sua sinalização;

- os processamentos não inspecionados são executados a uma taxa $\lambda=0,20$ peça/minuto (segundo uma distribuição exponencial);

- os processamentos inspecionados correm a uma taxa $\lambda_{i}=0,15$ peça/minuto (segundo uma distribuição exponencial), que é menor devido às avaliações a realizar;

- sinalizações de outras inspeções são aguardadas tão logo uma inspeção é iniciada e o intervalo de tempo para que uma nova inspeção seja si- 


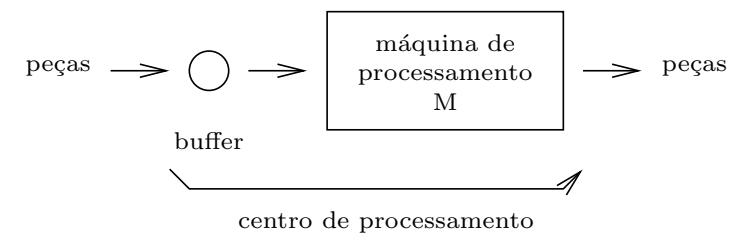

Figura 4.8: Centro de processamento de peças

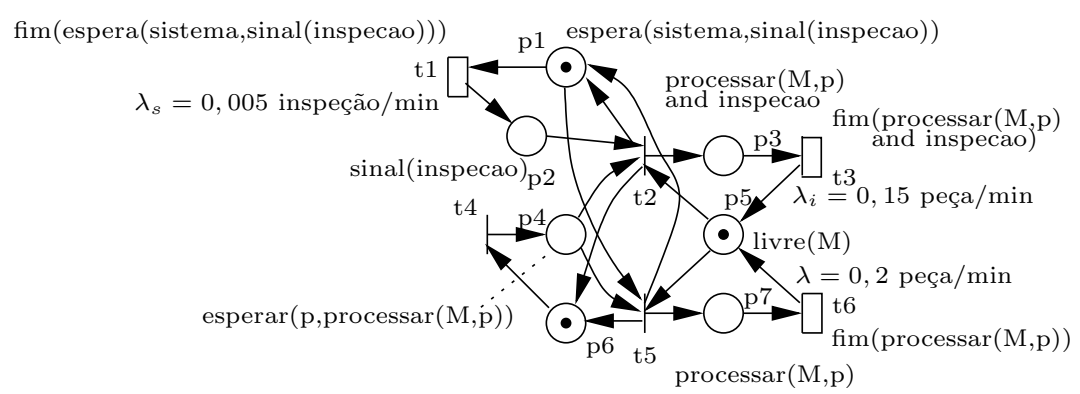

Figura 4.9: Rede de Petri estocástica generalizada GSPN1

nalizada segue uma distribuição exponencial de parâmetro $\lambda_{s}=0,005$ inspeção/minuto.

O objetivo do experimento é obter a taxa de processamentos concluídos pelo centro de processamento de peças (por exemplo, para dimensionar os recursos para a embalagem das peças processadas).

A partir da rede GSPN1, obtém-se as marcações tangíveis (ver apêndice A) do modelo e, com estas e outras informações do modelo, gera-se a cadeia de Markov isomórfica. Na figura 4.10, apresentam-se:

- o grafo de alcançabilidade tangível (CHIOLA; DONATELLI; FRANCESCHINIS, 1991), a cujos arcos, associam-se uma transição estocástica e uma seqüência de transições imediatas (omitidas na figura, pois não contribuem quantitativamente nesse caso em particular (MARSAN; CONTE; BALBO, 1984)), cujos disparos, nessa seqüência, levam a rede da marcação na origem do arco àquela no destino;

- o grafo que representa a cadeia de Markov isomórfica;

- seguindo as diretrizes para representação dos vínculos semânticos entre modelos, os termos designados para representar os estados vinculados de ambos 


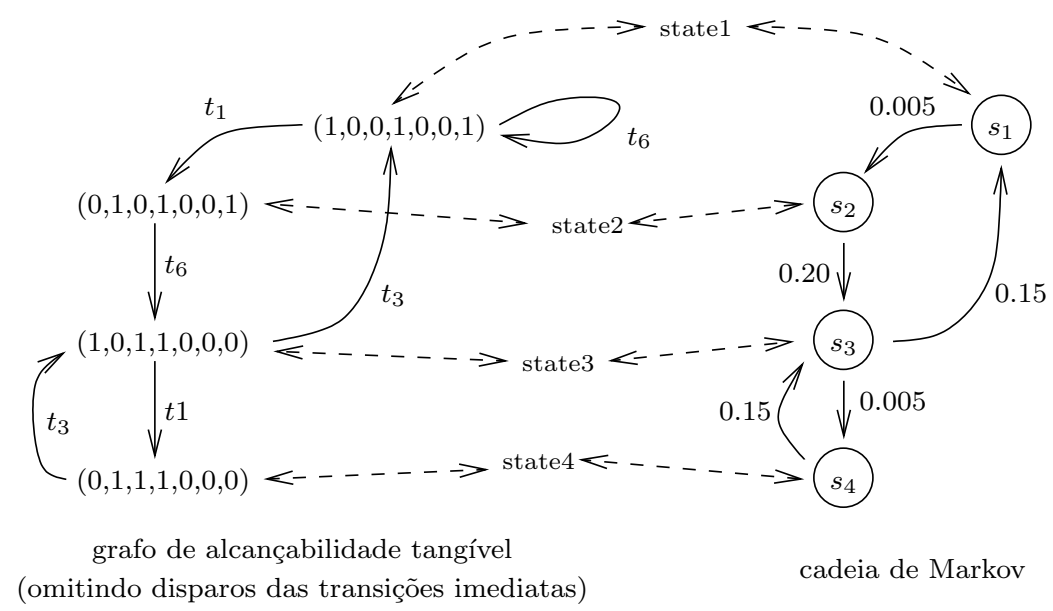

Figura 4.10: Marcações tangíveis e a cadeia de Markov correspondente (via isomorfismo)

os modelos.

Analisando-se a cadeia de Markov, obtém-se a distribuição de probabilidades em regime permanente (KULKARNI, 1995), dado pelo vetor:

$$
\boldsymbol{\pi}=[0,944 ; 0,031 ; 0,024 ; 0,001]
$$

que fornece as probabilidade de se encontrar o sistema nos estados s1, s2, s3 e s1 (conforme a cadeia de Markov ilustrada na figura 4.10) respectivamente.

Assim, a partir da rede GSPN1, do conjunto de alcançabilidade tangível (o conjunto das marcações tangíveis facilmente obtido do grafo de alcançabilidade tangível (CHIOLA; DONATELLI; FRANCESCHINIS, 1991)), da cadeia de Markov e da distribuição de probabilidades $\boldsymbol{\pi}$, pode-se elaborar as seguintes asserções (entre chaves para indicar que se trata de uma mesma dinâmica):

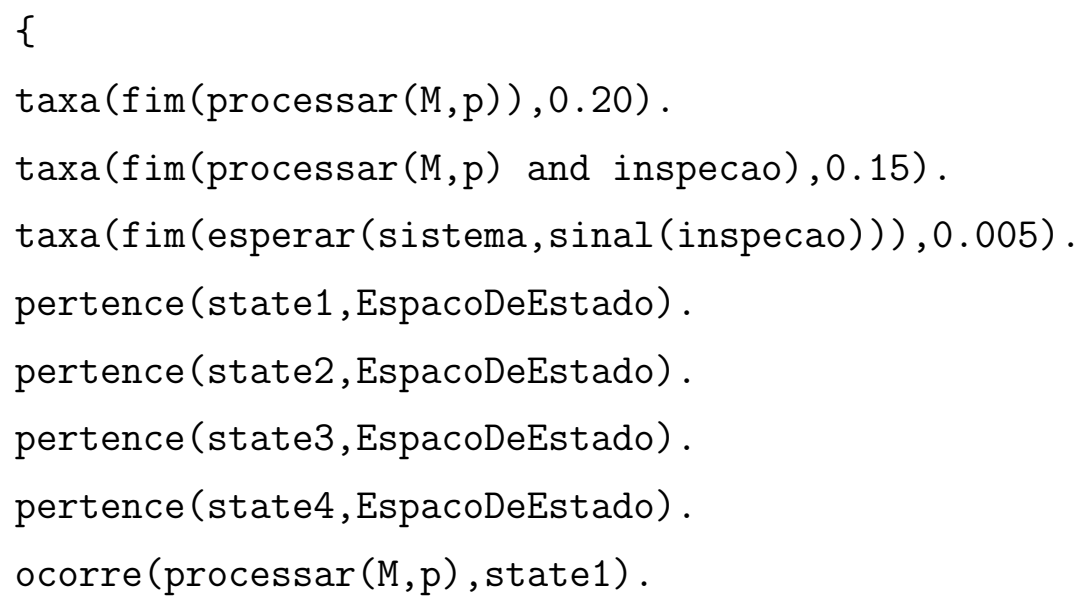




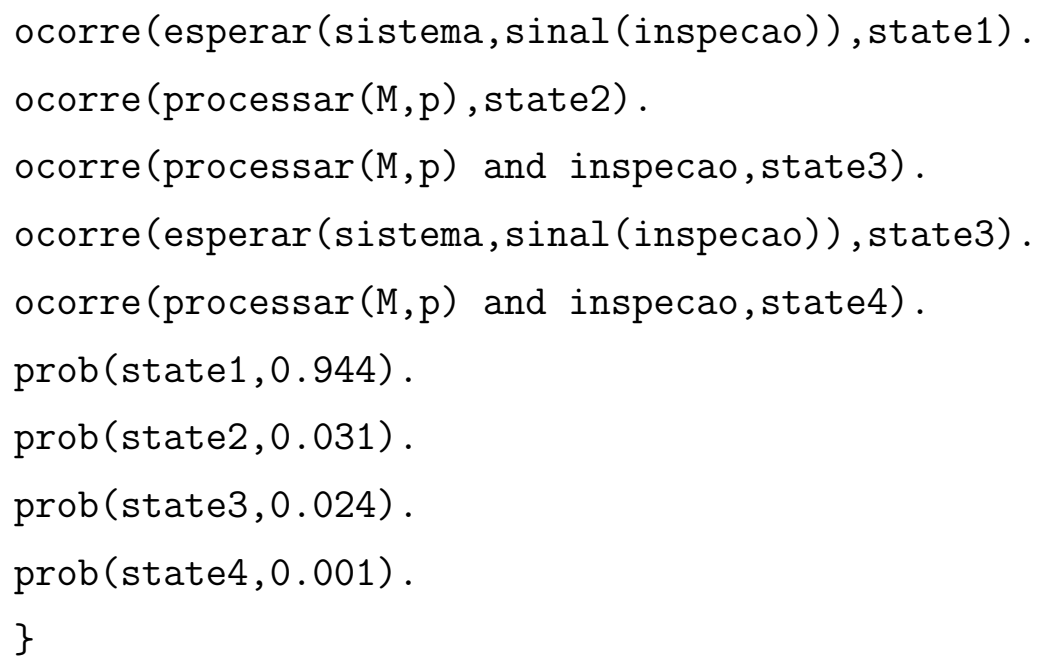

Os predicados com nome taxa relacionam eventos a suas taxas de ocorrência, sendo elaborados a partir da GSPN1.

Os termos state1, state2, state3 e state4, utilizados nos predicados com nome pertence, são usados para representar tanto as marcações da rede GSPN1 como os estados da cadeia de Markov que lhe é isomórfica (explicitando os vínculos entre esses elementos); o termo EspacoDeEstado é utilizado para representar o espaço de estados da dinâmica considerada; assim, esses predicados representam a pertinência dos estados a um espaço de estados. Tais predicados são obtidos, no caso, do conjunto de estados tangíveis alcançáveis, por sua vez obtidos da análise da rede GSPN1.

Os predicados com nome ocorre indicam que um fato ocorre num certo estado: tem-se que nos estados denotados por state1 e state2, ocorre o processamento de peça p pela máquina $M$ sem inspeção; naqueles denotados por state3 e state4, os processamentos são inspecionados. Nos estados denotados por state1 e state3, tem-se a espera por sinalização de inspeção. Estes predicados são obtidos por propagação das anotações às marcações.

Os predicados com nome prob indicam a probabilidade dos estados indicados, elaborados a partir da distribuição das probabilidades de regime permanente dos estados, por propagação dos termos associados aos estados da cadeia de Markov.

Assim, com a consistência das anotações dos elementos dos modelos, da propagação de elementos de representações de semânticas e da representação dos vínculos semânticos, tem-se mecanismos para evitar os problemas relativos aos conflitos de nomenclatura e os estruturais mencionados no início desta seção. 
Estes elementos são importantes para que a apresentação das informações associadas aos modelos seja efetivamente integrada, explicitando as diversas formas de relações. Deve-se destacar o fato de que, desta forma, a heterogeneidade dos modelos é transparente nessa descrição.

A transparência da heterogeneidade, além de fornecer uma descrição integrada das informações associadas aos modelos de SEDs, faz com que se evite ter de lidar com as diferentes organizações de informações (que os modelos heterogêneos apresentam). Isso é particularmente interessante no caso de análises que pressupõem a integração de modelos, principalmente no que diz respeito ao acesso às suas informações. Por exemplo, para se calcular a taxa média de finalização de processamentos (MOLLOY, 1980), isso envolveria:

- identificação das transições da rede GSPN1 correspondentes a essa finalização;

- utilização das taxas de disparo dessas transições;

- elaboração de uma lista das marcações alcançáveis em que essas transições estão habilitadas e em que possam disparar efetivamente;

- associação dessas marcações a estados da cadeia de Markov isomórfica;

- verificação das probabilidades desses estados, fornecidas pela distribuição de probabilidades de regime permanente, obtidas da análise dessa cadeia.

No exemplo desenvolvido, todas essas informações podem ser obtidas através da representação feita por predicados. E outras análises podem ser feitas, como a probabilidade de um processamento se encontrar em inspeção. De fato, quanto maior o grau de acessos a essas informações, seja para consulta seja para análise, sem ter que lidar com as diferentes estruturas dos modelos matemáticos de SEDs, mais evidente se tornam os benefícios dessa descrição integrada.

Com relação à implementação por predicados e functores, esse exemplo se beneficia da capacidade de inferir um mesmo fato a partir da representação de situações diferentes em que tal fato ocorre: para determinar quais transições representam fim de alguma atividade, no caso de exemplo desenvolvido, basta verificar se a anotações apresentam um functor com nome fim; o argumento desse functor indica a atividade finalizada e, portanto, para se determinar se a transição 
corresponde ao fim de um processamento, deve-se testar se, desse argumento, é possível inferir o functor processar $(\mathrm{M}, \mathrm{p})$; no caso do exemplo, duas transições satisfazem essas condições e, portanto, devem ser consideradas. Isso mostra como a capacidade de inferir a partir das representações das informações semânticas é importante para a consistência e processabilidade das representações.

Essa forma de integração de informações é similar ao uso do que Borgida e Mylopoulos (2004) denominam de esquema mediador para integração de dados de fontes heterogêneas: tal esquema mediador se coloca entre o usuário e as fontes heterogêneas de informação, tendo a função de integrar as informações dessas fontes de forma que o usuário, que acessa essas informações com base nesse esquema, não tenha que se preocupar em lidar com a heterogeneidade das fontes de informações. A descrição por conjunto de predicados exerce, assim, um papel semelhante a esse esquema mediador.

A definição das informações a serem utilizadas nas anotações e nos predicados está relacionada ao processo de modelagem de SEDs descrito na seção 2.4. De fato, tal definição documenta as decisões feitas nesse processo, como o mapeamento entre elementos do modelo e aspectos da sua dinâmica e como os resultados da análise se relacionam com esses mesmos aspectos. Isso significa que as anotações e os predicados são elaborados tendo em vista a finalidade da modelagem e das análises e, em função disto, mais ou menos elementos são elaborados.

\subsection{Consistência horizontal}

Enquanto o foco na seção é nos relacionamentos verticais, ou seja, aqueles envolvendo uma mesma dinâmica, pode-se planejar as representações das informações semânticas dos modelos de SEDs de modo que apresentem consistência horizontal.

A consistência horizontal refere-se àquela constatada ao se observar os conjuntos de predicados referentes a diferentes dinâmicas (que podem ser decorrentes da consideração de diferentes configurações de sistemas e cargas).

Considere-se o caso da figura 4.11, onde se vê trechos de diferentes redes de Petri. Para todos os casos, a taxa de processamentos finalizados é igual à soma 

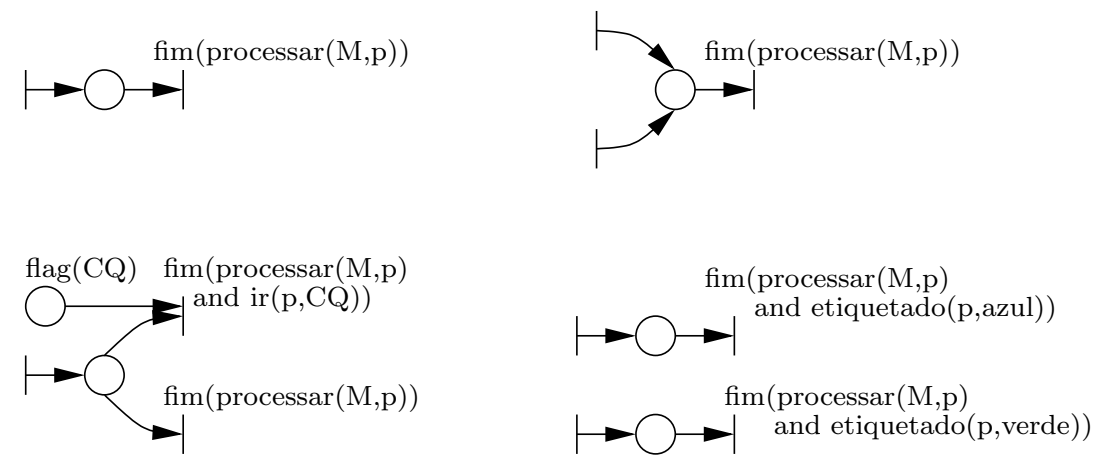

Figura 4.11: Trechos de diferentes redes de Petri

das taxas de disparos média efetiva das transições que contém como anotação o functor fim e, do argumento desse functor, pode-se inferir processar (M,p). Ou seja, além do uso consistente dos mesmos functores, um mesmo algoritmo pode ser utilizado para obter uma mesma informação de todos os modelos (no caso, a referida taxa).

Considerando-se o exemplo da figura 4.12, que ilustra uma rede de Petri estocástica generalizada GSPN2 que modela o mesmo sistema tratado na seção anterior, do centro de processamento de peças com uma máquina e um buffer, mas considerando uma dinâmica diferente: a diferença é que não há inspeções. Gerando-se os mesmos modelos (grafo e conjunto de estados tangíveis alcançáveis, cadeia de Markov de tempo contínuo e distribuição das probabilidades de regime permanente), pode-se elaborar o seguinte conjunto de predicados:

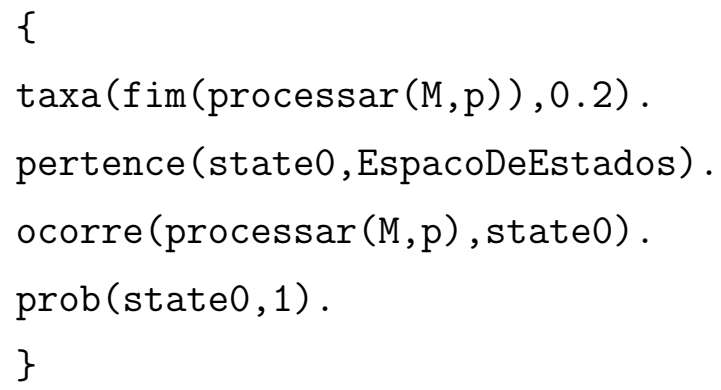

Apesar da diferença com o conjunto de predicados relativos a rede GSPN1 da seção anterior, este conjunto tem uma estrutura bastante semelhante. Assim, além da utilização de um mesmo vocabulário (termos, functores e predicados), a consistência se manifesta, também, pelo fato de um mesmo procedimento para calcular as taxas de processamentos completos poder ser elaborado com base 

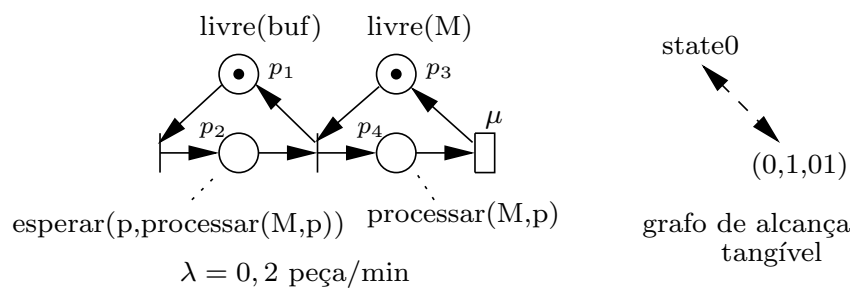

grafo de alcançabilidade tangível

Figura 4.12: Rede de Petri estocástica generalizada GSPN2, o respectivo grafo de alcançabilidade tangível e o termo utilizado para representar o estado tangível

nas informações disponibilizadas pelas representações da semântica dos modelos. Assim, tal taxa $T_{p}$ pode se calculada por:

$$
T_{p}=\sum_{s \in S} T_{p \mid s} \pi(s)
$$

onde $S$ é o espaço de estados tangíveis (obtido pelo exame dos predicados pertence), $T_{p \mid s}$ é a taxa de processamentos completos estando no estado $s$ e $\pi(s)$ é a probabilidade de regime permanente do estado $s$, obtido dos predicados prob. A taxa $T_{p \mid s}$ é calculada por:

$$
T_{p \mid s}=\frac{1}{\sum_{q \in H(s)} r(q)} \sum_{x \in P(s)}[r(x)]^{2}
$$

onde

- $H(s)$ é o conjunto de functores ativ tais que o predicado ocorre $(a t i v, \mathrm{~s})$ é verdadeiro, ou seja, refere-se ao conjunto de atividades que ocorrem num estado $s$;

- r(ativ) é o segundo argumento dos predicados com nome taxa e o primeiro argumento é fim(ativ), ou seja, o valor da taxa de finalização da atividade denotada por ativ;

- $P(s)$ é o conjunto de functores proc tais que o predicado ocorre (proc, s) é verdadeiro e processar (M,p) pode ser inferido de proc, ou seja, é o conjunto de atividades de processamento de peça por M num estado $s$.

Note-se que o procedimento inclui operações de inferência baseada em functores e de tratamento de conjunto de predicados (sendo formas de processar 
informações semânticas). Também, é interessante notar que a transparência em relação à heterogeneidade dos modelos de SEDs (dado que o cálculo é feito apenas em função dos elementos contidos nos predicados) tem um papel importante na horizontalidade desta computação.

\subsection{Comentários do capítulo}

Este capítulo apresenta um enfoque complementar de representação de modelos de SEDs, que tem uma orientação mais interpretativa dos modelos, em contraposição à conformidade formal exigida pelas técnicas matemáticas de análise, tratada no capítulo 3.

Este capítulo apresenta algumas maneiras importantes de se tirar proveito da representação da semântica dos modelos de SEDs:

- como meio de visualizar o mapeamento entre elementos do modelo e o que é representado por eles, exercendo um papel documental e como uma forma de se identificar quais os elementos do modelo se referem a um certo aspecto da dinâmica;

- na construção de representações computacionais de modelos;

- na elaboração de um descrição uniforme, estruturada e consistente das informações fornecidas pelos vários modelos (possivelmente heterogêneos);

- na implementação de análises que pressupõem integração de modelos.

Um fator importante na adequação da representação é a sua consistência, na medida que impede que conflitos, como os de nomenclatura e de estrutura, escondam relacionamentos importantes para uma descrição fiel da integração de modelos.

Além de fornecer uma representação efetiva da integração dos modelos de SEDs, importante na sua interpretação, tal representação pode ser aproveitada em análises que pressupõe integração de modelos. Mais ainda, esse aproveitamento pode ocorrer em nível vertical como horizontal. E, à medida que mais modelos são introduzidos, e mais configurações de sistemas e cargas são consideradas, maior a necessidade de organizar as informações. A representação desses elementos e 
a capacidade de processá-los computacionalmente são um suporte efetivo para lidar com tal aumento de escala nos experimentos. 


\section{Exemplo de implementação de linguagem}

Este capítulo traz uma implementação de uma linguagem de modelagem e análise de modelos de SEDs. O propósito da linguagem é apenas de ilustrar os conceitos apresentados nos capítulos anteriores, de modo que certas características desejáveis em linguagens utilizadas para uso concreto são colocadas em segundo plano; em particular, o foco é nas representações de modelos heterogêneos e em como estas interagem com outros elementos dos experimentos de modelagem e análise. Basicamente, mostra-se que é possível ter abrangência e uniformidade de modelos com uma linguagem relativamente simples. Apresentase, também, os benefícios que a representação de informações semânticas pode trazer aos experimentos.

\subsection{Linguagem LiMA}

A linguagem LiMA (Linguagem de Modelagem e Análise), é destinada à realização de experimentos de modelagem e análise de SEDs, compreendendo montagem e expressão de representações computacionais de modelos e implementação e execução de análises. A LiMA têm alguns elementos inspirados na linguagem de especificação formal Z (WOODCOCK; DAVIES, 1996), como é o caso do emprego de conjuntos homogêneos tipados ${ }^{1}$ nas representações. Conforme pode ser constatado neste capítulo, a LiMA tem capacidade de representar uma razoável variedade de tipos de modelos de SEDs, de modo a atender aos requisitos de heterogeneidade e extensibilidade para linguagens voltadas a modelos heterogêneos de SEDs.

\footnotetext{
${ }^{1}$ Conjuntos homogêneos tipados são aqueles em que todos os seus elementos são de um mesmo tipo, onde tipo se refere a uma categoria de entidades que compartilham uma mesma estrutura formal (WOODCOCK; DAVIES, 1996).
} 
A LiMA implementa mecanismos de disjunção (ver subseção 3.2.3) baseados no particionamento dos termos utilizados (através de um sistema de tipos) e na utilização de metamodelos.

\section{Definição 5.1 (Metamodelo)}

É um modelo de modelos, ou seja, uma descrição de modelos composta de aspectos de interesse específico.

No caso, um metamodelo descreve a composição das representações de modelos de SEDs de um mesmo tipo.

Os metamodelos, ao descreverem e definirem um formato de representação, têm um papel importante na eliminação de redundâncias (de representação e de processamento), conforme tratado na subseção 3.2.4.

\subsubsection{Expressão das representações}

Assim, a LiMA descreve três tipos de dados: átomos, conjuntos homogêneos e ênuplas.

Primeiramente, todos os identificadores (nomes de variáveis, átomos, tipos e outros) utilizados na linguagem têm a forma de uma cadeia contendo caracteres alfanuméricos ou o caracter "_, onde o primeiro caracter deve ser, necessariamente, alfabético. Um outro aspecto é que todas as sentenças terminam com "ponte-e-vírgula" ( ";").

Nas descrições que se seguem, primeiramente, exemplifica-se como cada tipo de dado é definido e, em seguida, qual a formação das instâncias do respectivo tipo de dado.

Átomos são as partículas elementares com os quais os demais objetos de todos os tipos são constituídos; um tipo atômico A é assim definido por :

\section{A is atomic;}

e a declaração de um átomo a1 como sendo desse tipo é feita por:

a1 typeis A; 
Os números, aos quais se associam os tipos Integer (para números inteiros) e Real (números reais), são considerados tipos atômicos que possuem significados e operações específicas (apresentados adiante). Uma observação: como é comum nas linguagens de programação, os valores dos números reais apresentam-se com a parte inteira separando-se da parte decimal através de um ponto.

Conjuntos homogêneos são agregados de objetos de mesmo tipo. Um conjunto de elementos de tipo A pode ser definido por:

$\mathrm{SA}$ is setof $\mathrm{A}$;

Assim, pode-se dizer que, no exemplo abaixo, o conjunto atribuído à variável \$setA é compatível ao tipo SA (variáveis são tratadas mais adiante, mas seu uso no texto, como um elemento de armazenamento de dados, é essencialmente convencional e de conhecimento geral):

a1, a2, a3 typeis A;

$\$$ set $A:=\{a 1, a 2, a 3\}$;

Dois conjuntos homogêneos são iguais se e somente se um deles é uma permutação de elementos do outro, como no caso dos conjuntos $\{e 1, e 2, e 3\},\{e 2, e 3, e 1\}$ e $\{\mathrm{e} 3, \mathrm{e} 1, \mathrm{e} 2\}$.

Ênuplas são agregados de tamanho fixo e que podem incluir elementos de tipos diferentes, onde os tipos, a ordem e o número de elementos é relevante, tanto que, para cada posição, existe um nome e uma especificação do tipo de elemento que pode ocupá-la. por exemplo, na seguinte definição:

T_SA_B is (first is setof A,last is $B$ );

o tipo T_SA_B descreve ênuplas de dois elementos, onde o primeiro recebe a denominação de first, devendo ser um conjunto de átomos de tipo A; o segundo elemento recebe a denominação de last e deve ser um átomo de tipo B. No exemplo abaixo, a variável \$ab_tuple recebe uma ênupla compatível com T_SA_B:

a1, a2, a3 typeis A;

b5 typeis B;

\$ab_tuple := (\{a1, a2 , a3 $\}, \mathrm{b} 5)$; 
Duas ênuplas são do mesmo tipo se e somente se os elementos nas mesmas posições forem do mesmo tipo e possuírem os mesmos nomes. Duas ênuplas são iguais se e somente se os elementos nas mesmas posições forem iguais.

É interessante observar que objetos com padrões complexos podem ser descritos com esses elementos; por exemplo, dado:

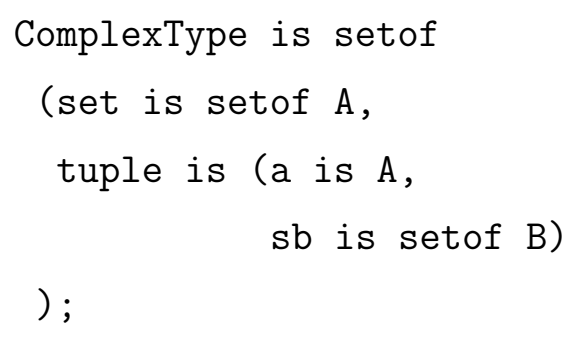

uma estrutura compatível pode ser exemplificada pelo que é atribuído à variável \$complex abaixo:

a1, a2, a3, a4, a7, a9 typeis A;

b1, b2, b3 typeis B;

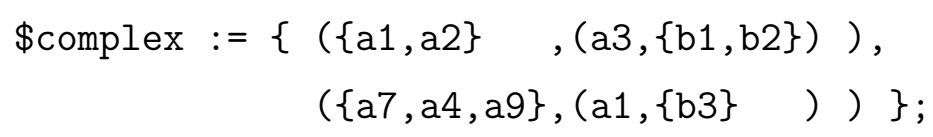

O que é mostrado a seguir é que os metamodelos são apresentados sob a forma de definição de tipos de dados, enquanto que os modelos são representados por instâncias de tipos de dados.

\subsubsection{Exemplo: cadeias de Markov de tempo contínuo}

Uma cadeia de Markov de tempo contínuo (ver apêndice A) pode ser representada por um grafo orientado, onde os nós correspondem aos estados de um sistema e os arcos correspondem às transições entre esses estados; aos arcos, estão associados grandezas denominadas taxas de transição que são medidas do tempo de permanência nos estados (de onde se originam os arcos) até que as transições ocorram.

Um metamodelo é apresentado na listagem 5.1. O elemento construtivo básicos são os estados das cadeias (representado pelo tipo atômico State). Uma 


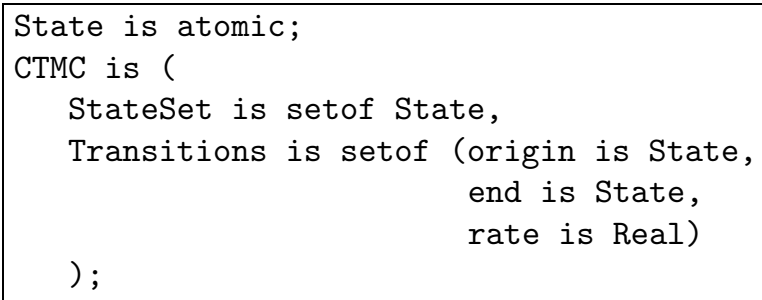

Listagem 5.1: Metamodelo de cadeia de Markov de tempo contínuo

representação de uma tal cadeia é dada por uma ênupla de dois elementos (identificadas por StateSet e Transitions). O StateSet deve ser um conjunto de átomos de tipo State (referente ao espaço de estados). As transições são representadas pelo conjunto (Transitions), ênuplas, cada uma indicando um estado de origem (elemento com nome origin), um estado final (elemento com nome end) e a taxa de transição correspondente (elemento com nome rate de tipo Real).

Uma instância deste tipo pode ser exemplificada pelo que está sendo atribuído à variável \$ctmcmodel:

s1,s2,s3 typeis State;

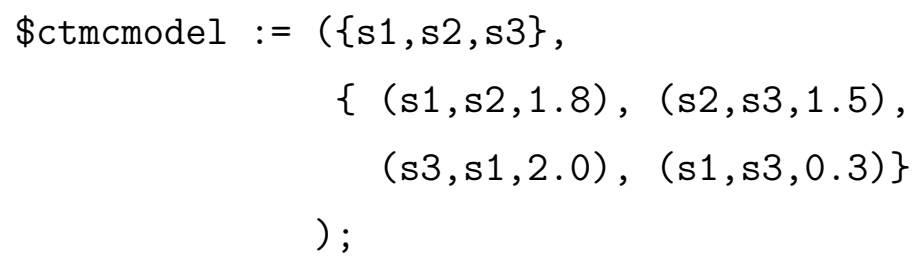

\subsubsection{Exemplo: redes de Petri marcadas}

Considere-se, agora, as redes de Petri marcadas (ver apêndice A):

A listagem 5.2 apresenta um metamodelo de redes de Petri marcada. Os elementos básicos de construção são os lugares (tipo atômico P) e as transições (tipo atômico T). Uma representação de rede de Petri (sem marcas), segundo descrita pelo tipo de dado PetriNet, deve indicar o conjunto de lugares (elemento Places), o conjunto de transições (elemento Transitions) e as conexões (ponderadas) entre lugares e transições - o elemento I refere-se às conexões de lugar para transição, descrito por um conjunto de ênuplas que indica os luga- 


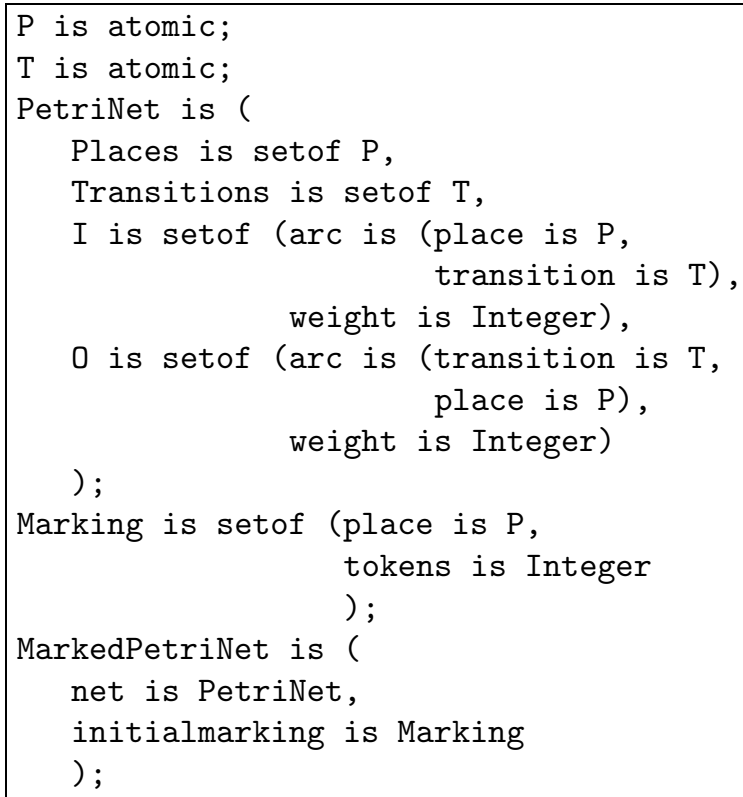

Listagem 5.2: Metamodelo de redes de Petri marcadas

res e transições envolvidas e os pesos dos arcos; da mesma forma ocorre para o elemento 0 , referente às conexões de transições a lugares.

Em seguida, define-se como representar as marcações, o que é feito pela definição do tipo Marking.

Uma rede de Petri marcada pode ser especificada através da estrutura de uma rede de Petri sem marcas e da definição de sua marcação inicial, o que é feito pela ênupla descrita para o tipo MarkedPetriNet.

Um exemplo de representação de rede de Petri marcada é atribuída à variável \$mpnmodel:

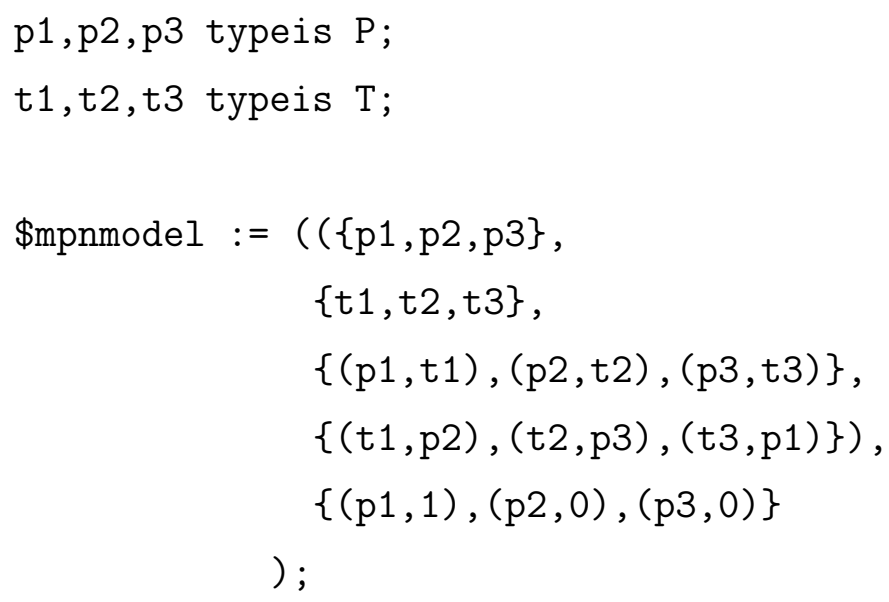




\subsubsection{Exemplo: grafos de solicitação/alocação}

Nesta subseção, um exemplo é elaborado com tipos de modelos introduzidos por Miyagi, Santos-Filho e Arata (2000) para a síntese de compensadores que previnem o deadlock (ver apêndice A) a partir de redes de Petri, apresentadas na seção anterior e cujo metamodelo lá desenvolvido continua sendo válido para este exemplo.

O que a técnica faz é gerar, a partir de uma rede de Petri, um grafo de solicitação/alocação, definido a seguir.

Sejam:

- um conjunto de recursos $R=\left\{r_{1}, \ldots, r_{R}\right\}$;

- um conjunto de produtos $Q=\left\{q_{1}, \ldots, q_{Q}\right\}$;

- para cada produto $q$, tem-se uma seqüência de $n_{q}$ etapas de processo descrita por $S_{q}=\left\{s_{q}(1), \ldots, s_{q}\left(n_{q}\right)\right\}$, onde $s_{q}(k)$ refere-se à k-ésima etapa da seqüência de processos relativa ao produto $q$;

- para cada etapa $s_{q}(k)$ corresponde um recurso denotado por $r_{q}(k)=r$, onde $r \in R$.

Um grafo de solicitação/alocação é um grafo orientado $(R, S)$, onde $S=S_{q_{1}} \cup$ $\ldots \cup S_{q_{Q}}$, ou seja, os nós do grafo correspondem aos recursos e os arcos referem-se às etapas dos processos. As conexões são definidas:

- pelos pares de alocação $(r, s)$, que correspondem a um nó e um arco que dele se origina, tal que, se o arco é $s=s_{q}(k)$, o nó deve ser $r=r_{q}(k)$, ou seja, deve corresponder ao recurso usado por aquela etapa;

- pelos pares de solicitação $(s, r)$, correspondentes a um arco e a um nó para o qual ele aponta, tal que, se o arco é $s=s_{q}(k)$, o nó deve ser $r=r_{q}(k+1)$, ou seja, deve corresponder ao recursos usado na próxima etapa.

Na listagem 5.3, tem-se um metamodelo, definido pelo tipo de dado RAG, contendo a descrição de grafos de solicitação/alocação. Ela define que as representações desses grafos são construídas por dois tipos de termos, que se referem aos recursos (tipo atômico $\mathrm{R}$ ) e aos produtos (tipos atômico Q). Define-se, também: 


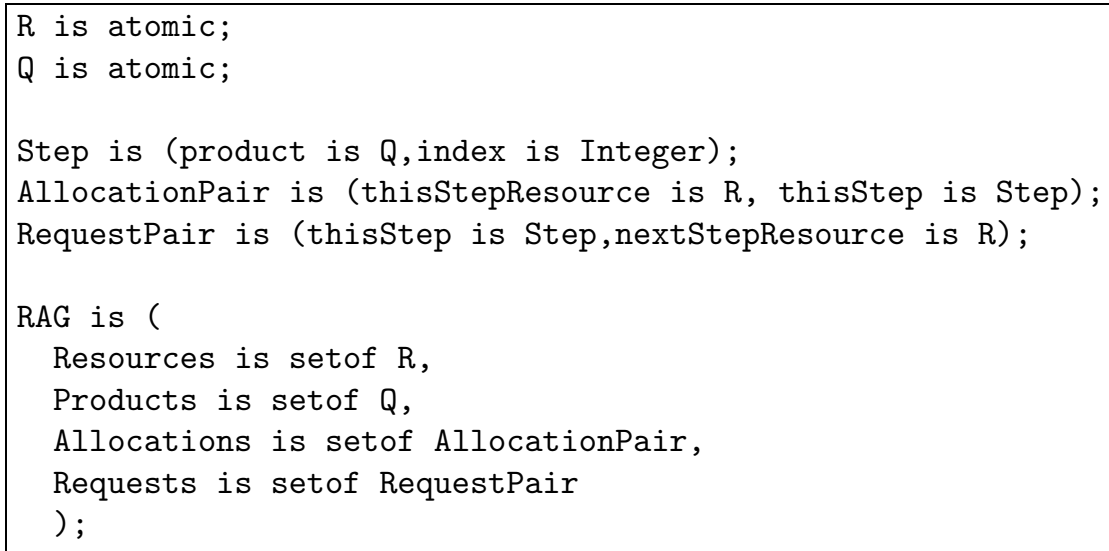

Listagem 5.3: Metamodelo de grafo de solicitação/alocação

- Step, uma ênupla que se refere às etapas de processamento de cada produto;

- AllocationPair, uma ênupla que se refere aos pares de alocação;

- RequestPair, uma ênupla que se refere aos pares de solicitação.

Com isso, uma representação de grafo de solicitação/alocação deve apresentar:

- um conjunto de recursos,

- um conjunto de produtos,

- um conjunto de pares de alocação e

- um conjunto de pares de solicitação.

Desta forma, pode-se verificar que uma mesma linguagem é capaz de descrever modelos de tipos bastante diversos, usando um número relativamente pequeno de estruturas básicas, conferindo uniformidade às representações de modelos de SEDs, o que possibilita utilizar o mesmo conjunto de operações para várias atividades envolvendo estes modelos.

\subsection{Operações da linguagem LiMA}

Como a ênfase neste trabalho está na questão das representações dos modelos, considera-se que boa parte das operações para manipulação dos dados são similares àquelas presentes em várias linguagens de programação, sendo, portanto, 
apresentados de modo breve e informal. Também, não há uma intenção de oferecer um conjunto de operações para todas as situações, mas, sim, um que atenda às necessidades de ilustrar os conceitos desenvolvidos nos capítulos anteriores.

No que se refere ao tratamento de representações, a linguagem sendo apresentada segue um esquema similar ao descrito por Arata e Miyagi (2005), que distingue duas classes de estruturas: uma que este trabalho denomina de protorepresentações e outra que é denominada de representações bem-formadas de modelos (ou simplesmente representações). As proto-representações são estruturas construídas com elementos que pertencem a algum tipo atômico, que são combinadas segundo formas de agregação bem definidas, ou seja, ênuplas e conjuntos homogêneos. A diferença entre as proto-representações e a representações é que as últimas passaram por um processo de verificação com relação a um tipo de modelo (via metamodelo), que examina se a estrutura e os tipos dos átomos correspondem ao que está prescrito no metamodelo.

Utilizando-se os diagramas desenvolvidos no capítulo 3, a configuração sendo descrita é ilustrada na figura 5.1: as operações de montagem envolvem protorepresentações (que fazem o papel de estruturas intermediárias); para se obter uma representação bem-formada a partir de uma proto-representação, esta deve ser submetida a uma operação de verificação juntamente com um metamodelo de um certo tipo de modelo denotado por $\Phi$ (que pode ser redes de Petri, cadeias de Markov ou outro); assim, o conjunto-alvo da linguagem de composição é o conjunto das representações bem-formadas. Também, a figura ilustra que os procedimentos que implementam análises tomam representações bem-formadas como entradas e geram, também, representações bem-formadas como resultados. Porém, trata-se de uma visão parcial da configuração sendo desenvolvida: ao final do capítulo, uma descrição completa é apresentada, que inclui as representações das informações semânticas, tratadas adiante.

Assim, as próximas subseções apresentam os elementos operacionais da LiMA.

\subsubsection{Variáveis}

As variáveis são elementos de armazenamento de estruturas. São denotados por um cadeia de caracteres alfanuméricos, onde o primeiro deve ser alfabético, precedida por "\$”. Por exemplo, \$valor denota uma variável. As atribuições 


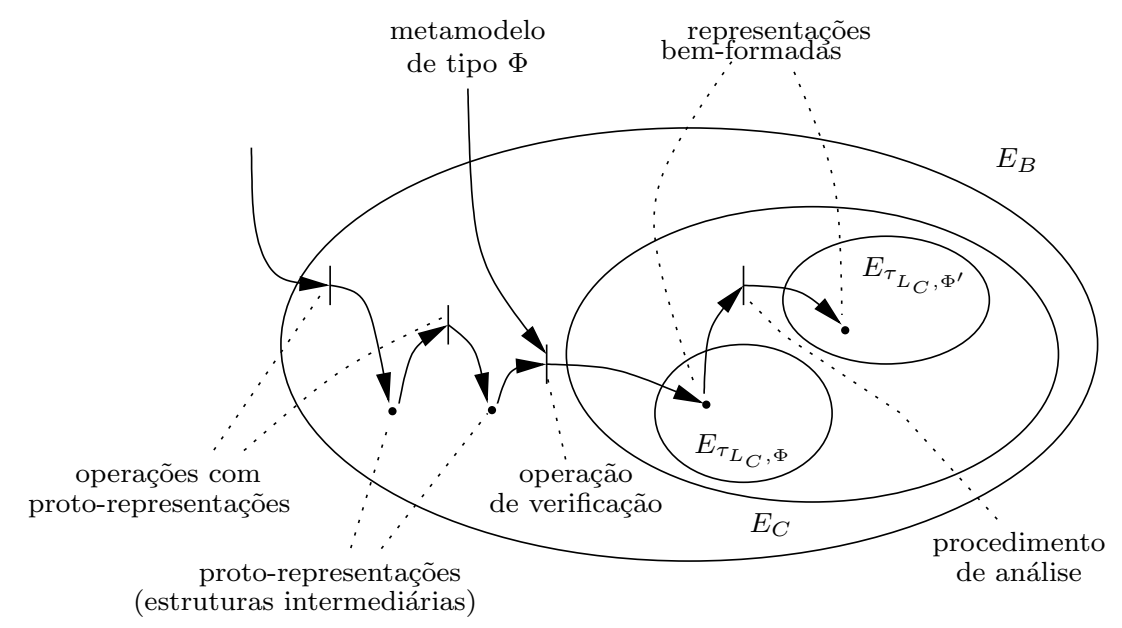

Figura 5.1: Diagrama com os conjuntos-alvos da linguagem de composição $\left(E_{C}\right)$, da linguagem de montagem $\left(E_{B}\right)$ e das transcrições referentes aos tipos de modelos $\Phi$ e $\Phi^{\prime}\left(E_{\tau_{L_{C}, \Phi}}\right.$ e $E_{\tau_{L_{C}, \Phi^{\prime}}}$ respectivamente).

são as operações que armazenam valores nas variáveis, o que é feito através do operador ":="; por exemplo:

$\$ a:=1$

significa que o valor 1 está sendo armazenado na variável \$a.

O valor armazenado na variável pode ser utilizado posteriormente, bastando apresentar a designação dessa variável; por exemplo:

$\$ \mathrm{~b}:=\$ \mathrm{a}+1$

O valor da variável \$a é utilizado nessa operação de adição, cujo resultado é armazenado na variável \$b.

Conforme pode ser constatado adiante, as variáveis assumem a "personalidade" das entidades que lhes são atribuídas, ou seja, se uma variável armazena um conjunto, operações referentes a conjuntos passam a ser aplicáveis à variável, conforme apresentado a adiante.

$\mathrm{Na}$ atribuição, no caso de átomos, conjuntos e ênuplas, o que ocorre é a geração de uma cópia de uma dessas entidades e é essa cópia que é armazenada na variável e não a mesma entidade. Assim, por exemplo, após as seguintes atribuições: 
$\$ c j A 1:=\{a 1, a 2, a 3\}$

$\$ c j A 2:=\$ c j A 1$

qualquer ação sobre a variável \$cjA1 (como inclusão de novo elemento) não altera o conteúdo de \$cjA2, porque após as atribuições, esta variável armazena uma entidade independente, apesar de ter o mesmo conteúdo.

No caso de objetos, a atribuição armazena referências aos mesmos. Neste caso, considerando-se que uma variável \$objA armazena uma referência a um objeto, a seguinte atribuição:

\$objB := \$objA;

implica que tanto \$objA e \$objB armazenam referências a um mesmo objeto e, portanto, qualquer operação que altere o conteúdo desse objeto envolvendo uma dessas variáveis, acaba refletindo na outra variável. No caso do texto, os tipos de objetos apresentados são: as representações bem-formadas, os módulos e as vinculações.

\subsubsection{Operações envolvendo proto-representações}

As operações na LiMA são feitas através do uso de operadores e da execução de funções e procedimentos.

O uso de operadores segue a forma infix, ou seja, o operador é apresentado entre os operandos, como ocorre com o operador + para a operação de soma aritmética:

$\$ \operatorname{var} A:=\$ \operatorname{var} B+1$

A forma de chamada das funções e procedimentos são idênticas, que diferem na sua semântica, ou seja, enquanto as funções não alteram o conteúdo de seus operandos e retornam um resultado, os procedimentos alteram o conteúdo de seus operandos e não retornam resultado. Assim, a chamada de uma função ou de um procedimento é feita apresentando-se um nome seguido, entre parênteses, de uma lista de argumentos (os operandos); caso não haja argumentos, segue-se apenas um par de parênteses delimitando nenhum conteúdo. Assim, em: 
$\operatorname{procP}(\$ \arg 1, \$ \arg 2) ;$

$\$ \operatorname{varC}:=\operatorname{funcF}(\$ \arg 4, \$ \arg 9, \$ \arg 1)$;

tem-se um procedimento procP, que opera sobre dois argumentos (os conteúdos das variáveis \$arg1 e \$arg2), e uma função funcF, que opera sobre três argumentos (os conteúdos das variáveis \$arg4, \$arg9 e \$arg1) e retorna um resultado que é armazenado na variável \$varC.

A notação do ponto pode ser também utilizada para funções e procedimentos, na qual, após uma variável (que é um dos operandos), segue-se um ponto e uma chamada de função ou de procedimento; no exemplo:

\$varM. $\operatorname{procPM}(1)$;

\$varN := \$varQ.funcFQ('azul');

tem-se, adotando a notação do ponto, a chamada de um procedimento procPM na variável \$varM e de uma função funcFQ, na variável \$varQ.

Os operadores lógicos são aqueles que resultam em valores lógicos, que podem ser true (verdadeiro) ou false (falso). Os operadores lógicos que aparecem no texto são os mesmos encontrados em muitas linguagens de programação, como a igualdade ("=="), a diferença " ! =" e, para o caso de números, o teste de ">" (maior) e "<" (menor).

Entre as operações com os átomos, tem-se a criação de átomos (não numéricos) e as operações aritméticas dos tipos numéricos. A criação de novos átomos é feita pelo comando create, como no seguinte exemplo:

$\$ \mathrm{a}:=\operatorname{create}(\mathrm{P})$;

onde um átomo de tipo atômico P (que deve ter sido definido anteriormente) é criado e sua denominação é armazenada na variável \$a; o sistema de execução da linguagem se encarrega de garantir que tal denominação não será definida ou gerada em outras situações.

Os operadores aritméticos, que envolvem elementos dos tipos numéricos (como Integer e Real), são a adição '+', a subtração '-', a multiplicação ‘*' e a divisão $\%$ '. 
Além de sua forma literal (lista de estruturas separadas por vírgulas e entre chaves), pode-se, também, lidar com conjuntos após estes serem atribuídos a variáveis, através das quais algumas operações podem ser efetuadas, como por exemplo:

$\$ \subset j A:=\{\}$

$\$ c j B:=\{b 1, b 2\}$;

\$cjA.append(a1); \# inclui o atomo a1 no conjunto

\$nElemB := \$cjB.length (); \# numero de elementos de \$cjB : 2

$\$ c j C:=\operatorname{merge}(\$ c j A,\{a 1, a 3, a 4\}) ; \#$ atribuicao de $\{a 1, a 3, a 4\}$

Neste caso, inicialmente, a variável \$cjA é inicializada com um conjunto vazio e \$cjB, com um conjunto de dois elementos; a operação append (a1) inclui o átomo a1 no conjunto; a função length () retorna o número de elementos do conjunto; o comando merge retorna o conjunto união dos conjuntos que são seus argumentos (como na Teoria de Conjuntos, na união de conjuntos, elementos comuns em ambos os conjuntos resultam em apenas um elemento).

Para acessar o i-ésimo elemento de um conjunto, utiliza-se a notação "[i]" (o primeiro elemento é indicado pelo número 1), por exemplo, tendo-se

$\$ c j D:=\{(d 1,1),(d 2,4),(d 3,9),(d 4,16),(d 5,25)\}$

a expressão \$cjD [4] refere-se à ênupla $(d 4,16)$.

Com relação às ênuplas, o processo é semelhante, podendo-se utilizar as operações append, element e length e, também, a notação "[i]". A diferença é que a ordem dos elementos diferencia ênuplas que apresentam exatamente os mesmos elementos; com relação ao comando append, pode-se incluir o átomo especial _nulı para denotar um espaço não ocupado na ênupla (tal átomo pode ser também usado em literais, como em (a1, null, a3, a4)); o átomo _null tem um significado especial na operação merge.

A operação merge para ênuplas exige que sejam ênuplas com o mesmo número de campos e que campos na mesma posição tenham estruturas de mesmo tipo; assim, o resultado da operação merge em duas ênuplas é uma ênupla em que seus elementos são resultados de operações merge aplicadas nos elementos de mesma posição das ênupla sendo operadas. Por exemplo, na atribuição: 
\$enuplaM := merge $((\{a 1, a 2, a 3\},\{(b 1,1),(b 2,2),(b 3,3)\}, c 1, d 4)$, $\left.\left(\{a 1, a 4\},\{(b 1,10),(b 2,10)\}, c 1, \_n u 11\right)\right)$;

tem-se que a variável \$enuplaM contém a ênupla

$(\{a 1, a 2, a 3, a 4\},\{(b 1,1),(b 2,2),(b 3,3),(b 1,10),(b 2,20)\}, c 1, d 4)$

ou seja, o primeiro campo de \$enuplaM tem o resultado de merge operando em dois conjuntos (ou seja, sua união); da mesma forma ocorre com o segundo campo; os terceiro e quarto campos mostram as únicas duas formas válidas da operação merge envolvendo tipos atômicos: a operação só é válida se os átomos forem idênticos, caso em que o resultado é esse mesmo átomo, ou quando um dos elementos for o átomo especial null, caso em que o resultado é o átomo diferente de _null (a menos que ambos sejam _null, onde o resultado é nnull, caindo no primeiro caso).

Um comando interessante para conjuntos de ênuplas de dois elementos é o comando pairto. Por exemplo, dado:

$\$ c j:=\{(a, 1),(b, 2),(c, 3)\} ;$

o comando pairto $(\$ c j, b)$ retorna o segundo elemento da ênupla em que seu primeiro elemento é b; no caso, o comando retorna o valor 2. Caso haja mais de uma ênupla com um mesmo primeiro elemento, o comando retorna o primeiro que encontrar.

\subsubsection{Operações envolvendo representações bem-formadas}

A primeira operação que envolve representações bem-formadas é wellFormed que verifica se uma proto-representação tem estrutura de acordo com o que especifica um metamodelo. Considerando-se o metamodelo para cadeias de Markov de tempo contínuo da listagem 5.1, tem-se o seguinte exemplo:

s1,s2,s3 typeis State;

\$protoCM := (\{s1, s2, s3\}, $\{(\mathrm{s} 1, \mathrm{~s} 2,1.8),(\mathrm{s} 2, \mathrm{~s} 3,1.5)$, 
$(s 3, s 1,2.0),(s 1, s 3,0.3)\}$

\$representacaoCM := wellFormed(CTMC, \$protoCM);

apresenta uma proto-representação que é atribuída à variável \$protoCM; em seguida, \$protoCM e o metamodelo CTMC são utilizados como argumentos na execução de wellFormed, que, caso a verificação de que a proto-representação se "encaixa" na descrição do metamodelo seja positiva, retorna a um referência a uma representação bem-formada; no caso do exemplo, esta referência é armazenada em \$representacaoCM. A partir dessa referência, pode-se acessar os elementos da representação utilizando-se os nomes definidos no metamodelo. Por exemplo, considerando-se as linhas abaixo:

\$cjEstados := \$representacaoCM.StateSet;

\$cjTransicoes := \$representacaoCM.Transitions;

\$taxaQuartaTransicao := \$representacaoCM.Transitions [4].rate;

a variável \$cjEstados contém

$\{s 1, s 2, s 3\}$

\$cjTransicoes contém

$\{(\mathrm{s} 1, \mathrm{~s} 2,1.8),(\mathrm{s} 2, \mathrm{~s} 3,1.5),(\mathrm{s} 3, \mathrm{~s} 1,2.0),(\mathrm{s} 1, \mathrm{~s} 3,0.3)\}$

e \$taxaQuartaTransicao contém o valor do campo com nome rate da ênupla correspondente ao quarto elemento do conjunto referente ao nome Transitions, isto é, 0,3 .

Também, os procedimentos de análise envolvem exclusivamente representações bem-formadas, tanto como dados de entrada como em seus resultados. A forma de chamada da execução é semelhante a de outras funções, ou seja, o nome seguido pela lista de argumentos entre parênteses. Por exemplo, em:

\$pi := steadyStateProbability (\$representacaoCM)

o procedimento de análise steadyStateProbability é executado sobre a representação bem formada apresentada pela variável \$representacaoCM e o resul- 
Point is atomic;

Chain is (points is setof Point,

arcs is setof (origin is Point,fim is Point));

Listagem 5.4: Metamodelo de cadeias de pontos

tado, uma referência a uma representação bem formada referente ao produto da análise, é atribuído à variável \$pi.

\subsubsection{Módulos}

Módulos são estruturas padronizadas e parametrizadas a partir dos quais pode-se gerar várias instâncias com essa estrutura. A definição de um módulo tem a seguinte configuração:

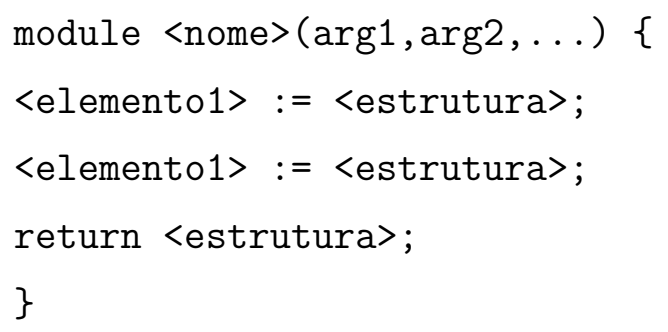

A palavra module indica que se está iniciando a definição de um módulo. Seguese a indicação de um nome para o módulo e uma lista de nomes de parâmetros referentes às estruturas necessárias para se construir instâncias desse módulo. A seguir, uma lista de atribuições que armazenam, nos elementos do módulo, as estruturas correspondentes; esses elementos podem ser acessados após a instanciação. Iniciando-se com a palavra return, indica-se a estrutura que se deseja representar, expressa em termos dos elementos do módulo da lista há pouco construída.

Considere-se o metamodelo da listagem 5.4, que se refere a uma cadeia de pontos conectados por arcos orientados como na figura 5.2. Nessa mesma figura, algumas estruturas repetitivas, sob a forma de ciclos de quatro de pontos, são mostradas em destaque; essas estruturas são definidas em termos de módulos.

Tal módulo é definido pelo seguinte: 


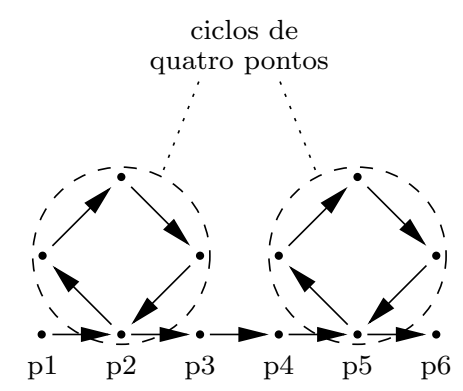

Figura 5.2: Cadeia de pontos

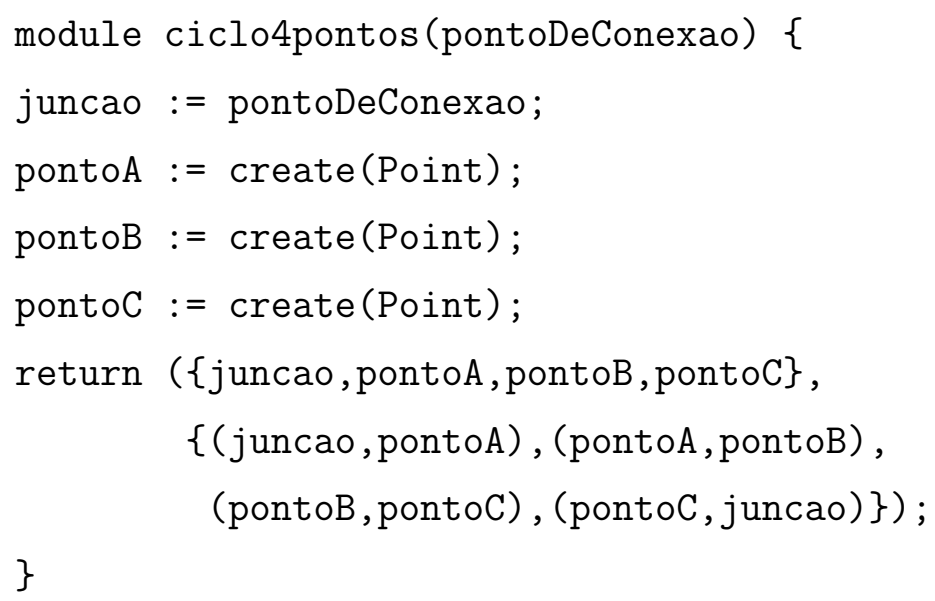

Enquanto o elemento de nome juncao refere-se a uma estrutura fornecida ao módulo, os elementos pontoA, pontoB e pontoC referem-se a estruturas (no caso átomos) que são gerados pelo módulo. A linha com a palavra return apresenta a estrutura referente ao ciclo.

Por exemplo, o ciclo que se conecta ao ponto p5 da figura, pode ser definido pelo seguinte:

\$moduloP5:= ciclo4pontos (p5);

Pode-se acessar os elementos desse módulo utilizando-se o nome do elemento; assim \$moduloP5 . segundo retorna o elemento com nome segundo desse módulo. A estrutura elaborada pelo módulo pode ser conseguida pela operação get ():

\$estrutModuloP5 := \$moduloP5.get();

A figura 5.3(a) mostra um cadeia "linear" ao qual deve se conectar uma cadeia cíclica (com a configuração descrita) no ponto p5. Se a cadeia "linear" é representada por: 


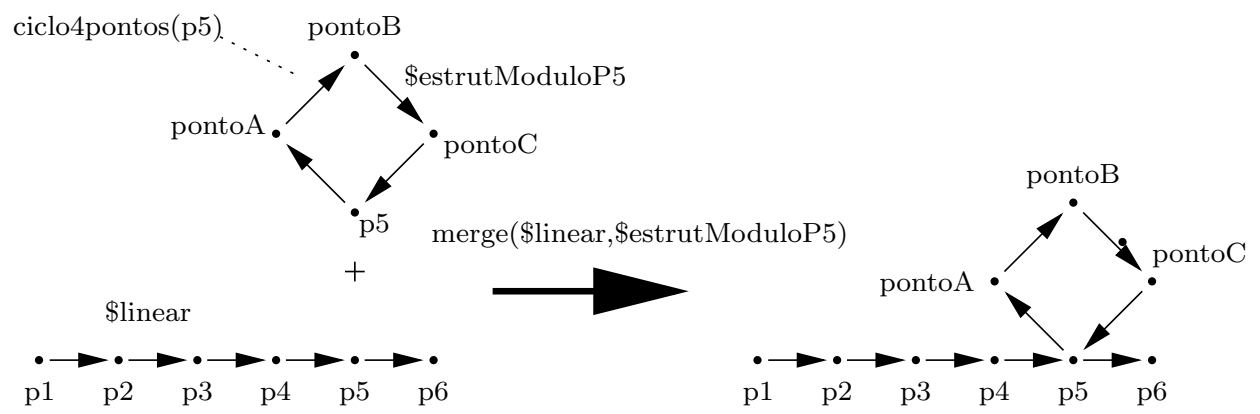

(a)

(b)

Figura 5.3: Operação merge para unir um módulo a uma proto-representação

\$linear := (\{p1,p2,p3,p4,p5,p6\}, $\{(\mathrm{p} 1, \mathrm{p} 2),(\mathrm{p} 2, \mathrm{p} 3),(\mathrm{p} 3, \mathrm{p} 4),(\mathrm{p} 4, \mathrm{p} 5),(\mathrm{p} 5, \mathrm{p} 6)\})$;

o módulo anteriormente criado pode ser conectado a esta cadeia através da operação merge:

\$cadeiafinal := merge (\$linear, \$estrutModuloP5);

onde a variável \$cadeiaFinal armazena a proto-representação referente à figura $5.3(b)$.

\subsubsection{Elementos de controle de fluxo de execução}

Nos exemplos, São utilizados duas formas de controle de fluxo de execução dos comandos: a iteração e a execução condicional.

As iterações empregadas têm a seguinte forma:

foreach $\$$ i in $\$$ conj \{

<comandos>

\}

Inicia-se com a palavra foreach, seguida de uma variável (no caso, \$i), da palavra in, de um conjunto (no caso, representado pela variável \$conj) e de um bloco 
de comandos entre chaves. Este bloco é executado uma vez para cada elemento do conjunto especificado. A cada iteração, à variável $(\$ i)$ é atribuído um dos elementos do conjunto, podendo ser acessado dentro do bloco.

No caso de seqüência de números, o comando intSet (\$inicio, \$fim, \$passo) é útil, pois gera um conjunto de números inteiros tal que se inicia com o valor dado pelo primeiro argumento (no caso, dado pela variável \$inicio), ao qual vai se somando, antes de iniciar cada iteração, o valor do terceiro argumento (\$passo); a iteração se encerra se, após essa soma, o resultado ultrapassar o valor dado pelo segundo argumento (\$fim).

A execução condicional tem a seguinte forma:

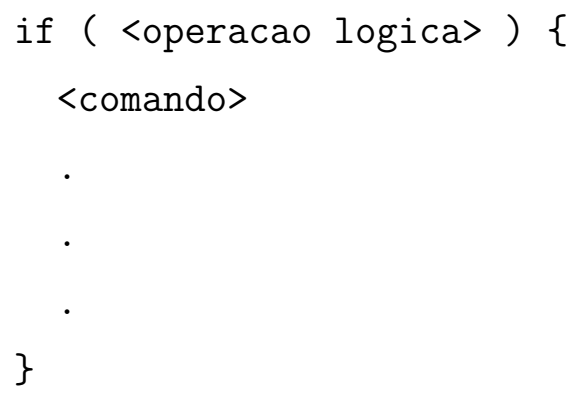

se o resultado da operação lógica que se encontra entre parênteses depois da palavra if retornar true, o bloco de comandos entre chaves é executado; caso contrário, a execução continua com o que estiver após o bloco de comandos.

\subsection{Representação de informação semântica na linguagem LiMA}

Nesta parte, são utilizados predicados, a exemplo do que foi feito no capítulo 4. No entanto, a fim de melhorar o acesso aos elementos dos functores e predicados, estes devem ser primeiramente definidos conforme se segue:

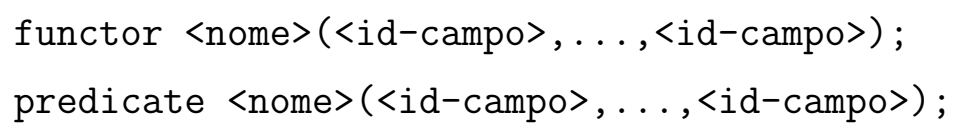

ou seja, inicia-se com a palavra reservada functor ou predicate conforme o caso, seguido do nome do elemento, após o qual segue-se uma lista entre parênteses dos identificadores de campos, que são associados aos argumentos. 
Assim, com a seguinte definição

functor processar (quem, oQue);

functores com nome processar possuindo dois argumentos podem ser utilizados.

Nesta implementação, toda expressão semântica (ou seja, termos, functores, expressões e predicados) deve ser apresentada entre apóstrofos (').

Em muitos casos, esses elementos podem ser considerados átomos, exceto que com algumas peculiaridades. Isso quer dizer que podem ser armazenados em variáveis e utilizados em conjuntos e ênuplas.

Assim, por exemplo, o functor

'processar (maquinaM, umaPecaB)'

pode ser usado para representar que "uma máquina $M$ processa uma peça de tipo B", de modo que ao identificador de campo quem está associado o termo maquinaM e, ao identificador de campo oQue, associa-se o termo umaPecaB.

Assim, considerando-se a seguinte variável

\$funct := 'processar (maquinaM, umaPecaB)'

tem-se que \$funct.quem retorna o termo 'maquinaM' e \$funct.oQue retorna o termo 'umaPecaB'. Todos os functores possuem o identificador especial name, que corresponde ao seu nome; portanto $\$$ funct. name retorna o nome do functor que neste caso é 'processar'.

Da mesma forma como apresentado no capítulo 4, functores podem se apresentar sob a forma de expressões de functores usando o operador and de forma a denotar conjunção (ou seja, os operandos ocorrem simultaneamente).

Assim, considerando-se os seguintes functores:

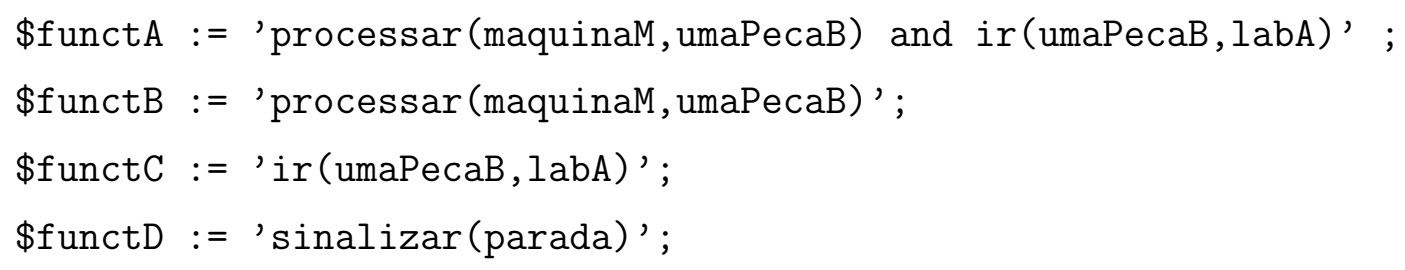


o operador lógico infers retorna true (verdadeiro) se o operando à direita puder ser inferido do operando à esquerda (conforme apresentado no capítulo anterior), ou seja,

\$functA infers \$functB

$\mathrm{e}$

\$functA infers \$functC

retornam true, enquanto que

\$functA infers \$functD

retorna false.

A operação match retorna um conjunto de elementos que correspondem a uma especificação de functor. Por exemplo, dado um functor

\$expr := 'processar(M,pecaTipoA) and processar(M2,pecaTipoB)'

o comando match (\$expr, 'processar (M, pecaTipoA)') retorna o conjunto, no caso, com um elemento, $\{$ 'processar (M,pecaTipoA)') $\}$.

Um elemento importante para o operador infers e o comando match é a variável anônima, denotada pelo caracter ".". A variável anônima é usada para indicar que seu particular valor não importa. Por exemplo, considere-se a operação

\$expr infers 'processar $\left(\mathrm{M} 1, \_\right)$'

o operando da direita indica que o que importa é que o functor tenha nome 'processa' e primeiro argumento 'M1', não importando qual do segundo argumento; como, no caso, há um functor com tais nome e primeiro argumento e um segundo argumento sendo 'pecaTipoA' (que é irrelevante), a operação retorna true.

No caso do comando match (\$expr, ' $\operatorname{processar}\left(\mathrm{M} 1,{ }_{-}\right)$'), retorna-se o conjunto de functores que satisfazem o functor referente ao segundo argumento, ou seja, \{'processar(M1, pecaTipoA)'\}. 
A operação \$expr infers 'processar $\left({ }_{-},{ }_{-}\right)$' retorna true; enquanto que a operação match (\$expr, 'processar $\left(_{-},{ }_{-}\right)$') retorna o conjunto

$\{$ 'processar (M1, pecaTipoA)', 'processar(M2, pecaTipoB)'\}.

Seguindo o que foi apresentado no capítulo 4, os predicados são processados quando apresentados como elementos de um conjunto. O processamento apresentado é feito pelo comando match, com um mecanismo absolutamente similar ao que ocorre com functores, ou seja, retorna um conjunto de predicados que satisfazem um padrão definido por um outro predicado, que, como no caso com functores, pode empregar variáveis anônimas.

Por exemplo, considere-se os seguintes functores e predicados:

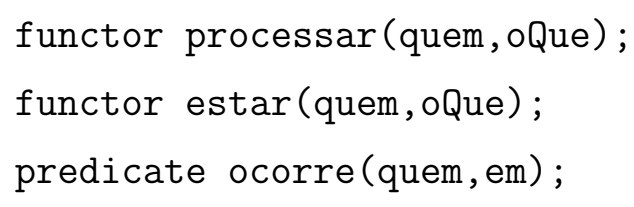

usados para representar, respectivamente, o processamento de algo por alguém, que algo se encontra numa determinada condição e que algo ocorre numa situação. Assim, dadas as máquinas M1, M2 e M3 e peças de tipo A e de tipo B, o seguinte conjunto de predicados descrevem os fatos que ocorrem em diversos estados (estado0, estado1 e estado2):

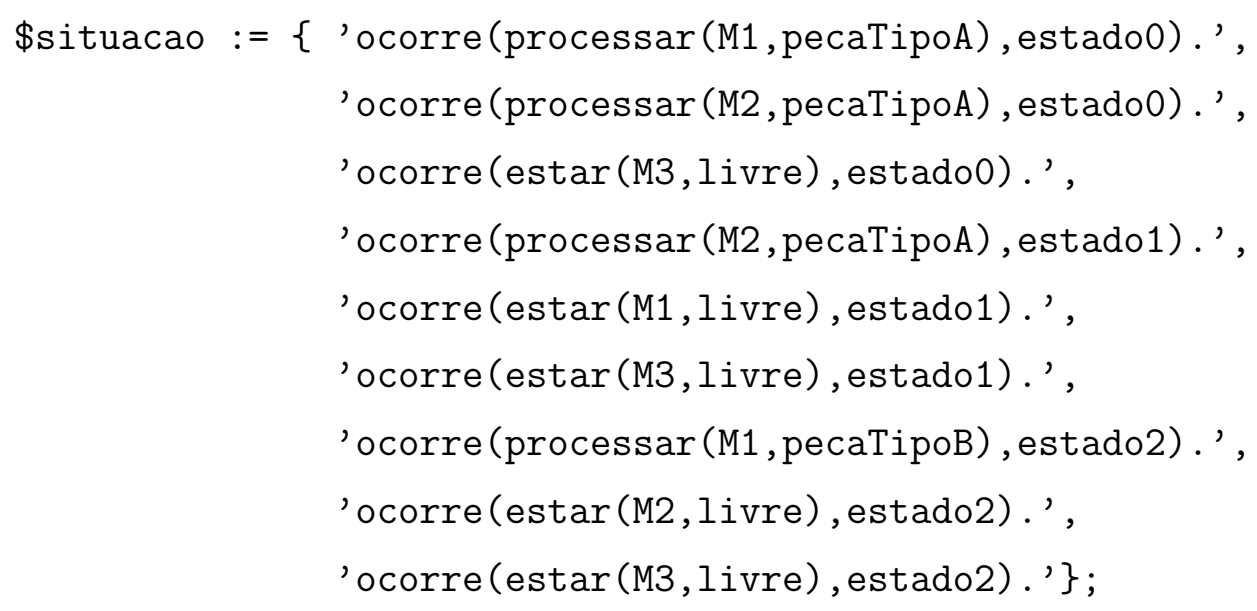

Por exemplo, para se saber o que ocorre num determinado estado (por exemplo, estado0), o comando match (\$situacao, 'ocorre(_, estado0). ') pode ser executado, retornando o conjunto dos predicados que descrevem aquele estado: 


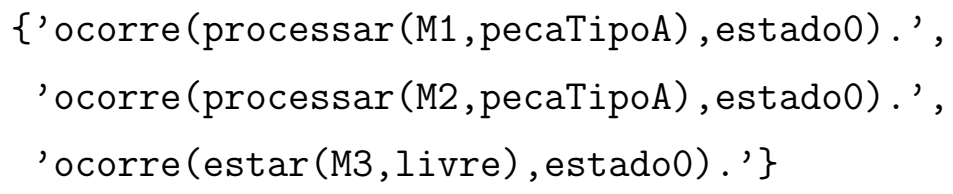

Para se saber em quais estados há máquina livre (não importa qual), o comando match (\$situacao, 'ocorre (estar(_, livre), _)') pode ser empregado, tal que se tem o seguinte resultado:

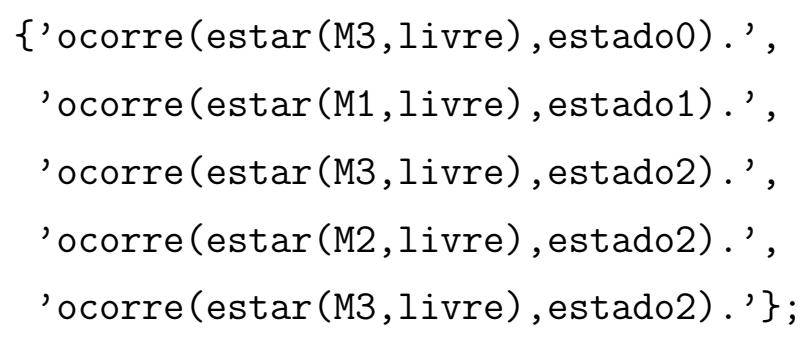

Para acessar um dos predicados do conjunto (o i-ésimo, por exemplo), basta utilizar a notação "[i]"; assim, se o conjunto acima estiver armazenado numa variável \$resultado:

\$predicado := \$resultado[3];

a variável \$predicado contém 'ocorre(estar(M3, livre), estado2).'. Para acessar os elementos dos predicados, basta utilizar os identificadores de campos definidos para o predicado, ou seja, a expressão \$predicado.quem retorna 'estar(M3,livre)', \$predicado.em retorna 'estado2' e \$predicado. name retorna 'ocorre'. Por sua vez, a expressão \$predicado.quem.quem retorna 'M3'.

Uma maneira de formar functores ou predicados é com a utilização de variáveis dentro de tais elementos, desde que as variáveis contenham elementos compatíveis, ou seja, termos, functores, expressões ou números. Por exemplo, se a variável \$agente contiver o termo 'CNC', a seguinte linha

\$functProcesso := 'processar (\$agente,peca)';

atribui à variável \$functProcesso o functor 'processar (CNC, peca)'.

Uma forma simples de montar uma conjunção de functores é com o uso do operador " $*$ ": 
\$conjuncao := 'processar (CNC, peca)' * 'estar (peca, OK)';

à variável \$conjuncao é atribuída a expressão conjuntiva

'processar (CNC,peca) and estar(peca,OK)'

As chamadas strings são úteis para a montagem dos termos a serem utilizados em functores e predicados. São cadeias de caracteres alfanuméricos apresentados entre aspas. Uma operação interessante das strings é a concatenação: usando o operador "+", que une duas seqüências dessas cadeias, uma depois da outra. No exemplo:

$\$$ pecaB := '(peca') + 'Tipo' + '(B');

a variável \$pecaB armazena a string ' pecaTipoB' '.

Nesta linguagem, pode-se concatenar números a strings; no seguinte exemplo:

\$num := 15;

\$nome := "estado"' + \$num

tem-se que a variável \$nome contém a string ' estado15' '.

As strings podem ser utilizadas na criação de termos a serem utilizados em functores e predicados, através do comando term; em:

\$estado := term('(estado15'));

a variável \$estado passa a armazenar o termo 'estado15' (observar os apóstrofos ao invés de aspas).

Os functores são associados aos elementos de modelagem através das vinculações, que são elementos criados com o comando bindings(). As vinculações apresentam a operação de associação bind, que liga um elemento de modelagem a um termo ou functor; apresenta, também, operações que, dado um elemento de modelagem, retorna o functor correspondente e vice-versa. No exemplo:

$\mathrm{P}$ is atomic;

p1,p2 typeis P; 
\$anotacoesPN := bindings ();

\$anotacoesPN. bind (p1, 'processar (M, p)');

\$anotacoesPN.bind (p2, 'estar (M, livre)');

\$elemento := anotacoesPN.element('processar $(M, p)$ ') ;

\$anotacao := anotacoesPN.meaning $(\mathrm{p} 2)$;

uma vinculação é criada e armazenada na variável \$anotacoesPN; as mencionadas associações são introduzidas na vinculação pela operação bind (primeiro argumento é um elemento de modelagem e o segundo, um functor); através da operação element, pode-se obter o elemento de modelagem que é associado a um functor (caso não haja nada, retorna um conjunto vazio \{\} ); através da operação meaning, obtém-se o functor que lhe é associado (caso não haja nada, retorna um conjunto vazio \{\}$)$. No caso, \$elemento contém p1 e \$anotacao contém 'estar(M, livre)'.

\subsection{Exemplo: montagem de representações}

Primeiramente, considere-se as redes de Petri estocásticas generalizadas (ver apêndice A) GSPN1 e GSPN2 apresentadas nas figuras 5.4 e 5.5: tratam-se dos mesmos modelos apresentados e descritos nas seções 4.4 e 4.5 (nas figuras 4.9 e 4.12 respectivamente), cujas representações gráficas são novamente apresentadas para facilitar a consulta. As proto-representações destes modelos, estruturadas conforme o metamodelo da listagem 5.5, servem de base para a construção das representações de outros modelos que são baseados neles, conforme procedimento computacional descrito em seguida. Uma observação quanto ao metamodelo na listagem 5.5: o campo randomSwitch da definição de GSPNType considera apenas os casos de conflitos não envolvidos em situações denominadas de confusão (ver apêndice A); também, as probabilidades não mudam com a marcação.

Nos exemplos, os functores e predicados definidos na listagem 5.6 são utilizados.

As listagens de 5.7 a 5.11 apresentam um procedimento computacional, des- 


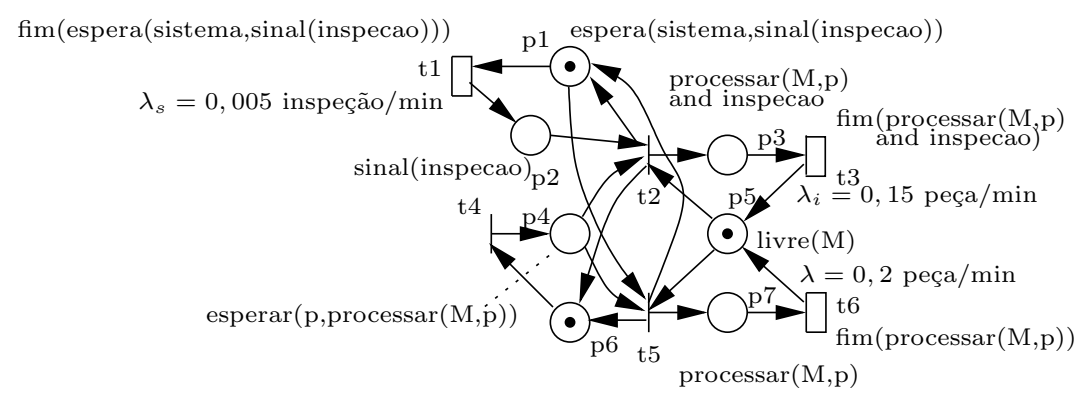

Figura 5.4: Primeira rede de Petri estocástica generalizada inicial (GSPN1)

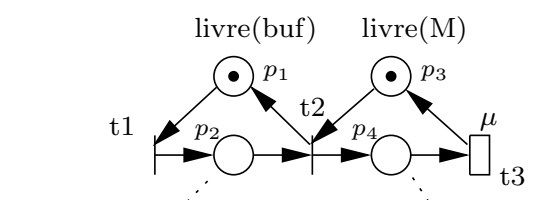

esperar(p,processar(M,p)) procéssar(M,p)

$\lambda=0,2 \mathrm{peça} / \mathrm{min}$

Figura 5.5: Segunda rede de Petri estocástica generalizada inicial (GSPN2)

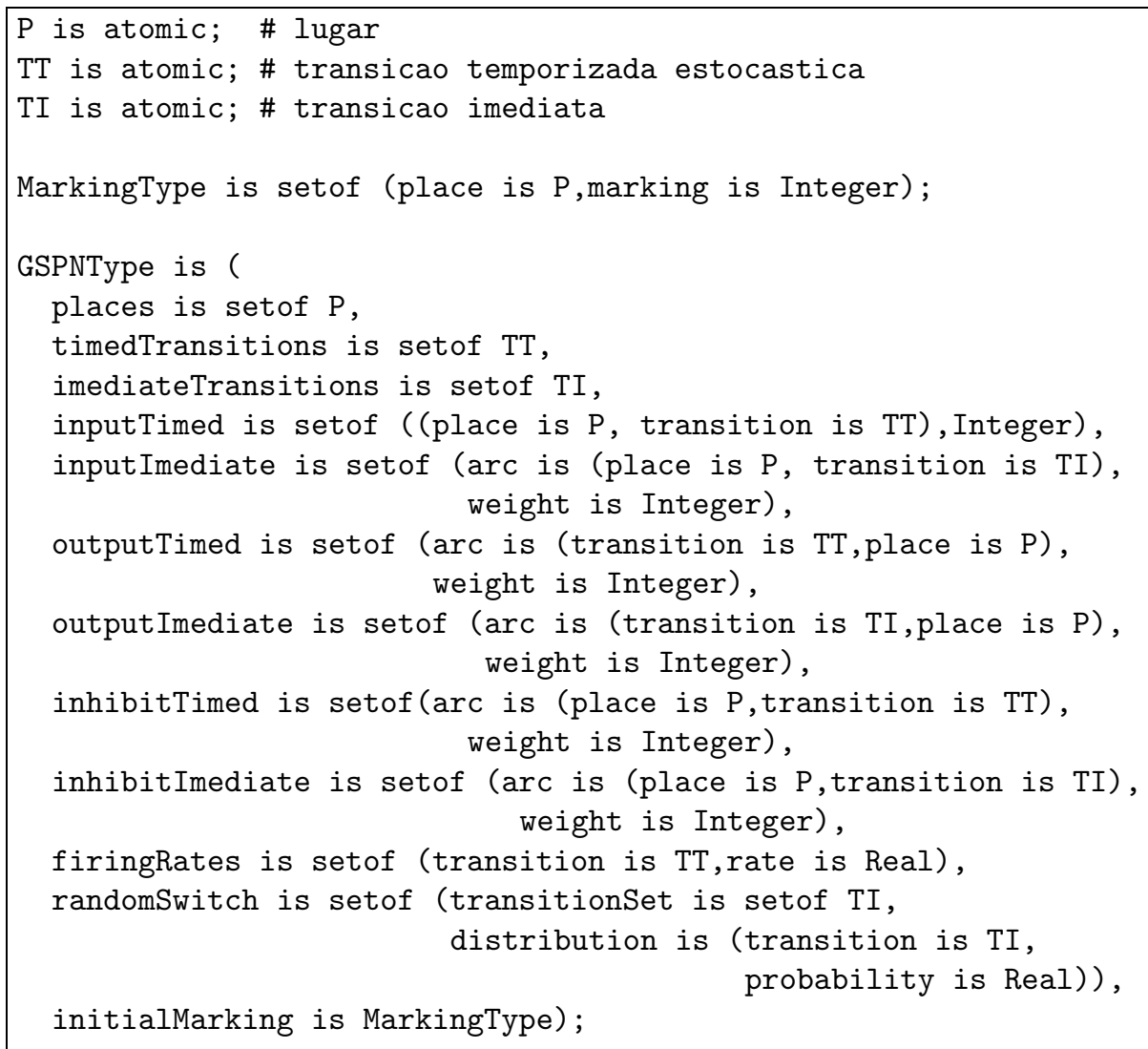

Listagem 5.5: Metamodelo para redes de Petri generalizadas estocásticas marcadas e com arcos inibidores (tipo de dado GSPNType) 


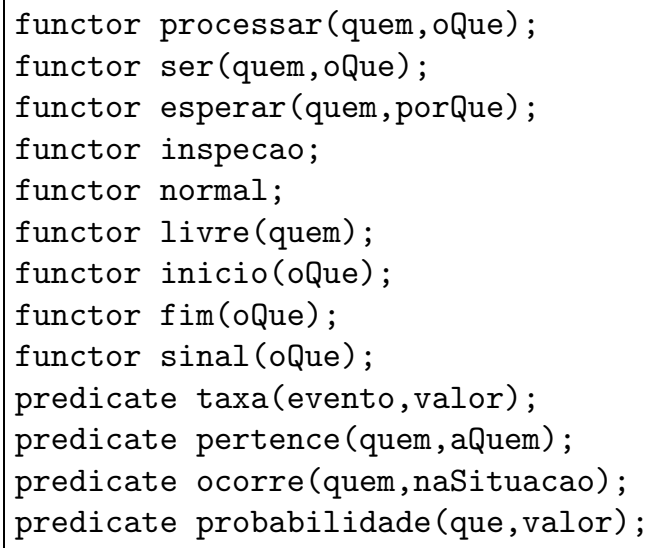

Listagem 5.6: Definição de functores e predicados (somente os utilizados no experimento)

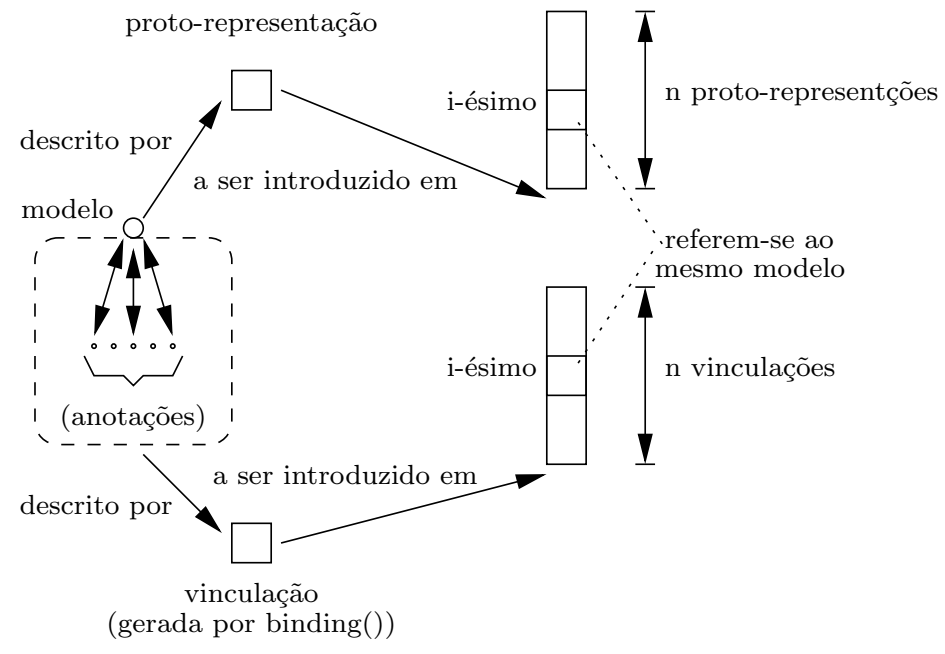

Figura 5.6: Os conjuntos nas variáveis \$protos e \$anotacoes

crito na linguagem de modelagem apresentada, para montagem de representações baseadas nas duas redes de Petri estocásticas generalizadas descritas há pouco. Conforme ilustrado pela figura 5.6, as proto-representações e as correspondentes anotações de seus elementos (armazenadas nas vinculações geradas pelo comando binding()) são armazenadas nos conjuntos referenciados pelas variáveis \$protos e \$anotacoes respectivamente; tal armazenamento ocorre de modo que, para todo $i$, a $i$-ésima proto-representação em \$protos e a $i$-ésima vinculação em \$anotacoes referem-se ao mesmo modelo; a inclusão de novos modelos deve seguir essa mesma ordenação.

Assim, pela listagem 5.7, o exemplo começa com a inicialização das variáveis \$protos e \$anotacoes com conjuntos vazios. Em seguida, monta-se as proto- 
representações correspondentes aos modelos iniciais. Cada uma dessa protorepresentações são introduzidas no conjunto em \$protos, assim como vinculações são criadas e introduzidas no conjunto em \$anotacoes, nas quais anotações (functores) são associados aos elementos das representações.

Baseado nesses dois modelos iniciais, deseja-se, também, analisar outros dois que consideram o caso em que, logo no início do processamento, após a verificação da peça, conclui-se que esta possui características especiais (por exemplo, sendo uma peça cilíndrica, a variação do diâmetro é inferior a uma certa percentagem, o que é importante para certas aplicações); por esta razão esta peça especial deve passar por um processamento específico, após o qual terá um encaminhamento adequado; estatisticamente, considere-se, por exemplo, que isso ocorre em $1 \%$ dos casos e que o processamento específico ocorre a uma taxa de 0,25 peça/minuto.

A figura 5.7 mostra o trecho de rede de Petri estocástica generalizada a ser anexada aos modelos básicos: assim que as tarefas de processamento se iniciam (disparo da transição tInicio), ocorre uma verificação da peça a ser trabalhada (lugar pVerifica); o disparo da transição tPecaNormal, que ocorre com uma probabilidade de 99\%, indica que a peça é uma peça comum e, portanto, deve passar pelo processamento normal (representado pelo lugar pProcessamento); o disparo da transição tPecaEspecial, que ocorre com uma probabilidade de 1\%, indica que a peça é especial e, portanto, seu processamento deve, também, ser especial, o que é indicado por uma marca no lugar pProcessamentoEspecial, que habilita a transição tProcessamentoEspecial; o disparo desta última transição, a uma taxa de 0,25 peças/minuto, indica o término do processamento da peça especial, o que acaba, também por liberar a máquina (entrada de marca no lugar pMLivre).

A listagem 5.8 mostra o módulo PecaEspecial. A listagem 5.9 apresenta sua instanciação e sua anexação aos modelos iniciais. Basicamente, o que se faz é localizar os elementos correspondentes aos parâmetros pProcessamento, tInicio e pMLivre do módulo, o que é feito através das anotações (as relações entre as anotações dos elementos é apresentada na figura 5.8):

1. determina-se o lugar referente à disponibilidade da máquina $\mathrm{M}$, que tem a anotação 'livre(M)';

2. determina-se quais lugares representam o processamento de peça, o que 


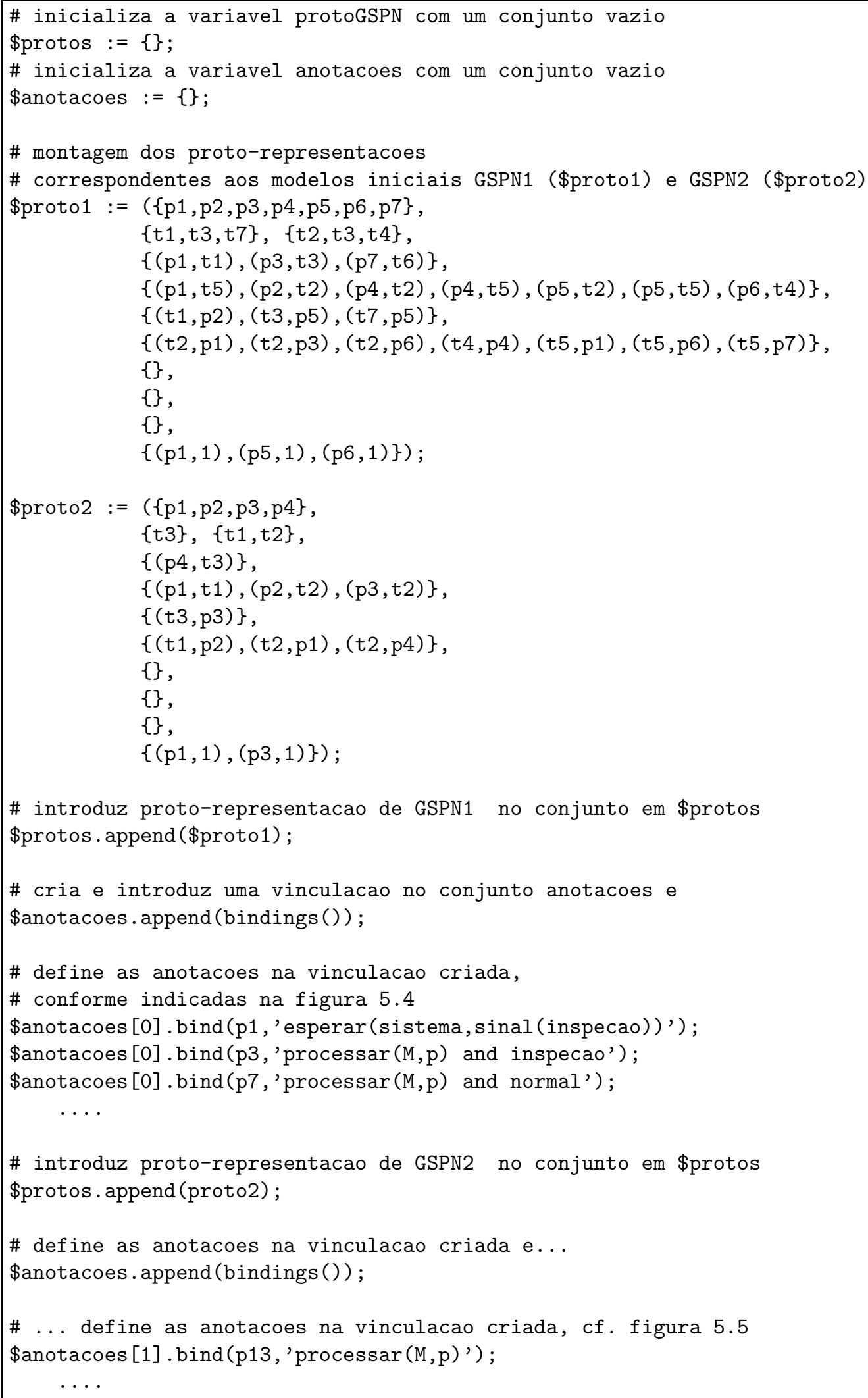

Listagem 5.7: Exemplo de montagem de representações envolvendo estruturas intermediárias e informações semânticas (continua) 


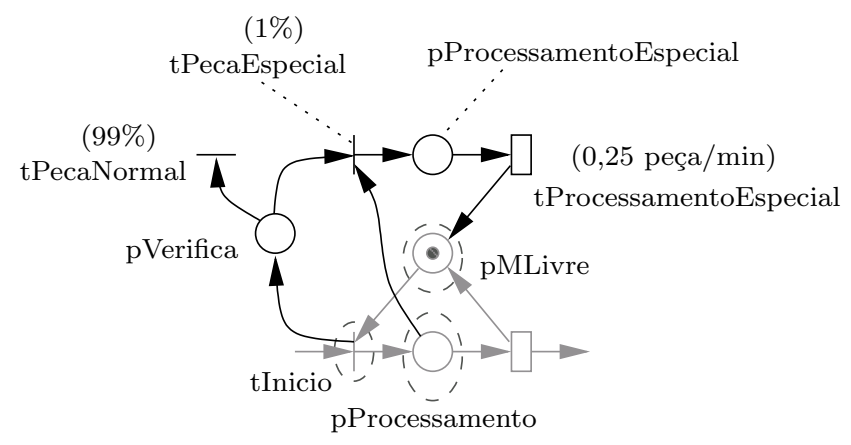

Figura 5.7: Módulo referente a processamento de peça com características especiais (os ítens em cinza representam os elementos do modelo que interagem ou que sejam avizinhados ao módulo)

pode ser verificado ao se procurar pelas anotações das quais se pode inferir o functor 'processar $(M, p)$ ';

3. em seguida, para cada um desses lugares, identifica-se qual a transição à sua entrada, que, por padrão, contém um functor 'inicio' com argumento igual à anotação desse lugar;

4. feito isso, cria-se o módulo, parametrizado nesses três elementos, e faz-se a anexação (através do comando merge);

5. associa-se, ao lugar referente ao elemento pProcessamentoEspecial do módulo criado, uma anotação igual ao do lugar que se refere ao elemento pProcessamento do mesmo módulo, exceto que em conjunção com o functor 'ser (p, especial)', indicando a condição especial da peça.

Ao final, adiciona-se as novas proto-representações e as respectivas vinculações aos conjuntos em \$protos e \$anotacoes respectivamente. Aplicando esse procedimento às proto-representações iniciais, tem-se as proto-representações de mais dois novos modelos (totalizando quatro). É interessante notar outros relacionamentos envolvendo elementos do modelo, além daqueles considerados pelas redes de Petri estocásticas generalizadas, e que são explicitados pela representação de informação semântica.

Outro elemento que se deseja analisar adicionalmente é a ocorrência de falhas na máquina $\mathrm{M}$ e dos respectivos reparos durante a operação. A figura 5.9 mostra a sub-rede com o padrão considerado: a falha ocorre (disparo de tFalha) quando a máquina está processando e, ao ocorrer, a peça sendo processada é descartada e, 


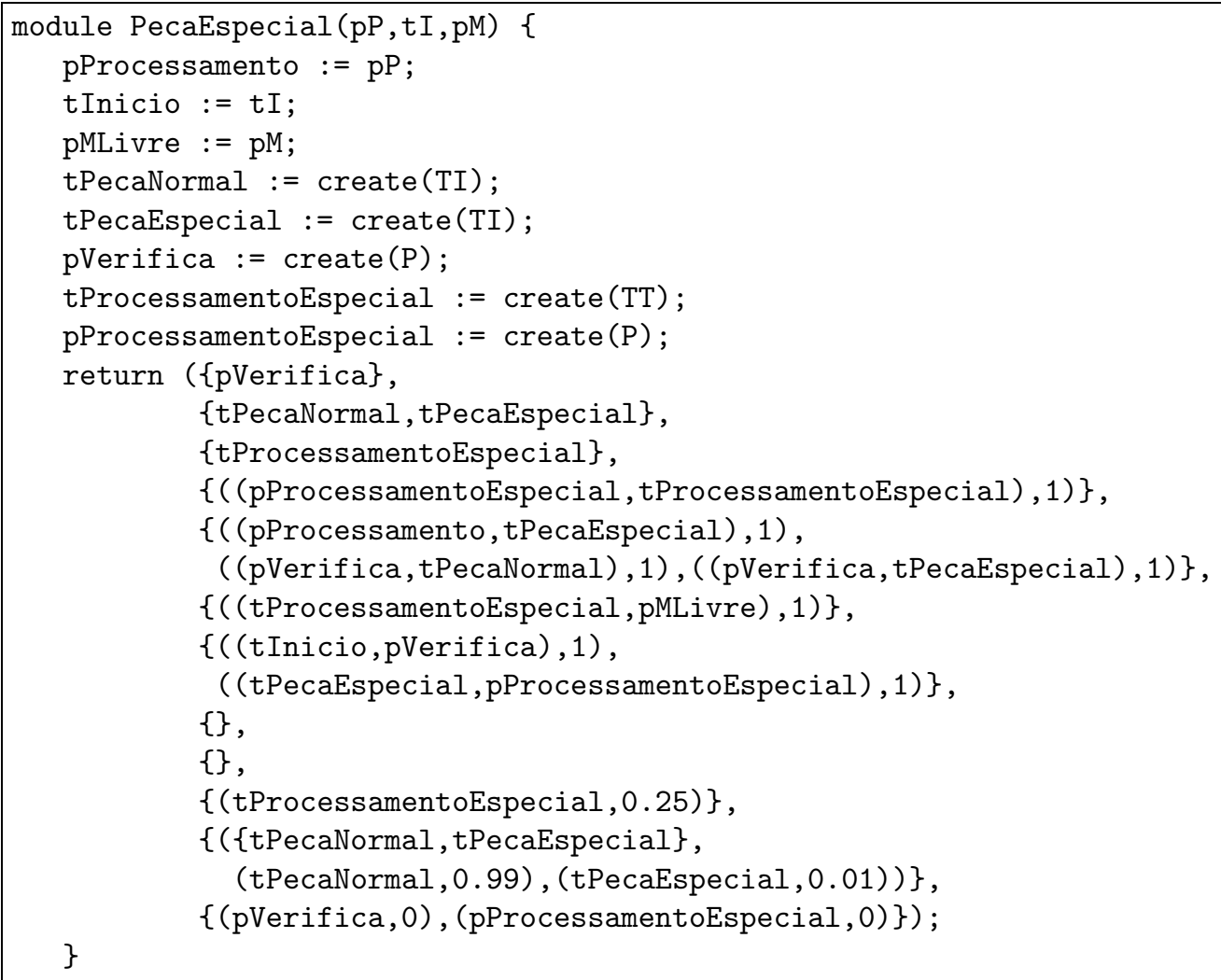

Listagem 5.8: Exemplo de montagem de representações envolvendo estruturas intermediárias e informações semânticas (continuação - 1).

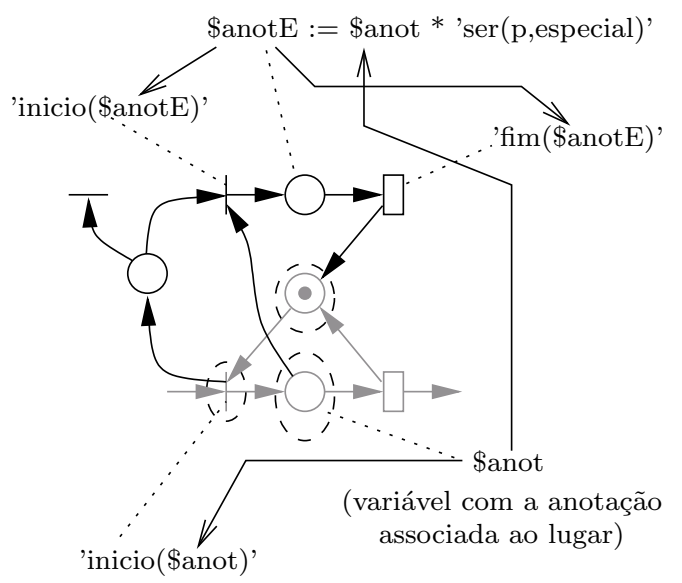

Figura 5.8: Relações entre anotações no caso de processamento de peças com características especiais 


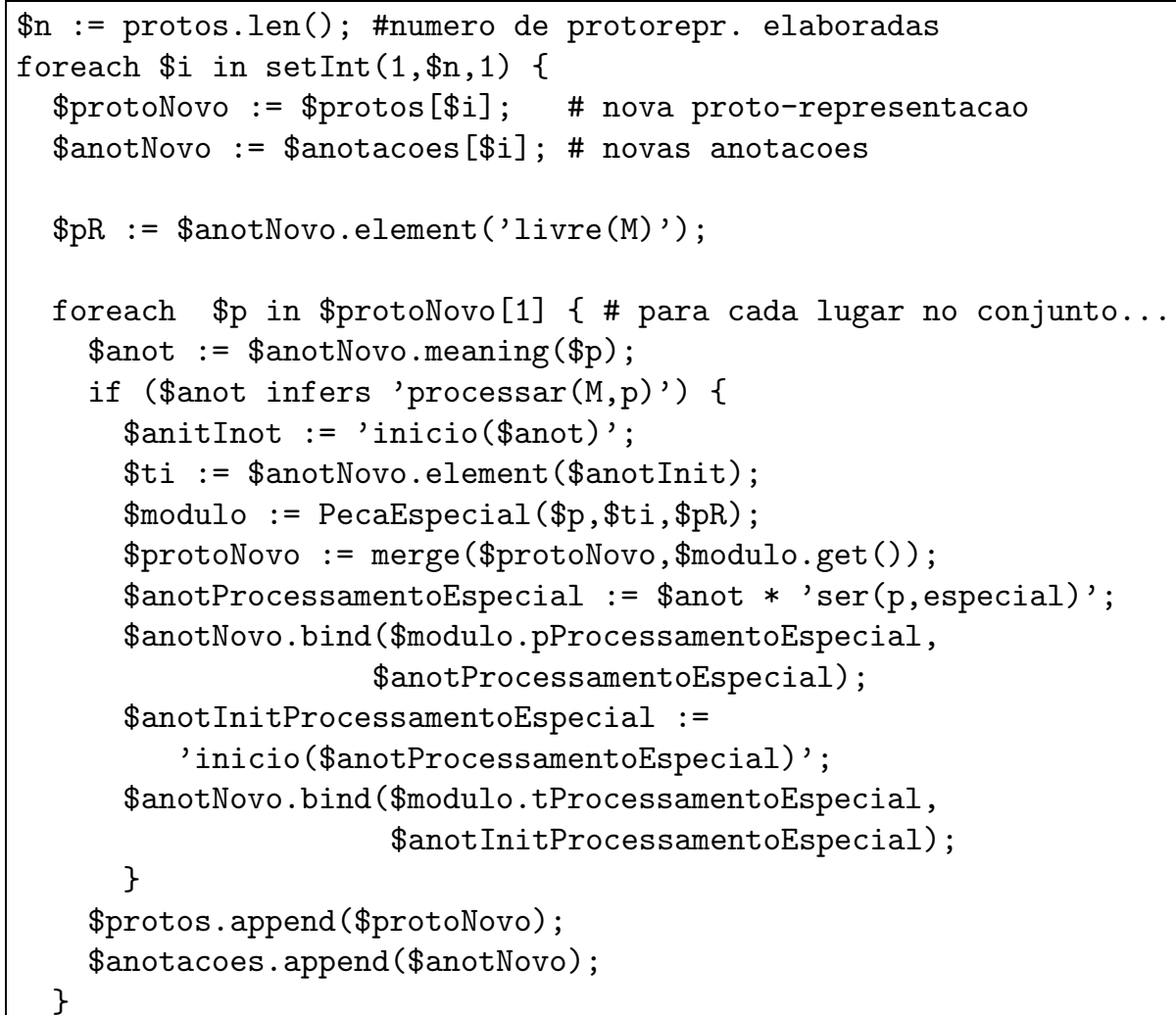

Listagem 5.9: Exemplo de montagem de representações envolvendo estruturas intermediárias e informações semânticas (continuação - 2). 


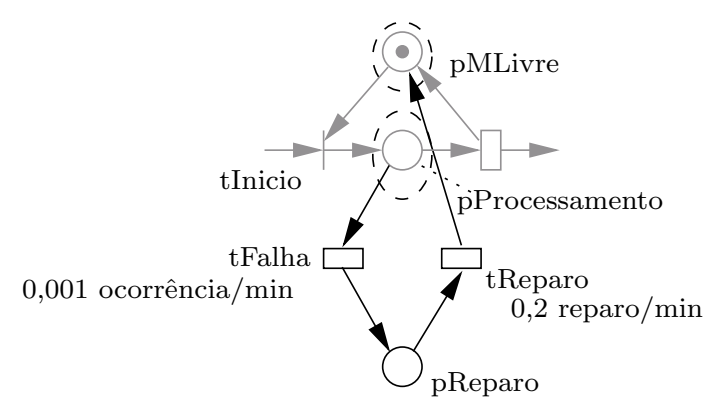

Figura 5.9: Módulo referente à ocorrência de falha e seu reparo (os ítens em cinza representam os elementos do modelo que interagem ou que sejam avizinhados ao módulo)

imediatamente, tem-se o início do reparo (marca no lugar pReparo); ao término do reparo (disparo de tReparo), a máquina disponibiliza-se para outros processamentos (marca no lugar pMLivre). Considera-se, por exemplo, que a taxa de falhas é de 0,001 ocorrência/min e a taxa de reparos é de 0,2 reparo/min.

A listagem 5.10 apresenta como o módulo referente à falha e seu reparo é implementado e como anexá-lo às proto-representações em \$protos. O procedimento é análogo ao caso anterior: determinar quais elementos das protorepresentações fazem conexão com instâncias desse módulo, criar essas instâncias e anexá-las. Neste caso, basta identificar os lugares que significam processamento pela máquina M, que correspondem ao lugar pProcessamento no módulo. São os lugares de cujas anotações pode-se inferir 'processar $(\mathrm{M}, \mathrm{p})$ '. Ao finalizar a aplicação nas proto-representações presentes em \$protos, tem-se mais quatro proto-representações.

Uma outra ocorrência que se deseja considerar é que, de tempos em tempos, há necessidade de sinalizar a reinicialização do sistema. A sub-rede da figura 5.10 ilustra como isso pode ser modelado: considerando-se uma condição inicial de operação normal (com o lugar pNormal marcado), a sinalização de reinicialização ocorre (com o disparo da transição tReinicializar) com uma freqüência de 0,001 sinalização/minuto; ao ocorrer a sinalização, passa-se a uma condição de reinicialização (marca no lugar pReinicializando), que termina (com o disparo

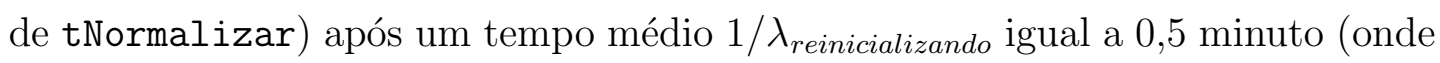
$\lambda_{\text {reinicializando é a taxa de disparo de tNormalizar), voltando à primeira condição }}$ (com o lugar pNormal marcado). Na condição de reinicialização, se algum processamento estiver em curso (lugar pProcessamento marcado), este é interrompido 


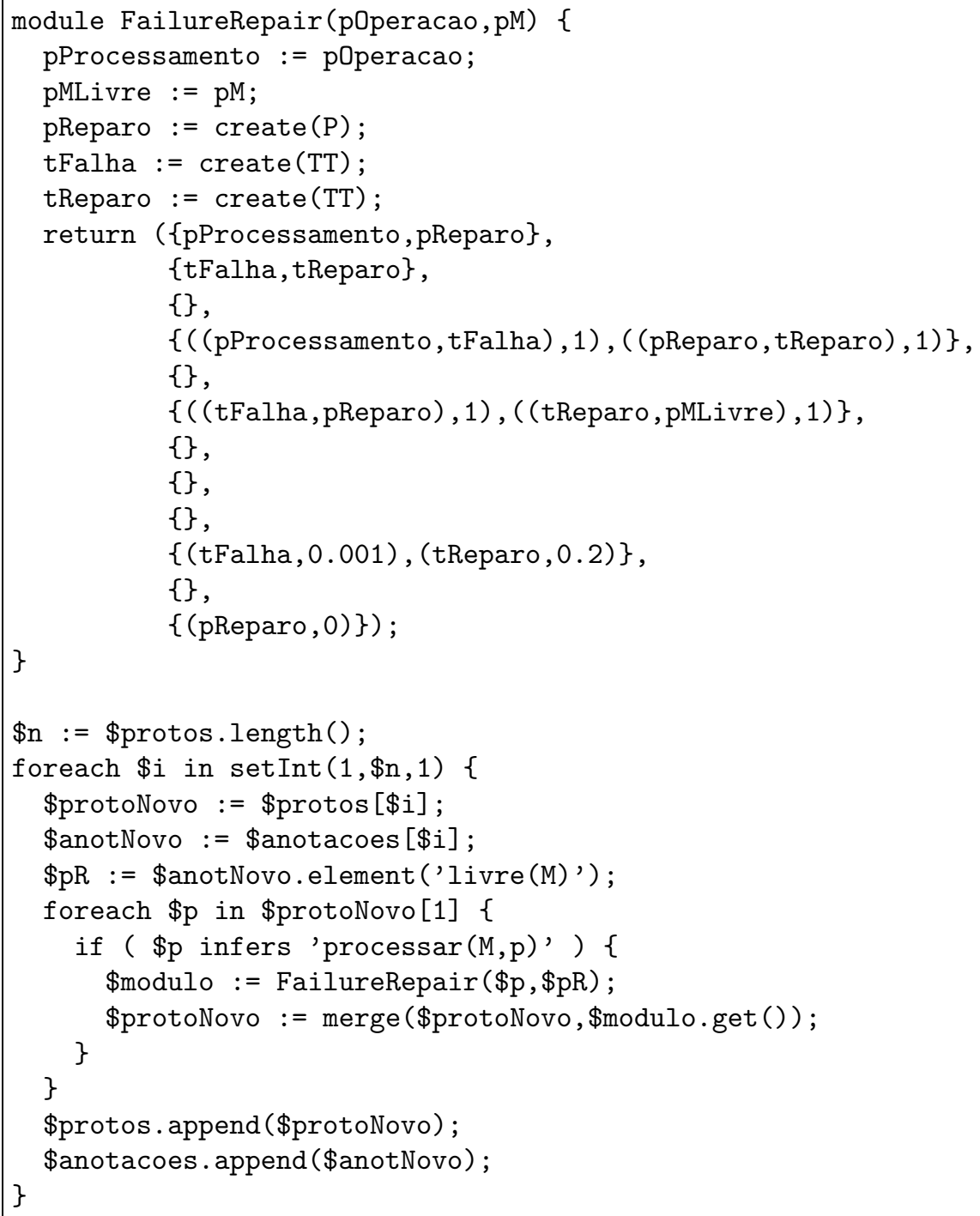

Listagem 5.10: Exemplo de montagem de representações envolvendo estruturas intermediárias e informações semânticas (continuação - 3). 


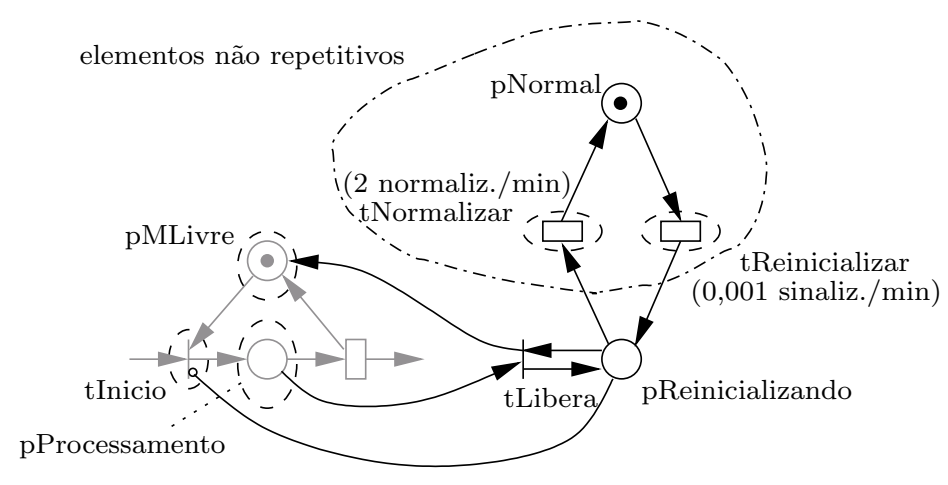

Figura 5.10: Elementos adicionais não repetitivos e módulo de reinicialização (os ítens em cinza representam os elementos do modelo que interagem ou que sejam avizinhados ao módulo)

(disparo de tLibera) e a peça em questão é descartada e a máquina M volta a estar livre; ao mesmo tempo, não se pode iniciar processamento nessa condição (conforme indicado pelo arco inibidor na transição tInicio).

A listagem 5.11 mostra o módulo referente à reinicialização e sua aplicação nas proto-representações até aqui elaboradas. Num mesmo modelo, para cada lugar que corresponda a "máquina M processando", uma instância desse módulo deve ser "conectada". Novamente, deve-se encontrar as representações dos elementos do modelo base que se conectam às instâncias do módulo:

1. primeiramente, há três elementos que devem ser acrescentados às protorepresentações, independentemente do número de instâncias a serem anexadas: o lugar pNormal e as transições tReinicializar e tNormalizar; os demais elementos dos módulos devem ser "repetidos" conforme instâncias são criadas;

2. assim, para cada lugar referente a um processamento, ou seja, de cuja anotação possa se inferir processar $(M, p)$, cria-se uma instância de tal módulo, cujos parâmetros são:

- o lugar em questão,

- as duas transições do item anterior;

- a transição de entrada desse lugar, cuja anotação é um functor com nome inicio e um argumento igual à anotação do mesmo lugar citado no primeiro item; 


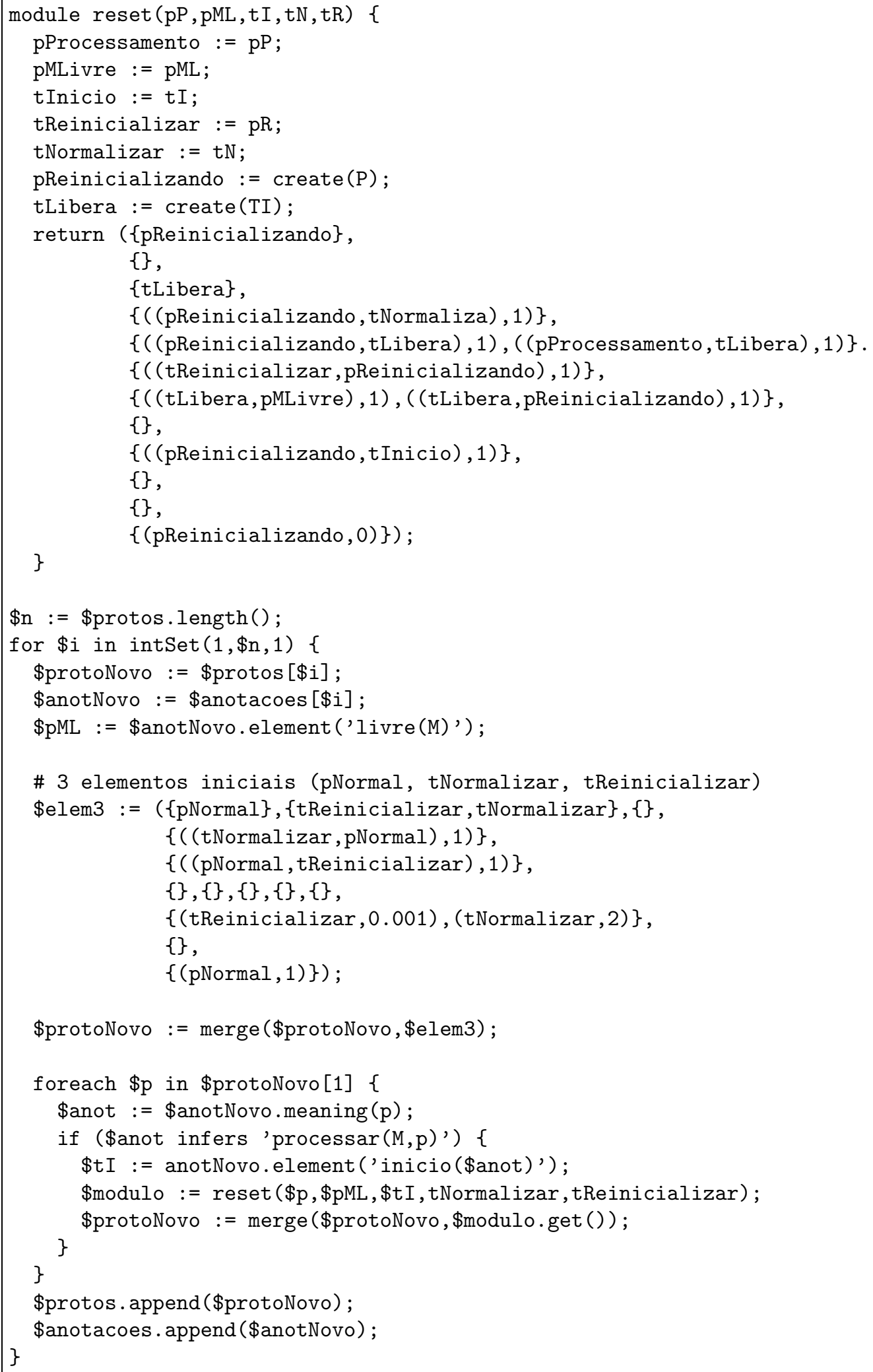

Listagem 5.11: Exemplo de montagem de representações envolvendo estruturas intermediárias e informações semânticas (conclusão - 4). 
- o lugar que indica que a máquina está livre, conforme anotado pelo functor livre(M);

uma vez criada, a instância do módulo é anexada à proto-representação.

Ao final, tem-se mais oito proto-representações, totalizando dezesseis.

Neste exemplo, pode-se constatar a utilidade do reaproveitamento de estruturas intermediárias para construção de múltiplos modelos que compartilham partes comuns e da consideração das semânticas dos elementos dos modelos na construção das representações computacionais de modelos. Neste último caso, note-se que outros modelos iniciais poderiam ser considerados e que os mesmos procedimentos computacionais de montagem de representações baseadas neles poderiam ser aplicados, desde que as anotações sigam o padrão adotado para os modelos apresentados. Também, o aproveitamento de relacionamentos ao nível da semântica dos elementos dos modelos mostra-se útil na construção das representações computacionais - o exemplo mostra a construção de representações de modelos cada vez maiores e com padrões de acoplamentos cada vez mais complexos, que torna a visualização e, portanto, os trabalhos com as representação cada vez mais complicados.

\subsection{Exemplo: integração e montagem de repre- sentações}

Nesta seção, ilustra-se como o isomorfismo entre redes de Petri estocásticas generalizadas e cadeias de Markov (MARSAN; CONTE; BALBO, 1984), similar àquele que envolve redes de Petri estocásticas, já discutido nos capítulos anteriores, pode ser abordado e aproveitado computacionalmente. Na prática, este relacionamento é utilizado numa forma em que a modelagem do sistemas é feita em termos de redes de Petri estocásticas (generalizadas ou não), que em boa parte dos casos é mais tratável que as cadeias de Markov; a partir das redes de Petri estocásticas, cadeias de Markov isomórficas são geradas; da análise das cadeias de Markov, geram-se, por exemplo, as distribuições da probabilidades de regime permanente; dessas probabilidades de estados e das informações das marcações tangíveis da rede de Petri estocástica correspondente (ver apêndice A), pode-se calcular uma série de grandezas que permitem avaliar quantitativamente 


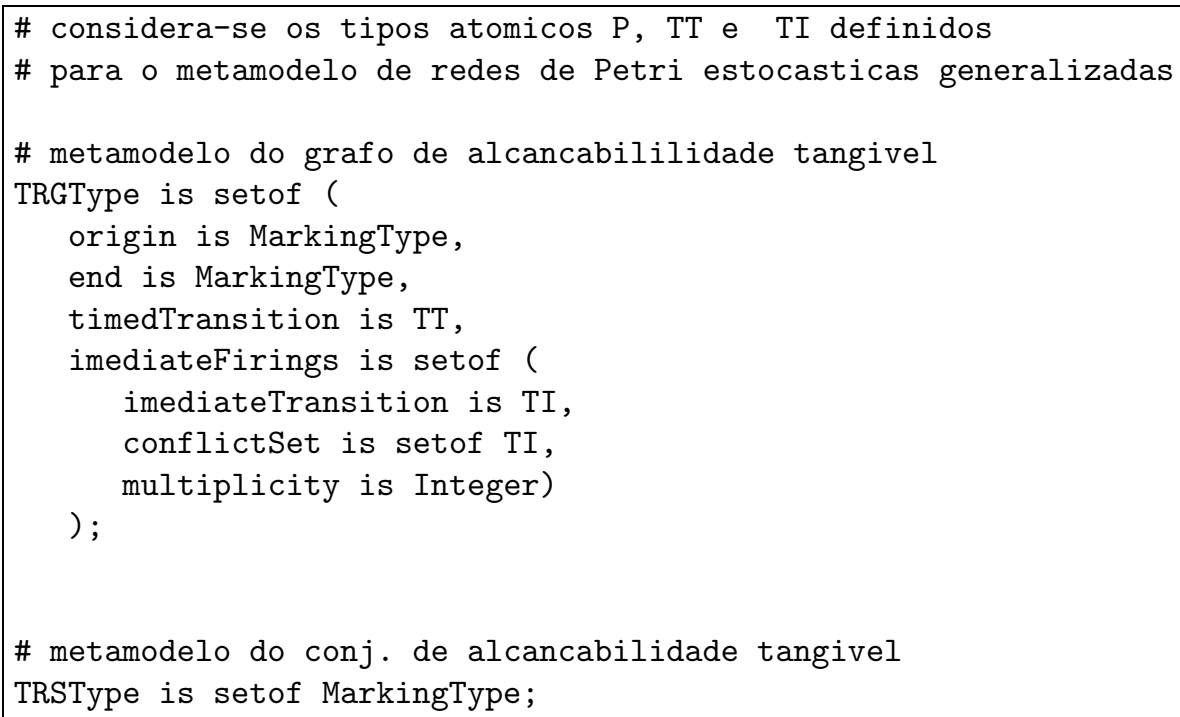

Listagem 5.12: Definição dos metamodelos referentes aos grafos de alcançabilidade tangível e aos conjuntos de alcançabilidade tangível

o sistema modelado (MOLLOY, 1980). É esta trajetória entre a rede de Petri estocástica até a distribuição das probabilidades de regime permanente que se descreve a seguir.

Considerados nos exemplos que se seguem, os metamodelos referentes ao grafo de alcançabilidade tangível e o conjunto de alcançabilidade tangível (CHIOLA; DONATELLI; FRANCESCHINIS, 1991) são apresentados na listagem 5.12.

Considerando-se a listagem 5.13 e acompanhando o esquema ilustrado pela figura 5.11, tem-se, primeiramente, que uma representação bem-formada de uma rede Petri estocástica generalizda está armazenada na variável \$gspn. Dessa representação são gerados o grafo de alcançabilidade tangível, armazenado na variável \$trg, e o conjunto de alcançabilidade tangível, armazenado na variável \$trs, a partir dos procedimentos genTRG(\$gspn) e genTRS(\$trg) respectivamente.

O vínculo entre redes de Petri estocásticas e cadeias de Markov tratado na seção 4.4 é implementado aqui: gera-se um átomo referente a um estado da cadeia de Markov para cada marcação tangível da rede de Petri estocástica generalizada (em \$trs); um mesmo termo é associado a uma marcação tangível de rede de Petri estocástica e a um estado da cadeia de Markov, como forma de representar tal vínculo; as associações entre os termos e as marcações tangíveis são introduzidas na vinculação (gerada pelo comando bindings()) armazenada na variável 


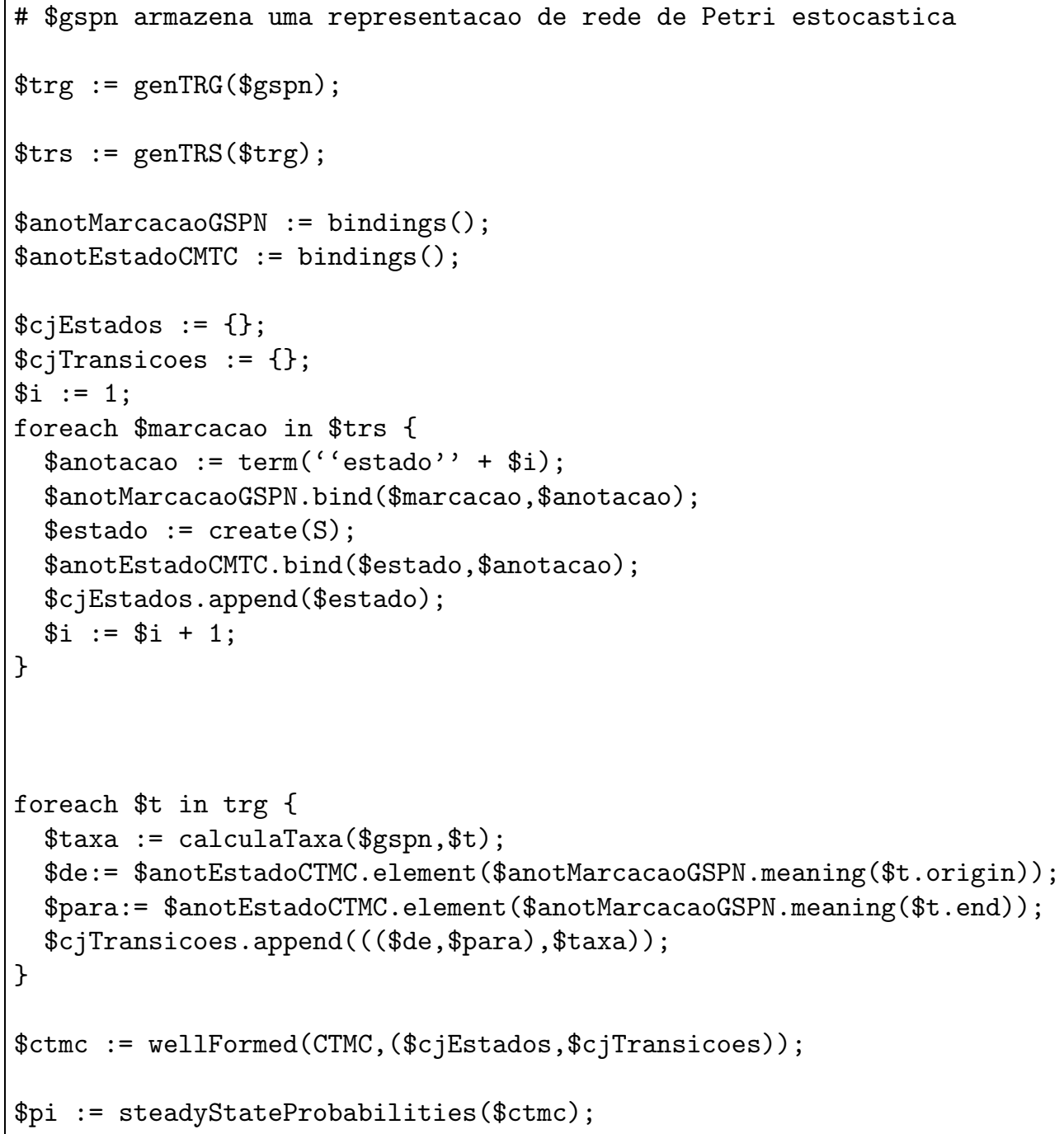

Listagem 5.13: Programa para montagem da cadeia de Markov isomórfica a uma rede de Petri estocástica 


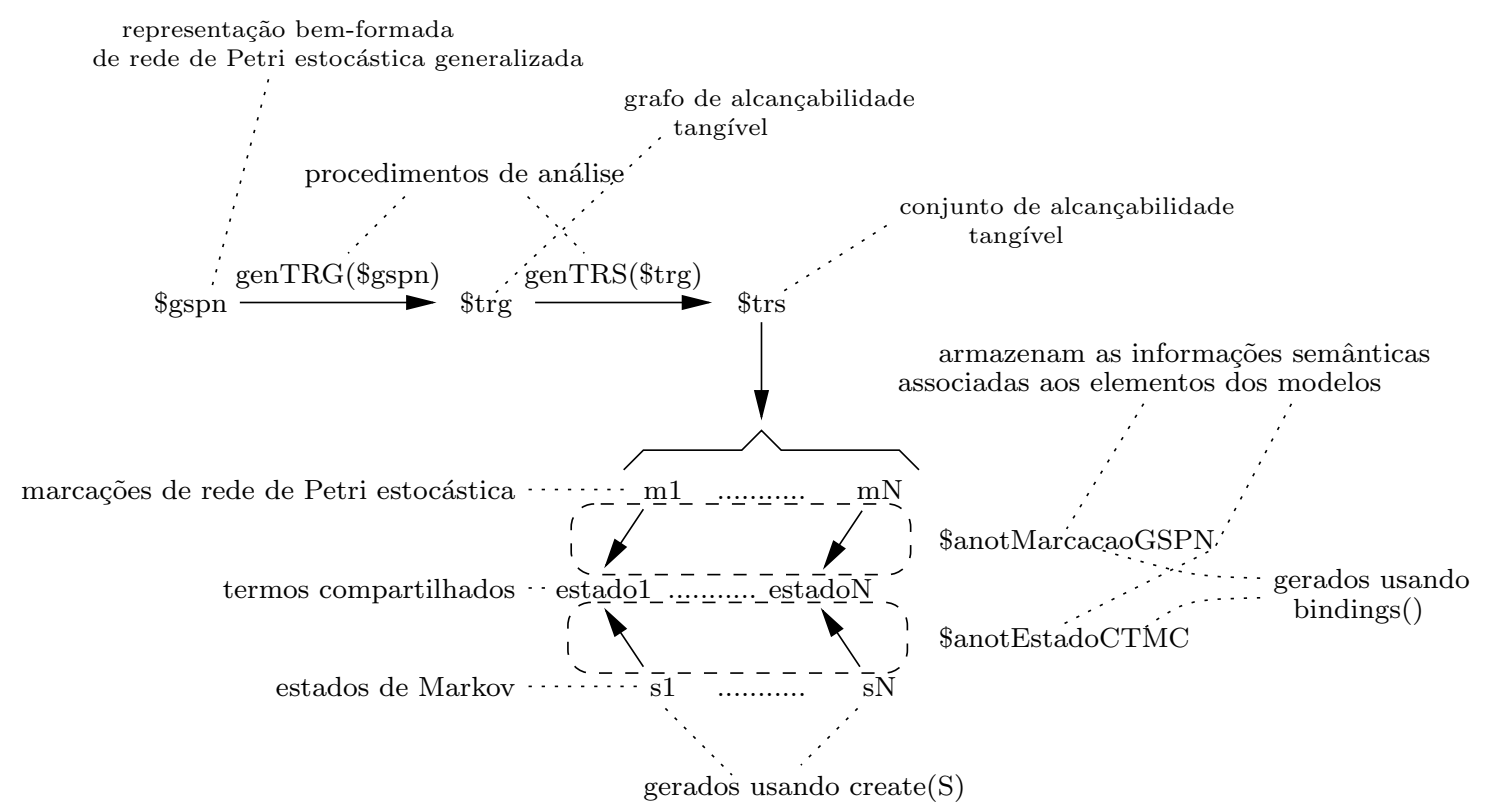

Figura 5.11: Geração de modelos e os vínculos entre elementos intermodelos

\$anotMarcacaoSPN; as associações entre os termos e os estados da cadeia de Markov são introduzidas na vinculação armazenada na variável \$anotEstadoCTMC.

A seguir, monta-se o conjunto de representações das transições entre os estados da cadeia de Markov. Para isto, usa-se o grafo de alcançabilidade tangível, que mostra como as marcações tangíveis se alteram conforme as transições disparam, segundo o metamodelo 5.12, conforme ilustrado na figura 5.12. Utilizando-se as vinculações em \$anotMarcacaoSPN e \$anotEstadoCTMC, as taxas de disparo referentes às transições da rede de Petri envolvidas na mudança de marcação e uma função para o cálculo das taxas das transições da cadeia de Markov (calculaTaxa), monta-se tal conjunto. A partir desse conjunto e do conjunto de estados da cadeia de Markov, uma representação bem-formada, em conformidade com o metamodelo CTMC da listagem 5.1, é armazenada na variável \$ctmc.

Por fim, da execução de steadyStateProbabilities (\$ctmc), obtém-se a distribuição das probabilidades de estados de regime permanente da cadeia de Markov, cujo resultado é armazenado em \$pi.

Esta é uma forma de integração entre modelos de tipos que se desenvolveram separadamente. Desta forma, todos os algoritmos implementados para cadeias de Markov de tempo contínuo (seguindo um mesmo metamodelo) podem ser 


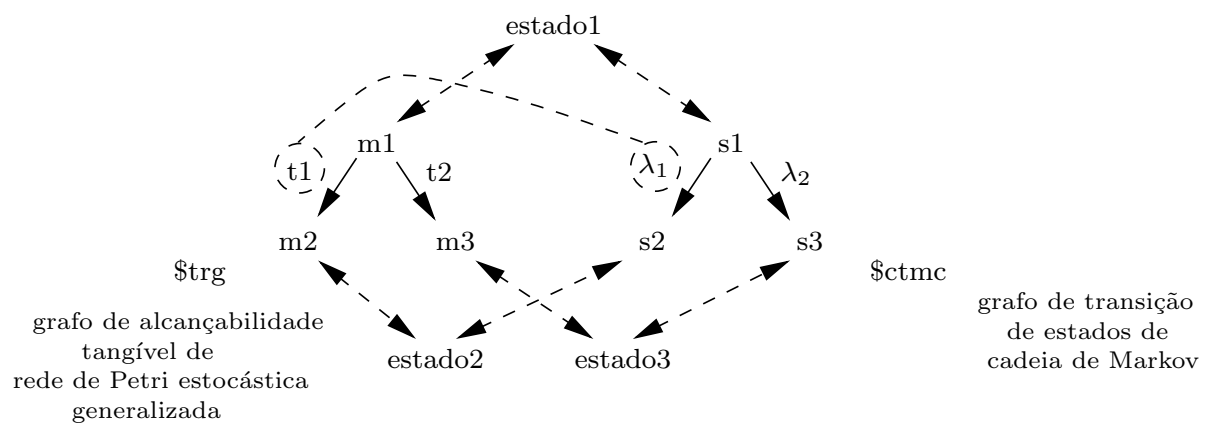

Figura 5.12: Isomorfismo

aplicados para a representação armazenada em \$ctmc.

\subsection{Exemplo: relacionamentos horizontais}

Conforme mostrado na seção 4.5, diferentes dinâmicas podem ser descritas com a utilização consistente de termos, functores e predicados. Isto fornece as bases para que procedimentos computacionais de análises comuns possam ser implementados para lidar com essas dinâmicas, conforme discutido a seguir.

Considere-se as dinâmicas modeladas pelas redes de Petri estocásticas generalizadas GSPN1, GSPN2 e GSPN3 apresentadas nas figuras 5.13, 5.14 e 5.15. Os modelos GSPN1 e GSPN2 referem-se a funcionalidades exercidas por um mesmo sistema, o mesmo descrito na seção 4.3; de fato, esses dois modelos são mais uma vez reutilizados (como na seção 5.4), sendo descritos nas seções 4.4 e 4.5 e inicialmente apresentados nas figuras 4.9 e 4.12 respectivamente.

Já o modelo GSPN3 modela a operação de um sistema, conforme ilustrado na figura 5.16, em que peças de dois tipos diferentes, as mesmas que dos outros dois exemplos e as de tipo B, são processadas alternadamente; cada tipo de peça possui um buffer (buf e bufB respectivamente), ambos com capacidade para apenas uma peça; assim, que a vaga de um buffer é liberada, uma peça do respectivo tipo é ali colocada, onde aguarda sua vez no processamento; a peças de tipo B são processadas a uma taxa $\lambda_{B}=0,30$ peça/minuto e as demais, a uma taxa de $\lambda=0,20$ peça/minuto.

As listagens 5.14, 5.15 e 5.17 apresentam um experimento envolvendo a análise dos três modelos descritos. As representações dos modelos são introduzidas no 
fim(espera(sistema,sinal(inspecao))) p1 espera(sistema,sinal(inspecao))

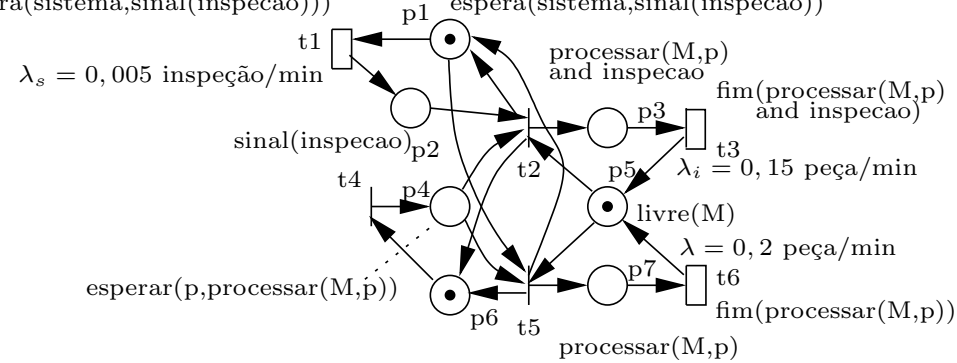

Figura 5.13: Rede de Petri estocástica generalizada GSPN1

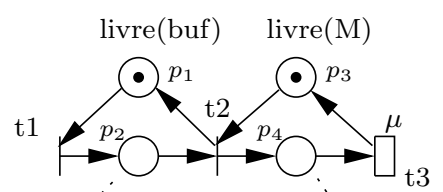

esperar(p,processar $(\mathrm{M}, \mathrm{p}))$ procèssar $(\mathrm{M}, \mathrm{p})$

$$
\lambda=0,2 \mathrm{peça} / \mathrm{min}
$$

Figura 5.14: Rede de Petri estocástica generalizada GSPN2

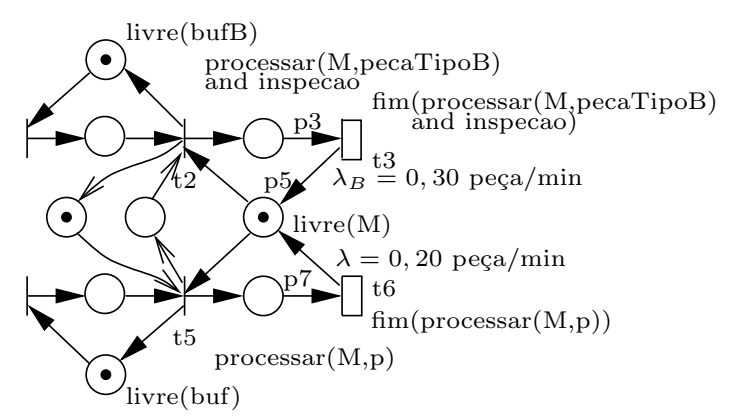

Figura 5.15: Rede de Petri estocástica generalizada GSPN3

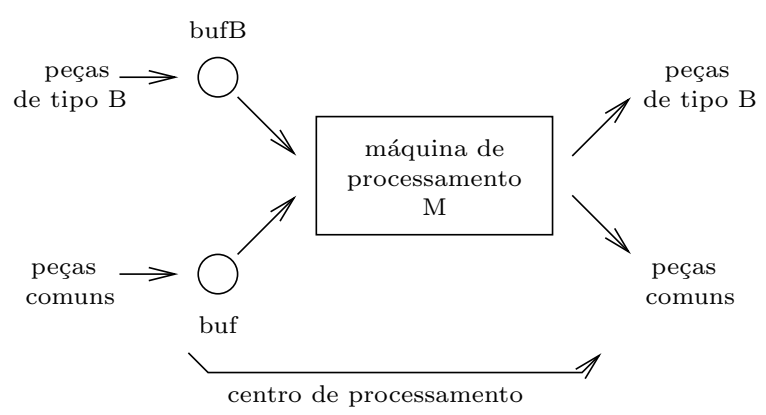

Figura 5.16: Centro de processamento para peças comuns e peças de tipo B 
conjunto referenciado pela variável \$GSPN. Cada elemento do conjunto referenciado pela variável \$anotMarcacaoGSPN trata-se de uma vinculação (gerada pelo comando bindings()), contendo as anotações relativas aos elementos de cada modelo; tal como na seção 5.4, representações e anotações correspondentes ocupam a mesma posição nos respectivos conjuntos.

A obtenção da distribuição de probabilidades de estados de regime permanente é descrita na listagem 5.14, numa implementação que é uma adaptação simples do procedimento descrito na seção anterior. Os grafos de alcançabilidade tangível, os conjuntos de alcançabilidade tangível, as cadeias de Markov e as distribuições de probabilidades de regime permanente geradas são armazenadas nos conjuntos referenciados pelas variáveis \$TRG, \$TRS, \$CTMC e \$PI respectivamente. As variáveis \$anotMarcacaoGSPN e \$anotEstadoCTMC contém as vinculações (geradas por bindings ()) que fazem a associações entre marcações tangíveis da rede de Petri estocástica e estados da cadeia de Markov através da utilização de termos comuns, numa forma que a integração decorrente do isomorfismo possa ser considerada nas representações da dinâmica (tal como indicada na seção 4.4).

Na listagem 5.15, conforme apresentada na seção 4.4, descreve-se a construção dos predicados com nomes taxa, pertence, ocorre e probabilidade. Os elementos do conjunto referenciado pela variável \$dinamica são conjuntos de predicados referentes às dinâmicas analisadas, apresentados na listagem 5.16.

Cada um dos conjuntos da listagem 5.16 traz uma representação da dinâmica em termos das informações semânticas associadas aos modelos gerados. A adequação desta representação está no fato de que os aspectos comuns tratados pelos vários modelos são representados de uma maneira consistente, não escondendo relações existentes e não insinuando relações inexistentes, o que, do contrário, limita o aproveitamento da integração dos modelos. Tal representação também acaba por amenizar a heterogeneidade dos modelos que são a fonte das informações descritas: com esta representação, não é necessário lidar com as diferenças estruturais dos diferentes modelos, facilitando a visualização da informações e seu tratamento.

De fato, é fácil perceber que existe uma parte importante comum aos conjuntos de predicados, em termos de vocabulário e em termos de construções sentenciais. Esta é a base da consistência horizontal, que permite visualizar as partes 


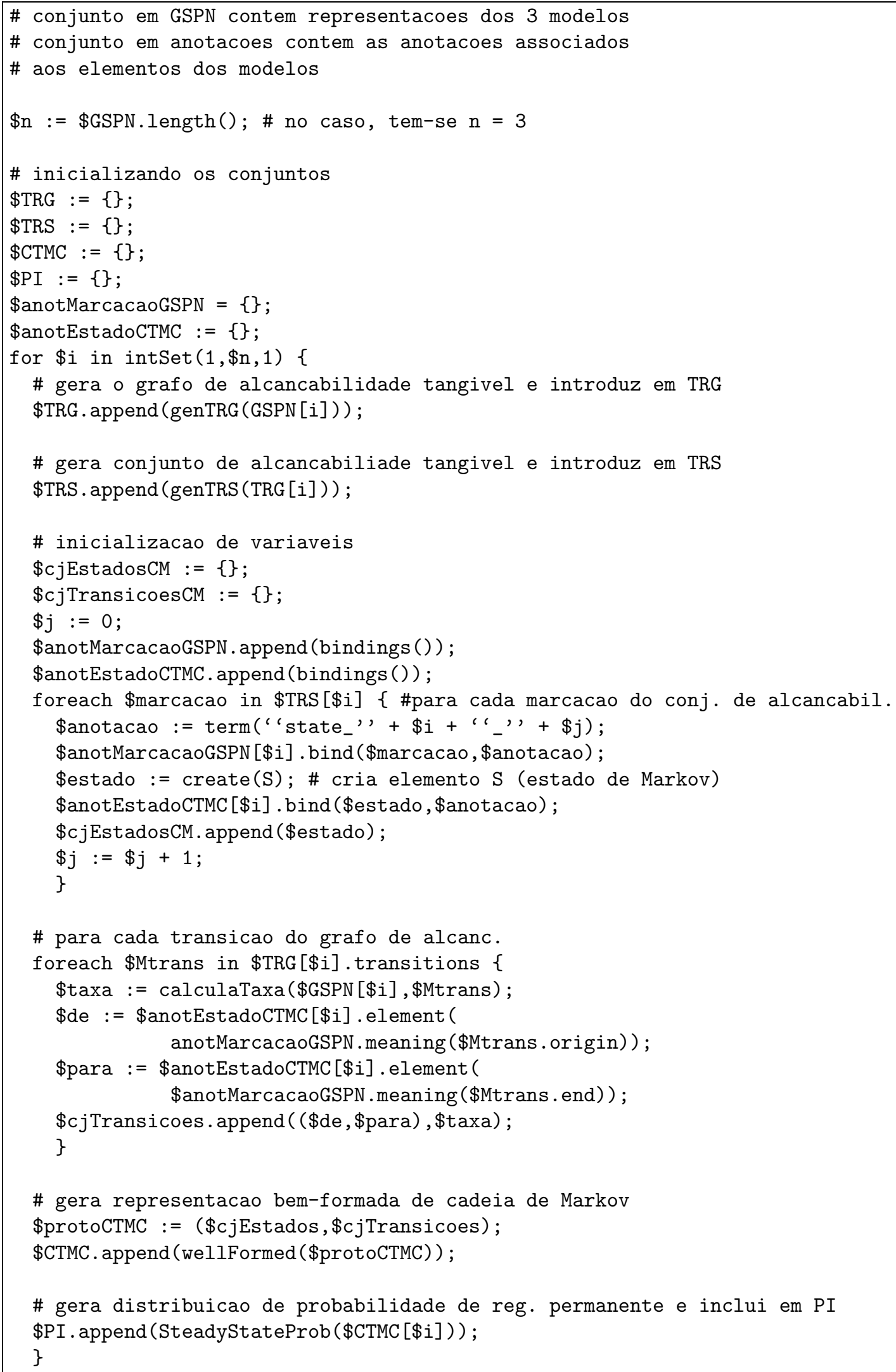

Listagem 5.14: Experimento: montagem e análise de modelos 


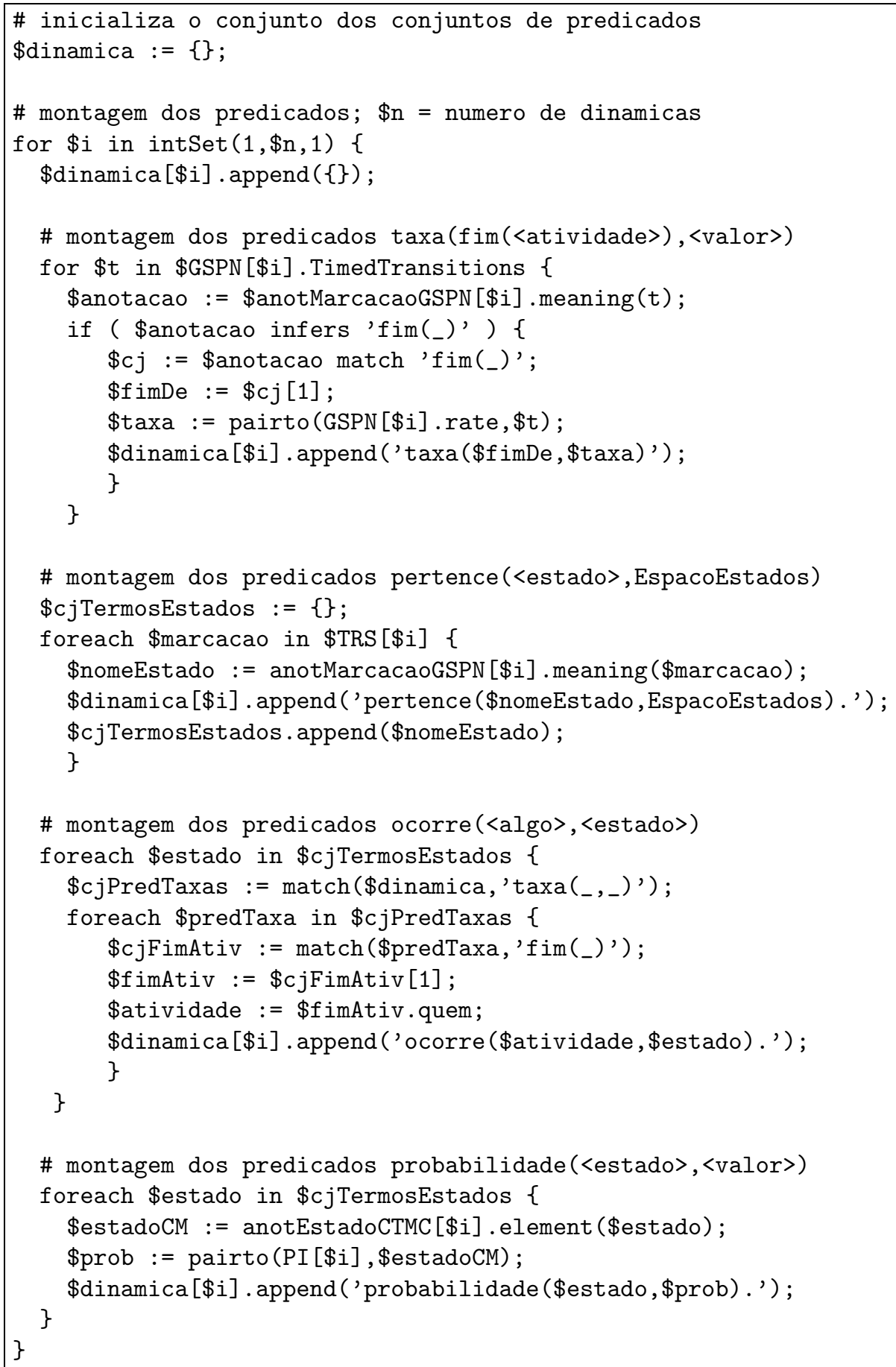

Listagem 5.15: Experimento: montagem dos conjuntos de predicados 


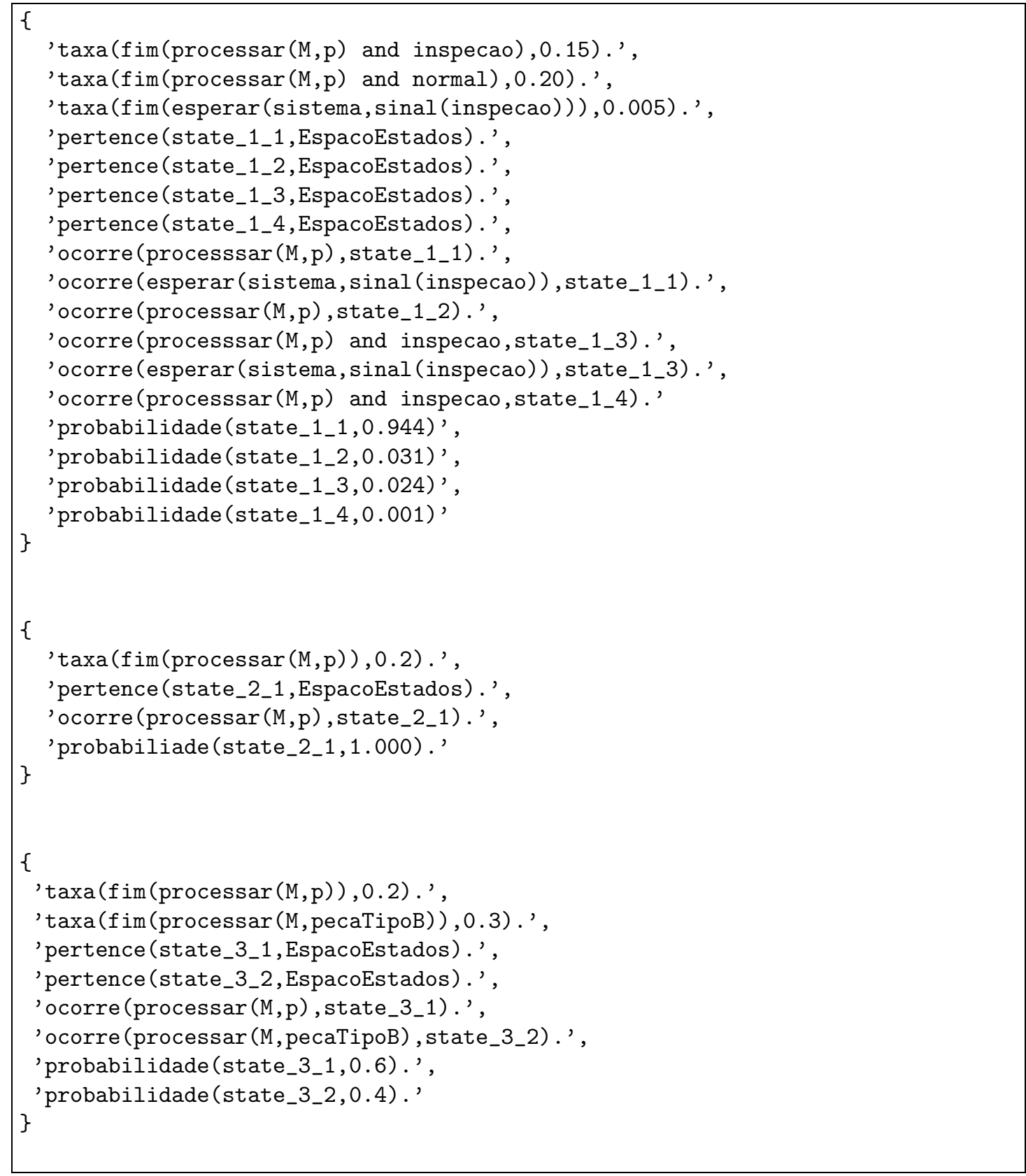

Listagem 5.16: Experimento: conjuntos de predicados referentes às dinâmicas modeladas pelas redes de Petri estocásticas apresentadas nas figuras 5.13, 5.14 e 5.15 


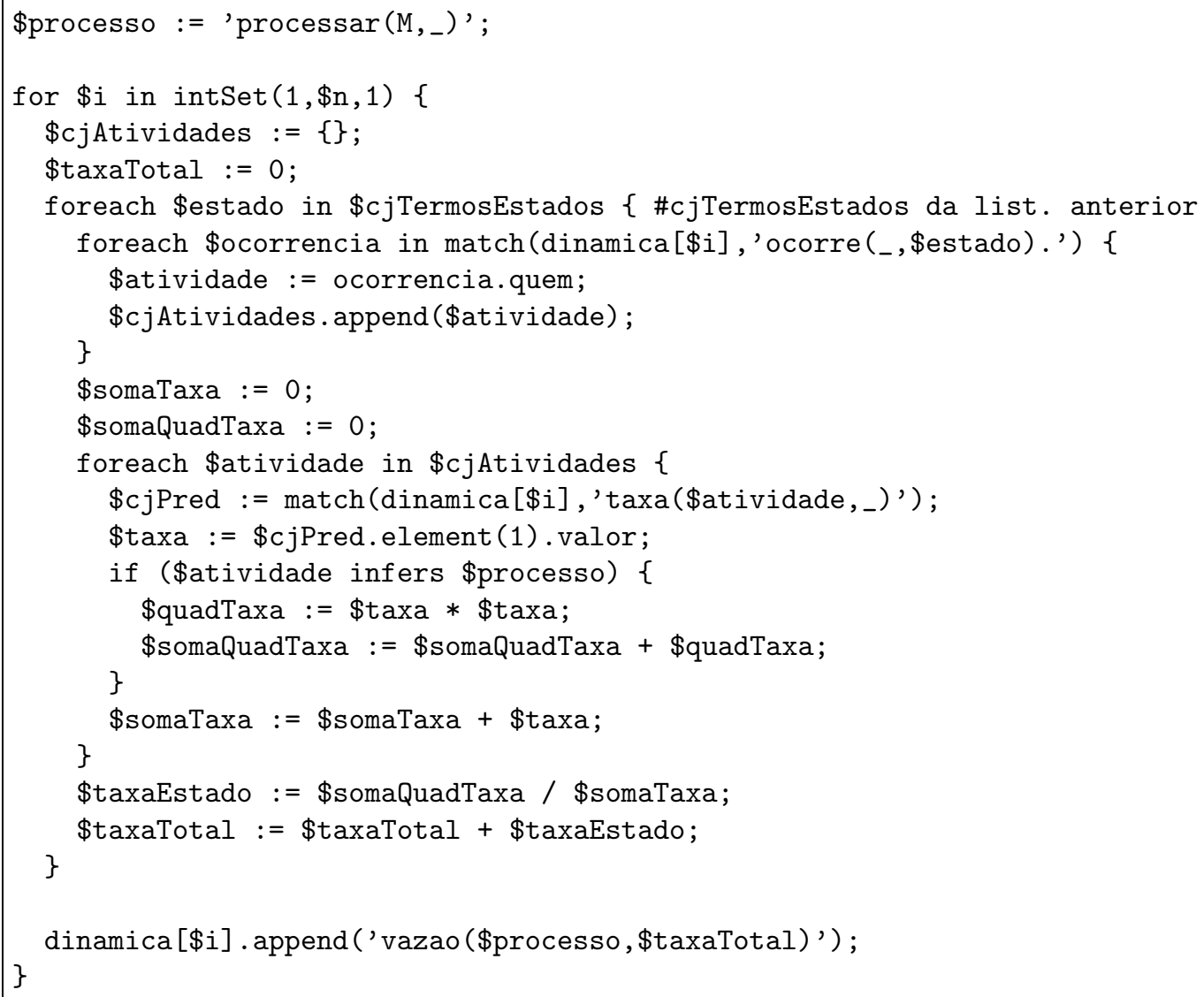

Listagem 5.17: Experimento: análise horizontal

comuns e as diferenças entre as descrições. Na listagem 5.17, com base nas partes comuns entre os conjuntos, implementa-se um procedimento, tal como descrito na seção 4.5, para o cálculo da taxa de finalização de processamento da máquina M. É importante notar que, apesar das informações representadas serem originadas de modelos de SEDs, a análise é feita com base apenas nos conjuntos de predicados.

É interessante observar que, se a taxa de finalização de processamento pela máquina $\mathrm{M}$ desejada fosse apenas àquela referente ao processamento de peças "normais" (excluindo a peças de tipo A), bastaria utilizar, na atribuição à variável processo, o functor processar (M,p) no início da listagem 5.17.

\subsection{Comentários do capítulo}

A linguagem apresentada neste capítulo tem os elementos básicos para lidar com a heterogeneidade matemático-formal dos modelos de SEDs e com a 
integração via representação de informação semântica.

Com relação à heterogeneidade dos modelos de SEDs, a linguagem mostra que uma variedade ampla de tipos de modelos podem ser representada (isto é, com abrangência), de forma simples e com relativamente poucos elementos (isto é, com uniformidade). Apresenta mecanismo de disjunção baseados em tipos, de modo que não haja confusão entre as representações de modelos de diversos tipos (conforme descrito na subseção 3.2.3). Relacionado com esta questão, um elemento importante da linguagem são os metamodelos, que descrevem a composição e estrutura das representações dos modelos dos tipos a que se referem e, para isso, são utilizados os recursos de definição de tipos complexos da linguagem. Como foi observado na subseção 3.2.4, além do papel de referências, os metamodelos são também importantes para evitar redundâncias de representações.

Com relação à representação de informação semântica, esta foi baseada em predicados e elementos afins (seguindo o que foi apresentado no capítulo 4). Para que essas informações sejam efetivamente úteis, é preciso que possam ser processadas computacionalmente. Assim, a linguagem apresenta meios para associar tais informações a elementos dos modelos (tal como no caso das anotações apresentadas no capítulo 4), para acessar os componentes dos predicados e dos functores e expressões e para realizar formas básicas de inferências (como no caso dos operadores infers e do comando match).

Nos exemplos apresentados, pode-se verificar:

- que se pode representar uma grande variedade de tipos de modelos de SEDs;

- que a linguagem permite o pleno uso de estruturas intermediárias, o que é importante no caso em que modelos compartilham partes ou quando da presença de padrões repetitivos nos modelos;

- que as informações nas anotações dos elementos dos modelos, desde que representadas e tratadas adequadamente, podem ser úteis na construção de representações, algumas das quais mostram acoplamentos entre elementos dos modelos que não são óbvios somente com o modelo em si — é interessante notar que as informações das anotações simplesmente documentam aquelas que são utilizadas na elaboração de modelos (conforme descrito na seção 2.4); 
- que, da mesma forma que ajudam na construção de representações, a consistência da representação de informação semântica é útil no aproveitamento dos relacionamentos horizontais, desde que a consistência abranja diferentes dinâmicas.

Com relação à representação dos modelos orientada às análises matemáticas, os elementos fornecidos pela linguagem LiMA permitem atender a várias questões que podem dificultar o trabalho com modelos heterogêneos. Apesar de sua simplicidade, além de poder expressar vários tipos de modelos, destaca-se também a igual simplicidade das operações para lidar com as estruturas elaboradas, que é reflexo da forma de expressar as representações.

No que diz respeito ao conjunto de predicados, pode-se, também, perceber dos exemplos que, quanto maior o volume de informações a lidar, quanto maior a necessidade de manipulação das informações associadas aos modelos, mais evidente fica o benefício de uma descrição integrada das informações associadas aos modelos. Isso ocorre pois diminui-se o contato com estruturas heterogêneas de organização de informações que são as formas assumidas pelos modelos matemáticos de SEDs (impostas pelos formalismos e pelas hipóteses das técnicas de análise de tais modelos).

Em termos dos diagramas apresentados no capítulo 3, a linguagem apresentada pode ser representada pelo diagrama da figura 5.17. Na figura, pode-se observar o papel das proto-representações como estruturas intermediárias e que o conjunto de estruturas válidas (conjunto-alvo da linguagem de composição) é formado pelas representações bem-formadas e pelos conjuntos de predicados (representados pela área com perímetro tracejado-pontilhado). Os arcos com setas nas duas pontas mostram as associações entre os elementos dos modelos com os predicados: é importante notar que as associações referentes a modelos que descrevem uma mesma dinâmica envolvem o mesmo conjunto de predicados.

De certa forma, os conjuntos de predicados podem ser vistos como modelos, uma vez que descrevem, de forma abstrata, aspectos de interesse de determinada dinâmica. Uma diferença importante é que, enquanto que, na elaboração dos modelos para análise de SEDs, deve-se adequar as informações da dinâmica de forma a se encaixarem nos formalismos dos modelos, os conjuntos de predicados têm um caráter mais interpretativo, no sentido de que procuram explicitar in- 


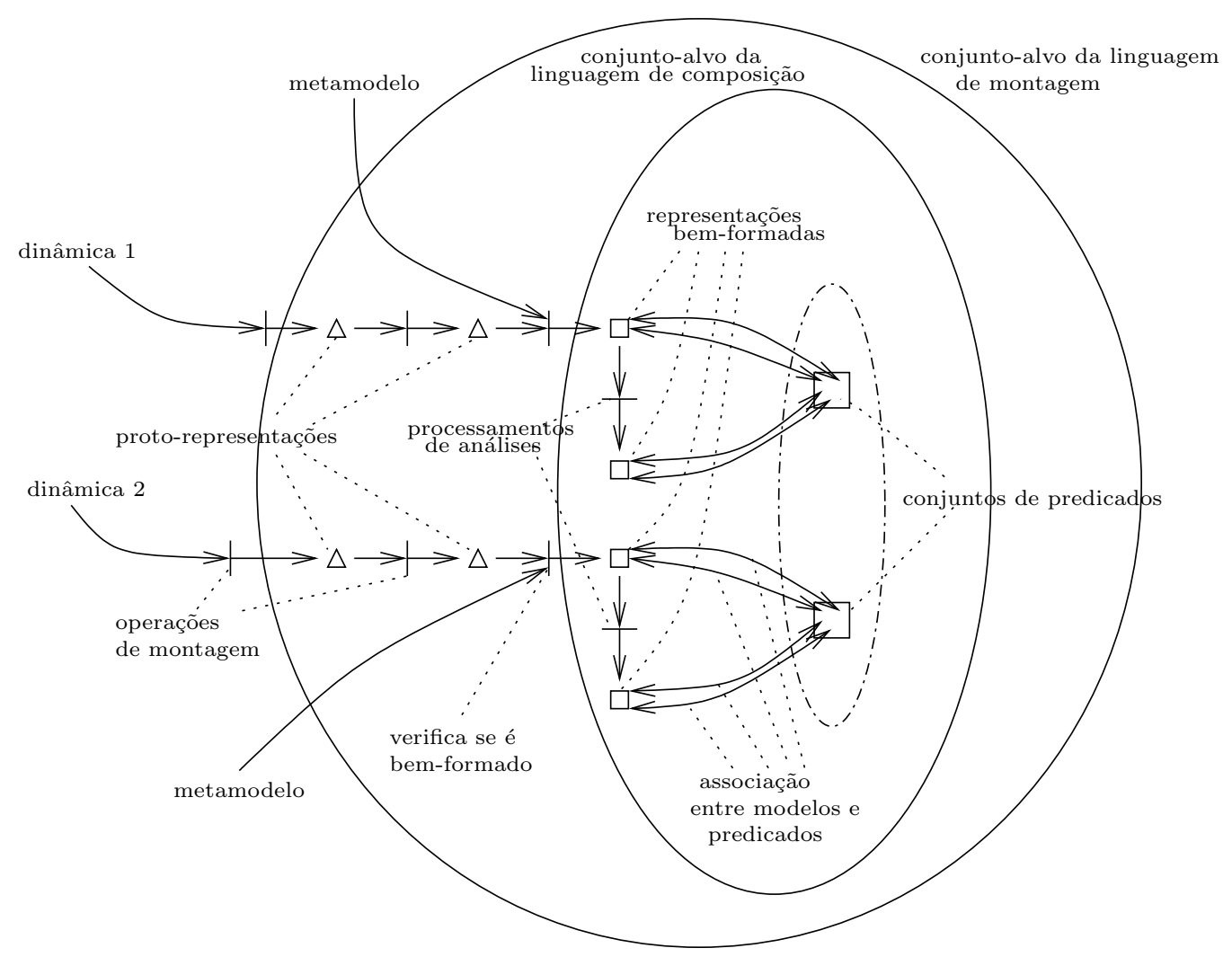

Figura 5.17: Diagrama de conjuntos-alvos para a linguagem LiMA

formações referentes a relacionamentos importantes para visualizar a integração das informações associadas a diferentes modelos. 


\section{Conclusões}

Foi apresentado, no capítulo 2, o quadro de heterogeneidade dos modelos de SEDs e suas razões. Mostrou-se, também, como modelos heterogêneos são utilizados, de forma integrada, a fim de tirar proveito do melhor de cada um. Também, que a questão da representação computacional desses modelos é importante para que sistemas de suporte computacionais possam dar um apoio amplo e adequado às atividades de experimentos envolvendo modelagem e análise de SEDs.

O capítulo 3 mostrou como um AMA com uma linguagem de modelagem voltada para modelos heterogêneos de SEDs se mostra mais vantajoso que configurações envolvendo diversas implementações de AMAs e diversas linguagens de modelagem. Um conjunto de características para que um AMA propicie um racional fluxo de trabalho nos experimentos foi apresentado e justificado, dentre as quais se destaca a abrangência e a uniformidade na representação de modelos heterogêneos de SEDs. A grande vantagem da uniformidade é que as representações de modelos de vários tipos podem ser manipuladas computacionalmente através de um mesmo conjunto de operações computacionais. Estas características vão no sentido de maximizar a compatibilização da heterogeneidade matemático-formal dos modelos de SEDs. Um outro ponto importante e que deve ficar claro é que essas características são ainda mais importantes quanto maior o grau de heterogeneidade de modelos e maior o grau de integração entre modelos. Cabe, também, destacar a utilização dos diagramas de conjuntos-alvos que permitem visualizar, de maneira eficaz, as diversas configurações de AMAs e as diversas interações entre o poder de expressão, a capacidade de montar estruturas, os procedimentos de análise e a heterogeneidade dos modelos de SEDs.

Mesmo com a compatibilização obtida via abrangência e uniformidade na representação de modelos heterogêneos de SEDs, a heterogeneidade inerente dos modelos não pode ser eliminada. Assim, principalmente no que se refere à in- 
terpretação dos modelos e dos resultados de suas análises, as diferenças na composição e estrutura dos modelos continuam sendo um obstáculo, mesmo no caso em que se referem a um mesma dinâmica. A abordagem adotada no capítulo 4 foi da representação de informações semânticas associadas aos modelos através de predicados e elementos afins. A partir das informações obtidas dos modelos sendo integrados, são elaborados conjuntos de predicados que descrevem a dinâmica por eles modelada, com os quais se pode visualizar as relações entre as informações obtidas dos diversos modelos, numa forma em que a heterogeneidade dos modelos é transparente. A característica importante nessas descrições é a consistência na representação das informações semânticas, pois, com ela:

- pode-se evitar que relacionamentos importantes fiquem escondidos nas informações referentes aos modelos;

- pode-se evitar que relações inexistentes possam ser inferidas;

- cria-se bases para a comparação, uma vez que deixa claro o que é igual e o que é diferente a partir das representações de diferentes situações descritas.

No capítulo 5, a linguagem LiMA mostrou como a abrangência e a uniformidade de representação com relação à heterogeneidade matemático-formal dos modelos de SEDs podem ser implementadas de modo relativamente simples. Mostrou-se, também, como a representação de informação semântica pode ser implementada. Nos exemplos apresentados, diversos aspectos discutidos nos capítulos anteriores foram ilustrados (mecanismos de disjunção, uso de metamodelos como referências, o aproveitamento de estruturas intermediárias na construções de representações de diversos modelos, uso de informação semântica na construção das representações e a análise baseada em consistência horizontal de representações). Nesses exemplos, fica claro que, além da capacidade de expressar informações, deve haver recursos adequados para processar suas representações, sem o que não haveria um aproveitamento eficaz dessas informações.

Um aspecto a destacar das informações semânticas representadas é que estão relacionadas com os mapeamentos entre modelo e dinâmica modelada. Tais mapeamentos são estabelecidos no processo de modelagem, de modo que sua representação desempenha, nesse contexto, um papel documental desse processo.

Ainda sobre as informações semânticas, pelos exemplos apresentados no texto, 
percebe-se a sua importância na consideração da horizontalidade nos experimentos de modelagem e análise, tanto em termos de montagem de representações de modelos como de interpretação das informações de modelos que se integram. Essa questão é fundamental, pois importantes decisões sobre qual a configuração de sistema é adequada (segundo algum critério) dependem da comparação de diversas configurações. De fato, quanto mais fatores e quanto mais níveis desses fatores (JAIN, 1991), maior a quantidade de configurações a lidar. Isso se traduz em mais modelos a montar e a analisar e, portanto, um suporte computacional adequado torna-se essencial e a representação das informações semânticas mostrase um elemento com significativas contribuições. Certamente, o fato de lidar com muitos tipos de modelos se beneficia, também, da abrangência e uniformidade no tratamento da heterogeneidade matemático-formal dos modelos.

Ao longo do trabalho, fica claro que a adequação das formas de representação das informações, em especial no caso de modelos de SEDs, é importante em termos de eficiência e qualidade na realização de experimentos de modelagem e análise de SEDs. Porém, a representação desses elementos não é para ser feita incondicionalmente: dentro de uma racionalidade de custo/benefício, deve haver uma infraestrutura para que o esforço em elaborá-la seja compensado pelos resultados obtidos. Ou seja, além da questão da abrangência e uniformidade no tratamento da heterogeneidade matemático-formal dos modelos de SEDs e da consistência na representação de informações semânticas dos modelos, é preciso que se desenvolva meios que permitam elaborar tais representações de forma eficiente e, também, processá-las de forma a tirar o máximo proveito dessas informações. Nesse aspecto, o papel da representação é central, pois é de sua forma que depende a configuração dessa infraestrutura (basta lembrar a simplicidade das operações da LiMA decorrente dos poucos, mas abrangentes, elementos de estruturação de modelos e da acessibilidade e inferabilidade das descrições baseadas em predicados). Portanto, essa infraestrutura é uma outra dimensão da adequação das representações que foram tratadas neste trabalho.

Com isto, o trabalho atingiu os objetivos a que se propôs, equacionando e identificando os elementos importantes para proporcionar um fluxo de trabalho eficiente ao lidar com a heterogeneidade matemático-formal dos modelos de SEDs e explicitando o modo como a representação de informações semânticas associadas aos modelos pode ser utilizada para tirar efetivo proveito da integração de modelos 
heterogêneos de SEDs.

Por fim, há alguns pontos que ainda merecem ser considerados, dos quais pode-se citar:

- o desenvolvimento de mecanismos, como os de herança (BOOCH; RUMBAUGH; JACOBSON, 1998) e outros a investigar (por exemplo, hibridização de tipos de modelos), que possam auxiliar na definição de novos tipos de modelos;

- a pesquisa de outras formas de representar informações semânticas (SOWA, 2002);

- o desenvolvimento de padrões para expressão de entidades, fatos e relacionamentos que possam ser utilizados, de modo sistematizado, nas descrições semânticas a associar aos modelos;

- o desenvolvimento de uma metodologia para a especificação de informações semânticas associadas aos modelos. 


\section{Referências}

ANDREWS, J.; DUGAN, J. Dependency modelling using fault tree analysis. In: INTERNATIONAL SYSTEM SAFETY CONFERENCE, 17., 1999. Proceedings... [S.l.: s.n.], 1999. p. 67-76.

ARATA, W. M.; MIYAGI, P. E. Uniform computational treatment of heterogeneous discrete-event dynamic system models. In: IEEE INTERNATIONAL CONFERENCE ON EMERGING TECHNOLOGIES AND FACTORY AUTOMATION,9., 2003, Lisboa. Proceedings... [S.l.]: IEEE, 2003. v. 1, p. 47-53. ISBN 0-7803-7937-3.

ARATA, W. M.; MIYAGI, P. E. Ambiente Integrado de Análise de Sistemas de Manufatura. São Paulo: Escola Politécnica da Universidade de São Paulo, 2005. (Boletim Técnico, BT/PMR/0503).

BASHARIN, G. P.; LANGVILlE, A. N.; NAUMOV, V. A. The Life and Work of A. A. Markov. Linear Algebra and its Applications, v. 386, p.3-26, 2004.

BAUSE, F.; BUCHHOLZ, P. Queueing petri nets with product form solution. Performance Evaluation, v. 32, n. 4, p. 165-299, 1998.

BOLCH, G.; GREINER, S.; MEER, H.; TRIVEDI, K. S. Queueing Networks and Markov Chains: modeling and perfomance evaluation with computer science applications. New York: Wiley-Interscience, 1998. ISBN 0-471-19366-6.

BOOCH, G. Object-Oriented Design with Applications. Redwood City: Benjamin/Cummings, 1991. ISBN 0-805-30091-0.

BOOCH, G.; RUMBAUGH, J.; JACOBSON, I. The Unified Modeling Language User Guide. Reading: Addison-Wesley, 1998. ISBN 0-201-57168-4.

BORGIDA, A.; MYLOPOULOS, J. Data semantics revisited. In: SWDB. Toronto: [s.n.], 2004. v. 3372, p. 9-26. ISBN 3-540-24576-6.

CAMPOS, J.; COLOM, J. M.; JUNGNITZ, H.; SILVA, M. Approximate throughput computation of stochastic marked graphs. IEEE Trans. Softw. Eng., IEEE Press, v. 20, n. 7, p. 526-535, 1994. ISSN 0098-5589.

CAO, X.-R. A comparison of the dynamics of continuous and discrete event systems. Proceedings of IEEE, v. 77, p. 7-13, 1989. 
CARDELLI, L.; WEGNER, P. On understanding types, data abstraction, and polymorphism. ACM Computing Surveys, v. 17, n. 4, p. 471-522, 1985.

CARDoso, J.; VAletTe, R. Redes de Petri. Florianópolis: Editora da UFSC, 1997.

CASSANDRAS, C. G. Discrete Event Systems: Modeling and

Performance Analysis. Burr Ridge: Richard D. Irwin Inc., 1993. ISBN 0-256-11212-6.

CHIOLA, G.; DONATELLI, S.; FRANCESCHINIS, G. GSPNs versus SPNs: What is the actual role of immediate transitions? In: INTERNATIONAL WORKSHOP ON PETRI NETS AND PERFORMANCE MODELS (PNPM'91), 4., 1991, Melbourne. Proceedings... [S.l.]: IEEE Computer Society Press, 1991. p. 20-31.

CHRISTENSEN, S.; HANSEN, N. D. Coloured petri nets extended with place capacities, test arcs and inhibitor arcs. In: INTERNATIONAL CONFERENCE ON APPLICATION AND THEORY OF PETRI NETS, 14., 1993, Illinois.

Proceeedings... [S.l.]: Springer, 1993. p. 186-205. (Lecture Notes in Computer Science, v. 691). ISBN 3-540-56863-8.

CIARDO, G.; III, R. L. J.; MINER, A. S.; SIMINICEANU, R. Logical and stochastic modeling with smart. In: INTERNATIONAL CONFERENCE TOOLS 2003, 13., 2003, Urbana. Proceedings... [S.1.]: Springer, 2003. p. 78-97. (Lecture Notes in Computer Science, v. 2794). ISBN 3-540-40814-2.

CIARDO, G.; JONES, R. L.; MINER, A. S.; SIMINICEANU, R. Smart: Stochastic model analyzer for reliability and timing. In: TOOLS OF AACHEN 2001 INTERNATIONAL MULTICONFERENCE ON MEASUREMENT, MODELING AND EVALUATION OF COMPUTER-COMUNICATINO SYSTEMS, 2001, Aachen. Proceedings... [S.1.:s.n.], 2001. p. 29-34.

CIARDO, G.; LINDEMANN, C. Analysis of deterministic and stochastic petri nets. In: INTERNATIONAL WORKSHOP ON PETRI NETS AND PERFORMANCE MODELS (PNPM93), 5., 1993, Toulouse. [S.l.]: IEEE Computer Society Press, 1993. p. 160-169.

CIARDO, G.; MINER, A. S. Smart: Simulation and markovian analyzer for reliability and timing. In: INTERNATIONAL COMPUTER PERFORMANCE AND DEPENDABILITY SYMPOSIUM (IPDS '96), 2., 1996. Proceedings... [S.1.]: IEEE Computer Society, 1996. p. 60. ISBN 0-818-67484-9.

COHEN, G.; DUBOIS, D.; QUADRAT, J.; VIOT, M. A linear system-theoretic view of discreteevent processes and its use for performance evaluation in manufacturing. IEEE Transactions on Automatic Control, AC-30, p. 210-220, 1985.

CRUZ, I. F.; RAJENDRAN, A.; SUNNA, W.; WIEGAND, N. Handling semantic heterogeneities using declarative agreements. In: ACM INTERNATIONAL 
SYMPOSIUM ON ADVANCES IN GEOGRAPHIC INFORMATION SYSTEMS (GIS'02), 10., 2002, New York. Proceedings... New York, NY, USA: ACM Press, 2002. p. 168-174. ISBN 1-581-13591-2.

DEAVOURS, D. D.; SANDERS, W. H. Möbius: Framework and atomic models. In: INTERNATIONAL WORKSHOP ON PETRI NETS AND PERFORMANCE MODELS, 9., 2001, Aachen. Proceedings... [S.l:s.n.], 2001. p. 251-260.

DERANSART, P.; CERVONI, L.; ED-DBALI, A. Prolog: the standard: reference manual. London, UK: Springer-Verlag, 1996. ISBN 3-540-59304-7.

FRICKS, R.; HIREL, C.; WELLS, S.; TRIVEDI, K. The development of an integrated modeling environment. In: WORLD CONGRESS ON SYSTEMS SIMULATION (WCSS '97), JOINT CONFERENCE OF INTERNATION SIMULATION SOCIETIES, 2., 1997, Singapore. Proceedings... [S.l.:s.n.], 1997. p. 471-476.

GELENBE, E.; PUJOLLE, G. Introduction to Queueing Networks. [S.l.]: John Wiley \& Sons, 1987. ISBN 0-471-90464-3.

GENRICH, H. J. Predicate/transition nets. Advances in Petri nets 1986, part I on Petri nets: central models and their properties. [S.l.]: Springer-Verlag, 1987. p. 207-247. ISBN 0-387-17905-4.

HASEGAWA, K.; MIYAGI, P. E.; SANTOS-FILHO, D. J.; TAKAHASHI, K.; MA, L. Q.; SUGISAWA, M. On resource arcs for petri net modeling of complex shared resrouces systems. Journal of Intelligent and Robotics Systems, v. 26, n. $3 / 4$, p. $423-437,1999$.

HASEGAWA, K.; TAKAHASHI, K.; MIYAGI, P. E. Application of the mark flow graph to represent discrete event production systems and system control. Transactions of the Society of Instrument and Control Engineers, v. 24, n. 1, p. 69-75, 1988.

HIREL, C.; SAHNER, R. A.; ZANG, X.; TRIVEDI, K. S. Reliability and performability modeling using sharpe 2000. In: INTERNATIONAL CONFERENCE ON COMPUTER PERFORMANCE EVALUATION: MODELING TECHNIQUES AND TOOLS, 11., 2000, Schaumburg, IL, USA. Computer Performance Evaluation / TOOLS. [S.l.]: Springer, 2000. p. 345-349. (Lecture Notes in Computer Science, v. 1786). ISBN 3-540-67260-5.

HOWARD, R. Dynamic Probabilistic Systems. New York: John Wiley \& Sons, 1971. ISBN 0-471-41665-7.

JAIN, R. The art of computer systems performance analysis. New York: John Wiley and Sons, 1991. ISBN 0-471-50336-3.

KLEINROCK, L. Queueing Systems. New York: John Wiley and Sons, 1975. ISBN 0-471-49110-1. 
KULKARNI, V. G. Modeling and Analysis of Stochastic Systems.

London: Chapman \& Hall, 1995. ISBN 0-412-04991-0.

LAKOS, C. A. The Object Orientation of Object Petri Nets. In: INTERNATIONAL WORKSHOP ON OBJECT-ORIENTED PROGRAMMING AND MODELS OF CONCURRENCY, 1., INTERNATIONAL CONFERENCE ON APPLICATION AND THEORY OF PETRI NETS, 16., 1995, Torino. Proceedings... [S.l:s.n.], 1995. p. 1-14.

MACKAY, D. S. Semantic integration of environmental models for application to global information systems and decision-making. SIGMOD Record, v. 28, n. 1, p. 13-19, 1999.

MARCOTTY, M.; LEDGARD, H. Programming Language Landscape:

Syntax, Semantics, and Implementation. New York: Macmillan Publishing Company, 1986. ISBN 0-574-21945-5.

MARKOV, A. A. Rasprostranenie zakona bol'shih chisel na velichiny, zavisyaschie drug ot druga. Izvestiya Fiziko-matematicheskogo obschestva pri Kazanskom universitete, 2-ya seriya, tom 15, p. 135-156, 1906.

MARSAN, M. A.; CONTE, G.; BALBO, G. A class of generalized stochastic petri nets for the performance evaluation of multiprocessor systems. ACM Transactions on Computer Systems, v. 2, n. 2, p. 93-122, May 1984.

MIYAGI, P. E.; HASEGAWA, K.; TAKAHASHI, K. A programming language for discrete event production systems based on production flow schema and mark flow graph. Transactions of the Society of Instrument and Control Engineers, v. 24, n. 2, p. 183-190, 1988.

MIYAGI, P. E.; SANTOS-FILHO, D. J.; ARATA, W. M. Design of deadlock avoidance compensators for anthropocentric production systems. Advanced Network Enterprises. [S.l.]: Kluwer Academic Publishers, 2000. (IFIP Conference Proceedings, v. 181), p. 287-294. ISBN 0-7923-7958-6.

MOLLOY, M. K. Performance analysis using stochastic petri nets. IEEE Transactions on Computers, C-31, n. 9, p. 913-917, 1980.

MOORSEL, A.; HUANG, Y. Reusable software components for performability tools, and their utilization for web-based configurable tools. Lecture Notes in Computer Science 1469, p. 37-50, 1998.

MURATA, T. Petri nets: Properties, analysis and applications. Proceedings of IEEE, v. 77, n. 4, p. 541-580, 1989.

NEUTS, M. Matrix-Geometric Solutions in Stochastic Models: An Algorithmic Approach. Baltimore: Johns Hopkins University Press, 1981. ISBN 0-486-68342-7.

ORSINI, L. Q. Introdução aos Sistemas Dinâmicos. Rio de Janeiro: Guanabara Dois, 1985. 
PETERSON, J. Petri net theory and the modeling of systems. Englewood Cliffs: Prentice-Hall, 1981. ISBN 0-136-61983-5.

PETRI, C. A. Kommunikation mit automaten. 1962. Tese (Doutorado) Institut für Instrumentelle Mathematik, Bonn, 1962.

SANDERS, W. H.; COURTNEY, T.; DEAVOURS, D.; DALY, D.; DERISAVI, S.; LAM, V. Multi-formalism and multi-solution-method modeling frameworks: The möbius approach. In: SYMPOSIUM OF PERFORMANCE EVALUATION - STORIES AND PERSPECTIVES, 2003, Vienna, Austria. Proceedings... [S.l.: s.n.], 2003. p. 241-256.

SANDERS, W. H.; MEYER, J. F. Stochastic activity networks: formal definitions and concepts. In: EEF/EURO SUMMER SCHOOL ON TRENDS IN COMPUTER SCIENCE, 1., 2002. Lectures on formal methods and performance analysis: first EEF/Euro summer school on trends in computer science. Springer-Verlag New York, Inc., p. 315-343, 2002.

SHETH, A. P. Panel: Data semantics: what, where and how? In: MEERSMAN, R.; MARK, L. (Ed.). DS-6. London: Chapman \& Hall, 1995. (IFIP Conference Proceedings, v. 74), p. 601-610. ISBN 0-412-72600-9.

SILVA, E.; R.R.MUNTZ. Métodos Computacionais de Solução de Cadeias de Markov: Aplicações A Sistemas de Computação e Comunicação. Gramado, 1992.

SMITH, A. A Riqueza das Nações: Investigação sobre sua natureza e suas causas. Tradução de João Luiz Baraúna. São Paulo: Nova Cultural, 1985.

SOWA, J. F. Semantic Networks. 2002. Disponível em: <http: //www.jfsowa.com/pubs/semnet.htm>. Acesso em: 05 de jun. de 2005.

STEWART, G. Introduction to Matrix Computations. Boston: Academic Press, 1972. ISBN 0-12-670350-7.

TRIVEDI, K. S. Sharpe 2002: Symbolic hierarchical automated reliability and performance evaluator. In: DSN. [S.l.]: IEEE Computer Society, 2002. p. 544. ISBN 0-7695-1597-5.

URBAN, S. D. A semantic framework for heterogeneous database environments. In: INTERNATIONAL WORKSHOP ON INTEROPERABILITY IN MULTIDATABASE SYSTEMS, 1., 1991, Kyoto. Proceedings... [S.l.:s.n.], 1991. p. 156-163.

VALAVANIS, K. P. On the hierarchical modeling analysis and simulation of flexible manufacturing systems with extended petri nets. IEEE Transactions on Systems, Man and Cybernetics, v. 20, n. 1, p. 94-110, 1990.

WOODCOCK, J.; DAVIES, J. Using Z: Specification, Refinement, and Proof. Hertfordshire: Prentice Hall Europe, 1996. ISBN 0-13-948472-8. 
ZISMAN, A. Towards interoperability in heterogeneous database systems. London: Department of Computing, Imperial College of Science, 1995. (Research report, DOC 95/11). 


\section{Apêndice A - Formalismos de Sistemas a Eventos Discretos}

Este apêndice apresenta uma introdução a três das mais conhecidas abordagens de modelagem e análise de Sistemas a Eventos Discretos e que são bastante referenciados ou usados como exemplos neste trabalho. As abordagens tratadas são:

-Redes de Petri

-Cadeias de Markov

-Redes de Petri estocásticas

\section{A.1 Redes de Petri}

As redes de Petri (MURATA, 1989) constituem-se numa técnica matemática que pode ser utilizada para o estudo de Sistemas de Eventos Discretos, e cujos elementos e relações podem ser expressos por meio de grafos. Tais grafos são bipartidos e orientados (ver figura A.1), ou seja, são considerados dois tipos de nós, os lugares (representados por círculos) e as transições (representadas por barras ou retângulos), que são ligados por arcos orientados ("setas") tal que cada um liga um lugar a uma transição ou vice-versa, não admitindo ligações entre nós do mesmo tipo. Em algumas representações de redes de Petri, os arcos podem ser ponderados por valores inteiros positivos, onde o peso representa o número de arcos entre o lugar e a transição (na figura A.1, 3 arcos ligam $p_{8}$ a $t_{9}$ ).

Uma rede de Petri é dita marcada se houver marcas no interior de lugares (como em $p_{1}, p_{3}, p_{4}, p_{7}$ e $p_{8}$, na figura A.1). A marcação de um lugar é dado 


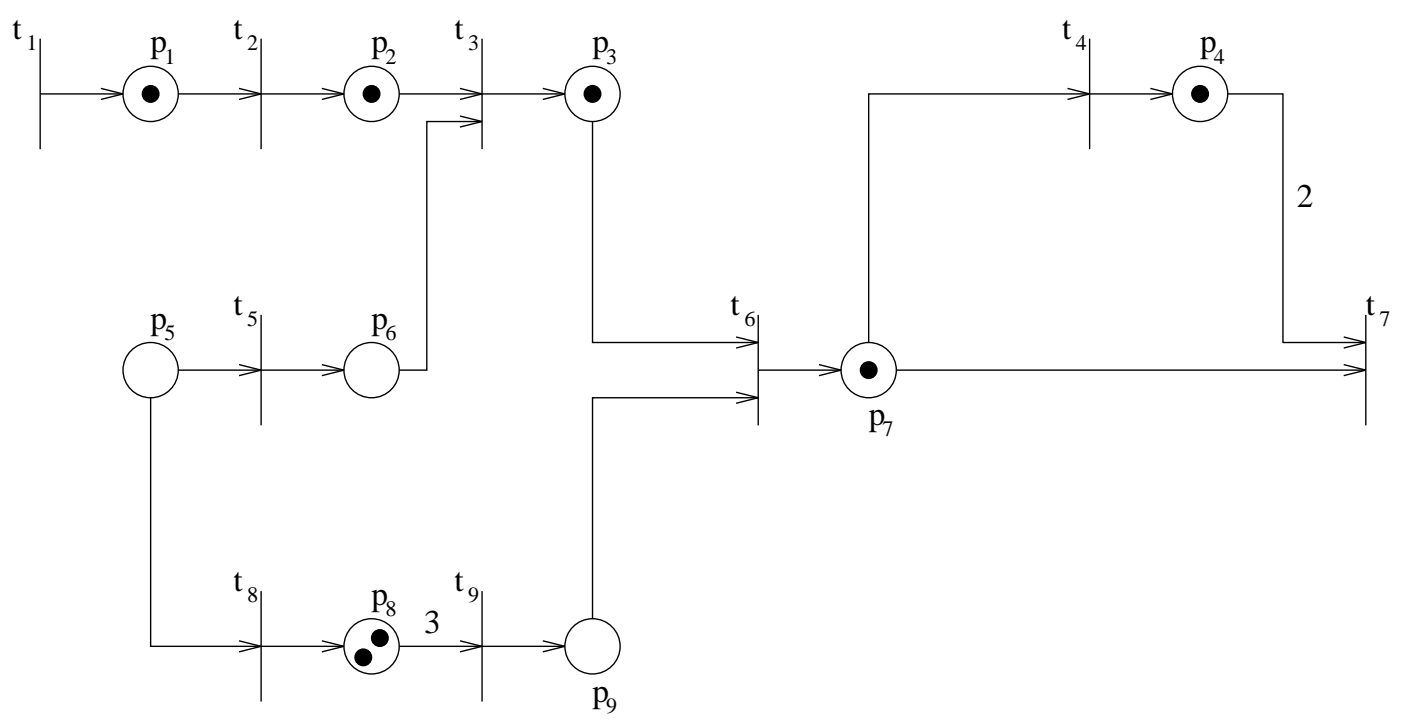

Figura A.1: Rede de Petri

pelo número de marcas no mesmo. A marcação da rede refere-se à disposição das marcas pelos lugares da rede (geralmente representada na forma de $n$-upla ordenada). Na figura A.1, a marcação do lugar $p_{8}$ é 2 e a marcação da rede pode ser representada por $(1,0,1,1,0,0,1,2,0)$.

Cabe observar que as redes de Petri aqui abordadas são do tipo Lugar/Transição ("Place/Transition" ou P/T) que, ao contrário das redes de Petri Condição/Evento, admitem mais de uma marca nos lugares e múltiplos arcos ligando um lugar a uma transição e vice-versa num mesmo sentido (PETERSON, 1981).

As marcas podem fluir pela rede de Petri, mudando a sua marcação, mas tal fluxo deve observar algumas regras:

1.Habilitação: uma transição é dita habilitada se todos os lugares à sua entrada (ou seja, aqueles dos quais se originam os arcos que terminam na transição em questão) contiverem marcas. No caso de haver $n$ arcos entre um lugar à entrada e a transição (ou um arco com peso $n$ ), deve haver $n$ marcas naquele lugar para habilitar a transição (além de considerar os outros lugares à entrada). As transições sem lugares de entrada são consideradas como que sempre estando habilitadas.

2.Disparo de uma transição: estando uma transição habilitada, ela pode ser disparada. Ocorrendo o disparo, o efeito é de retirar marcas dos lugares à 
entrada e colocar marcas nos lugares à saída (ou seja, aqueles nos quais terminam os arcos que têm origem na transição em questão). No caso de haver um arco com peso $n$ (ou $n$ arcos ligando), deve-se retirar $n$ marcas do lugar de entrada ou adicionar $n$ marcas no lugar de saída, conforme o caso. No caso de não haver lugares à saída, o disparo somente retira marcas dos lugares de entrada; não havendo lugares de entrada, há somente adição de marcas nos lugares de saída.

Na rede da figura A.1, $t_{1}, t_{2}, t_{4}$ e $t_{7}$ estão habilitadas. Para $t_{6}$ se tornar habilitada, é necessário que haja marca também em $p_{9}$. No caso de $t_{9}$, como o arco que vem de $p_{8}$ tem peso 3 , seria necessário mais uma marca em $p_{8}$ para torná-la habilitada. Conforme o estabelecido, $t_{1}, t_{2}, t_{4}$ e $t_{7}$ podem ser disparadas.

Na figura A.2, são mostrados os efeitos para várias situações onde ocorrem disparos.
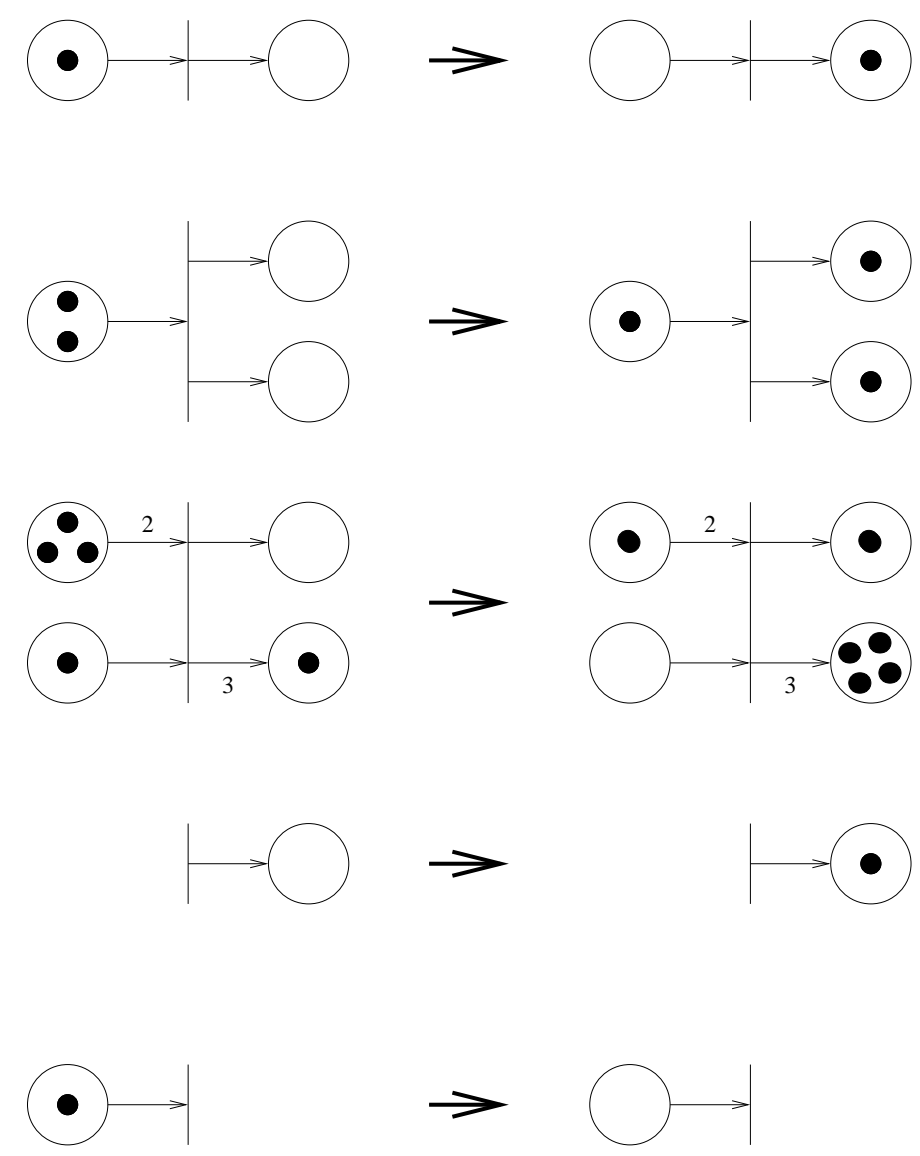

(a) antes do disparo

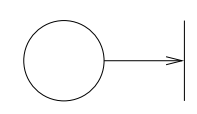

(b) depois do disparo

Figura A.2: Efeitos dos disparos de transições 


\section{A.1.1 Estruturas observadas nas redes de Petri}

Faz-se, aqui, a apresentação de algumas características e situações que podem ser modeladas por redes de Petri, descritas com maior detalhe, juntamente com outras, por Murata (1989) e Cardoso e Valette (1997).

\section{A.1.1.1 Paralelização ("fork")}

Um exemplo é representado pela figura A.3, onde o disparo da transição $t_{1}$ acrescenta marcas em vários lugares; a partir dessas marcas, podem vir a ocorrer fluxos paralelos de marcas.

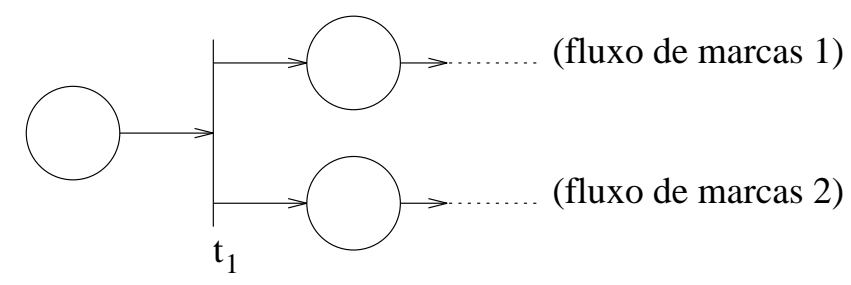

Figura A.3: Paralelização ("fork")

\section{A.1.1.2 Sincronização ("join")}

A regra de habilitação obriga que a transição $t_{2}$ da figura A.4 tenha seus lugares de entrada devidamente marcados. Se, por exemplo, $p_{1}$ tiver marcas e $p_{2}$, não, o disparo deverá esperar para que marcas cheguem a $p_{2}$. Tem-se, assim, uma situação de sincronização, que é uma forma de contenção do paralelismo.

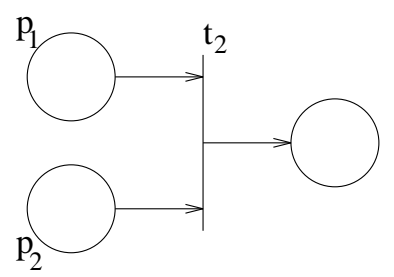

Figura A.4: Sincronização ("join")

\section{A.1.1.3 Conflito}

O conflito é a situação representada na figura A.5, onde somente uma das transições pode retirar a marca do lugar de entrada comum $\left(p_{1}\right)$, o que demanda 
um processo de decisão de qual será disparada, o qual não é representado na rede, ocorrendo externamente a esta: as redes de Petri especificam somente o que ocorre no caso de se disparar uma ou outra transição. Note-se também que, se $p_{2}$ estivesse sem marcas, somente $t_{1}$ estaria habilitada e não haveria o conflito.

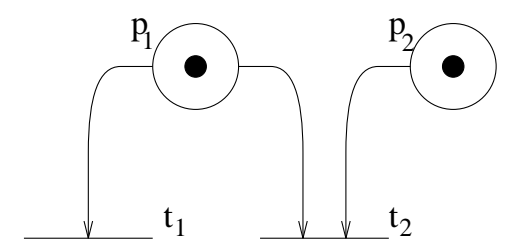

Figura A.5: Conflito

\section{A.1.2 Grafo de alcançabilidade}

O grafo de alcançabilidade (MURATA, 1989) mostra como a marcação da rede evolui com os disparos das transições. Os nós do grafo de alcançabilidade correspondem às marcações da rede e os arcos, que são orientados, correspondem aos disparos de transições, ligando uma marcação a outras geradas com os disparos das transições respectivas. Dada uma rede de Petri, diferentes grafos de alcançabilidade podem ser obtidos conforme a marcação inicial $M_{0}$ : assim, a notação $G A\left(R, M_{0}\right)$ indica o grafo de alcançabilidade de uma rede $R$ com marcação inicial $M_{0}$. O conjunto de marcações que compõe $G A\left(R, M_{0}\right)$ formam o espaço de alcançabilidade, denotado por $E A\left(R, M_{0}\right)$. Por exemplo, seja a rede da figura A.6: seu grafo de alcançabilidade, para aquela marcação inicial, é dado pela figura A.7; o espaço de alcançabilidade corresponde às marcações relativas aos nós deste último grafo.

No caso de um nó que não seja origem de arco algum, tem-se que na marcação correspondente ocorre um "deadlock", ou seja, uma situação onde nenhuma transição pode disparar, pois nenhuma está habilitada (caso que ocorre na rede da figura A.8, cujo grafo de alcançabilidade é dado na figura A.9).

Outro comportamento que pode ser observado é o que ocorre no caso da figura A.10, onde a transição $t_{i}$ pode ser disparada um número infinito de vezes, o que levaria o lugar $P$ a comportar um número infinito (ilimitado) de marcas. Numa situação em que pode ocorrer um tal acúmulo infinito de marcas, tem-se uma regra para abreviar a explosão no número de nós do grafo de alcançabilidade, 


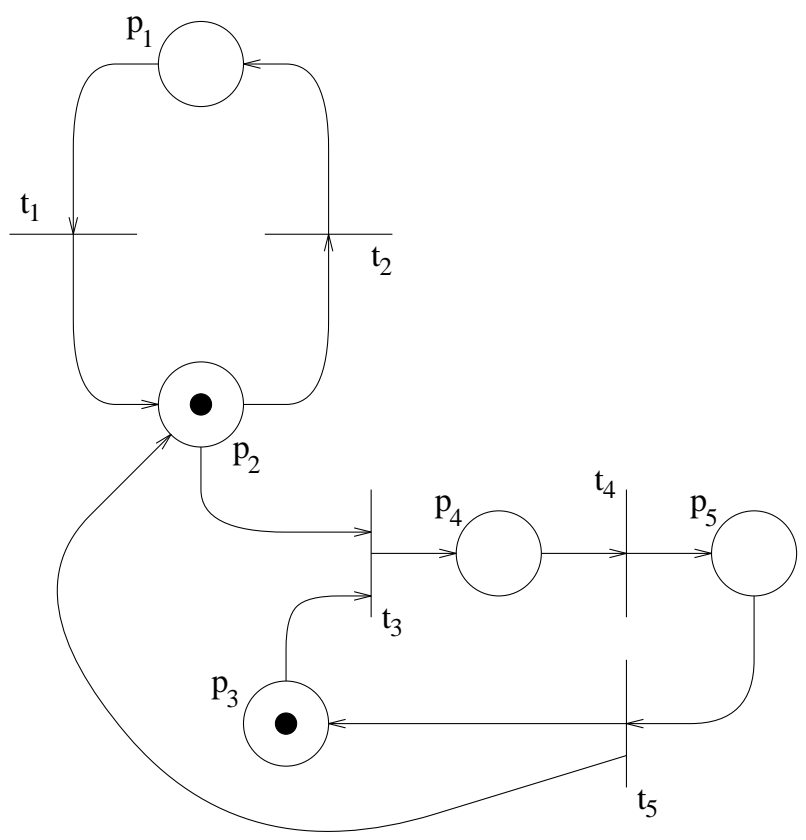

Figura A.6: Rede de Petri $R d P$ com marcação $M_{0}$

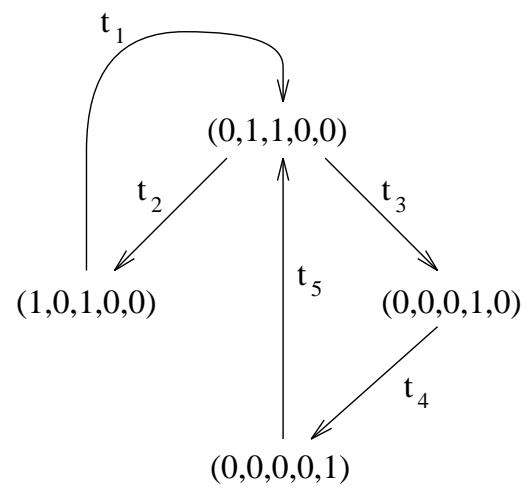

Figura A.7: Grafo de alcançabilidade $G A\left(R, M_{0}\right)$ relativo a $R d P$

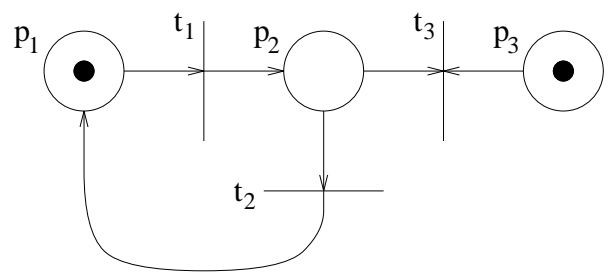

Figura A.8: Rede $R_{\text {dead }}$ com "deadlock" 


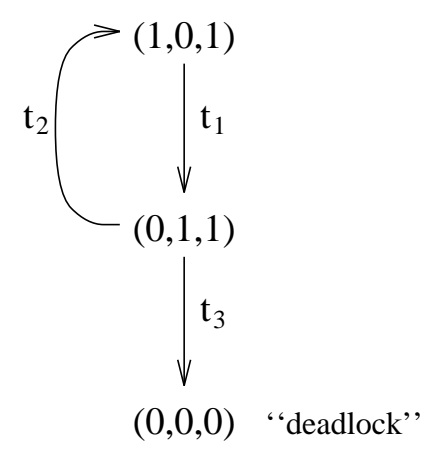

Figura A.9: Grafo de alcançabilidade da rede $R_{\text {dead }}$ com "deadlock"

que é melhor descrita por Peterson (1981), Murata (1989) ou Cardoso e Valette (1997). Neste trabalho, este caso não é levado em consideração.

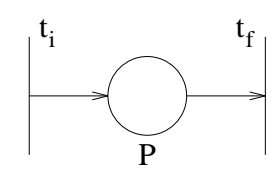

Figura A.10: Rede que permite acúmulo infinito de marcas em $\mathrm{P}$

\section{A.1.3 Propriedades das redes de Petri}

Com relações às propriedades de redes de Petri, o texto que se segue é baseado nos trabalhos de Murata (1989) e Cardoso e Valette (1997)

\section{A.1.3.1 Vivacidade}

\section{Definição A.1}

Dada uma rede de Petri $R$ com marcação inicial $M_{0}$, uma transição $t$ é dita viva se, a partir de qualquer marcação $M$ pertencente a $G A\left(M_{0}\right)$, existir um caminho sobre $G A\left(M_{0}\right)$ (ou seja, há uma seqüência de disparos) no qual seja possível atingir uma marcação $M^{\prime}$ tal que $t$ esteja habilitada.

\section{Definição A.2}

Uma rede de Petri $R$ com marcação inicial $M_{0}$ é dita viva se todas as suas transições forem vivas.

A rede da figura A.6 é viva. A rede da figura A.8 não é viva, pois há uma marcação que se trata de um "deadlock" (onde nenhuma transição pode ser disparada). Já o caso da figura A.11 é de uma rede não viva, pois, na marcação inicial mostrada, a transição $t$ pode disparar apenas uma vez. 


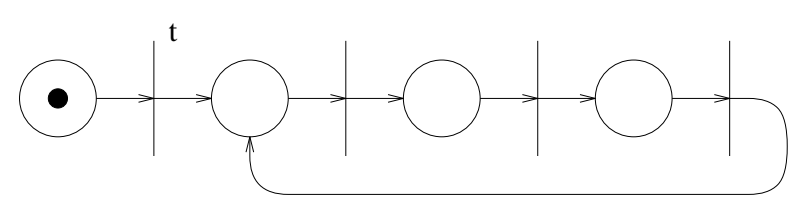

Figura A.11: Rede não viva

\section{A.1.3.2 Limitação}

\section{Definição A.3}

Dada uma rede de Petri $R$ com marcação inicial $M_{0}$, um lugar é dito limitado se não há uma seqüência de disparos que permita o acúmulo infinito de marcas no seu interior.

\section{Definição A.4}

Uma rede $R$ com marcação inicial $M_{0}$ é limitada se todos os seus lugares forem limitados.

Desta forma, se $R$ for limitada, $E A\left(R, M_{0}\right)$ é finito.

Os exemplos das figuras A.6, A.8 e A.11 são de redes limitadas (o número de marcas nunca excede a unidade). A rede da figura A.10 é não limitada.

\section{A.1.3.3 Reiniciabilidade}

\section{Definição A.5}

Dada uma marcação inicial $M_{0}$ de uma rede de Petri $R$, a rede é dita reinicializável se, a partir de qualquer marcação $M$ do espaço de alcançabilidade $E A\left(R, M_{0}\right)$, existe uma seqüência de disparos que leva a rede à marcação inicial $M_{0}$.

Por exemplo, as redes das figuras A.6 e A.10 são reinicializáveis, enquanto as das figuras A.8 e A.11 não são.

\section{A.1.3.4 Determinação das "boas propriedades"}

As tratadas propriedades (vivacidade, limitação e reiniciabilidade) são chamadas de "boas propriedades" (CARDOSO; VALETTE, 1997), pois são desejáveis num grande número de redes de Petri. No mesmo trabalho, é descrito um método que permite verificá-las a partir de um grafo de alcançabilidade $G A\left(R, M_{0}\right)$ relativo a uma rede de Petri $R$ com marcação inicial $M_{0}$. O método consiste no seguinte: 
1.Prova-se que $R$ é limitada, o que é feito pela construção de $G A\left(R, M_{0}\right)$; caso não seja, não é possível realizar a determinação das demais "boas propriedades" por este método.

2.Provada a limitação, deve-se mostrar que $G A\left(R, M_{0}\right)$ é fortemente conexo, ou seja, que é sempre possível encontrar um caminho entre quaisquer dois nós do grafo seguindo-se os arcos do mesmo. Caso afirmativo, tem-se que $R$ é reinicializável. Caso contrário, a aplicação do método é encerrada aqui.

3.Demonstrada a limitação e a reiniciabilidade, verifica-se se todas as transições disparam pelo menos uma vez (o que garante que $R$ é quase-viva) através da observação de $G A\left(R, M_{0}\right)$. Assim, se $R$ é reinicializável, tem-se que:

$$
R \text { é quase-viva } \Longrightarrow R \text { é viva }
$$

Além deste método, há outras técnicas que visam redes de Petri com características específicas (como os grafos marcados e as máquinas de estado (MURATA, 1989)), mas que, em contrapartida, são menos trabalhosas do ponto de vista da análise.

\section{A.1.4 Modelagem por redes de Petri}

Primeiramente, se for estabelecido que o estado de um sistema é dado por um conjunto de variáveis de estado, tem-se que uma condição representa um subconjunto dessas variáveis. As redes de Petri enfocam, justamente, as condições observáveis no sistema e a forma como estas interagem à medida que surgem e desaparecem. Vem deste fato a capacidade de abordar os paralelismos dos sistemas, através da representação de condições ocorrendo simultaneamente e das evoluções independentes de tais condições em "pontos" diversos do sistema.

Neste texto, será adotada a convenção de representar condições (por exemplo, operações em andamento, condições de espera e de término de operação) por lugares e início e fim (ou geração e extinção) dessas condições por transições. É possível adotar a convenção inversa, conforme mostra Peterson (1981), sem qualquer prejuízo para a coerência do modelo.

Assim, seja o modelo ilustrado na figura A.12 sobre os processos que ocorrem numa estação de fixação de rodas de carros. Os lugares marcados representam 
atividades concomitantes ocorrendo em lados opostos do carro e as evoluções de cada lado são representadas separadamente, sendo um exemplo de como as redes de Petri modelam o paralelismo dos sistemas.

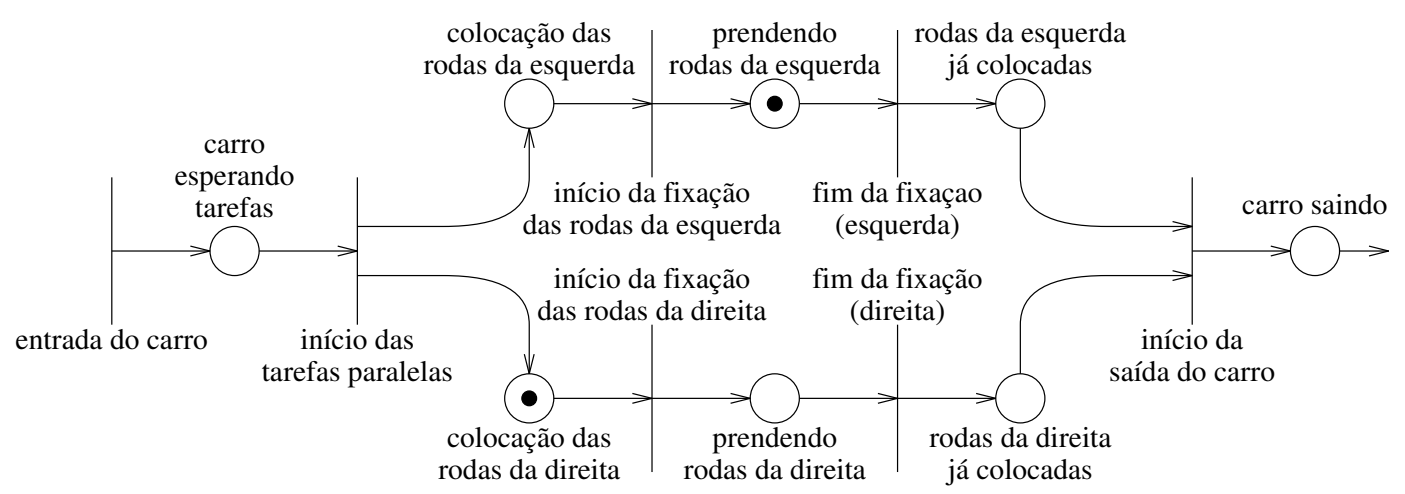

Figura A.12: Colocação de rodas num carro feita numa estação

No que diz respeito às características dos sistemas modeláveis por redes de Petri, pode-se classificá-las em relações de seqüência, de paralelismo e de decisão.

As relações de seqüência indicam que, para se verificar uma certa condição a partir de outra, é necessário que exista uma seqüência de transições válidas. Em redes de Petri, isto é traduzido pela necessidade de existir uma seqüência de disparos que implemente tal seqüência. Desta forma, por exemplo, podese modelar as restrições quanto à obrigatoriedade de as operações seguirem uma certa ordem de operações: na figura A.12, para se ter as rodas presas, é necessário que o carro chegue à estação, as rodas sejam colocadas e os parafusos apertados, estritamente nesta seqüência.

As relações de paralelismo compreendem as de sincronização ("join") e de paralelização ("fork"). A paralelização, por exemplo, pode representar que um certo evento dá início a dois conjuntos paralelos de operações (por exemplo, na figura A.12, o evento de início de tarefas da estação). A sincronização representa o caso onde mais de uma condição devem estar presentes simultaneamente para que outras sejam geradas (para se retirar o carro da estação é preciso que as rodas de ambos os lados estejam presas).

As relações de decisão (representadas pelos conflitos) mostram que uma certa condição permite transições para outras duas ou mais condições, mas que somente uma dessas transições pode ocorrer; neste caso, associa-se um processo de decisão que escolhe qual transição a ocorrer. Como exemplos, pode-se citar: 
-num sistema de esteiras rolantes, chegando uma peça numa encruzilhada, deve-se decidir sobre sua rota (ver figura A.13);

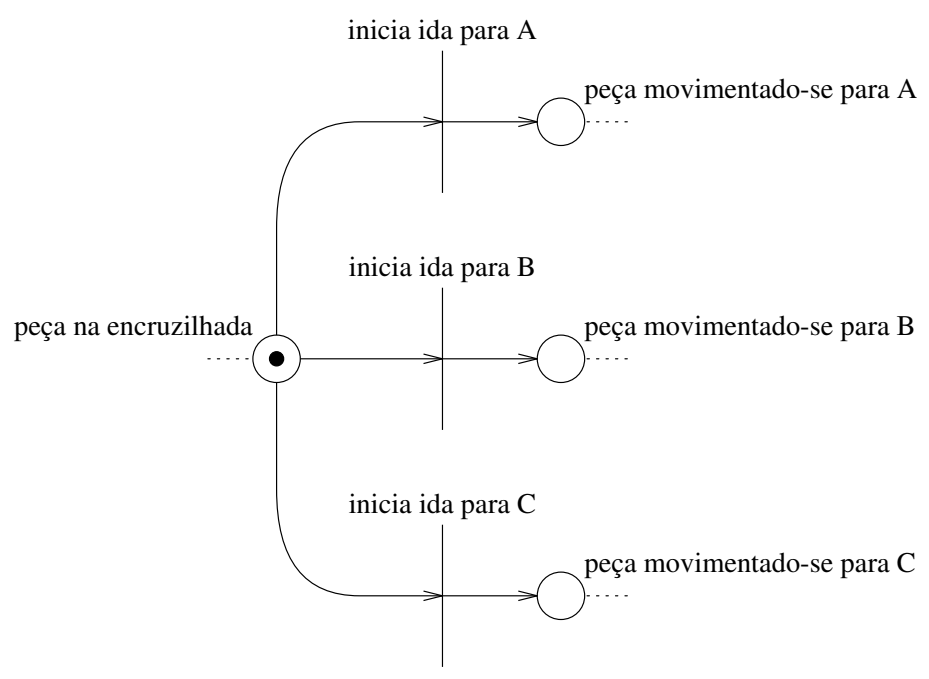

Figura A.13: Decisão sobre a rota da peça

-na figura A.14, uma máquina é requisitada para os processos $P_{1}$ e $P_{2}$, devendo-se escolher a qual deles irá atender; tal conflito representa uma outra característica importante nos Sistemas de Manufatura que é a competição por recursos (que, num sistema real, são finitos).

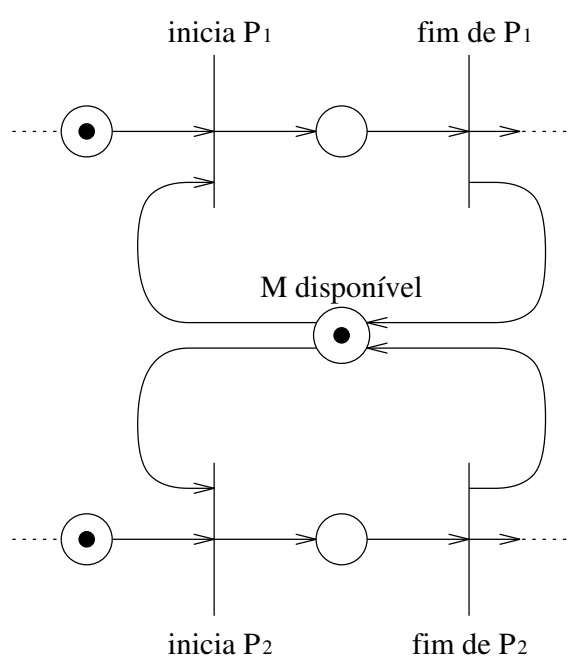

Figura A.14: Competição por recurso (máquina $M$ )

Quanto às informações que podem ser obtidas pela análise de redes de Petri, destacam-se as de cunho qualitativo como aquelas referentes à vivacidade, à limitação e à reiniciabilidade do sistema, que já foram discutidas: 
1.A vivacidade refere-se ao fato de que todos os eventos (como inícios ou fins de operações) especificados no modelo possam vir a ocorrer, independentemente do estado em que se encontre o sistema.

2.Uma rede de Petri limitada representa um sistema cujo espaço de estados é finito.

3.A reiniciabilidade é a capacidade do sistema poder retornar ao estado inicial, independentemente do estado em que se encontrar, através de uma seqüência qualquer de transições de estados.

\section{A.2 Cadeias de Markov de tempo contínuo}

As cadeias de Markov de tempo contínuo ou CMTC (KULKARNI, 1995; BOLCH et al., 1998) modelam sistemas de estados discretos $X(t)$ (onde $t$ se refere a um instante de tempo) cujas probabilidades apresentam a seguinte propriedade:

$$
\begin{aligned}
& P\left\{X\left(t_{n}\right)=x_{n} \mid X\left(t_{n-1}\right)=x_{n-1}\right\}= \\
& P\left\{X\left(t_{n}\right)=x_{n} \mid X\left(t_{n-1}\right)=x_{n-1}, X\left(t_{n-1}\right)=x_{n-1}, \ldots, X\left(t_{0}\right)=x_{0}\right\}
\end{aligned}
$$

onde $t_{n}<t_{n-1}<t_{n-2}<\ldots<t_{1}<t_{0}$.

Interpretando a definição: tendo-se informações sobre os estados assumidos pelo sistema nos instantes $t_{n-1}, t_{n-2}, \ldots, t_{1}$ e $t_{0}$, basta apenas o conhecimento de o estado $X\left(t_{n-1}\right)$ ter sido $x_{n-1}$ para efeito de cálculo da probabilidade condicionada de $X\left(t_{n}\right)$ ser $x_{n}$, tornando o conhecimento dos estados em instantes anteriores redundante.

Deve-se notar que, na definição de CMTC dada, é especificada uma propriedade, mas não se indica quais processos podem ser representados por CMTC. Conforme tratado por Kleinrock (1975), sistemas onde os tempos de permanência nos estados (antes da ocorrência das transições de estado) que têm distribuições exponenciais apresentam tal propriedade; tais distribuições têm funções densidade de probabilidades (f.d.p.) da forma a seguir:

$$
f\left(t_{i j}\right)=\lambda_{i j} e^{-\lambda_{i j} t_{i j}}
$$

onde: 
$t_{i j}=$ o tempo de permanência no estado $i$ antes de passar ao estado $j$

$\lambda_{i j}=$ taxa de transição do estado $i$ para o estado $j$ (em número de transições por unidade de tempo)

A esperança matemática (ou média) da variável aleatória $t_{i j}$ é dada por:

$$
E\left[t_{i j}\right]=\frac{1}{\lambda_{i j}}
$$

O valor $\lambda_{i j}$, que é o único parâmetro da distribuição exponencial, pode ser interpretado como uma medida da "velocidade" de ocorrência da transição: se $\lambda_{i j}$ for grande, o tempo médio de permanência em $i$ é pequeno (a transição ocorre mais rapidamente), conforme indica $E\left[t_{i j}\right]$.

As CMTC podem ser representadas por grafos orientados denominados Diagramas de Transição de Estados (DTE), onde os nós representam os estados da cadeia e os arcos, as transições entre estados. Os arcos são caracterizados por valores denominados taxas de transições referentes aos estados por eles ligados.

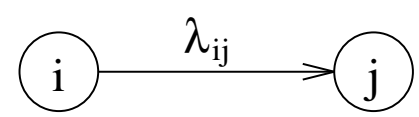

Figura A.15: CMTC com dois estados $\{\mathrm{i}, \mathrm{j}\}$

O grafo da figura A.15 representa uma cadeia de Markov com dois estados ( $i$ e $j$ ), onde, se o sistema estiver no estado $i$, a taxa de transição do estado $i$ para $j$ é dada por $\lambda_{i j}$, o que deve ser interpretado da seguinte forma: a f.d.p. do tempo de permanência em $i$ até que ocorra a transição para $j$ (que é instantânea) é dada por $f\left(t_{i j}\right)=\lambda_{i j} e^{-\lambda_{i j} t_{i j}}$. No estado $j$, não há nenhuma transição definida para algum outro estado, não havendo possibilidade de o sistema mudar de estado.

No caso do grafo da figura A.16, tem-se o seguinte: a partir do estado $i$, podem ocorrer duas transições, uma para o estado $j$, outra para $k$. Tem-se, assim, duas distribuições implícitas:

$$
\begin{aligned}
& f_{i j}\left(t_{i j}\right)=\lambda_{i j} e^{-\lambda_{i j} t_{i j}} \\
& f_{i k}\left(t_{i k}\right)=\lambda_{i k} e^{-\lambda_{i k} t_{i k}}
\end{aligned}
$$

A interpretação é que, estando o sistema no estado $i$, há duas transições 


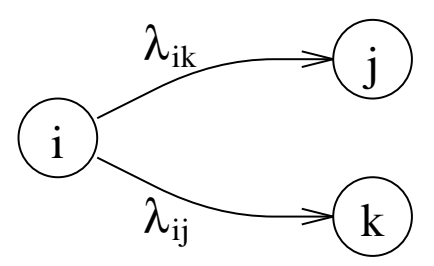

Figura A.16: CMTC com 3 estados $\{i, j, k\}$

"competindo" para determinar qual será o próximo estado (ou $j$, ou k). A “competição" (ou "race", em inglês) é resolvida do seguinte modo: o próximo estado será determinado pela transição que ocorrer primeiro (HOWARD, 1971).

A partir das duas f.d.p., é possível ter-se uma estimativa de qual será o próximo estado. Supondo-se que $\lambda_{i j}>\lambda_{i k}$ e que o estado atual é $i$, pode-se dizer que, em média, $t_{i j}$ é menor que $t_{i k}$, ou seja, em média, é mais provável que o próximo estado seja $j$. A chance de o próximo estado ser $k$ é menor, mas existe.

\section{A.2.1 Equações da cadeia de Markov}

Este texto limita-se a descrever os elementos que compõem a descrição matemática do comportamento das CMTC, que são tratados com mais detalhes, por exemplo, por Kulkarni (1995) e Bolch et al. (1998). Assim, para uma CMTC com $N$ estados, são importantes os seguintes elementos:

1.Vetor probabilidade de estado, $\boldsymbol{p}(t)$ tal que:

$$
\boldsymbol{p}(t)=\left[p_{1}(t), p_{2}(t), \ldots, p_{N}(t)\right]
$$

onde $p_{i}(t)$ é a probabilidade de o sistema estar no estado $i$ no instante $t$. Como todos os estados estão representados em $\boldsymbol{p}(t)$, observa-se que:

$$
p_{1}(t)+p_{2}(t)+\cdots+p_{N}(t)=1
$$

2.Matriz das taxas de transição, que tem a seguinte forma:

$$
\boldsymbol{Q}(t)=\left[q_{i j}(t)\right]_{N \times N}
$$

que é a matriz que relaciona estados atuais e posteriores, representando as transições definidas pela CMTC. Os elementos de $\boldsymbol{Q}(t)$ são definidos como 
a seguir:

$$
q_{i j}=\left\{\begin{array}{cl}
0 & \text { se não houver transição de } i \text { para } j \\
\lambda_{i j}(t) & \text { se } i \neq j \\
-\sum_{k \neq i} \lambda_{i k}(t) & \text { se } i=j
\end{array}\right.
$$

Caso as taxas de transição variem com o tempo, tem-se uma CMTC heterogênea; se as taxas de transição forem constantes no tempo, tem-se uma CMTC homogênea, isto é, $\boldsymbol{Q}=\left[q_{i j}\right]_{N \times N}$, que é o caso considerado neste trabalho.

3.Equação de transição, expressa por:

$$
\frac{\partial}{\partial t} \boldsymbol{p}(t)=\boldsymbol{p}(t) \boldsymbol{Q}(t)
$$

Por exemplo, considere-se a CMTC homogênea representada pelo grafo na figura A.17.

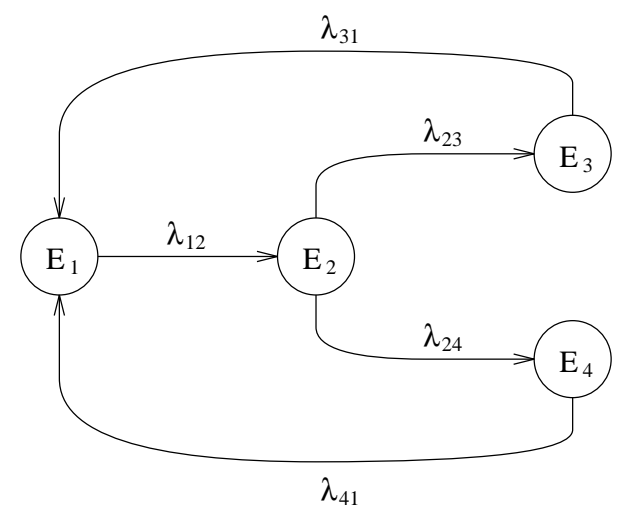

Figura A.17: CMTC com 4 estados $\left\{E_{1}, E_{2}, E_{3}, E_{4}\right\}$

A matriz das taxas de transição correspondente é a seguinte:

$$
\boldsymbol{Q}=\left[\begin{array}{cccc}
-\lambda_{12} & \lambda_{12} & 0 & 0 \\
0 & -\lambda_{23}-\lambda_{24} & \lambda_{23} & \lambda_{24} \\
\lambda_{31} & 0 & -\lambda_{31} & 0 \\
\lambda_{41} & 0 & 0 & -\lambda_{41}
\end{array}\right]
$$

que pode ser utilizada na equação:

$$
\frac{\partial}{\partial t} \boldsymbol{p}(t)=\boldsymbol{p}(t) \boldsymbol{Q}
$$


onde

$$
\boldsymbol{p}(t)=\left[p_{1}(t), p_{2}(t), p_{3}(t), p_{4}(t)\right]
$$

Em particular, caso seja certo que o sistema se inicia no estado $E_{1}$, tem-se que $\boldsymbol{p}(0)=[1,0,0,0]$.

\section{A.2.2 Propriedade da ausência de memória}

Para a distribuição exponencial, a probabilidade de um evento $\mathcal{E}$ ocorrer entre 0 e $t$ é, integrando-se a f.d.p. sobre esse intervalo, dado por:

$$
P\{0<\mathcal{E}<t\}=1-e^{-\lambda t}
$$

Sendo $\mathcal{E}$ o evento de fim de processamento e sabendo-se que $\mathcal{E}$ não ocorreu antes de $t_{0}$, deseja-se encontrar a probabilidade de $\mathcal{E}$ ocorrer entre $t_{0}$ e $\left(t_{0}+t^{\prime}\right)$, ou seja, deseja-se calcular:

$$
\begin{aligned}
P\left\{t_{0}<\mathcal{E}<t^{\prime}+t_{0} \mid \mathcal{E}>t_{0}\right\} & =\frac{P\left\{t_{0}<\mathcal{E}<t^{\prime}+t_{0} \cap \mathcal{E}>t_{0}\right\}}{P\left\{\mathcal{E}>t_{0}\right\}} \\
& =\frac{P\left\{t_{0}<\mathcal{E}<t^{\prime}+t_{0}\right\}}{P\left\{\mathcal{E}>t_{0}\right\}} \\
& =\frac{e^{-\lambda t_{0}}-e^{-\lambda\left(t^{\prime}+t_{0}\right)}}{e^{-\lambda t_{0}}} \\
& =1-e^{-\lambda t^{\prime}}=P\left\{0<\mathcal{E}<t^{\prime}\right\}
\end{aligned}
$$

Pode-se ver que as distribuições de $t$ e de $t^{\prime}$ são as mesmas, demonstrando a invariância das expectativas. A ausência de memória significa que, sabendo-se que $\mathcal{E}$ não ocorreu até $t_{0}$ (está no mesmo estado), a distribuição (ou expectativa) do tempo até o fim do processamento não se altera (ver figura A.18).

\section{A.2.3 Cadeias de Markov de tempo contínuo ergódicas}

As cadeias de Markov de tempo contínuo ergódicas (CMTCErg) são aquelas que apresentam a seguinte propriedade:

$$
\lim _{t \rightarrow 0} \boldsymbol{p}(t)=\boldsymbol{\pi}
$$




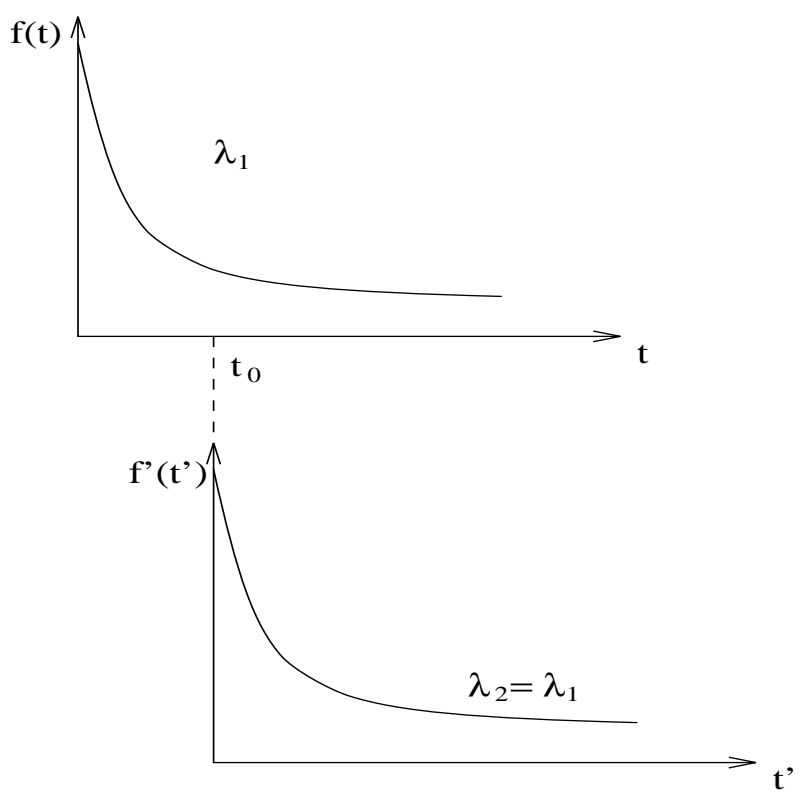

Figura A.18: Interpretação gráfica da ausência de memória

onde $\boldsymbol{\pi}$ independe da distribuição inicial $\boldsymbol{p}(0)$ e é calculado por

$$
\begin{gathered}
\boldsymbol{\pi} \boldsymbol{Q}=\mathbf{0} \\
\boldsymbol{\pi}[1,1,1, \ldots, 1]^{T}=1
\end{gathered}
$$

Note-se que, se num instante $t, \boldsymbol{p}(\mathrm{t})=\boldsymbol{\pi}$,

$$
\frac{\partial}{\partial t} \boldsymbol{p}(t)=\boldsymbol{p}(t) \boldsymbol{Q}=\boldsymbol{\pi} \boldsymbol{Q}=\mathbf{0}
$$

donde se tem a razão pela qual $\boldsymbol{\pi}$ é considerado o vetor das probabilidades de regime permanente. Portanto, as probabilidades nas CMTCErg tendem a se estabilizar num patamar de valores $(\boldsymbol{\pi})$ "no longo prazo". Tais probabilidades são também denominadas de estacionárias (sendo a derivada nula, tendem a não se alterar) ou de probabilidades de equilíbrio (qualquer que seja $\boldsymbol{p}(0)$ inicial, as probabilidades tendem a $\boldsymbol{\pi})$.

Em particular, se uma CMTC for finita (quanto ao número de estados) e irredutível (ou seja, a partir de qualquer estado é possível atingir todos os demais), tem-se uma CMTCErg (KLEINROCK, 1975).

Por exemplo, considere-se a CMTC representada na figura A.19. Trata-se de 
uma CMTC finita, mas que não é irredutível, pois não é possível atingir o estado $E_{1}$ a partir dos estados $E_{2}$ e $E_{3}$.

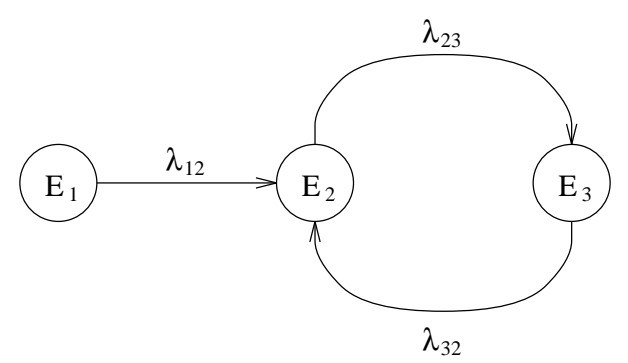

Figura A.19: CMTC finita e redutível

Um outro exemplo é dado pela figura A.20, que se trata de uma CMTCErg, pois é finita e é irredutível, o que pode ser facilmente constatado pelo grafo. As probabilidades de equilíbrio são dadas por

$$
\boldsymbol{\pi}=\left[\begin{array}{llll}
0,0109 & 0,7608 & 0,1196 & 0,087
\end{array}\right]
$$

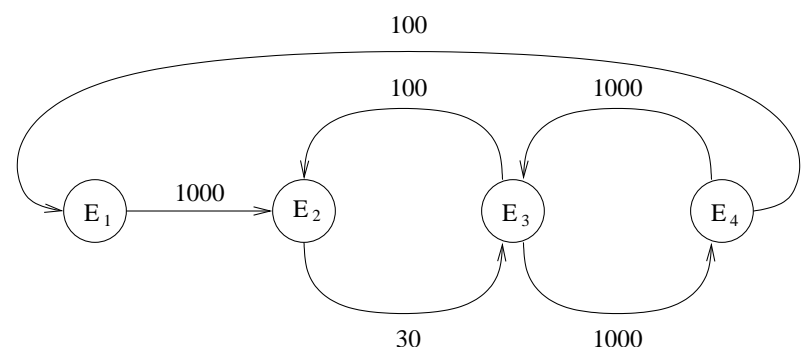

Figura A.20: Cadeia de Markov ergódica (isto é, finita e irredutível)

\section{A.2.4 Aplicação}

Em termos de modelagem, a análise de CMTC fornece as probabilidades de ocorrência de cada um dos estados que compõem a CMTC num certo instante e as derivadas destas probabilidades em relação ao tempo, tratando-se, portanto, de uma técnica para a Análise Quantitativa.

Considere-se, como exemplo, o caso de um sistema com apenas uma máquina. Neste caso, o estado do sistema coincide com o estado deste único componente. O comportamento a ser modelado é o do ciclo disponibilidade-processamento-quebra $(D-P-Q)$ da máquina, conforme representado na figura A.21. 


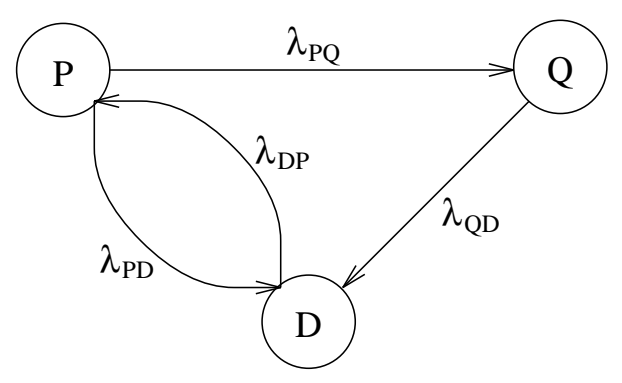

Figura A.21: CMTC do ciclo disponibilidade-processamento-quebra

Neste exemplo, estando disponível $(D)$, a máquina pode iniciar um processo $(P)$; estando em processo, a máquina pode tornar-se disponível de novo (fim de processo) ou quebrar (ir para o estado $Q$ ); estando quebrada, ocorre o conserto da máquina, após o qual a máquina retorna à disponibilidade (transição do estado $Q$ para $D$ ). Os pesos nos arcos referem-se às taxas de transição e têm os seguintes significados:

$\lambda_{D P}$ : estando a máquina disponível, caracteriza o tempo de espera para chegada de ordem de processamento.

$\lambda_{P D}$ : caracteriza o tempo médio de processamento

$\lambda_{P Q}$ : caracteriza o tempo médio para ocorrência de quebra, considerando-se a que a máquina está em processo

$\lambda_{Q D}$ : caracteriza o tempo médio de conserto da máquina quebrada.

Considere-se, agora, o caso de um sistema com duas máquinas $M_{1}$ e $M_{2}$, nas quais ocorre o mesmo ciclo disponibilidade-ocupação-quebra. O estado global do sistema pode ser representado por um par ordenado, onde o primeiro elemento representa o estado da máquina $M_{1}$ e o segundo, $M_{2}$. Para a CMTC relativa a este sistema, tem-se o diagrama representado na figura A.22. Por este exemplo, pode-se ter uma noção de como a obtenção dos estados e das transições entre estes pode tornar-se difícil à medida que é aumentado o número de componentes e as interações entre estes.

Em termos da dinâmica dos sistemas, o modelo em CMTC não modela explicitamente os paralelismos (se existirem) dos sistemas, tanto que não lhes interessam qual parte do sistema é responsável pela transição do seu estado: interessam apenas os valores relativos aos tempos de permanência nos estados antes da 


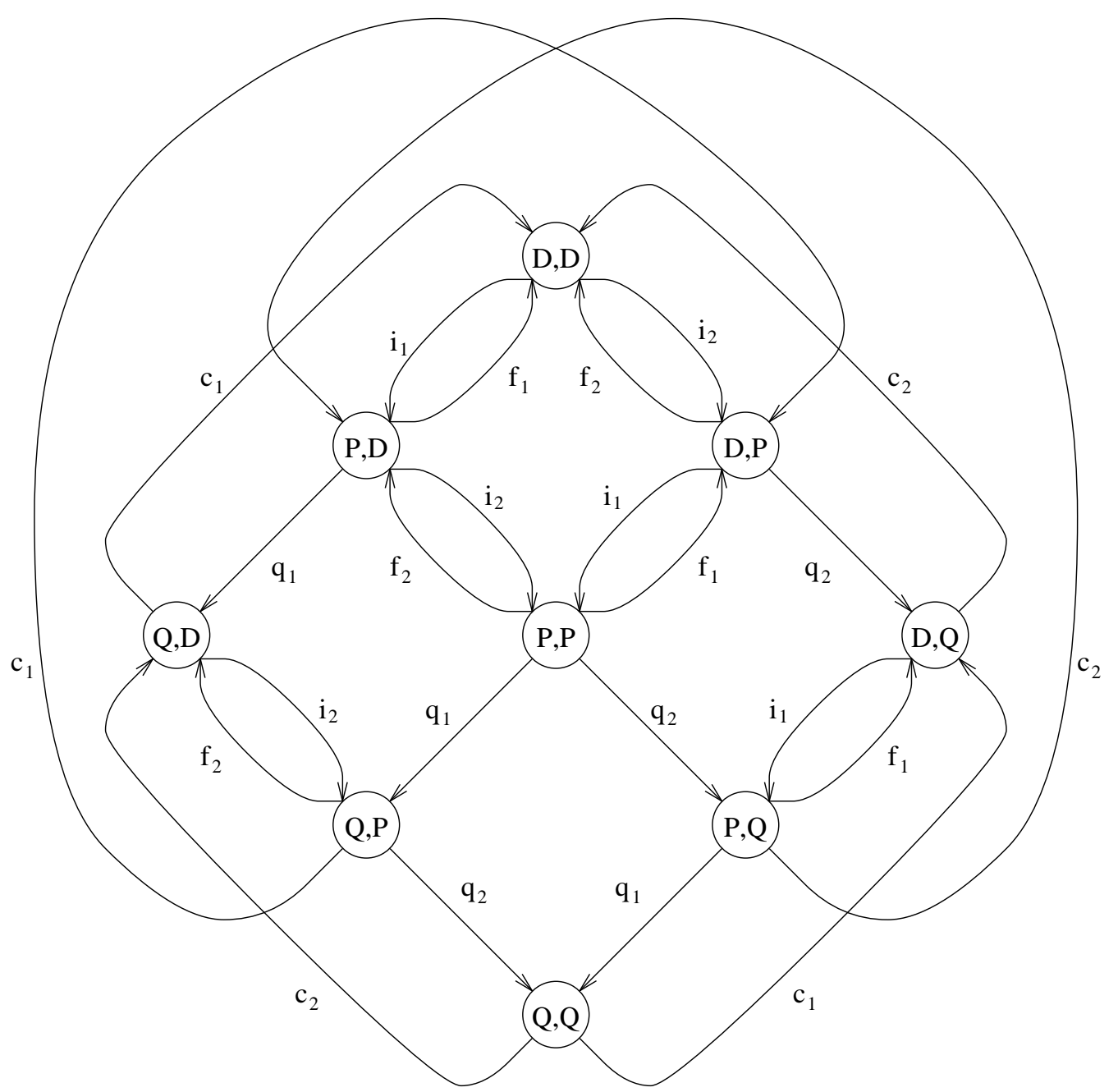

- $i_{1}$ e $i_{2}$ referem-se aos tempos de espera pela chegada de ordem de processamento das máquinas 1 e 2 respectivamente;

- $f_{1}$ e $f_{2}$ referem-se aos tempos médios de processamento das máquinas 1 e 2 respectivamente;

- $q_{1}$ e $q_{2}$ caracterizam os tempos médios de ocorrência de quebras das máquinas 1 e 2 respectivamente, considerando-se que estão em processamento;

- $c_{1}$ e $c_{2}$ caracterizam o tempo médio de conserto de máquina quebrada para as máquinas 1 e 2 respectivamente.

Figura A.22: CMTC para 2 máquina no ciclo D-P-Q 
ocorrência das transições (fato representado pelos parâmetros das distribuições exponenciais de tais tempos).

Enfim, tal instrumento de Análise Quantitativa, apesar de fornecer informações que podem ser utilizadas no cálculo de índices representativos do comportamento do sistema, tem, em sistemas de certo porte, a desvantagem (óbvia) da explosão no número de estados da cadeia e da complexidade nas especificações dos estados (globais) e das transições entre estes. Silva e R.R.Muntz (1992), Neuts (1981) e Stewart (1972) tratam destes aspectos.

\section{A.3 Redes de Petri estocásticas}

As redes de Petri estocásticas referem-se a uma classe de modelos que, às suas transições, são associados tempos estocásticos. Às vezes, porém, referem-se a uma classe específica dessas redes, onde a todas as transição associam-se tempos distribuídos exponencialmente, ou seja, as chamadas SPN (Stochastic Petri Nets). Uma outra categoria apresenta transições deste mesmo tipo e transições denominadas instantâneas, ou seja, as chamadas GSPN (Generalized Stochastic Petri Nets). Ambas as classes são descritas a seguir.

\section{A.3.1 Redes de Petri estocásticas (SPN)}

As redes de Petri estocásticas (SPN ou "Stochastic Petri Nets"), introduzidas por Molloy (1980), são redes de Petri que apresentam temporizações com as seguintes características (ver figura A.23):

1.Temporização nas transições, com a regra de disparo instantâneo, ou seja, decorrido o tempo de disparo, a transição retira marcas dos lugares a sua entrada e, simultaneamente, coloca outras nos lugares a sua saída.

2.As temporizações são estocásticas. Junto a tal transição, especifica-se sua taxa de disparo, geralmente denotada por $\lambda$, que é o parâmetro da função densidade de probabilidades da temporização (item seguinte).

3.A função densidade de probabilidade do tempo de disparo é do tipo exponencial:

$$
f(t)=\lambda e^{-\lambda t}
$$




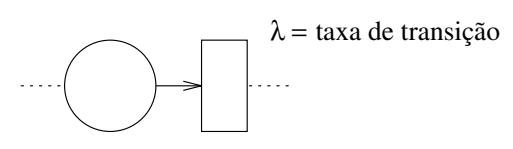

Figura A.23: Transição temporizada de uma rede SPN

onde $\lambda$ é medida em disparos por unidade de tempo. A média do tempo de disparo é dada por

$$
E(t)=\frac{1}{\lambda}
$$

4.Se um conjunto de transições estiver em conflito, a primeira delas a disparar retira as marcas dos lugares a sua entrada.

\section{A.3.1.1 Relação com cadeias de Markov}

Um ponto crucial para a análise quantitativa de redes SPN é a relação entre as redes SPN e as cadeias de Markov de tempo contínuo, que foi apresentada por Molloy (1980) com a utilização do conceito de isomorfismo e do teorema que estabelece a relação entre redes de Petri e processos de Markov (KULKARNI, 1995; BOLCH et al., 1998), que são reproduzidos a seguir:

\section{Definição A.6}

Dois sistemas de transições estocásticas são isomórficos se e somente se as condições a seguir forem verificadas:

1.Existe uma correspondência um-a-um e um mapeamento $F$ entre os espaços de estados dos dois sistemas.

2.São equivalentes as seguintes afirmações:

(a)existe uma transição em um sistema tal que se passa do estado $S_{u}$ para o estado $S_{v}$;

(b)existe uma transição no outro sistema tal que se passa do estado $F\left(S_{u}\right)$ para o estado $F\left(S_{v}\right)$.

3.As probabilidades $P\left[S_{u} \rightarrow S_{v}, T\right]$ e $P\left[F\left(S_{u}\right) \rightarrow F\left(S_{v}\right), T\right]$ são iguais, para quaisquer estados (a notação representa a probabilidade de, estando no estado $S_{u}$ (ou $F\left(S_{u}\right)$ ), passar para o estado $S_{v}$ (ou $F\left(S_{v}\right)$ ) dentro de um período de tempo $T)$. 


\section{Teorema A.1}

Qualquer rede de Petri estocástica (SPN) de lugares finitos e transições finitas é isomórfica a um processo de Markov de estados discretos unidimensional.

O grafo de alcançabilidade de uma rede SPN, que representa as transições entre os estados ou marcações da rede, apresenta uma topologia muito semelhante à do Diagrama de Transição de Estados de um processo de Markov que lhe é isomórfico. As somas das taxas de disparo das transições envolvidas nas mudanças entre duas marcações são iguais aos valores das taxas de transição de estados nas transições de estados correspondentes nos DTE. Portanto, é desta forma que a introdução de temporizações estocásticas permite a obtenção de um modelo analisável quantitativamente por técnicas desenvolvidas para processos de Markov.

Uma conclusão importante é a de que, observando-se as considerações feitas por Murata (1989), tem-se que se uma rede SPN for viva, limitada e reinicializável, tal rede é isomórfica a uma cadeia de Markov de tempo contínuo ergódica. A ergodicidade das cadeias de Markov é tratada na seção anterior, sendo a base com a qual interessantes análises quantitativas podem ser executadas em redes de Petri estocásticas.

\section{A.3.2 Redes de Petri estocásticas generalizadas (GSPN)}

As redes de Petri estocásticas generalizadas (GSPN ou "Generalized Stochastic Petri Nets" (MARSAN; CONTE; BALBO, 1984)) podem ser consideradas como uma generalização das redes SPN que, com a introdução de novos elementos, permitem modelar sistemas de forma que o número de estados considerados na etapa de análise de cadeias de Markov seja menor.

A diferença básica entre as redes GSPN e SPN é que, nas primeiras, são definidos dois tipos de transição:

1.Transições imediatas, que disparam instantaneamente, tão logo estejam habilitadas; sua representação gráfica é uma barra (ver figura A.24)

2. Transições temporizadas, que funcionam como as transições das redes SPN, tendo as mesmas características, e sua notação é de um retângulo, devendose especificar sua taxa de disparo da transição $\lambda$ (ver figura A.24); como nas 

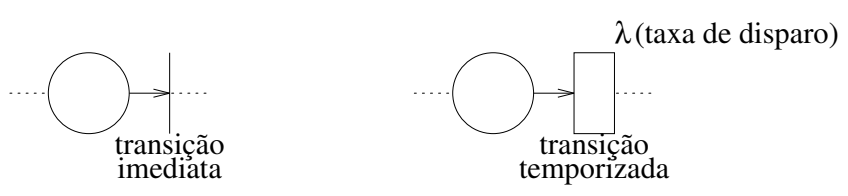

Figura A.24: Transições das redes GSPN

redes SPN, as transições seguem a regra do disparo instantâneo e as temporizações são estocásticas e com distribuições exponenciais de parâmetro $\lambda$.

Tal diferença entre as redes GSPN e SPN, que acarreta comportamentos diferentes no que tange aos disparos das transições, põe à tona a questão das formas de conflitos que podem ocorrer, tópico abordado logo a seguir. Ainda, é justamente o fato de haver transições imediatas que se obtém um menor número de estados a considerar na etapa de análise por cadeias de Markov (MARSAN; CONTE; BALBO, 1984).

Devido à existência de dois tipos de transições com comportamentos diferentes, são necessárias regras para a resolução dos seguintes tipos de conflitos:

1.entre transições temporizadas

2.entre transições imediatas

3.entre transições imediatas e temporizadas

Estes conflitos são tratados a seguir.

\section{A.3.2.1 Conflitos entre transições temporizadas}

A resolução de conflitos entre transições temporizadas numa rede GSPN (ver figura A.25) é realizada da mesma forma que nas redes SPN, ou seja, a primeira a disparar (aquela cuja temporização resultar num tempo menor de espera) é a que retira as marcas dos lugares envolvidos no conflito.

Esta forma de resolver conflitos, assim como as demais propriedades a respeito da temporização estocástica, não tem uma origem arbitrária: ela visa reproduzir o comportamento das cadeias de Markov de tempo contínuo, sobre as quais maiores detalhes são descritos por Howard (1971). 


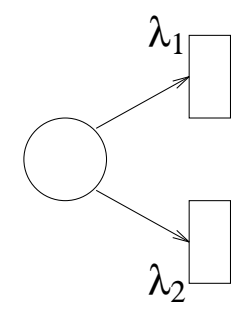

Figura A.25: Conflito entre transições temporizadas

\section{A.3.2.2 Conflitos entre transições imediatas}

Neste caso, nota-se que as regras de disparo para estas transições entram em choque, uma vez que foi definido que disparam no momento da habilitação, mas não é possível a retirada da(s) marca(s) do(s) lugar(es) em questão por todas as transições simultaneamente, pelo menos sem violar os mecanismos estabelecidos para as redes de Petri, das quais as redes GSPN são extensões. Para resolver este conflito, foi definido um mecanismo de arbitragem (processo de resolução de conflito) denominado "random switch". As "random switches" atribuem probabilidades às transições imediatas em conflito, que podem ser interpretadas como as percentagens de disparos de cada uma das transições num conjunto de ocorrências de conflito entre estas. Pode-se interpretar também que, se, num conflito, uma transição tiver uma probabilidade maior de disparo que as outra, aquela tem maior prioridade de disparo que as restantes. No caso de um conflito envolver apenas um lugar e todas as transições em conflito tiverem apenas esse lugar à entrada, a definição da "random switch" é simples: basta anotar as probabilidades de disparo de cada transição nos arcos respectivos. Note-se que a soma das probabilidades de todas as transições envolvidas deve ser igual a unidade (ver figura A.26).

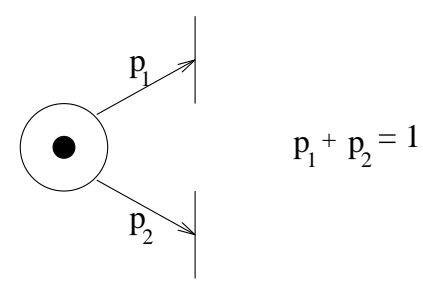

Figura A.26: "Random switch" no caso de um lugar à entrada

Em outros casos, não há outra saída senão definir os "random switches" para cada marcação em que ocorrer o conflito, que é o caso ilustrado na figura A.27 (no exemplo, para cada marcação da sub-rede $M=\left(M\left(p_{1}\right), M\left(p_{2}\right), M\left(p_{3}\right), M\left(p_{4}\right)\right)$, 


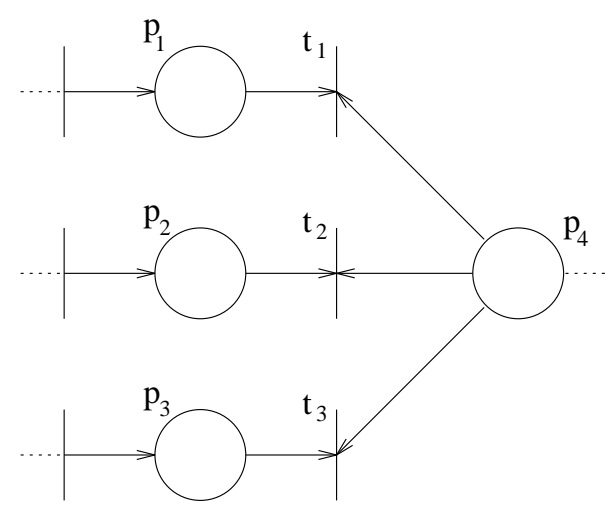

Figura A.27: Os conflitos que variam conforme a marcação

onde $M(p)$ é a marcação do lugar $p)$. Supondo-se que os lugares da sub-rede têm, no máximo, uma marca, são quatro as "random switches" que devem ser definidas, por exemplo:

$$
\begin{aligned}
& \text { Para a marcação }(1,1,0,1)\left\{\begin{array}{l}
p\left(t_{1}\right)=0,5 \\
p\left(t_{2}\right)=0,5
\end{array}\right. \\
& \text { Para a marcação }(1,0,1,1)\left\{\begin{array}{l}
p\left(t_{1}\right)=0,3 \\
p\left(t_{3}\right)=0,7
\end{array}\right. \\
& \text { Para a marcação }(0,1,1,1)\left\{\begin{array}{l}
p\left(t_{2}\right)=0,9 \\
p\left(t_{3}\right)=0,1
\end{array}\right. \\
& \text { Para a marcacao }(1,1,1,1)\left\{\begin{array}{l}
p\left(t_{1}\right)=0,5 \\
p\left(t_{2}\right)=0,3 \\
p\left(t_{3}\right)=0,2
\end{array}\right.
\end{aligned}
$$

Uma maneira simples encontrada para definir as "random switches" é o caso onde a probabilidade de disparo numa transição aumenta à medida que mais marcas a habilitam - considerando-se o exemplo da figura A.27, poder-se-ia ter o que se segue:

$$
\begin{aligned}
& p\left(t_{1}\right)=\frac{M\left(p_{1}\right)}{M\left(p_{1}\right)+M\left(p_{2}\right)+M\left(p_{3}\right)} \\
& p\left(t_{2}\right)=\frac{M\left(p_{2}\right)}{M\left(p_{1}\right)+M\left(p_{2}\right)+M\left(p_{3}\right)}
\end{aligned}
$$




$$
p\left(t_{3}\right)=\frac{M\left(p_{3}\right)}{M\left(p_{1}\right)+M\left(p_{2}\right)+M\left(p_{3}\right)}
$$

Uma outra situação que pode ocorrer é o caso de uma transição se envolver em mais de um conflito, como no caso da figura A.28 (em redes de Petri, tal ocorrência é conhecida por confusão (MURATA, 1989)). Na figura citada, a transição t está envolvida em dois conflitos; neste caso, o disparo de tal transição depende de:

•sua habilitação

• os processos de decisão de ambos os conflitos coincidirem pelo disparo de $t$

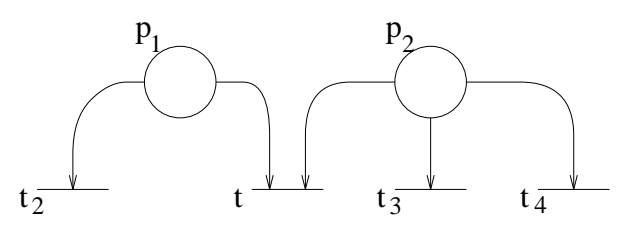

Figura A.28: Confusão

Nos casos de confusão, todos os conflitos envolvidos devem ser considerados em conjunto para se definir as probabilidades, uma vez que se interagem em razão das sincronizações. Na marcação do exemplo considerado, deve-se definir as probabilidades relativas aos possíveis disparos, no caso:

1.Probabilidade de disparo de $t$

2.Probabilidade de disparos de $t_{2}$ e $t_{3}$

3.Probabilidade de disparos de $t_{2}$ e $t_{4}$

Por fim, nada impede que, numa mesma marcação da rede, ocorram várias "random switches" (ver figura A.29).

Em redes GSPN de certo porte, é interessante que se elabore uma sistemática para a definição das probabilidades, principalmente se for considerado que as "random switches" devem ser definidas em cada marcação em que ocorrerem. 

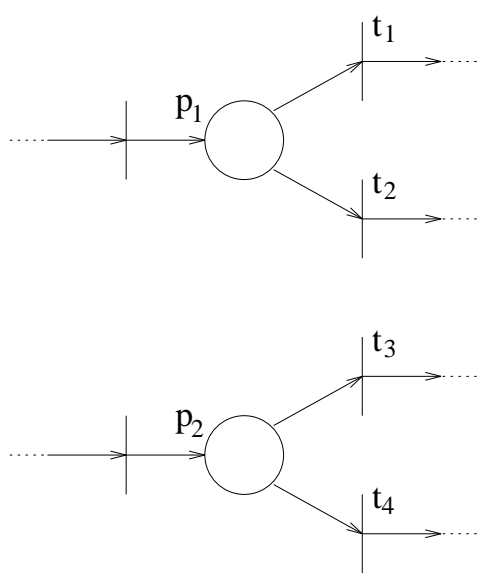

Figura A.29: Múltiplos "random switches" numa marcação

\section{A.3.2.3 Conflitos entre transições temporizadas e imediatas}

Neste caso (ver figura A.30), são as transições imediatas que disparam. Uma interpretação é que, considerando-se as distribuições exponenciais dos tempos de disparo das transições temporizadas, a probabilidade de ocorrer o disparo no instante $t=0$ é nula (a probabilidade num instante "pontual" é sempre nula, pois a probabilidade é sempre definida sobre um intervalo de valores da variável aleatória). Por outro lado, como a distribuição do tempo de disparo da transição imediata pode ser representada por uma função delta de Dirac no ponto $t=0$, pode-se dizer que a probabilidade "pontual" de ocorrer o disparo no instante $t=0$ é igual a 100\%, ou seja, dispara a transição imediata.

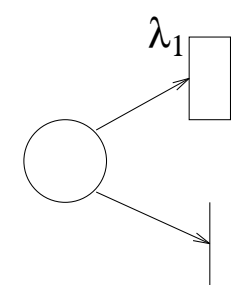

Figura A.30: Conflito entre transições imediata e temporizada

No caso de um conflito envolver transições temporizadas e mais de uma imediata, as transições temporizadas não disparam, mas é preciso resolver qual das imediatas será disparada, conforme a regra de resolução dos conflitos entre transições imediatas. 


\section{A.3.2.4 Marcações tangíveis e evanescentes}

Uma outra conseqüência da existência de dois tipos de transições é a ocorrência de dois tipos de marcações:

- marcações tangíveis: ocorrem quando somente transições temporizadas estão habilitadas - neste caso, a rede permanece nessas marcações até que uma dessas transições dispare, de modo que o tempo dessa permanência é finito e maior que zero;

-marcações evanescentes: ocorrem quando há pelo menos uma transição imediata habilitada - neste caso, assim que uma transição imediata é habilitada, passa-se para a marcação seguinte, de modo que o tempo de vida dessa marcação é nulo.

Com técnicas de eliminação de marcações evanescentes (CHIOLA; DONATELLI; FRANCESCHINIS, 1991), chega-se a cadeias de Markov com menos estados do que aquelas obtidas com redes de Petri estocásticas (SPN) topologicamente idênticas, facilitando o trabalho computacional no cálculo das probabilidades das marcações. 